HX00030031

RECAP 


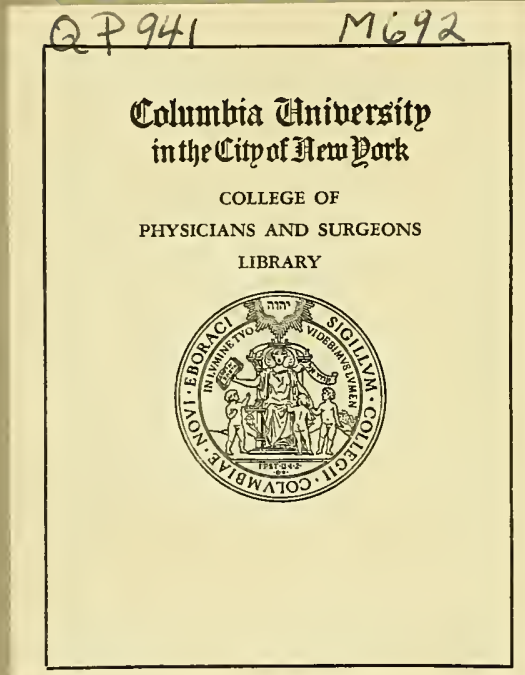



Digitized by the Internet Archive in 2010 with funding from Open Knowledge Commons

http://www.archive.org/details/researchesuponve00mitc 



\title{
SMITHSONIAN CONTRIBUTIONS TO KNOWLEDGF.
}

\section{R E S E A R C H S}

EPON TILE

\section{VENOM OF THE RATTLESNAKE:}

\begin{abstract}
WITH AN INVESTIGATION OF TIIE ANATONY AND PHYSIOLOGY
\end{abstract} OF TIIH ORGANS CONCERNED.

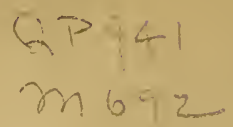

BY

S. WEIR MITCHELL, H. D., LECTURER ON PRYSIOLOCY IN THE PHLADELPHIA MEDICAL ASSOCIATION. 


$$
\begin{aligned}
& \text { Q } p q+1 \\
& n 1692
\end{aligned}
$$

\section{O II II I S S I O N}

TO WHICH THIS MEMOIR HAS BEEN REFERRED.

Frankiln Bache, M. D., Robley Dunglison, M. D.

JOSEPH HENRY, Secretary S. $I$. 
IN the following pages are set forth the results of a long and conscientious experimental study of the venom of the Rattlesnake.

During a large part of two years I have given to this work almost all the leisure which could be spared from the everyday exactions of my regular professional duties.

In its progress, I have been constantly aided and encouraged by many friends, principally members of the Academy of Natural Sciences, of Philadelphia; more especially am I in debt to my fellow-members of the Biological Department of the Academy, to Prof. Wm. A. Hammond, and to Mr. Vaux.

My thanks are due to the Smithsonian Institution, without the aid of which I should have been unable to procure the serpents which were essential to my purposes.

The historical references and the Bibliography owe much to the manuscript notes of Prof. John Le Conte, which were collected with much care and labor, that they night be used in a research which he at one time contemplated. Becoming aware of the investigation in which $\mathrm{I}$ was engaged, he most liberally placed at my disposal this collection of literary materials.

To Drs. Brinton and Kane I am greatly obliged for intelligent assistance in numerous experimental investigations, for which their ready surgical skill so well fitted them, and I am also in debt to Messrs. Cantrell and Picot, for like aid, which, owing to the nature of the service, was not always free from danger. My thanks are further due to Drs. La Roche and Stillé, to Dr. Fisher, the librarian of the Academy of Natural Sciences, and to Dr. T. H. Bache, the librarian of the College of Physicians, whose assistance in consulting its extensive collection of American journals has been to me of great service.

With the exception of the microscopic delineations, the plates were drawn by Dr. Packard, from my recent dissections, and owe their chief merit to his accurate pencil.

The conclusions arrived at in the pages of this Essay, rest alone upon experi- 
mental evidence. That in so varied and so difficult a research, it may be found that I have sometimes been misled, and at others erred in the interpretation of facts, is no doubt to be anticipated. I began this work, however, without preconceived views, and throughout its prosecution I have endeavored to maintain that condition of mind which is wanted in experimentation, and that love of truth which is the parent of rational inferences.'

\section{S. WEIR MITCIIELL.}

1226 Walnut St., Philadelphia.

1 The reader who desires further information in regard to the therapeuties of the subject, and to the relative value of the various antidotes still in repute, is referred to a fortheoming paper, by the author, in the North American Medico-Chirurgical Review, in which the whole subject will be considered from a purely medical point of view. The author takes this occasion to mention the omission in the medical portion of the present essay of the composition of Bibron's antidote. It contains five drachms of bromine, four grains of iodide of potassium, and two grains of corrosive sublimate. 


\section{TABLE OF CONTENTS.}

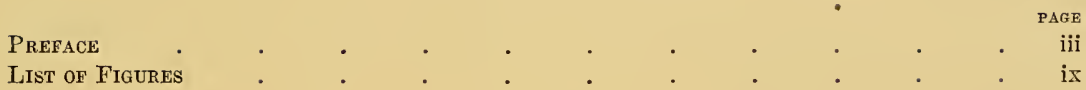

\section{CHAPTER I.}

OBSERVATIONS ON THE HABITS OF THE CROTALUS WHEN IN CAPTIVITY.

Inactivity of the Crotalus

Habit of fasting

Mode of artificial feeding

Necessity for water

Change of skin

Inflnence of the supply of water upon this process

Question of the loss of fangs at this period

Supposed power of fascination .

Odor of the Rattlesnake

\section{CHAPTER II.}

\section{ANATOMY OF THE VENOM APPARATUS.}

Osteology of the parts concerned

Myology of the parts concerned

Position of the venom gland

Weight of the gland as compared with the length and weight of the snake . . I1

Capsule of the gland.

Its suspensory and other ligaments

Receptacle of the poison

Microscopical anatomy of the gland

Course of the duct

Sphincter of the duct

Structure of the fang

Development of the fangs

Succession of fangs

\section{CHAPTER III.}

PHYSIOLOGICAL MECHANISM OF THE BITE OF THE CROTALUS.

Attitude of defence 
Fntrance of the fang into the part struck

Mechanism of the parts concerned in the injection of the poison

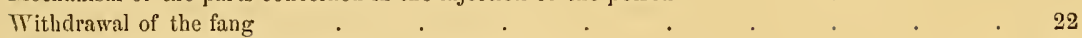

Observation as to the employment of one or both fangs $\quad . \quad$. $\quad . \quad 2 \quad . \quad 23$

Divergence of the fangs when used in biting . $\quad . \quad$. $\quad . \quad 4 \quad . \quad 23$

Neans employed to restrain the wasteful flow of the venom . . . . . . . $\quad 24$

Tenacity of life on the part of the Crotalus (note) . $\quad . \quad$. $\quad . \quad 24$

Circumstances that sometimes lessen or destroy the danger of the bite $\quad . \quad$. $\quad 25$

\section{CHAPTER IV.}

PIIYSICAL AND CHEMUCAL CHARACTERS OF THE VENOM.

Amount of venom in the ducts.

Manipulation (note) "

Capacity of gland as compared to length and weight of snake. $\quad . \quad 39$

Color of the venom of the Rattlesnake $\quad . \quad$. $\quad . \quad$. $\quad . \quad 29$

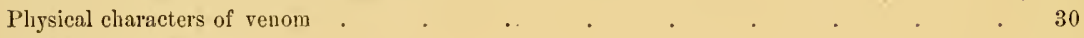

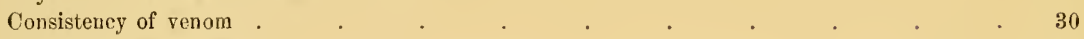

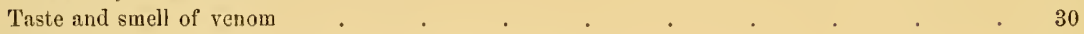

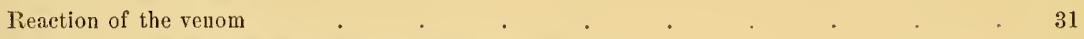

Reaction of the mucous membrane of the snake's month $\quad$. $\quad . \quad$. $\quad . \quad 31$

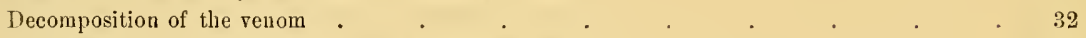

Crystals formed during the evaporation of diluted venom $\quad . \quad$. $\quad . \quad . \quad 32$

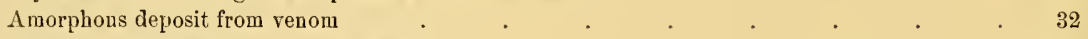

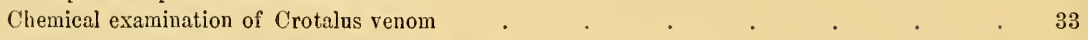

Temperature at which the venom coagulates . $\quad . \quad$. $\quad . \quad$. $\quad .33$

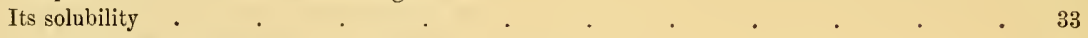

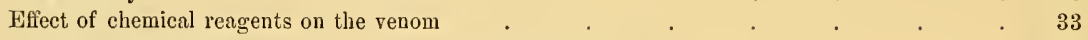

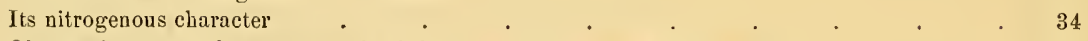

Observations as to the presence of sulphocyanide of potassium in venom . . . 34

Qualitative analysis of renom . $\quad . \quad$. $\quad . \quad 3 \quad . \quad 35$

Observations as to the power of venom to convert starch into grape sugar . . . . $\quad .38$

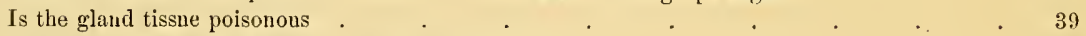

Analogy of the venom gland to the parotid gland $\quad . \quad$. $\quad . \quad 4 \quad . \quad 42$

Effect of varions temperatures on the activity of venom $\quad . \quad . \quad . \quad . \quad . \quad . \quad 43$

Table of the effect of various temperatures on the activity of venom . . . . 44

Influence of certain chemical a gents on the activity of venom . . . . . 45

\section{CHAPTER V.}

TOXICOLOGY OF THE VENOM OF THE CROTALUS.

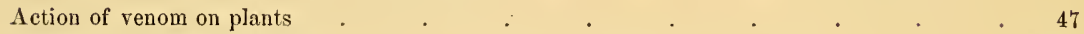

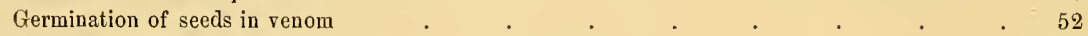

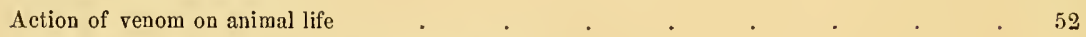

Development of animalculæ in decomposing venom . . . . . . . . $\quad .53$

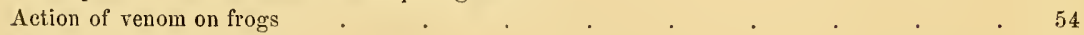

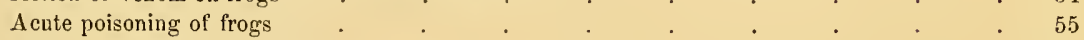

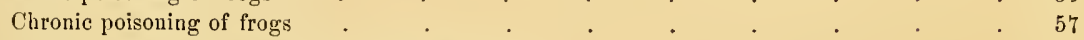

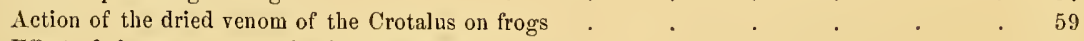

Effect of the venom upon the Crotalns itself . $\quad . \quad \ldots \quad . \quad . \quad . \quad . \quad 61$

Relative susceptibility of cold and warm-blooded animals _ . . . . . . . 63 


\section{CHAPTER VI.}

TOXICULOGICAL ACTION OF THE VENOM UPON WARM-BLOODED ANIMALS.

Action of the venom on birds.

Table of symptoms and lesions in seren cases of pigeons poisoned by Crotalus venom . . 67

Action of venom on rabbits

Table of symptoms in eight rabbits

Table of lesions in the same

Effect of Crotalus venom on dogs

Cases which recovered.

Fatal cases

\section{CHAP'TER VII.}

\section{ACTION OF VENOI ON THE TISSUES AND FLUIDS.}

The venom harmless when taken into the stomach

Pulmonary absorption of the venom in pigeons with fatal results . . . . . 77

Effect of the venom on the muscles

Effect of the venom on the rigor mortis

Ultimate effect of renom on muscles.

Effect of venom on the heart.

Effect of venom on the constant arterial pressure

Action of venom on the eapillary system

Action of venom on the intestinal movements.

Action of venom on the ciliary movement

Action of the venom on the nervons system .

Direct effect of venom on uerve trunks

Action of the venom on the sensory and motor nerves and upon the nerve centres

Effect of the venom apon the calorifacient function

Effect of renom on the blood.

Effect of venom on the blood in acute poisoning

Effect of venom on the blood in chronic poisoning

Table of blood changes

Loss of fibrin in chronic poisoning

Infinence on the blood-corpnseles

The rate at which the fibrin disappears from the blood

Conclusions

Altered relation between the blood and tissues.

Canse of death

Conclusions

Analogy between the symptoms of Crotalus poisoning and those of certain diseases

\section{CHAPTER VIII.}

CROTALUS POISONING IN MAN.

Table of Crotalus poisoning in man Sex of those bitten Situation of the wound 
Local symptoms

Local results

Constitutional symptoms

Fatal cases, mode of deatlr

Duration of cases

Rapidity of recovery in the favorable cases

Lesions in fatal cases.

Antidotes

General remarks on antidotes

Local therapeuties -

Interual treatment

Examination of supposed constitutional antidotes

Ammonia

Olive oil

Arsenic

Bibron's antidote

Alcoholic stimulus

Conclusion

An endueration of the genera and species of Rattlesnakes, with synonymy and ReFerENCES. By E. D. Cope 


\section{LIST $0 \mathrm{~F}$ W0OD-CUTS.}

Figure 1. Portion of cranium of Crotalos

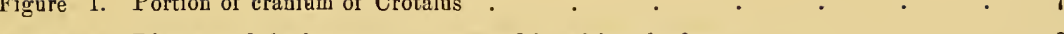

Figure 2. Diagram of the bony parts concerned in raising the fang . . . . . . $\quad 8$

Figure 3. Palatal view of the muscles of the upper jaw and base of the skull ${ }^{1} \quad$ - $\quad 9$

Figure 4. Side view of the right temporal muscles and renom gland $\quad \begin{array}{lllllllll} & \text {. } & & 9\end{array}$

Figure 5. Side view of the left temporal muscles, gland, duct, and fang . . . 10

Figure 6. A. The gland and temporal muscles seen from above. $B$. Diagram of duct and

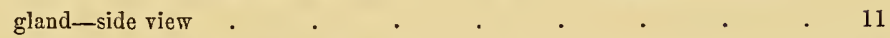

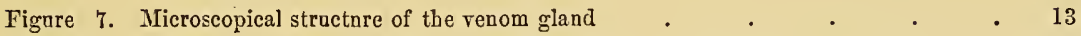

Figure 8. Epithelial cells of the main duct and receptacle at the base of the gland . . 14

Figure 9. Non-striated muscular fibre-cells of the sphincter of the duct . . . . 14

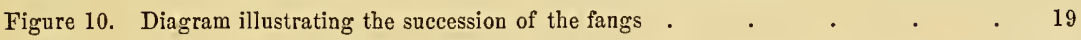

Figure 11. Crystals deposited from the diluted renom of the C. confluentus (Prof. Hammond) 32

Figure 12. Appearance of muscular fibre after contact with venom . . . . . . 80

1 In Fig. 3, p. 9, Description-d is deseribed as the spheno-palatine muscle. It should be labelled, Central raphe at the base of the skull. 


\section{•}




\section{N T R $0 \mathrm{D}$ U C T $10 \mathrm{~N}$.}

PopUlar tradition has long nourished a general aversion to serpents. This dread, fostered by the singular qualities of the snake tribe, has become so familiar an idea to most minds, as to lead to the belief that it is of instinctive origin, and not sown, as it surely is, by the hand of traditional prejudice.

However produced, dread and disgust seem to have had some influence in preventing physicians in this country from investigating the venom of the species of serpents, whose strange peculiarities and fatal powers have most urged them upon their notice. It has thus happened, that with the exception of the Essays of Barton and Brainard, the cis-Atlintic literature of this subject has been confined to scattered notices and incomplete statements of cases, to be found with difficulty in the pages of our numerous medical journals.

Apart from the European and East Indian publications upon snake-bites, we know or have learned but little that is new; and if we except the works of Fontana, Mangili, Bonaparte, and one or two others, in no part of the world has modern science done much to further this inquiry.

Such being the case, I conceive that no excuse is required in presenting the results of investigations upon a subject which has peculiar claims on the attention of our countrymen.

A large part of what is here set forth has some pretension to be regarded as original research; but the subject is so ample, and has presented itself under so many points of view, that I can scarcely regard this paper as more than a re-opening of the matter; and I feel that however full it may be upon some points, it is rather the pledge of future labors than a complete exposition of the subject upon which it treats. For the researches which form the novel part of the following essay, I claim only exactness of detail and honesty of statement. Where the results have appeared to me inconclusive, and where furtber experimental questioning has not resolved the doubt, I have fairly confessed my inability to settle the matter. This course I have adhered to in every such instance, thinking it better to state the known uncertainty thus created than to run the risk of strewing my path with errors in the garb of seeming truths.

In the following researches I have made use almost altogether of the single 
species of Rattlesnake, usually known as the Crotalus durissus. Of this I have had living specimens from Lake George, and from various localities in the Alleghanies of Pennsylvania and Virginia. In Mr. Cope's Summary at the end of this Essay, the reader will find all the necessary details as to the zoological characters of this serpent. 


\section{H A P T E R I.}

\section{OBSERVATIONS ON THE HABITS OF THE CROTALUS WHEN IN CAPTIVITY.}

DURING a large part of two years, the period which this research has occupied, I was a portion of each day in the room where the reptiles were kept, and consequently observed with care such of their habits as could be studied while they were in confinement. In regard to these I have a few observations to make, before considering their physiology and toxicology.

It is by no means my intention to give a full account of the habits of the Crotalus, since this would involve a great deal of detail which is to be found elsewhere, and which would be foreign to the general purpose of this essay.

The Rattlesnake of our Northern States, when at liberty, sometimes lives in the company of his fellows, but more frequently alone. I have had, in a single box, from ten to thirty-five snakes, and have never observed the slightest signs of hostility towards one another. Even when several snakes were suddenly dropped upon their fellows, no attempt was made to annoy the new-comers, while the sudden intrusion of a pigeon or a rabbit was met with ready resentment, whenever the suakes were fresh and in vigorous health.

The habits of Rattlesnakes, when in confinement, are singularly inactive. Even in warm weather, when they are least sluggish, they will lie for days together in a knotted mass, occasionally changing their position, and then relapsing into perfect rest. The contrast between this ordinary state of repose, or sluggish movement, and the perilous rapidity of their motion when striking, is most dangeronsly deceptive. In contrast also with their slow locomotion is the marvellously rapid action of their rattles, which, when annoyed or molested, they will sometimes continue to agitate for hours at a time.

It is the general experience of those who have kept rattlesnakes, that they seldom eat in captivity. I have known a snake to exist for a year without food, and although I have made every effort to tempt my own snakes, I have never seen any one of them disposed to avail itself of food, when placed within its reach. Dumeril states that this is the usual experience in the Garden of Plants, but that at the end of six or eight months they commonly accept food. He also adds that the very young pigeon is the food they are most inclined to eat.

After tempting the snakes with this, as well as with birds, mice, rabbits, etc., and finding the food as often untouched, I finally gave up the attempt, and contented myself with feeding, by force, such of them as seemed feeble and badly nourished. For this purpose, I used milk and insects, which I placed in their throats, while they were properly pinioned. To effect this, the snake was secured, and the lower jaw held in the grasp of a pair of forceps, while a funnel, with a 
long stem, was thrust down the oesophagus. Into this, insects, such as flies and grasshoppers, were pushed, or milk poured in proper quantity. Yet, even when this precaution of forcible feeding was not employed, the snakes remained healthy, and secreted, as usual, a sufficient amount of venom.

To preserve them, however, in good condition, it is absolutely necessary that they should be frequently supplied with water, especially in hot weather, and when they are about to shed their skins. The free snake is said, in this climate, to shed its cuticle in the month of August. My snakes lost their old integuments at clifferent periods, during the summer. In all cases, the old skin became very dark, as the new one formed beneath it. If, at this time, the snakes were denied access to water, the skin eame off in patches. Where water was freely supplied, they entered it eagerly at this peried, and not only drank of it, but lay in it for hours together. Under these circumstances, the skin was shed entire-the first gap occurring at the mouth, or near it. Through this opening, the serpent worked its way, and the skin reverting, was turned inside out, as it crawled forth in its new and distinctly-marked outer covering. When the old skin was very loose, the snake's motions were often awkward for a time. It is said to be blind during this period, which is probably true to some extent; since the outer layer of the cornea is shed with the skin, and there must obviously be a time when the old corneal layer lies upon the new formation. It is also said that the fangs are lost at the same time as the skin. In some instances, this was observed to be the case; but whether or not it is a constant occurrence, I am unable to say from personal observation.

It is most probable, as I have elsewhere stated, that not only are the fangs shed when the skin is lost, in summer, but that their loss is a frequent occurrence, like the loss of teeth in certain fisl, and takes place at intervals, more or less frequent, certainly oftener than once a year.

A general opinion prevails that, immediately after the loss of the skin, the snakes become most virulent. As they are slothful during the period of change, and strike then with reluctance, if at all, and as the loss of the fang involves, to some extent, the accumulation of poison in the gland cavities, this view may be correct. There is no ground, however, for supposing that the effect of this storing up of the venom would be greater at this period than after a similar amount of accumulation at another time.

After such numerous and long-continued opportunities of observation, it might be supposed that I should be prepared to speak authoritatively, as to the still disputed power of the snake to fascinate small animals. If the power exist at all, it is probable that it would only be made use of when the serpent required its aid to secure food. We have seen that even the most healthy suakes lose their appetite when imprisoned, and beyond this condition, my chances of observation have been limited. Those who are still curious in the matter will find the fullest account of it in the Essay of Dr. B. S. Barton. In despite of the learned and ingenious argument of this author, there are not wanting large numbers, who claim to have witnessed, again and again, the exercise of the power of charming on the part of the Rattlesnake and Black Snake. Dr. Barton, who does not deny that the appearance 
of fascination has been often observed, explains it by supposing that in these cases the parent bird, alarmed at the near approach of danger to her nest of young, hovers anxiously about the snake, as she would about any other cause of danger, and thus sometimes falls a victim to her maternal anxiety. This theory, Dr. Barton believes sufficient to account for the fluttering and strange movements of the bird, and the arguments with which this view is upheld, are certainly entitled to great respect. While the anxiety and terror of the parent bird would readily attract notice, the real object of the snake, and the true cause of the mother's approach to the very jaws of destruction, would be more than likely to escape the notice of such persons as are usually called upon to observe the supposed fact.

I have seen but one occurrence that might mislead as to the subject of fascination. I have very often put animals, such as birds, pigeons, gninea-pigs, mice, and dogs, into the cage with a Rattlesnake. They commonly exlribited no terror after their recovery from alarm, at being handled and dropped into a box. The sinaller birds were usually some time in becoming composed, and fluttered about in the large cage until they were fatigued, when they soon became amusingly familiar with the snakes, and were seldom molested, even when caged with six or eight large Crotali. The mice-which were similarly situated-lived on terms of easy intimacy with the snakes, sitting on their heads, moving round on their gliding coils, undisturbed, and unconscious of danger. Larger animals were not so safe, especially if they moved abruptly and rapidly about the snakes. The birds, nice, and larger animals, often manifested an evideint curiosity, which prompted them to approach the snake cautiously. Sometimes this was rewarded by a blow, as was sure to be the case, when a dog indulged his inquisitiveness by smelling the snake with his muzzle. Sometimes the snake retreated, and struck only wlien driven to bay. Usually, the smaller animals indulged their inquisitive instinct unlıurt, and were allowed to live for days in the same cage with the dreaded reptiles. ${ }^{1}$

These are the sole facts which I have seen, bearing any relation to the supposed fascinating faculty. They appear to me to lend no strength to the idea of its existence.

There is a popular belief which ascribes to the Rattlesnake a most disagreeable odor, and even naturalists have been led to believe that the serpent owed to this its power to lure and stupefy animals. In this matter, I agree with Barton. ${ }^{2}$ I have never perceived that any peculiar odor issued from my snake-box, and as to its ability to injure birds, the facts above stated should suffice to disprove it. As usual, however, this pound of error contains its grain of truth. When a Rattlesnake is roughly handled, especially about the lower half of its length, a very heavy and decided animal odor is left upon the hands of the observer. If the snake be violently treated, causing it to throw itself into abrupt contortions, thin streams of a yellow or dark brown fluid are ejected to the distance of two or three feet. This fluid appears to come from glands alongside of the cloaca. Its odor is extremely disagreeable, and it is irritant when it enters the eye, although not otherwise injurious.

1 It is proper to add, that the curiosity thus exhibited by animals, and especially by mice and dogs, was as active when the snake was not regarding the intruder, as at other times.

2 Barton, p. 24. 
CHA P T E R II.

\section{ANATOMY OF THE VENOM APPARATUS.}

The subject of the myology of the Rattlesnake has been considered at length, in several systematic works, and in the monographs referred to at the close of this paper. For the fullest details, it would be necessary to refer the reader to the books in question. Since, however, it is impossible otherwise to convey an accurate idea of the mode in which the fangs are employed, I am forced to describe the parts concerned, and the general mechanism of their motions. It is the more necessary to dwell, at least, briefly, on this matter, because some of the French observers have fallen into error, as regards the action of certain of the muscles concerned in the elevation and depression of the fangs.

I shall first describe, as shortly as possible, the bones involved; then the muscles, and lastly the gland and its duct. Thus prepared, we shall next study the mode in which the blow is given, and the mechanism, through the agency of which the poison is ejaculated.

The heads of the true serpents are so constructed as to admit of a large amount of movement in the component bones. Thus the zygomatic bones which support the lower maxillary bones, are loosely articulated to the mastoid bone, which is itself so mobile as to permit of the greatest possible expansion of the throat. Anteriorly the superior maxillary bones are united, by ligaments only, to the intermaxillaries, and the lower-maxillary bones of each side are also so connected anteriorly as to permit of their being widely separated, and of one or the other side of the inferior jaw being drawn down to some distance, without involving a corresponding motion on the part of its fellow. Finally, the superior maxillary bones, the pterygoid and palate bones admit of considerable movement, so that the arches which they form can be widened or narrowed as circumstances may require.

The mobility of these parts is essential to the motions which raise and depress the fang, and to the deglutition of the large animals upon which the snakes are accustomed to prey.

The poison fang, when at rest, projects downwards and backwards into the mouth of the serpent. It is firmly anchylosed in the alveolar process, which crowns the summit of the shortened upper maxillary bone, Fig. $1, d$, whose peculiar brevity is characteristic of venomous snakes. The superior maxillary bone is of a rather irregular triangular shape, abruptly cut off below to form the alveolar socket. One face of this bone is smooth, and looks inwards and slightly forwards. 
A second looks forwards and outwards. This facet is smooth below, ${ }^{1}$ but is excavated above into a deep fossa, which in the fresh snake is partially closed by

Fig. 1.

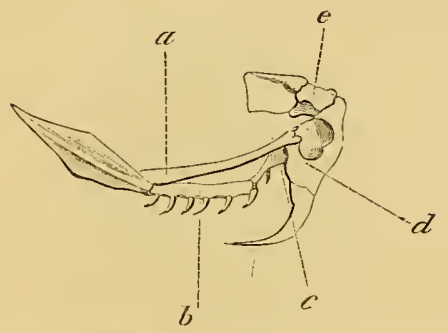

Portion of Cranidm of Crotalds. - Right side. Osteology. Bones concerned in the movements of the fang. a, external pterygoid bone; $b$, internal pterygoid bone; $c$, palatal bone; $d$, superior maxillary bone; $e$, lachrymal bone.

soft tissues, but is still sufficiently remarkable as lying between the eye and nares. In the dry bone this large fossa opens upwards freely through the base of the bone, and thus separates the two surfaces by which the bone articulates with the ectopterygoid and lachrymal bones respectively: Anteriorly, the superior maxillary bone presents a rounded angle, from which diverge the two lateral sides just described. Posteriorly, the superior maxillary exhibits a third face, which is flat only half way down the bone, and terminates in an abrupt edge forming the posterior boundary of the alveolar socket.

Anteriorly, and above, the maxillary bone articulates by a ginglymoid joint with the short triangular lachrymal bone, Fig. $1, e$, which projects forwards from the anterior external angle of the frontal bone. The articular facet of the maxilla lies at the upper end of its front angle. It moves with great freedom on the concave face of the lachrymal bone, its motion being partially restrained by a short, round, strong ligament, which runs from the posterior and inner edge of the lachrymal bone to be inserted on the back edge of the base of the maxilla, just above the articulation of the ecto-pterygoid bone.

The lachrymal bone has itself some movement on its frontal articulation, and by this the maxilla obtains indirectly an additional extent of forward motion. At the upper edge of the posterior surface of the maxillary bone, it receives the expanded and flattened end of the ecto-pterygoid bone, Fig. 1, a. Upon tracing the line of motion, of which this bone is capable, it will be seen that it lies below the lachrymal joint, and that, consequently, when it moves forwards, the fang must rise, as the superior maxillary rocks on the articulating face of the lachrymal bone.

The superior maxillary is indirectly attached to the palate bone, Fig. 1, $c$, and interual pterygoid, Fig. 1, $b$, by virtue of the strong connection of these bones with the ecto-pterygoid. This connection is so close that every free motion of either of 
the two former bones must inevitably affect the latter, and through it again the maxilla and its single tooth.

The motion of the maxillary bone on its lachrymal articulation will, perhaps, be better understood upon referenee to the accompanying diagram of the parts.

Fig. 2.

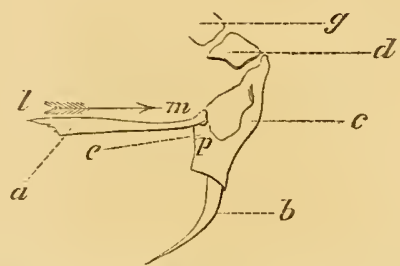

Diagrair of the Bonx Parts concerned in raising the FANG. $-a$, pterygoid bone; $l, m$, arrow marking its line of motion; $p, e$, pterygoideus externus muscle; $g$, frontal bone; $d$, lachrymal bone; $c$, superior imaxillary bone; $b$, fang.

The myology of the subject is more complicated; yet even here our purpose will still be answered, if we describe only the muscles concerned, begging the reader to remember that all further details would be misplaced and useless. On reference to Fig. 3, it will be seen that the spheno-pterygoid, a, a strong muscle, arises along the raphe at the base of the cranium, and running backwards and outwards, is inserted fan-like upon the pterygoid plate. Acting from the fixed base of the skull upon the movable pterygoid bone, it must draw this bone forward, and, rocking the superior maxillary on its lachrymal joint, erect the fang, Fig. 2, $l-m$ and arrow.

A second large muscle, the pterygoideus externus, Fig. 3, $b$, arises from the tough aponeurosis covering the zygomatico-mandibular articulation of the lower jaw, and as it runs forward below the poison gland and to its inner side sends a strong layer of white fascial tissue out upon the capsule of the gland. Some of its lower fibres are finally inserted directly into the two lips or edges of the mucous sheath of the tooth fang. A larger part of the muscle is inserted tendinously into an apophysis of the superior maxillary bone exteriorly to the articulation of that bone with the external pterygoid, and a little below it. The mechanical necessities arising from the position of this muscle are easily seen; for when the external pterygoid acts, it will necessarily depress the fang. This movement will be more readily comprehended on reference again to the diagram, Fig. 2, in the text, where $p-e$ marks the line of action of the force applied by the pterygoid muscle to the superior maxillary bone and to the edges of the vagina dentis, the sheath of the fang. The action of this muscle is probably aided by the spheno-palatine, which arises along the raphe of the base of the skull, above the spheno-pterygoid and thus nearer the skull, and running diagonally outwards and backwards finds

1 These bones rest posteriorly against the articulation of the mandibulæ of the lower jaw with the zygoma ; they consequently share, to some extent, in the movements of this joint. 
insertion along the inside of the palatal bone. As its fibres cross those of the spheno-pterygoid, its action antagonizes that muscle and aids the purpose of the

Fig. 3

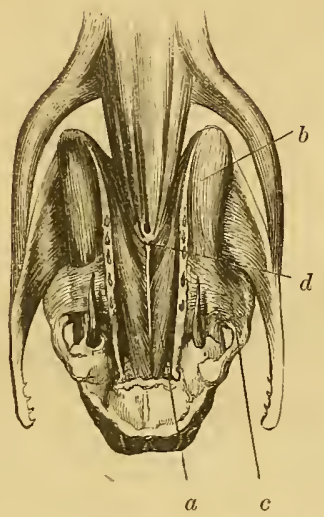

Mrocogr.-Palatal view of the muscles of the upper jaw and base of the skull. $a$, spheno-pterygoid muscle-the elevation of the fang is cansed by its action on the pterygoid and palate bones; $b$, external pterygoid muscle-the retractor of the fang-inserted into the outside of the snperior maxillary bone; $c$, fascial sheath of this muscle attached to the capsule of the renom gland; $d$, spheno-palatine moscle.

pterygoideus externus. The connection of the palate bone and the pterygoid bones, which we have already noticed, is essential to this result.

Almost all of the muscles about the head, neck, and jaws of the serpent, take part either in the motions which precede the blow, or those which inflict and follow it. Most of these muscles have functions which are obvious and easily demonstrable; and we shall, therefore, content ourselves with the briefest reference to all but the anterior temporal, which plays a far more important part, and requires a fuller description.

The mouth is opened by muscles, such as the costo-mandibular and the vertebromandibular, with the help of a muscular layer analogous to the platysma myoides. The articulation of the jaws is fixed by the double action of the digastricus and cervical angular muscles.

Of the temporal muscles there are three. The anterior temporal, Fig. 4, a, functionally the most important, arises from behind the orbit and from the upper

Fig. 4.

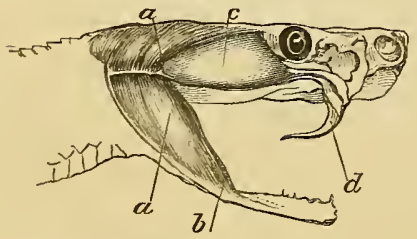

Exhibiting the Relation of the Temponal Mescles to the Venom Gland. $a-a$, anterior temporal muscle; $b$, its insertion in the lower jaw; $c$, venom gland; $d$, the fang half erected. 
two-thirds of the firm fascia of the poison gland. Its fibres run backwards over this body and descend between it and the middle temporal muscle. In this course the fibres lie posteriorly to the suspensory ligament, and the outer ones, as they fold about the articular end of the gland, lie in contact with the prolongation of the external lateral articular ligament upon that body. Finally, the muscle winds around the commissure of the lips, and is inserted in to the lower jaw some distance in front of the angle of the lips at $b$, Fig. 4 .

The middle and posterior temporal muscles, Figs. 4 and 5, arise chiefly from the

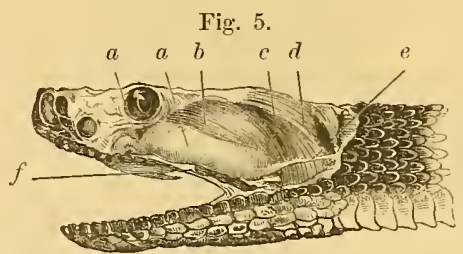

Mrology.-Lateral view. $a-a$, gland; $b$, anterior temporal muscle; $c$, posterior temporal muscle; $d$, digastricus mnscle; $e$, posterior ligament of the sheath of the gland; $f$, vagina dentis-the fang slightly raised.

temporal fossa and are inserted, one behind the other, into the lower jaw. As these two latter muscles descend nearly vertically, their obvious function is to close the jaws. The use of the anterior temporal is in part also the closure of the jaws, but its more obvious office is to press upon the poison gland, as we shall presently see.

The poison gland of the Crotalus occupies the side of the head, behind the eye, and beneath the anterior temporal muscle, Fig. 5 . Its posterior extremity extends three or four lines beyond the commissure of the lips. Its anterior end lies below and just behind the eye. Thus situated, the gland is in relation with the bony surface behind the eye, with the middle temporal muscle, with nerves which emerge under the suspensory ligament, and with the anterior temporal muscle above and behind, where that muscle descends to its insertion. Beneath, the gland is in contact with the external pterygoid muscle, with whose aponeurosis it has peculiar relations. So much of the gland as lies below the anterior temporal and above the line of the lip, is in relation with the skin which is here loosely connected with its fascia by areolar tissue.

The general form of the gland is that of a flattened, almond-shaped oval, the posterior end being somewhat obtuse, and the anterior tapering to the duct, which begins just behind and below the eyeball.

The length of the organ, from the insertion of the articular ligament to the begimning of the duct, was found to be eight-tenths of an inch, in a snake which was four feet long, and weighed two pounds and two ounces. Its breadth was nearly two-tenths of an inch, its thickness about one-eighth to one-tenth of an inch.

The poison-glands of six snakes were carefully weighed, after exhausting them of their contents, during the life of the snakes, and after the ducts and ligaments had been removed. In the following table, the weight of the gland, and the weight and length of the snake are given. 
It is proper to mention that almost all of these snakes had been in captivity during periods of from two to eight weeks.

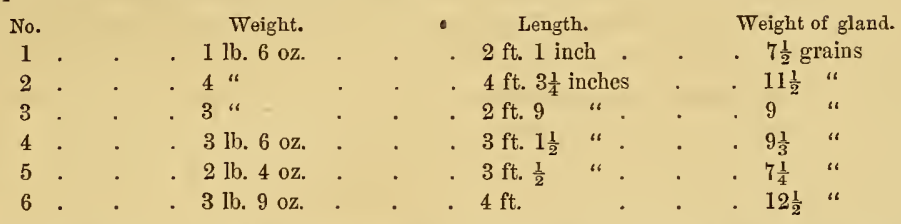

It will be seen from this table that very little relation can be established between the size and weight of the snake, and the weight of the gland, beyond the mere fact of the general increase in the size of the organ, with that of the snake.

The poison gland is invested with a double layer of white, and not very yielding fibrous tissue. The two layers of this membrane are united at the base of the gland, and becoming thinner anteriorly, they run off upon the duct, constituting a portion of its thickness. Besides furnishing attachment for the anterior temporal muscle, the ouler layer of this capsule gives off three remarkable ligamentous expansions which suspend and confine the gland.

The posterior of these is a narrow, but strong ribbon of fibrous tissue, see Fig. $5, e$, which runs from the posterior extremity of the gland to the articulation of the jaw, where it appears by its continuation backwards, to constitute one of the external ligaments of that joint.

The second, which we shall term the suspensory ligament, lies behind the gland, Fig. 6.
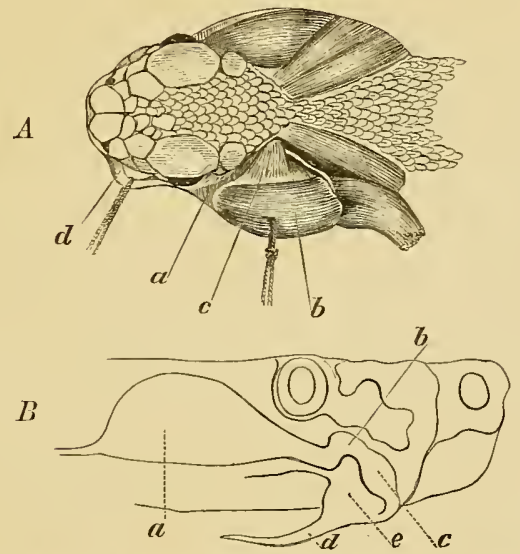

A. The Gland and Temporal Muscles Seen frou above. $a$, the gland; $b$, anterior temporal muscle; $c$, suspensory ligament of the gland extended; $d$, duct, drawn from its position.

B. Diagram of DUCT AND GlaND-SIDE view.- $a$, the venom gland; $b$, the duct, at its curve; $c$, the sphincter; $d$, fang; $e$, superior maxillary bone.

Fig. $6 A$, $c$, a little above its middle line. It arises as a fan-like expansion upon the capsule, and finally narrows to one-third, and is inserted on the bony surface 
to the inner side of the gland. This ligament is remarkably strong and unyielding; it supports the gland perfectly, and even acts as a passive antagonist to the force exerted by the anterior temporal muscle, while at the same time it shelters the large nerves which emerge beneath it from the skull.

The third attachment of the gland is by means of a fascia, which forms a strong expansion upon the external pterygoid muscle, Fig. 3, c, and then runs off laterally, to be inserted upon the outer capsule of the gland. This connection is principally with the lower and anterior portion of the gland. Its object will attract our attention in another place.

Anteriorly, and along its upper edge, the gland is secured by areolar tissue, connecting it with the edges of the temporal fossa, and the posterior edge of the orbit. At the extreme anterior point of the temporal muscle, however, a portion of its proper aponeurosis is gathered into a band, to which run also similar fibres from that part of the capsule of the gland which lies below the muscle. This collection of rather delicate fibres-for in the Crotalus it can scarcely be called a tendonruns forward above the flexure in the duct, and below the eye, to lose itself on the edge of the fossa, and about the base of the superior maxillary bone. Soubeiran describes in the Viper a tendinous insertion of the anterior temporal, as taking the track here described. I have been unable to discover this insertion in any of my dissections of the Crotalus.

In almost every account of the anatomy of the Crotalus, and in nearly all of the essays upon the effect of its venom, some allusion is made to a sac, or reservoir of poison. Strictly speaking, there is no such organ, and the only provision for the accumulation of venom is to be found in the duct, and its enlargement within the gland.

The duct expands somewhat suddenly, as it enters the gland, and being directed backwards and a little upwards, forms an irregularly-rounded cavity, which runs nearly the whole length of the gland. Into this receptacle, the smaller ducts of the gland empty their contents. From the sides of this cavity there run obliquely upwards, and a little backwards, from five to eight layers of white fibrous tissue, which, lying transversely to the long axis of the gland, separate its secreting portion into lobes, which narrow as they approach the central cavity. The septa here described are finally lost in the capsule of the gland. On their passage outwards, they send off numerous branches and thin sheets of tissue which proceed upwards, for the most part, but also across the lobes, and thus involve the secernent structure in a supporting scaffolding, of the firmest possible character.

The gland so constructed, resembles very strikingly, in section, the appearance of a small testicle. Its color is usually of a pearly or gray-white within, except under certain pathological conditions, when it is full of blood, and presents externally a darkly-mottled look.

The intimate structure of the poison gland resembles very closely that of the typical salivary glands. From the open space at the base of the gland, a number of ducts run up into its substance, and dividing, pass towards the periphery. The direction of these ducts is, for the most part, backwards and upwards. Owing to the strength of the fibrous bands which traverse the gland, and to the extreme 
softness of the intermediate tissue, I have found great difficulty in tracing the smaller ducts, Fig. $7, b$. Soubeiran ${ }^{\mathrm{I}}$ describes them in the Viper, as terminating in minute pouches of amorphous matter. Rymer Jones (article "Reptilia," Cyclopedia of Anatomy and Physiology) also speaks of the ducts dividing, to form smaller

Fig. 7.

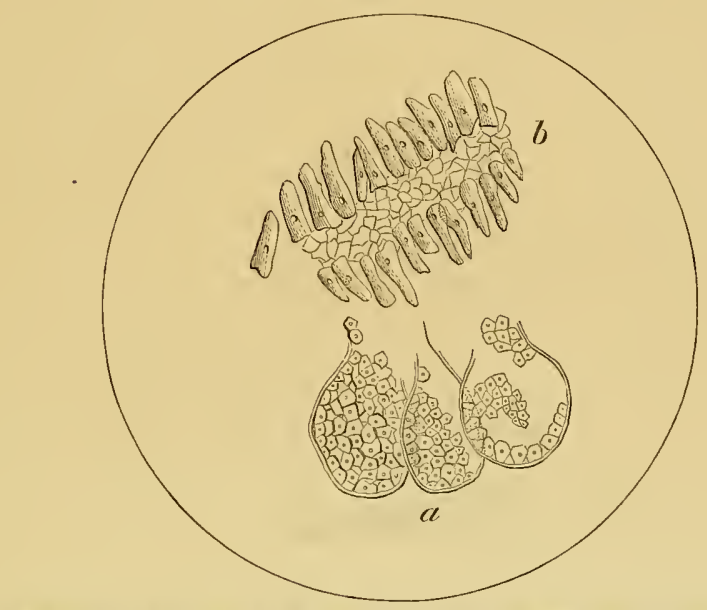

Microscopical Structure of the Venom Giand.- $a$, secernent cœca; $b$, small ducts.

tubes, on which are finally developed secernent cœeca, Fig. 7, $a$, like those of the ordinary salivary glands. In perfectly fresh specimens, these coeca can sometimes be made out. They are lined with pale tessellated and nucleated rounded epithelia, and are commonly filled with amorphous and granular matter, Fig. 7, $a$. The epithelia in question are very easily altered, and in glands kept for a few hours in summer, are scarcely to be recognized. The smaller ducts are lined with a pale and narrow columnar epithelial cell, Fig. $7, b$. The cavity at the base of the gland, as well as the main duct which connects with the fang, are lined with large pavement-epithelial cells, which possess distinct nuclei, Fig. 8, $\alpha$. This form of epithelia is not usually encountered in this position, in homologous glands, whose ducts are, on the contrary, covered internally with columnar epithelia. Outside of this cellular layer, the poison duct is made up principally of white fibrous tissue, with a small proportion of very fine fibres of yellow elastic tissue. The walls of the duct are provided throughout with an abundant supply of bloodvessels.

Just above the line of the lip, and consequently at the base and outer side of the maxillary bone, the duct, in turning to descend this bone, becomes abruptly larger, for a distance of a line, or a line and a half, Fig. $6 \mathrm{~B}, c$. Its color at this point is also a little redder than the rest of the duct. Beyond this point, the duct again becomes smaller. If now a probe be introduced into the duct, and its whole 
length divided, it will be observed that the calibre of the canal does not enlarge, until it reaches the gland, and that the appearance of increased size here described, is due to a distinct thickening of the walls of the tube.

Fig. 8.

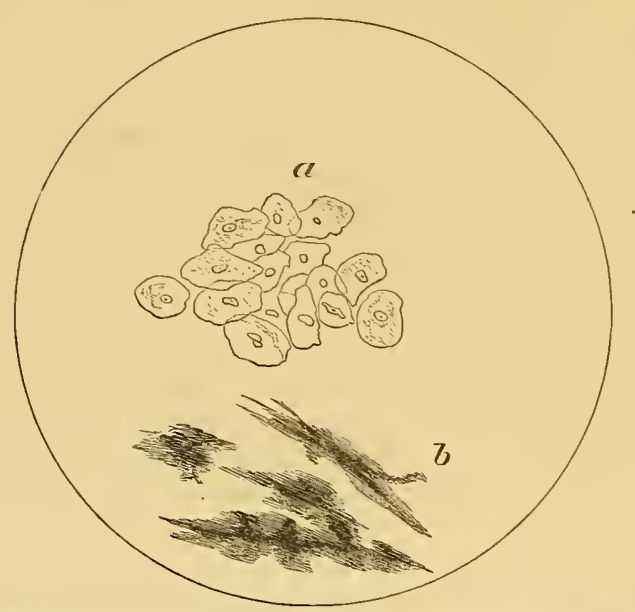

$a$, Epithelial cells of main duct, and of the receptacle at the base of the gland; $b$, pigment-cells of the duct.

Fig. 9.

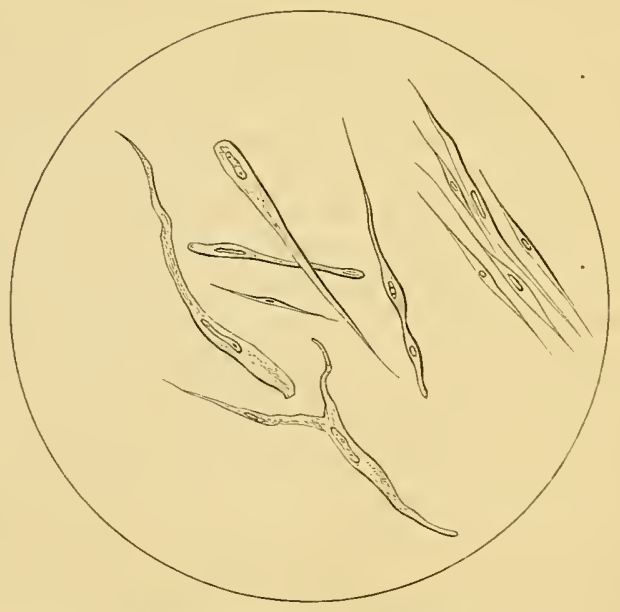

Non-striated Musctlar Fibre-cells of the Sphincter of the Doct.

Upon careful examination of the nature of this tissue, $I$ found it to be formed by an increase in the amount of fibrous tissue, and by the addition of a layer of 
elongated fusiform cells, Fig. 9, each having a single nucleus, and sometimes a long, dark nucleolus.

These elements are undoubtedly the characteristic cells of non-striated muscular tissue. $^{.} \quad$ Their presence, together with the form and position of this enlargement, enables us to view it as a sphincter placed upon the duct, for the purpose of restraining the wasteful flow of the secretion. This portion of the wall of the duct contains numerous irregular, stellate, pigment-cells, Fig. $8, b$. So far as I am aware, no author has described this adjunct to the venom apparatus. Of its purpose, however, I have no doubt; and that some such provision does exist, is plain, from the fact that, when in the living Rattlesnake the jaws are separated, and the fangs caught on the edge of a thin cup, and erected, it is usually very difficult to produce a flow of venom. Even when the operator presses upon the glands, the poison is rarely ejected, without the voluntary aid of the snake itself. ${ }^{2}$ After death, the remnant of fluid in the gland, although small in amount, is easily forced out along the duct, and through the fang. It is, therefore, very plain, that the snake has the power to restrain the flow of venom, even when the fangs are in such a position as that without the aid of the arrangement we have described, they must inevitably permit of the escape of the poison.

Beyond the sphincter, the duct becomes smaller in calibre, and the walls thinner. To reach the fissure at the base and anterior aspect of the fang-tooth, the duct runs up the posterior edge of the fossette, and winds over the rounded anterolateral shoulder of the superior maxillary bone to reach its anterior face, where it communicates with the fissure in the fang. The value of the course thus taken by the duct, we shall elsewhere consider.

Another peculiarity in the course of the duct, should, however, claim attention, as it has also a mechanical use. Just below the eye, the duct is abruptly bent, as indicated in Fig. 5.

In its passage from the gland to the tooth, the duct is held in place by a sheet of rather close areolar tissue, which admits of the curves in the tube being straightened, as occasion requires. The part nearest to the gland also receives some of the fibres from the dense fascia which invests the external pterygoid muscle.

The structure of the fang in venomous serpents has been so minutely described by Owen, ${ }^{3}$ that a brief synopsis of his views will be all that we shall require. I have carefully examined the fang-tooth by the aid of fine sections, and I have nothing to add to the following excellent description by the author above mentioned.

"To give an idea of the structure of this tooth, we may suppose a simple, slender tooth, like that of a boa-constrictor, to be flattened, and its edges then bent towards each other, and soldered together, so as to form a tube, open at both ends, and inclosing the end of the poison duct. The duct which conveys the poison,

${ }^{1}$ Dr. Woodward, who was so kind as to examine these structnres, agreed with me as to their nature.

2 This is only true of the active animal; when insensible from chloroform, the glands are easily emptied by pressure.

${ }^{3}$ Owen on the Skeleton and Teeth, Philada. 1854, p. 257, and Cyclopedia of Anatomy and Physiology, article 'T'eeth. 
although it runs through the centre of the tooth, is really on the outside of the tooth. The bending of the dentine beyond it, begins a little beyond the base of the tooth, where the poison duct rests in a slight groove, or longitudinal indentation, on the convex side of the fang; as it proceeds, it sinks deeper into the substance of the tooth, and the sides of the groove meet and coalesce, so that the trace of the inflected fold ceases, in some species, to be perceptible to the naked eye, and the fang appears, as it is commonly described to be, perforated by the duct of the poison gland."

The tooth fang, in the Rattlesnake, has a peculiar double curve. The lower curve is large, and has an anterior convexity; the upper involves only two or three lines of the length of the tooth from the point down, and is nearly straight, or presents a slight concavity anteriorly. The whole length of the fang, from point to base, was $\frac{5}{10}$ of an inch in a snake, four feet two inches long. One-tenth of an inch below the point.in this tooth, the poison canal opened on the anterior, or convex surface of the fang. Above this, the fang was solid; as the true pulp cavity terminated some distance lower down. The point of this singular weapon is brittle, but of an exquisite fineness. The tooth thus described, is firmly anchylosed to the submaxillary bone, its base being luted to the portion of bone around its side and anterior aspect. Posteriorly, the bone possesses a hollow, in which is lodged the tooth sac. In the open mouth of this alveolar process, within the mucous membrane, and upon the pterygoid bone, lie one behind and below another, the reserve fangs, each smaller than the one in front, and less and less developed, until the situation of the last which is visible, is marked by a minute papilla alone. I have counted from eight to ten of these on each side. A very good account of their gradual development has been given by W. J. Burnett. ${ }^{1}$ The details do not directly concern us here.

When the fang is lost by a natural process, it is replaced within a few days. When violently displaced, several weeks sometimes elapse before the next fang is fixed firmly enough to be useful to the snake.

If the functional fang be lost or shed, the next tooth gradually assumes its position, but of the mode in which the communication is re-established between the poison duct and the fissure of the lower part and front of the new tooth, we have had no correct knowledge until a recent period.

Burnett states, that "the original tooth follicle appears to him to become the poison gland or sac." He then goes on to support this view briefly, still speaking of the poison gland as possibly accompanying the tooth in its forward movement. Dr. Burnett must have made this statement under a misconception, as it is well known there is no poison sac or gland at the base of the fang, or in immediate connection with it.

More recently, the subject of the development of the fangs and the mode in which the fixed fang is replaced, when shed or broken, have been carefully studied by my friend, Dr. Christopher Johnston, of Baltimore, whose skill as an observer,

1 W. J. Burnett, M. D., Boston Nat. Hist. Soc., vol. iv. p. 311-323. 
as well as his peculiar knowledge of dental structures, entitle his views to great respect.

At my request, Dr. Johnston has repeated his observations, and most kindly placed them at my disposal. The following statement is in his own language :-

"The study of heads prepared by me, leads me to entertain the following opinion as to the manner in which secondary fangs establish a communication with the poison duct. There appears to me good reason to believe that there is a periodical fall of the venom fangs, quite independent of violence; and this is to be regarded as a physiological circumstance agreeing with what takes place in fishes, as Pike or Gar, and in reptiles, as Iguana, as well as with what occurs in the jarss of Megalosaurus, Hadrosaurus, etc. For I have not observed in the jaws of Crotali of the same species a constant relation between the size of the serpent and of its fangs; and when I couple with the disproportion alluded to, the fact, that at nearly all seasons, reserve fangs and germs are found in every degree of advancement or development, I cannot suppose that the almost mature secondaries are awaiting an accident to effect their promotion. We know that in Alligator especially, the secondaries occasion by their development the erosion of the base, and the consequent displacement of their predecessors, and assume positions from which they are to be in turn expelled.

"In Crotalus, the secondary fangs lie in separate capsules at the bottom of the dens in the mucous membrane, where the fangs crouch when not erected. Their pulps are arranged in order upon a gum which lies at the base and to the inner side of the functioning fang; and each developing fang is inclosed in a separate capsule and points directly backwards.

"Now a transverse section of a pulp in any part of its extent, gives a crescentic figure, hardly perceptible as a crescent at the point, evidently lunate with separate horns on either side of the distal aperture of the poison canal, and again a crescent, but with closely approximated cornua, throughout the rest of the crown, where the two longitudinal folds of dentine meet along the median line and are fused together.

"As the growth of the tooth advances, a slight annular enlargement marks its neck, or at least the limit of the crown, and then the two horns of the pulp diverge widely, at the upper part of the base, which is in process of formation, but again approach each other, yet without meeting, as the base goes on to completion. It may here be remarked, that the pulp acquires greater volume at this part of the fang, which is more extended along the posterior edge than in front, and is marked, both internally and externally, with conspicuous longitudinal flutings.

"The dentine of the basal portion in front, necessarily follows the modelling pulp; and as this, by the separation of the anterior lamellæ, leaves an ovoidal hiatus, so the tooth substance investing the matrix shows the free edge of its folds on either side as the margin of a large aperture, the inlet of the poison canal. All this occurs while yet the tooth-capsule is entire.

"In this condition the secondary fang remains until the fang in use falls spontaneously or by violence; and the secondaries behind it will be found to exhibit successive inferior stages of development. At length the prime fang is removed, if spontaneously, by the atrophy of the pulp, and, I believe, by erosion of the basal 
anchylosed portion; if it be broken off by violence, the freedom of the pseudo socket is accomplished by the same means. And now the first tooth of reserve is urged forwards into a recess in the maxillary bone directly adjacent to, and on the inner side of the fallen fang; and the requisite advancement is brought about by the developmental vis à tergo of the remaining reserve pulps, and probably also by the traction in front, exerted by the cicatrizing parts. It is evident that the fang emerges from its capsule, and that the point and crown repose in the den, but the base is closely invested with the capsular remains under the form of a periosteal expansion, which is the mediate bond of union between the base and the new and shallow socket of the maxilla.

"As may be perceived, upon examination at this stage, two sockets co-exist in the same jaw. The inner, new one, supporting the recently promoted fang, and the outer, old, and now vacant one, which is fast being disencumbered of the vestiges pertaining to its former resident. In this maxilla, the new fang occupies the innermost part, having the old socket on the outer side, while in the opposite maxilla, the older venom fang may be discovered in its normal situation, leaving the recess to its inner side vacant, for the temporary lodgment of its successor. Or, both fangs being recently fixed to the jaw, the vacuities will both be formed on the outside, and all the reserve fangs will appear to follow backwards and outwards in direct line.

"Now let us look at the situation of the poison duct, and examine into the mode by which it is brought into relation with the fang.

"The venom duct arising from the gland makes a bend upwards, immediately beneath the eye, then advances forwards under the skin, as far as the crotaline fossette, and lying upon the maxilla externally, plunges downwards, and pierces the gum in front of the fang, where it terminates in a papilla, which projects slightly into the proximal aperture of the tooth. In this position, it is maintained by the gum which clasps the base laterally and in front, with considerable firmness, its inferior or distal edge, encompassing the annular enlargement already alluded to. Nor is there any other than a mediate application of the poison papilla against the fang, for as the whole venom canal of each tooth is really upon the outside of the organ, no special membrane lines it which might be continuous with the duct that discharges into the upper aperture.

"Such is the condition of things in an old fang, occupying its normal exterior position. But when the tooth drops out, or is broken, the gum is left entire; or, if its exodus has been forced, the gum escapes with laceration only. In either case, however, the gum remains as a barrier, limiting the progress of the advancing reserve fang; and while the latter is establishing itself provisionally, the gum encircles it, clasps it tenaciously, and brings the poison papilla in apposition with its dental aperture. As time passes, the new fang moves gradually outwards to its permanent seat; the inner maxillary recess is restored, and the first fang of reserve is again discovered on the inner side of its senior, resting with its pulp attachment in the bottom of the recess.

"Thus, the reserve fang has become an adult functioning fang, nor does its pulp 
relax its hold, until fate or mischance dislodge the now fatally-armed tooth which it animates."

Before leaving this portion of the subject, it is proper to state that the views expressed by my friend Dr. Johnston, as to the want of direct continuity between the duct of the poison gland and the tooth canal, have been recently advocated by Prof. Jeffries Wyman, of Boston. It gives me great pleasure to point out this coincidence of opinion; and while acknowledging Prof. Wyman's priority of claim as established by publication, I must not omit to add that Dr. Johnston's manuscript notes-which I have quoted above-bear the date of Oct. 3d, 1859, since which time they have been in my own possession. ${ }^{1}$

The accompanying diagram, Fig. 1.0, illustrates our views as to the direction taken by the new fang, in its progress towards the alveolar socket.

It will have been observed that Dr. Johnston states, that the first reserve fang enters the semilunar socket in the maxilla, to the inside of the active fang. Although this is often or usually the case, it is not uncommon to find the two fixed

Fig. 10.

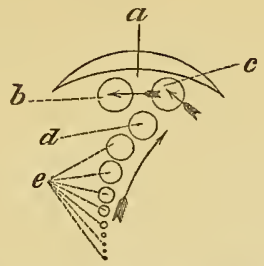

$a$, Alveolar socket; $b$, functionary fang ; $c$, its successor ; $d$, the next fang in order of age ; $e$, remaining germs.

fangs, unsymmetrically placed, one on the inner, the other on the outer side, of their respective alveolæ, or both on the-inner side; or again, both on the outer side of the said socket.

In all other points, my own researches agree with those of Dr. Johnston.

1. May 16th, 1860 ; Proc. Boston Nat. Hist. Soc. 


\section{CHA P TER III.}

\section{THE PHYSIOLOGICAL MECHANISM OF THE BITE OF THE CROTALUS.}

THE preceding details will enable us to understand the following statement of the functions of the various parts described, and to appreciate the mode in which they combine to effect a given purpose.

Of the many authors who have treated of the anatomy and physiology of the Rattlesnake and other venomous serpents, no one has entered fully into the subject of the mechanism of the movements which inflict the bite and inject the poison. Redi, Fontana, Tyson, Ranby, Smith, Home, Duvernoy, Soubeiran, and others, have nearly all in turn contributed something to this subject, but I find nowhere a full and complete account of the part played by the various muscles and of the exact uses of many of the peculiar arrangements of tissue which characterize the poison apparatus. Nothing, in fact, can be more admirable than the mode in which the motions in question are effected, and yet while they interest the physiologist, from the wonderful example they afford of a series of complex acts following one upon another in ordered sequence, to effect a certain end, they are not less interesting to the physician, who may learn from their study how he may be deceived as to the occurrence of poisoned wounds, and how the snake which appears to strike may really fail in its object, even though seeming to have inflicted a wound.

When the Rattlesnake is in repose and unmolested, it sometimes lies at length, sometimes coiled, or wrapped fold on fold in the loops formed by other snakes which may happen to be in the same box. So soon, however, as cause is seen for alarm, the snake extricates itself, if among others, and at once throws its body into the coil so familiar to any one who has seen serpents, whether venomous or not. Sometimes on the edge, more often in the centre of the coil, the tail projects far enough to admit of its vibrating freely, and with singular swiftness.

The head is raised a little above the rest of the body, but not, usually, more than three or four inches, even in large snakes. The neck and upper end of the trunk are not thrown into complete circles, but lie in two or three abrupt curves across the mass of the coiled body. The snake is now in position to strike. While thus at bay, in an attitude of singular grace, the long black tongue is frequently protruded, a common movement among all serpents when irritated. Just before the blow the snake makes a hissing sound, which is caused by the act of expiration, and is due to the passage of air through the narrow glottis. It is louder in certain inmocent serpents than in the Crotalus.

The mechanism of the forward cast of the body, which next occurs, is a very 
simple matter. The muscles which lie upon the convexity of the bendings formed by the upper part of the snake, are suddenly and violently contracted, so as abruptly to straighten the body, and thrust it forward in a direct line. The force resulting from this motion is not very great, as $I$ have often ascertained when a snake has struck the end of a pole which I was holding, nor would it alone suffice to bury the fang in a tough skin, were it not for the acts which follow and aid it. In effecting this forward thrust of the neck and head, the serpent employs only the upper part of its body, and, consequently, is unable, under any circumstances, to strike at a greater distance than one-half its length, while usually its projectile range does not exceed a third of its length. An impression prevails that when the snake lies coiled, its head is raised very high to enable it to strike downwards. It seems, however, to be of no moment, in what direction the danger threatens, since it can, at will, cast itself forwards, downwards, or almost directly upwards.

As the animal comes within reach, of which the snake does not always judge with accuracy, the latter executes the movement just described. At the instant, and while in motion, the jaws are separated widely, and the head is bent somewhat back upon the first cervical bones, so as to bring the point of the fang into a favorable position to penetrate the opposing flesh. Owing to the backward curve of the tooth, this, of necessity involves the opening of the jaws to such an extent, that an observer standing above the snake, can see the white mucous membrane of the mouth, as the blow is given. The peculiar articulation of the lower jaw upon an intermediary bone, in place of upon the body of the skull, greatly facilitates this action. On examining the neck and head, it will also be seen that the head, under the influence of the cervical prolongation of the mass of the spinal muscles, is capable of being bent backwards to no inconsiderable extent. Consentaneously with the forward thrust of the body, and with the opening of the mouth, the spheno-pterygoids act from their firm cranial attachments to draw forward the pterygoid plate, and thus, through its attachment to the maxillary to erect the fang. The function of elevating the fang belongs alone to this muscle, which has no analogue in the other vertebrate animals. I have frequently tested its power to raise the fang, by stimulating it with galvanic or other irritants, after decapitating the snake, and although some French observers seem to have had doubts as to the agencies which effect the elevation and depression of the fang, there does not seem to me to be any reason to doubt the share which the spheno-pterygoid takes in this mechanism. That the mere act of opening the mouth, of necessity raises the weapon, has often been affirmed, but it is only necessary to separate the jaws of a living Crotalus to be convinced that this is not the case, and that even when the mouth is widely opened, the animal has the most perfect control over the movement of the fang, raising or depressing it at will.

As the spheno-pterygoid acts, the submaxillary bone rocks forward upon its lachrymal articulation. When the motion reaches its limit, and is checked by the ligament which I have described, the supporting lachrymal bone, in turn, yields to the power applied through the maxillary bone. These movements elevate a little the muzzle of the snake, so as to give to the face a very singular expression during. the act of striking. Their more obvious and important result, is the elevation of 
the fang, which, rising, thrusts off, from its convexity, the cloak-like vagina-dentis so that it gathers in loose folds at its base.

As the unsheathed tooth penetrates the flesh of the victim, a series of movements occur, which must be contemporaneous, or nearly so. The body of the snake still resting in coil, makes, as it were, an anchor, while the muscles of the neck contracting, draw upon the head so violently, that when a small animal is the prey, it is often dragged back by the effort bere described. If now the head and fang remained passive, the pull upon the head would withdraw the fang too soon; but at this moment, the head is probably stayed in its position by the muscles below, or in front of the spine; while the pterygoideus externus and spheno-palatine, acting upon the fang through their respective insertions, into the posterior apophysis of the submaxillary bone, and the inside of the palate bone, draw its point violently backwards, so as to drive it more deeply into the flesh. The muscles alluded to, therefore, antagonize the spheno-pterygoid.

At this instant, occurs a third series of motions, which result in the further deepening of the wound, and in the injection of the poison.

The lower jaw is closed upon the bitten part, or member. Where the surface struck is flat and large, this action will have but slight influence. Where the jaw shuts on a small limb, or member, the consequent effects will be far more likely to prove serious, since the power thus to shut the mouth materially aids the purpose of the blow. The closure of the jaw is effected by the posterior middle, and anterior temporal muscles. The first two tend simply to shut the mouth; the anterior temporal, however, is so folded about the poison gland, that while it draws up the lower jaw, it simultaneously compresses two-thirds of the body of the gland. This force is applied in such a manner as to squeeze the fluids out of the upper and back parts of the gland, and drive them forwards into the duct. The anterior lower angle of the gland, as well as a portion of the duct, is subjected to similar pressure at the same instant, owing to the flat tendinous insertion of a part of the extermal pterygoid upon the parts in question.

It will thus be observed, that the same muscular acts which deepen the wound, fix the prey, and inject the venom through the duct, and into the tissues penetrated by the tooth. ${ }^{1}$ The whole process here described at such length, is the work of an instant, and the serpent's next effort is to disentangle itself from its victim. This step is effected by relaxing the muscles of the neck, so as to leave the head passive, while the continued traction of the muscles of the body pull upon it, aud thus withdraw the fang, over which glides the elastic mucous sheath as the

${ }^{1}$ It follows from the observations of Dr. Johnston, and Prof. Wyman, that no tissue connection exists between the venom duct and the basal opening in the fang. It becomes necessary, under these circumstances, to explain how the poison is carried from one to the other. Usually the projecting papilia at the end of the duct, is held by the gum in close contact with the fang opening, and when the fang, in rising, thrnsts back its mucons cloak, this presses upon the parts at the base of the fang so firmly, as to bring them into perfect apposition. This explanation is giveu by Prof. Wyman. It does very often happen, however, that a part only, or even none, of the venom enters the fang, but is violently ejected between that weapon and the edges of the vagina dentis. 
pterygoid, again acting, depresses the fang, and the serpent recovers its posture of defence.

It happens, not unfrequently, that the teeth of the lower jaw catch in the skin of the bitten animal, and thus prevent the snake from retreating at once. When this takes place, the serpent shakes its head from side to side, with a motion which so nearly resembles the shake a dog gives his prey, that it has been mistaken by at least one observer for an expression of rage. It is really an attempt to escape; nor is it always successful, since a large animal will often drag a snake until the fangs themselves break loose, and are left in, or on, the bitten part.

In considering this portion of our subject, it is well to notice what bas been too much overlooked, the fact that, while the snake commonly employs both fangs, it does often inflict but a single wound. When obtaining venom from living snakes, I have been accustomed to allow them to bite upon the inner edge of a cup, and I have observed that on some occasions both fangs were used at once, and that on others only one was active. Or, the fangs were used in succession, an appreciable interval of time intervening. If this occur, when a snake at freedom strikes an object, it is, of course, possible that the animal may escape before the second fang is driven in by the traction of its proper external pterygoid muscle. At all events, it is certain that these facts should receive due appreciation, in estimating the danger of a given bite, and the value of an antidote.

There remains for consideration one muscular motion, which $\mathrm{I}$ have observed to accompany the effort to bite, when the snake is held by the back of the neck. It consists in a turning outwards of the points of the fangs, so as to separate them from one another. ${ }^{1}$ This divergence of the fang points is disadvantageous, inasmuch as it causes them to enter somewhat obliquely, and frequently throws one fang beyond the part bitten, when that part happens to be small. It has a use with reference to the snake itself, since the fang-points, when thus widely separated, lie outside of the lower jaw, and are thus prevented from wounding it. This purpose is greatly aided by the action of a muscle analogous to the mylo-hyoid, which approximates the anterior extremities of the lower maxillary, or mandibular bones, so as to make narrow the extremity of the jaw. The protection thus obtained is very essential, since the serpent always closes the jaw violently when biting, but does not always succeed in seizing its prey. Whether or not this divergence of the fang-points occurs when the snake bites unrestrainedly, I cannot say; but as I have been very often astonished at the distance between the wounds, where both fangs had taken effect, it is highly probable that it occurs under all circumstances.

We have still left for consideration certain points of minor interest, in connection with the part played by the gland in the train of actions which $I$ have described. This organ, as we have seen, is violently compressed by the anterior temporal muscle, and perhaps by the posterior temporal, as well as indirectly by the external pterygoid. Under the pressure thus applied, the venom passes through the duct, and out of the fang. Now, as it is clear that the temporal muscles must be often used to

' I could not determine whether this divergence took' place when the suake, at freedom, struck an animal. 
close the jaws, under circumstances which do not demand the ejection of venom, we must suppose, either that the anterior temporal is, at times, functionally inactive, or else that some provision exists for restraining the flow of poison, when the gland is incidentally compressed during the ordinary movements of the lower jaw, as in gaping (a common action with snakes), deglutition, etc.

The closure of the duct is provided for in two ways, one of which is peculiarly ingenious. The first and most effective of these is the sphincter, which I have already described. The second consists in a peculiar relation between the maxillary bone and the duct. The antero-lateral surface of the bone is somewhat rounded, and the duct being confined at the base of the bone, and also perfectly fixed at its junction with the fang, it happens that when the fang tooth lies flexed in the mouth, the maxillary portion of the duct is stretched over the rounded shoulder of bone upon which it rests, thus flattening, and closing its canal more or less completely.

It is worthy of remark, that the abrupt curve of the duct under the eye, has, also, a mechanical value. First, as an additional means of interrupting the flow of venom, when the fang is not in use, and, second, as a provision for preventing injury to the duct, when, during the action of fixing the fang, the duct is drawn backward by the muscles, and forward by the sudden and momentary flexion of the fang, which occurs at this time. Under these two forces, the bend in the duct is temporarily obliterated.

The power with which the venom is ejected from the tooth, depends somewhat upon the amount contained in the gland and its ducts. When the snake fails to strike the object aimed at, the poison is sometimes projected several feet. In one case which is known to me, it was thrown into the eye of a man standing five or six feet from the snake, when it struck upwards at a stick held above its coil. ${ }^{1}$

1 For an account of many facts in conuection with snakes, which are of popular scientific interest, but remote from my present subject, the reader will do well to consult Professor Leconte's paper, Shaw's Zoology, the various Encyclopedia articles, and the memoir of Prof. Dumeril, to which I have already referred.

The great tenacity of life on the part of snakes, is allnded to by several of these anthors, and is well known in the form of a very singular popular belief. It is certainly very remarkable in the Rattlesnake, whose reflex motions are admirably retained for some hours after decapitation, and occasionally are seen as late as the 36 th hour. At this late period, they consist in wave-like morements, which run from the tail upwards, and are most readily exeited by pinching the parts about the cloaca. Immediately after the head has been cut off, the body writhes slowly along the floor, or, if hung np, returns on itself, twiniug the pendant trank around the tail. If, when the body is entirely fresh, we seize the tail, the headless trunk frequently returns on itself, in the effort to strike the offending hand. Occasionally, this morement is so perfectly executed, that the bleeding and headless trunk smites the operator's hand before it can be withdrawn. In one or two instances, persons who were ignorant of the possibility of this movement, have been so terrified at the blow which has greeted them, as to faint on the spot. To hold thus the headless suake, has been made a test of firmness in some parts of the Test; and few have been found composed enough to retain the tail until the innocent, but ghastly stamp, strnck the hand. Indeed, any one who may try this little experiment, will discorer that it is no easy task to keep a steady grasp upon the tail, even when, in ineffectual efforts, the bleeding neck is thrown towards the irritated parts, but does not fully succeed in reaching it. It is interesting to observe that, while the person whose nerres are thus tried, looks at the suake, he can scarcely ever so control himself as to be unmoved; bnt, if he close his 
The study of the complicated mechanism which we have endeavored to explain, will aid us in understanding several points of interest in connection with the bite of the Rattlesnake.

It must be perfectly apparent that in a sequence of movements so elaborate, it will occasionally happen that, from a failure in some one of the essential motions, the ultimate purpose of the whole will be interfered with. Thus, it sometimes chances that the serpent miscalculates the distance, and fails from this cause. Or, again, when the object aimed at is very near, the initial force of the blow is lost, and the tooth does not enter; no uncommon occurrence, where the animal struck is an old dog, with a tough skin. Again, if the upper jaw be not elevated sufficiently, the fangs are sometimes driven backwards, by the force of the forward impulse, as they touch the part attacked, and the venom is then apt to escape between the tooth and the covering mucous cloak. Upon one occasion, having allowed a small snake to strike a dog, the former became entangled, owing to the hooked teeth of the lower maxillary bone having caught in the skin. Upon examining the snake closely, the dog being held, I found that the convexity of the fangs lay against the skin, on which were thrown one or two drops of venom. On removing the snake, and inspecting the part struck, I could find no fang wound, although the skin was visibly torn by the smaller teeth. I have seen the Rattlesnake strike with great apparent ferocity, a number of times, when I have been unable to discover any fang wound whatsoever; and this has taken place, occasionally, with small animals, such as the rabbit, which must have been seriously affected by even a small amount of venom.

It scarcely ever happens that an animal is bitten, without a part of the injected venom being cast on the skin, near the wound made by the fangs. This wasted material probably escapes from the duct, where it is in apposition with the lower opening of the fang canal, and may be merely that excess of fluid which the fang cannot carry. In some cases, however, it is quite possible that the relations of the fang and the duct are so disturbed, that the venom never enters the tooth at all. It is certainly true, as has been already stated, and as Dr. Wyman has shown, that the fang must be fully erected in order that the duct shall be so firmly held in contact with the fang, as to insure the passage of the venom through this latter organ.

Finally, it sometimes happens, that the blow is given, the fang enters, and from the quick starting of the animal injured, or from some other interrupting cause, it is withdrawn so soon that the larger portion of the poison is thrown harmless upon the surface near the wound. Under these circumstances, the resulting symptoms are, of course, trifling; and how well such an occurrence would be calculated to deceive the observer, who employed an antidote in a like case, can be readily conceived.

eyes or look away, the source through which the involuntary start of alarm, or nerrousness, is, so to speak, dictated, appears to be cut off, and the intellectual and memorial recognition of the snake's powers is not sufficiently lively to overcome the force of will which is exerted to retain the grasp. 
When speaking of the difficulties which surround the study of antidotes to serpent poison, we shall return again to this subject. Here it is sufficient to have pointed out such of the fallacies as are due to a want of exact knowledge of the mechanism concerned in producing the poisoned wound.

The minute details, here given, of the mechanism of the bite, are collected from many sources already mentioned, and are carefully corrected by numerous. original observations, dissections, and experimental demonstrations of the mode in which different muscles acted under galvanic stimulus, applied after decollation and removal of the skin. So far as I am aware, it is the only full account of the mode in which the bite is given, and of the parts played by the different organs and tissues concerned. 
C H A P T E R I V.

\section{THE PHYSICAL AND CHEMICAL CHARACTERS OF THE VENOM.}

THE venom, the injection of which is the sole object of the mechanism we have been considering, will now claim our attention. In my own researches, I have felt seriously the want of statements as to the manipulation and mechanical means employed by preceding observers, when handling, and otherwise using, their snakes. For this reason, as well as to place the reader upon the same logical ground with myself, by giving him every known condition and accompaniment of each observation, I have, in all cases, described minutely the whole manual of each experiment. Where these details would have confused the statements of results, I have placed them in the form of notes.

It would have been an easy task to swell this Essay to an imposing bulk, by quoting throughout all the comparative results obtained by those who have experimented on venomous snakes, other than the Crotalus. So full a summary would not be without use and interest; but, since the mass of these researches have but little value, I have contented myself with the briefest relation of the opinions of others, where they did not directly concern the rattlesnake. My main object has been to present, with brevity, my own results, as regards the Crotalus, with such illustration, contrast, and comment, derived from the works of others, as seemed to me essential to this purpose.

Amount of Tenom in the Ducls.-The amount of venom contained at any one time in the ducts of the poison gland, varied with the size of the snake, and the period which had elapsed since the last bite. I have again and again collected the venom, and have found that serpents of from three to four feet long rarely threw out more than from two to four drops, after the first ejection had taken place. When perfectly fresh, healthy, and undisturbed for some weeks in summer, the first gush of their venom was sometimes astonishingly large. A snake which had served as a show in Washington, reached me in a box with a glass top, which was firmly fixed by screws. In all probability this snake had been several weeks without using its fangs. ${ }^{1}$ It was secured as usual, and the lip of a cup placed in its mouth. It

1 Manipulation.-The authors who have written upon serpents, have usually obtained their venom by killing the animal, and compressing the gland (Fontana), or by anæsthetizing it with chloroform (Burnett), and then exerting pressure, until the fluid exuded through the duct. Where snakes are abundant, the first method is perhaps the best, if the head be cut off rapidly and suddenly, without 
struck at once with the right fang, but missing the cup, poured a large amount of renom into its own mouth. The left fang struck an instant after, and threw into

allowing the snake to bite at any object, and thus exhaust its venom. Where the snakes are not easily replaced, this plan is plainly not economical.

Others have allowed the snake to bite upon soft substances which imbibed the renom readily, and from which it conld be removed by water (Bonaparte). The methods which, after long practice, I have found most arailable, I will detail here, after describing the various means which I have found useful in securing the snakes for experiment, or in removing them from box to box.

In moving suakes, it is customary to employ long-bandled tongs, or forceps, which are apt to pinch aud otherwise injure them. I hare been in the habit of using for this purpose, a bar of wood four feet long, and eut off at the end, so as to present a slightly roughened surface, one and a half inches square. On one side of the end, a piece of soft and pliant leather strap was nailed securely. This strap was then carried across the end of the bar, and through a flat staple upon the side opposite to that on which the strap was fastened. A stout cord, attached to the strap above the staple, was held in the operator's hand. To use this simple instrument, the strap was drawn down, so as to form a loop, which was easily slipped orer the head of a snake, and there tightened by drawing on the cord. Where it was desirable merely to secure the venom, the loop was slipped over the head and drawn closely around the neck.

Thus prepared, the snake was placed on the table and retained by an assistant, while the operator obtained the venom. When it was desirable to have an animal bitten without placing it in the cage, the loop was carried to the middle of the snake's body, and it was thus allowed movement enough to enable it to draw back and strike. It is nnnecessary to add that during these manipulations, the utmost caution is necessary to avoid accident.

As it is sometimes essential to detain the snake on the table for some time, without being forced to employ a person to guard it, I devised a little apparatus, which, although imperfect, answered my ends well enongh. A box, about four inches square, and thirty-six inches long, was divided lengthwise, and arranged with hinges so as to close readily. The trro sections were deeply grooved, so that where the sides of the box met, the grooves formed a tube large enough to receive the body of a serpent five feet in length. The large end of the box was fitted with a sliding door which could be secured by a wooden wedge driven in behind it. The lower edge of the door was made concave, and a piece of leather was tacked across the concavity, designed to press on the snake's neck, and secure witbout iujuring it.

To employ this arrangement, the box was closed and the door raised, a cord having been previously run through the central tube. This cord bore on its extremity a loop which was thrown over the tail of the snake, and carried up between tbree and four inches. To effect this manœurre, I was usually obliged to hold the snake down with a long stick notched at the end. The serpent being thus noosed, the loop was tightened, and an assistant tilted the box over the cage, and rapidly drew the snake backwards into the tube, while a second person standing in front, guided the snake with a long rod.

As soon as the tail appeared at the small end of the box, it was secured by the assistant, and the looped string which held it was wound around a nail. At this instant, the head sometimes retreated into the box. After waiting a moment, it usually reappeared again, and was then seized with a pair of long forceps, and held while the door was pushed down on the neck, and made fast with the wedge. When the snake was small, it sometimes contrived to turn around in the box before the tail emerged, and thus reverse its desired position. This occurrence twice exposed the operator to great danger. It was finally prorided against by the aid of a large cork, which was strung upon the cord, and was used to close the small end of the tube, when the snake was of a size to make it possible for it to turn in the tube. When the snake was thus properly imprisoned, it could be placed on the table and studied to great advantage, while it was still able to bite with sufficient vigor.

At various times I have employed all the methods of procuring venom, which I have enumerated at the commencement of this note. I have finally laid aside all but the plan of stupefying the snake by chloroform. This is accomplished by seizing the suake about the middle with the looped staff, and placing it on the table. An assistant then controls the bead and neck, by confining the latter with a notched stick, while with the other hand be slips over the head a glass vessel about two inches wide, and containing at the closed end a sponge soaked in chloroform. The snake breathes for a time with only 
the cup fifteen drops of venom. This is the largest quantity which $I$ have ever seen ejected by natural process. In a subsequent attempt, the next day, this serpent, which bit eagerly, threw out only one or two drops from each fang. The snake was fifty-three inches long, and weighed two pounds four ounces.

It is difficult to compare the amount of venom ejected by the Crotalus, with that excreted by the Viper, and the Naja, since, although both Russell ${ }^{1}$ and Fontana ${ }^{2}$ speak on this point, they seem to have secured the poison from the exsected gland, or, at least, by pressure after death, and they are, moreover, silent as to the length and weight of the animals examined.

$J$ Jet $^{3}$ states that the enlarged duct at the base of the poison gland will hold usually about ten drops, when distended with accumulated poison.

In four snakes I filled the duct and gland with water. The injection was made by introducing a small syringe into the duct itself outside of the gland. The fluid was afterwards expressed from the gland, and measured. In place of estimating the fluid by the gross plan of dropping it, I employed the following means: A narrow tube was graduated, so that each division represented a drop of distilled water. The point being drawn to a fine capillary termination, enabled me to collect, by gentle suction, the venom, or other fluid, even when it was spread over a rough surface, or accidentally spilled.

In the accompanying table, I have given the weight and length of the serpents used, and the amount in water-drops which a single gland in each snake was capable of containing.

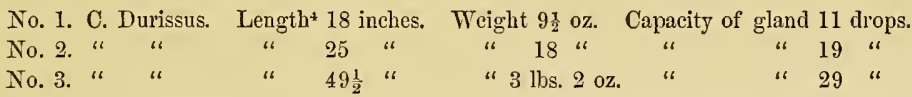

Color of Venom.-The color of the venom varied from a pale emerald green to orange and straw color. Where the poison had remained a long time in the gland, it was deeper in hue than when its ejection followed rapidly upon its formation.

I have also observed that in some snakes, it was uniformly of a darker color

a few inches of lung which lie in front of the stick, but as it becomes more insensible, the pressure of the stick is removed, and the strap of the staft loosened. About twenty minutes are required to complete the process. If it is then found that the lower jaw hangs relaxed when opened, the neek is seized firmly, the fangs caught on a saucer edge, and the glands stripped from behind forwards by pressure with the thumb and forefinger. The venom usually escapes alongside of the fang, from under the mucous cloak. To secure all of the available renom, it is best to wash the fang and the vagina dentis with the aid of a little water, and a pipette; but one objection can be urged against this method. One snake in every four died within from two to five days, and this after apparent recovery from the effects of the chloroform. It is not impossible that too severe a compression of the venom glands may produce rupture of its substance, and consequent blood-poisoning. This, however, is but conjecture; and I have not further examined the subject experimentally.

1 Russell on the Poison Serpents of India, p. 40.

${ }^{2}$ Fontana on Poisons, Trans. by J. Skinner. Lond. 1787, vol, i. 277-287.

${ }^{3}$ Poisoned Wounds, etc., a Report of a Committee to the Med. Assoc. of Missouri, by A. F. Jeter, M. D., p. 10.

* Not inclusive of the rattles. 
than in others; but of the cause of this difference I know nothing, nor am I able to associate an increased virulency with any particular hue of the poison.

Fontana ${ }^{1}$ describes the color of the renom of the Viper as yellow. Jeter speaks of the Crotalus poison as being more frequently of a greenish tint, though sometimes yellowish. Russell gives no information as to the color of Cobra venom, or that of other East India serpents.

Specific Grarity.-On the subject of the specific grarity of the venom, all authors are silent, usually contenting themselves with the statement that it is heavier than water.

As it is very difficult to collect at any one time enough of the venom to admit of the use of the specific gravity bottle, I was obliged to resort to other means.

Having prepared a solution of sugar in water, of a specific gravity of 1030 , I threw into it with a pipette, a drop of pure renom. Finding that it sunk rapidly, I increased the strength of the sugar solution, until the renom was found to float in it midway. This rather coarse means enabled me to estimate the avernge specific gravity of the clear poison at 104t. The specimen employed came from a snake which had been unmolested for several weeks. To test the matter further, I collected some poison from the same snake on the two following days, obtaining but a drop or two on each occasion. The first of these specimens had a specific meight of 1030 . The second was estimated at 1035, so that it is probable that the poison becomes concentrated by long residence in the gland.

The method of examination here ernployed is, of course, open to criticism, and can furnish only approximate calculations; but, as I know of no other facts in this direction, I do not deem it proper to omit eren the imperfect results thus attained.

Physical Characters.-The venom examined by me was always more or less glutinous. In the Viper, it so nearly resembled a gum, that it was described by Fontana as such. ${ }^{3}$ That of the Crotalus dries very slomly, and is as adhesive as thick solutions of gum-acacia. When completely desiccated, it resembled dried albumen, and presented itself in thin jellow and transparent layers, traversed by numberless cracks which in the Viper-poison were supposed by Mead to be the edges of crystals peculiar to the secretion.

Whether fluid or dried, the poison of the Crotalus was deroid of taste, and also of smell, unless it had undergone putrefaction, to which, like other albuminoid solutions, it is liable. I hare tasted the rattlesnake poison repeatedly, once by design, and several times throngh accident, when engaged in collecting it by sucking it into a pipette.

I could not perceive that it had the slightest taste or acridity. Mead alone describes the renom of the viper as acrid and caustic to the tongue. Fontana could discern no taste in it, but thought that it benumbed the part on which it was placed. Brainard" states that the Crotalus renom has "a peculiar and dis-

${ }^{1}$ Fontana on Poisons, TI. p. 12. Skinner's Translation.

a Jeter on Poisoned Wonds, p. 20.

s Fontana, p. 263, rol. i. Skinner's Trausl., where the Abbé examines and disprores this idea.

4 Brainard, Smithsonian Institation, Annnal Report of, for 1854, p. 125. 
agreeable odor, and is said to have a pungent taste." No authority is given for the latter statement. Jeter ${ }^{1}$ speaks of it as tasteless, but ascribes to it the power to benumb the tongue when a drop is placed on that organ. I can only add that I have never experienced the sensation in question. As respects Prof. Brainard's account of its odor, it is proper to observe that, although, as I have said, the venom was usually free from smell, specimens which had remained a long time in the gland, sometimes had the peculiar animal odor of the snake itself.

Reaction of the Venom.-The subject of the acidity or alkalinity of the venom of the European viper, was very early a matter of keen dispute. Mead and James both asserted that it reddened litmus, and was of a distinctly acid reaction. Mead afterwards disavowed this idea, and agreed with Fontana in calling it neitral. Jussieu, who followed Mead in his earlier view, also agreed with him in recommending the local and general treatment by volatile alkali, in the hope of neutralizing the acid in question. Dr. Brickell, ${ }^{2}$ of Savannah, appears to have been the first to examine the reaction of rattlesnake poison. This observer found that the venom was strongly acid, and reddened litmus paper. Dr. Harlan, ${ }^{3}$ of Philadelphia, also describes it as invariably acid. Brainard, Barton, Jeter, and others, do not seem to have examined the question.

My own observations on this subject were very numerous, and were directed, not only towards ascertaining whether or not the venom was acid, but also as to the normal reaction of the snake's mouth, when free from venom.

I find in my notes the record of eight observations, in all of which the venom reddened litmus paper more or less distinctly. In a great many unrecorded ohservations I obtained no other result. It was uniformly acid, and this reaction was common to all specimens of the poison, whether moist or dry, dark colored or pale in tint. One of these specimens was two years old, and, when placed on litmus paper, and touched with a drop of water, it reddened the paper distinctly. I do not think that the venom increases in acidity upon being kept; nor, on the other hand, does the acid of the venom appear to be volatile, since litmus once reddened by it, kept the red hue, until exposed to an alkali, which restored the original blue tint of the test paper. That, finally, the acid was not due to changes which occurred, exterior to the body of the snake, was shown by the constancy of the acid reaction in specimens obtained by allowing the serpent to bite upon test paper folded so thickly as to arrest the fang, and receive the poison directly from it.

The reaction of the mucous membrane of the mouth was almost as consistently alkaline as that of the venom was acid. This observation of course suggested the possibility of neutralization taking place, when the poison accidentally reached the mouth. It was found, indeed, that litmus reddened by the venom became blue again when left in the serpent's jaws; but, although the acid was neutralized,

\footnotetext{
1 Jeter, p. 20.

Brickell, Med. Depository, conducted by S. L. Mitchill, M. D., and E. Miller, M. D., New York, 1805 , second hexade, vol. ii. p. 441.

s Harlan, Med. and Phys. Researches, 1835, p. 502.
} 
the poisonous properties of the fluid remained unaltered, as I shall have frequent occasion to demonstrate.

The want of agreement among observers, as to the reaction of viper poison, is such, that the point in question should be re-examined by some competent person. Prince Louis Lucien Bonaparte, ${ }^{1}$ to whom we owe a chemical analysis of viper poison, does not appear to have touched the matter, and contents himself with stating that echidnine or viperine, the essential principle, is neutral, making no allusion to an acid, when detailing the other ingredients present.

Decomposition of the Venom.-Like most albuminoid matters, the venom entered into decomposition when long kept in the moist state, but although it then developed vibriones, and even low confervoid growths, and smelt most horribly, it was still poisonous. How long it would retain its virulence under these circumstances, and what extent of putrefactive change might be needed to destroy this quality, I cannot state from my own experience.

Many specimens of venom let fall, on repose, a white sediment, which, in a few cases, was very abundant. The clear poison presented no points of interest when viewed microscopically. When dry, it cracked like dried white of egg, but under no management has it afforded me crystals. My friend Prof. Hammond $^{2}$ has been more successful, and has obtained crystals by diluting the venom of the $C$. confluentus, and allowing the mixture to dry slowly, sheltered by a cover-glass. (Fig. 11.) The crystals thus formed, resembled those of ammoniacomagnesian phosphate, which affect the feathery form of crystallization.

Fig. 11.

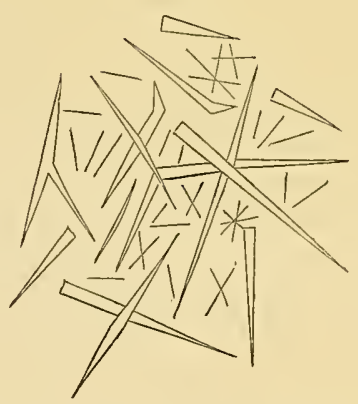

The white deposit was composed chiefly of amorphous, granular matter, with a few pavement epithelial cells, compound granular bodies of oleaginous character, and finally of the peculiar masses known and described as colloid bodies, ${ }^{3}$ and in

1 Prince Lonis Lucien Bonaparte, Gazetta Toscana, delle Scienze Medico-fisiche, Anno primo, Firenze, 1843. I have been unable to find this memoir, and have been forced to employ Orfila's quotation of his results. Orfila, Tox. Gen., p. 844.

2 Fig. 11 is taken from Prof. Hammond's drawing, which he kindly put at my disposal.

s Wedl, Pathological Histology, Trans. of the Sydenham Society, pp. 38, 264, 271, etc. 
appearance so much resembling starch granules, as to have induced me to neglect them at first, and to suppose them to be really that substance, accidentally present. These corpuscular bodies were marked with delicate radiating lines. Iodine stained them of a yellowish-brown. They were doubtless due to some concrete modification of albuminous material.

Occasionally, when the snake had been seriously maltreated, the venom contained more or less blood.

Chemical Examinatim.-I much regret having been unable to collect the venom of the Crotalus in such amount as would have enabled a competent chemist to make of it an ultimate analysis, to which I believe it has never yet been submitted.

In the following examination, I have contented myself with a qualitative analysis, which, although not so perfect as I could have desired, appears to me to have thrown some light on this novel and curious subject.

The fresh venom of the Crotalus begins to coagulate at $140^{\circ} \mathrm{F}$., and is almost solid at $160^{\circ}$. The mode in which I accomplished this observation upon minute amounts of venom, without desiccating it, will be found detailed in the account of the influence of temperature upon the virulency of the venom. ${ }^{1}$

When a drop of the pure poison was thrown upon platinum foil and heated, it boiled, whitened, and at last became charred before it took fire.

When a drop of venom was thrown into cold distilled water, it fell rapidly, and presented a white appearance, which became marked, as it dispersed through the fluid. It finally dissolved in the water, without residue. This phenomenon of the whitening of the venom in water, has also been noticed in regard to fresh white of egg similarly treated.

The pure venom of the Crotalus was subjected to the action of various chemical reagents, either with the primary object of learning how they would affect it, or with the purpose of observing whether or not they altered its power to poison.

Nitric acid threw down from Crotalus venom a dense precipitate. Added in excess, it re-dissolved the larger part of the precipitate, and formed a thin yellowish fluid, in which floated undissolved minute yellow flocculi. Liquor ammoniæ, added in excess, did not re-precipitate the dissolved material.

Chlorohydric acid threw down a dense white precipitate, and, added in excess, completely re-dissolved it, forming a solution colorless, or of a pale yellow, from which ammonia in excess re-precipitated the dissolved substance in opaque white masses.

Sulphuric acid threw down from the venom a white precipitate, which, if the acid were hastily added, or if heated, became yellow or brown.

Acetic acid caused no precipitate from the venom, whether added to it in large or small amount.

Tannic acid produced a dense white precipitate, which proved to be insoluble in water, and in an excess of the acid, but was re-dissolved on the addition of a small amount of ammonia.

1 These observations were amply verified at another time, when larger quantities of venom were used. 
Chlorine water caused a dense precipitate. A solution of iodine and iodide of potassium caused a precipitate which redissolved in an excess of the reagent. ${ }^{1}$

Soda and potassa had no visible effect on the venom.

Ammonia was also without action upon it, as was also lime-water.

Bichloride of mercury gave with the venom a dense white precipitate.

Sulphate of soda produced a dense precipitate, which redissolved on the addition of water in excess. The precipitate was, therefore, soluble in a weak solution of the salt employed.

Sulphate of magnesia, in like manner, cansed a precipitate which proved soluble in an excess of water, as in the last observation.

In both cases the precipitate could be reproduced by increasing the amount of the salt present, and again, an added excess of water was competent to redissolve the new precipitate.

Alcohol invariably produced in the venom a heavy, flocculent precipitate, which, when carefully dried, turned of a pale yellow, and was still more or less soluble in water. The latter fact was observed, even when the poison had been kept in alcohol during five weeks. I have also examined the poison found in the ducts of Rattlesnakes, which had remained in alcohol for two years or more. It proved to be very slightly soluble in water. There is in this observation, however, a cause of error; since in snakes which die violent deaths, the whole gland is often filled with blood, so that the coagulated substance in the ducts can, with no certainty, be regarded as venom alone; unless we are informed very fully as to the condition of the organs, when first immersed in the preserving fluid. This question is one of considerable interest, and will engage our attention in another place.

An aqueous solution of the venom was evaporated to dryness. A drop of a solution of sulphate of copper was then added, and the mixture treated with a solution of canstic potassa in excess. In a few minutes it exhibited the violet color characteristic of albuminous matters thus tested.

The venom was next examined for sulphocyanide of potassium, a constituent of human saliva, although with slight expectation of detecting it. Five drops were tested with sulphate of sesquioxide of iron. It produced a heavy white precipitate, but no red color was observed. Seven drops of the venom were evaporated to dryness, and treated with the same salt of iron, but without any appearance of the red hue which indicates the presence of the sulphocyanide mentioned. These examinations were repeated several times on as many specimens of the poison, but always with a negative result. From the small amount of venom employed, they did not entirely satisfy me, and the subject may still repay a fuller examination. At present it is only safe to affirm that the sulphocyanide, if it exist in the venom at all, can only be present in a very minute amount, and can in no way be considered as a causative element, in the production of the symptoms which follow upon the insertion of the venom into the tissues of living animals. ${ }^{2}$

${ }^{2}$ Brainard's antidote-Iod. potass. grs. $\mathbf{x x}$; iodine grs. $\mathrm{x}$; water $\tilde{\mathrm{zj}}$.

${ }^{2}$ In the following work by M. Bernard: Leçons sur les Propriétés Physiologiques, et les Altérations Pathologiques des Liquides de l'Organisme, vol. ii. p. 242, he says: "Ainsi on a dit d'abord, que la présence du sulfocyanure de potassium dans la salive, rappelait les glands à venin des serpents vemineux." 
Thus far we have only learned, from the preceding details, that the venom of the Crotalus is an acid-fluid, abounding in albuminous matter, and yielding precipitates, or coagula, with certain reagents.

It was highly probable, for various reasons, that the active element of the venom was to be sought in the albuminoid compound just referred to. Accordingly, the greatest attention was paid to this substance, and at every step in the analysis the coagula and filtered solutions were studied toxicologically, as well as chemically.

Prince Charles Lucien Bonaparte has given us the only analysis of a snake venom with which I am acquainted; it is that of the viper. I have been unfortunate in not having had access to the original Essay of this observer, and have been forced to content myself with such analyses of his paper as are to be found in the systematic works on poisons, and in one of M. Bernard's recent volumes. ${ }^{1}$ Thus aided, I have partially followed M. Bonaparte's method of analysis; but have found it insufficient for the thorough examination of rattlesnake venom.

The observations and analyses which I have thus introduced, were conducted in the following manner:-

1st. Ten or twelve drops of pure Crotalus venom were secured, as usual. Of this, a minute amount was employed as a toxicological test of the activity of the specimen about to be studied.

$2 d$. The remainder of the venom was mixed with two drachms of cold water, and thoroughly boiled for five or ten minutes. A dense coagulum took place, and settled quickly, leaving above it a pearl-colored fluid, free from sedimentary matter. On shaking the test-tube, so as to mingle the coagulum and the supernatant fluid, and then injecting one-half into the breast tissues of a pigeon, it was found that the mixture proved speedily fatal. Boiling had not destroyed its power.

3d. The remaining half of the mixture (coagulum and fluid), was cast on a small filter, and when the pearly fluid had passed through, the coagulum which remained was carefully washed, drop by drop, with cold water. On the filter was finally left the white coagulum, thoroughly washed; in the filtrate were all the parts of the venom which could be dissolved either in cold or boiling water.

4 th. The toxicological test was now introduced, to decide whether the poisoning activity lay in the clot formed by heat, or in the separated fluid. Upon numerous repetitions of this observation, it invariably happened that the coagulum was innocent, and that the pearly supernatant fluid, with the washings of the coagulum, was a deadly poison. The experiments were made as usual, by injecting the venom into the breast or leg tissues of healthy pigeons.

5th. As I was aware that alcohol threw down all of the albuminoid elements of venom, it occurred to me that it might also precipitate from the boiled venom the material which appeared to escape the coagulating influence of the heat. Accordingly, a considerable quantity of venom, about fifteen drops, was boiled, in half an ounce of water. When the coagulum settled, the opalescent supernatant liquid was decanted with care, the coagulum washed on a filter, and the wạshings mixed with

1 Orfila, Toxicologie Génerale, Art. Vipère. Bernard Cl. Leçons sur les Effets des Substances toxiques et médicamenteuses. Paris, 1857, p. 393. Nysten, Dict. de Médecine, Art. Échidnine. 
the liquid. To this was now added a small amount of alcohol of 95 per cent. A cloud of a white and granular character was immediately seen at the line where the alcohol and water met. Upon this an ounce and a half of the alcohol was added, when the fluid clouded throughout, and a white precipitate soon settled to the bottom. The supernatant alcohol and water being poured off and carefully evaporated at a temperature of $100^{\circ} \mathrm{F}$., was examined toxicologically as usual. The evaporation was, of course, carried nearly to dryness, so as to avoid the risk of killing the bird with alcohol. No poisonous results were observed, except in two cases, where the alcohol originally used proved to have been diluted with water, and to have acted as a partial solvent for the active material. It is necessary, on this account, to employ the strongest alcohol.

6 th. The precipitate caused by the alcohol was washed repeatedly with successive portions of that fluid, and allowed to settle. Then the last alcohol used to wash it was removed by pipette, and the precipitate spread on a plate to dry. On testing it toxicologically, it was found to be actively poisonous, giving rise, even when employed in minute amount, to all the local and general phenomena of Crotalus poisoning.

The material thus obtained, was of a pale yellowish tint when dried, and was perfectly neutral in reaction. It dissolved readily enough in water, cold or hot, and its aqueous solutions were troubled by alcohol. Its nitrogenous nature was established by its reaction with Millon's test of nitrate of mercury, and with the cupro-potassa test. As it appeared to me to be the active toxicological element of the venom, I propose to distinguish it by the name of Crotaline.

It seemed from the statements of those who quote Prince Bonaparte's method of analysis of viper-poison that he procured the essential principle, which he termed échidnine, or viperine, in the following manner: The venom was treated with an excess of alcohol, and filtered; the residue on the filter being well washed with fresh portions of alcohol. The alcoholic solution was evaporated to dryuess, and found to contain a coloring matter, and a small amount of an undetermined substance, which, of course, was soluble in alcohol. The coagulum was next washed, drop by drop, with cold water, so as to dissolve the échiduine, and leave the "mucosine," become now insoluble from the influence of the alcohol. The échidnine was separated from the aqueous solution by evaporation. In all essential particulars, échidnine and crotaline are alike. Upon repeating and varying M. Bonaparte's method of analysis, I found, however, some discrepancy of results.

Thus, if to the renom of the Crotalus an excess of alcohol be added, a large precipitate occurs. In some instances, all of this precipitate was soluble in water; in other cases, a small proportion remained undissolved, behaving as ov-albumen would do after being coagulated by alcohol. Generally, as I have said, the bulk of the alcohol precipitate was soluble in water. The aqueous solution thus obtained could be coagulated by boiling, so as to throw down a harmless precipitate, and to leave above it a fluid still actively venomous, but representing in its dissolved albuminoid substance but a small part of the nitrogenous precipitate caused by the alcohol in the first instance. In other words, the aqueous solution of the alcoholic precipitate behaved in the presence of heat exactly like the diluted venom itself. 
On reviewing these facts, it appears that in Crotalıs venom, 1st, alcohol precipitates all the albuminoid material, innocent, as well as poisonous. 2d. That heat throws down from diluted venom the bulk of these albuminous compounds in an insoluble and harmless form, and that the residual water still contains an albuminoid body uncoagulable by heat, but precipitable by alcohol, and of great poisonous activity.

Now, the yield of crotaline from the plan first mentioned, and that of M. Bonaparte, is very different. So much larger is the quantity obtained by the latter means, that I cannot help suspecting that, besides seizing on the active principle, the water also takes up from the alcoholic precipitate a certain quantity of albuminous material which is quite innocent, and can only be coagulated by a heat of $160^{\circ}$ and upwards.

Besides the two albuminoid bodies, whose presence in venom I have thus made probable, there is also at times a little nitrogenous matter which behaves like the ordinary egg albumen.

The ether washings of dried venom I found to contain now and then a little oil, which was only to be detected under the microscope. As in M. Bonaparte's analysis, when the alcoholic solution was evaporated, it was found to contain a small quantity of uncrystalline flakes of some unknown body, tinged yellow, and dotted here and there with specks of a deeper hue.

Besides these elements, we have also a small amount of saline constituents, probably chlorides and phosphates of alkalies. The determination of these bodies seemed to be of no great moment in the present case, and I have therefore failed to study them with minute attention.

We have thus far determined that the venom of the Rattlesnake is composed of-

1. An albuminoid body. Crotaline, not congulable by heat of $212^{\circ}$.

2. An albuminoid compound coagulable by a temperature of $212^{\circ} \mathrm{F}$.

3. A coloring matter, and an undetermined substance, both soluble in alcohol.

4. A trace of fatty matter.

5. Salts, chlorides, and phosphates.

At this period of our investigation it would be interesting to compare the venom more carefully with the ordinary salivary fluids, a step which is rendered necessary by the fact that De Blainville and others have considered the venom gland as the analogue of the parotid, and the venom as only a peculiar salivary fluid.

Before we carry on such a comparison, it is necessary to state the results of a number of experiments and observations, which, while they aid us in elucidating the present branch of our subject, have also an important bearing upon the question of the true character of the poison of the venom. We shall proceed, therefore, to the statement of the observations in question, and afterwards to the discussion of the claims of the poison gland and its secretion, to the titles of salivary gland and saliva.

If the poison gland is a salivary gland at all, it is, of course, from its anatomical relations a parotid gland, and its secretion is comparable only with the parotid secretion. In the lack of information as to the nature of this saliva in serpents generally, we can only compare the venom with the parotid saliva of the horse, 
dog, and man, a circumstance which necessarily impairs the interest and value of this particular branch of our subject.

Since the discovery by Leuchs, of the power of saliva to convert boiled starch into grape sugar, observers have been undecided as to whether or not pure parotid saliva possesses this power. The weight of authority at present is undoubtedly against it, but in the absence of any positive decision, I have conceived it necessary to learn whether or not the supposed venom saliva had this faculty.

Experiment.-In three test tubes of the same size, was placed an equal amount of boiled starch-water, in which I had failed to detect the presence of grape sugar. To the first of these were added three drops of pure renom. To the second were added three or four drops of mixed saliva from my own mouth. The third was left without any addition, and all were exposed to a temperature of $78^{\circ} \mathrm{F}$.

No. I. Venom and starch-water was examined at intervals, but gave no reaction with the cupro-potassa test until forty-eight hours had elapsed, when sugar was found to be present, but not in large amount.

No. II. Starch-water and saliva contained sugar at the close of half an hour. Within three hours the sugar was present in abundance.

No. III. Starch-water alone exhibited no traces of sugar until forty-eight hours had elapsed, when it was to be detected, although present in no large quantity.

In a second series of experiments, results so nearly similar were obtained, that it is needless to relate them here.

Since it has been asserted by Wright, that acid saliva does not possess the same converting power as the ordinary alkaline fluid, and as the venom saliva was constantly acid, I repeated the experiments with the following modification.

Experiment.-In two test tubes was placed about half an ounce of thin starchwater. To the first were added four drops of venom, which I had rather more than neutralized with potassa.

The second I left without this addition, and exposed them both to a temperature of from $77^{\circ}$ to $87^{\circ} \mathrm{F}$. At the close of twenty-four hours, neither of them exhibited any traces of sugar, but after twenty-eight hours, sugar was present in the venom tube and not in the other. These experiments were also repeated on subsequent occasions with like results.

I conceive that we have a right to infer that the venom has no peculiar power to convert boiled starch into grape sugar, and is, in this respect, almost absolutely inactive.

My next observations were directed towards ascertaining whether the venom gland, like the ordinary salivary glands, would yield to water its active principles, and so give rise to infusions, in each case, resembling the saliva of the respective glands. Thus, since MI. Bernard's researches, it is well known that an infusion of the submaxillary or parotid glands has all the properties of the normal saliva of these organs. According to this author, the solid matters of the various salivas are constantly deposited in the glands, and are rapidly washed out of them by a flow of thin solvent fluid from the bloodvessels, at such times as the secretion may be needed. If, now, the solid matter of the venom be in like manner a constant portion of the bulk of the gland, it was to be presumed that an infusion of 
the gland tissues would afford a considerable amount of venomous fluid, manufactured, as it were, artificially.

This question divides itself naturally into two queries:-

1st. Is the gland tissue poisonous?

$2 d$. Are infusions of the gland tissue poisonous?

At first sight, nothing seems easier than to answer these questions, by inoculating animals with infusions of the gland, or portions of its tissue. On direct experiment, sources of fallacy at once appeared. 'The first of these was due to the difficulty of clearing the gland of poison already contained in it, in the form of venom, filling its smaller ducts. Supposing us to have eliminated this element of doubt, and to have ready a gland tissue washed clear of its actual secretions, if we should have in its secerment cells but a small amount of poison, it may not act upon a large animal. On the other hand, if a very small animal be employed, the reagent may prove too delicate a test, and the animal die from a mere trace of the venom remaining in the ducts, or even of the operation required to insert a whole venoin gland under its skin.

Experiment.-A large Crotalus, fifty-three inches long, was secured as usual, and four drops of venom obtained from it. It was then replaced in its box, supplied with a bath, and not disturbed during five days, after which an attempt was made to rob it of the poison formed in the interval. It yielded but one drop, although it struck several times at the collecting vessel. Seeing this, and knowing, from previous experience, that it might be retaining its venom, I placed within its jaws a pigeon's thigh, freed from its feathers. The serpent bit fiercely, the animal dying in twenty-nine minutes. A second pigeon having been plucked, so as to expose the breast, the snake was allowed to bite it three times. It died stupefied, at the close of an hour.

A third pigeon was next arrauged, so as to be bitten four times about the breast. The snake, by this time, was very unwilling to use its fangs. The pigeon died in two hours and a half. It is clear from these experiments, that in confinement at least, the venom is formed but slowly, and that in the present case the gland was, in all probability, well emptied of its juices. The snake's neck was next severed about two inches below the head, and the glands of both sides rapidly removed.

The ducts were cut away near to the gland, the gland tissue pressed between two slips of board, and finally washed by repeated injections, and subsequent compression, until at length the returning fluid brought away with it no sediment. The whole of one gland was then minced up with twenty-five drops of water, and introduced under the skin of the breast of a pigeon. None of the usual local or general evidences of Crotalus poisoning followed, and within fifty hours the wound looked dry and healthy. After this time, an extensive slough took place above the site of the gland. As the previous signs and appearances did not warrant the idea that any poisoning could have taken place, I made several experiments to learn how far the skin of the pigeon can be separated from subjacent tissues, without endangering its vitality. These observations soon taught me that any foreign tissue which raised the pigeon's skin for a circumference of more than three or four lines, was apt to occasion a slough. 
Experiment.-In this experiment, I prepared a large gland, as above described, and inserted it in seven localities about the body, back, and legs of a pigeon. Around two of these, on the back, a little darkening was visible, and one of them sloughed after several days.

Experiment.-A snake thirty inclies long was properly secured, a pigeon arranged as usual, and placed within reach. The snake bit it on the neck, where a local discoloration showed itself at once. On further provocation, by pinching its tail, it bit the pigeon several times, until, as I supposed, the venom was exhausted. As the snake had been used to kill a rabbit five days before, I presume the quantity of venom not to have been large, nor, indeed, could it have been so, as the pigeon did not die for forty minutes. The snoke's head was next cut off. Placed on a plate, it bit eagerly, but threw out no venom, even when I galvanized the anterior temporal muscle after removing the cuticle.

Both of the venom glands were removed, squeezed thoroughly, divided lengthwise and across, and repeatedly wiped with a soft towel. Twelve drops of water were then added, and both glands hashed up with it, a drop or two being added as it dried. The temperature was that of the air, $75^{\circ} \mathrm{F}$. At the close of thirty-five minutes, I carefully removed all the fluid with a pipette, and injected it under the breast-skin, and into the muscles of a pigeon. Five hours later, the bird was well, and the wound quite dry. Eighteen hours after inoculation, it yielded, upon pressure, a little serous fluid, and around the part, infiltrated with the artificial secretion, there was a slight darkening of the skin, whether due to the presence of a small amount of poison, and the consequent extravasation, or to my having wounded small vessels, I an unable to say. Certainly, no other evidences of poison were noted, and the wound healed after a little serous oozing. No slough took place.

Experiment.-The gland tissue employed in the last observation, was dried by frequent wiping, and being minutely divided, was put under the skin of a rabbit's back. The animal had no constitutional disturbance as a consequence, and was sacrificed after five days to another purpose. A small abscess had formed around the foreign tissues, and was making its way outwards. No extravasation was visible.

Experiment.-On another occasion, an infusion of two small glands from a snake twenty-nine and a half inches long, was used upon a rabbit, without effect visible to the eye. The fluid seemed to have been absorbed without local or general injury to the animal.

Experiment.-The whole tissue of the glands just mentioned was finally minced, bruised, dried in bibulous paper, and carefully introduced under the skin of a pigeon's breast, by pushing in a small tube laterally, and through this distributing the crushed gland tissue as the tube was withdrawn. In this way, the inoculation was effected without much separation of the skin from the parts beneath. In despite of this precaution, extensive inflammation ensued, and a large slough of skin took place, the tissues about the wound becoming infiltrated with serum. No local or general symptoms of poisoning were noted, but the bird sank, became thin, refused food, and died at the close of eight days. 
It was evident from these experiments that, for some reason, the gland and its infusions were less virulent than had been anticipated. Reflecting npon the great relative size of the gland, and upon the minute amount of secretion elaborated by it, it seemed to me possible that the quantity of gland matter stored up for its production, might also be but small, and that if this were so, the pigeon might not suffice as a test of its existence. The following experiments were the result of this view.

Experiment.-A large snake, weighing four pounds, and measuring three feet eight inches, was secured, and allowed to bite a reed-bird, which died within one minute, exhibiting both local and general symptoms. The snake was then teazed until it struck, and threw out a drop or two of poison from each gland, after which its head was cut off, the ducts divided, and the gland thoroughly emptied by pressure. It was then finely divided as usual, washed, and dried in bibulous paper. Thus prepared, the gland was considered to be free from any poison which might have been already secreted in a fluid form, and was treated with twenty-five drops of water, and kept at a temperature of $90^{\circ} \mathrm{F}$. for thirty minutes, during which time it was frequently stirred, and compressed with a small pestle, while the water was renewed as it evaporated. The whole of the fluid was next drawn up into a fine tube, and carefully injected under the skin of the breast of a reed-bird. After four hours and twenty minutes, the bird was seen to be weak, but the local signs were of uncertain value. Twenty-one hours after poisoning, the bird was found dead. Its muscles were firm, the blood dark and loosely coagulated.

Experiment.-The remnant of gland tissue was put under the skin of a reedbird, one portion being placed in the breast, another in the thigh. This bird died within twenty-one hours, and in it, also, the symptoms of local poisoning were deficient. The blood was even better coagulated than in the last case.

Experiment.-A snake of middle size (about two and a half feet long) was made to employ its glands, and was then decollated, the glands extracted, divided, and washed as usual. Ten drops of water were mixed with the tissue of this gland, and being placed in a test-tube, it was left at a temperature of $85^{\circ} \mathrm{F}$. for two hours. The fluid was then drained from the gland, and injected into the thigh of a reedbird. In two hours and four minutes the bird was becoming weak, and the extravasation of blood-which is the most marked symptom of Crotalus poisoning-was sufficiently distinct. Two hours later, the bird was rocking on its feet, and the extravasation was larger. It died during the following night. On examination, the muscles about the wound were softened, and even decomposing, and the blood was chiefly uncoagulated with an occasional clot of minute size and loose texture.

Experiment.-The remnant of gland used in the last observation was again treated with ten drops of water, which became slightly milky in hue on being agitated, and incorporated with the bruised tissue. After half an hour it was finally drained from the gland, and injected as usual under the breast skin of a reed-bird; proper precaution being always observed to avoid raising the skin too much. Within two hours and ten minutes the bird was weak, and the breast tissues contained a little extravasated blood. One hour and ten minutes later, the local symptoms were unaltered, and the bird weaker. It died during the ensuing 
night. Its wounds were slightly tinted with effused blood; but the muscles were not softened to the same extent as in the last case, nor were they at all decomposed. The blood of this bird was imperfectly congulated.

Upon considering the foregoing experiments, it will be seen that all the pigeons escaped but one, that the rabbit was also unhurt, and that the reed-birds all died. These little birds are, however, uncommonly hardy, and, as we shall see in future, do not succumb readily when mechanically injured. Again, when, at this period, I subjected other reed-birds, to the number of ten, to similar wounds, and injected these with water and infusions of fresh muscle, only two out of the ten died. It is difficult, therefore, to avoid the belief that the reed-birds which received in their tissues the minced gland and its infusions, really perished from the rattlesnake poison; a belief which, on the whole, was strengthened by the state of their blood and muscles, and by the local signs which some of them exhibited. It is also to be observed that the reed-bird is remarkably susceptible to Crotalus venom, and will frequently die from a quantity of poison so minute that it would be hard to conceive of its power to destroy life, until we had made the experiment. Thus, while half a drop will often kill a reed-bird in a minute or two, one-eighth of a drop will prove fatal after a lapse of from two to eight hours; so that it is probable that even a smaller quantity would be found sufficient to destroy its existence. Now, as it is possible that quantities so minute may escape any mode of separation, and thus may remain in the gland tissue until the final infusion is formed, or even afterwards, we are not logically called upon to infer from the last series of experiments, that the material for a sudden temporary supply of venom-saliva is stored away in the gland in a semi-solid state. In this respect, therefore, the venom secretion is probably unlike saliva.

Again, unlike saliva, venom is formed slowly, and thence we have some right to infer that those provisions for rapid secretion, which belong to the salivary glands of man or the dog, need not exist in the poison gland of the serpent, and this view is certainly fortified, upon the whole, by the general result of the experiments above detailed.

In despite of what has here been urged, it is still desirable that these experiments should be repeated, with every possible modification; since, as I have endeavored to show, this, like all other portions of our subject, is girt about with such difficulties as may well baffle the most careful.

We have now to ascertain how much right the venom gland has to be regarded as a salivary organ, analogous to the parotid gland.

The argument from anatomy alone would certainly teach us to respect this view as correct, and to consider the poison gland as a true salivary organ. Its position and general structure all favor this idea, just as the appearance and minute anatomy of the pancreas were once believed to authorize us in placing that organ among the salivary bodies, and in giving to it the name of the abdominal salivary gland. But in this case, as in the one before us, the broader light of physiological inquiry has revealed the truth, that anatomical resemblance, even to the minutest details, does not of necessity involve physiological likeness. When, therefore, we turn from the anatomy of the poison gland to examine it under other points of 
view, we learn that in Crotalus its secretion is constantly acid, and in the Viper neutral, while the saliva of the parotid in all animals yet examined is as unchangeably alkaline. Again, while saliva is a secretion of rapid formation, and appropriated to specific mechanical and chemical purposes within the economy, the venom fluid is slowly elaborated, slowly reproduced when lost, and destined to no end within the body which produces it. Lastly, its singular nature as a ferment, poisonous to other animals as well as to its owner, constitutes a distinction, which, with the other points of difference already considered, forbid the physiologist to regard it as, in any true sense, a salivary secretion, or its forming organ as a salivary gland.

Effect of Various Temperatures on the Activity of Venom.-When I contemplated a series of researches upon the antidotes to Crotalus poisoning, I planned and executed a large number of experiments directed towards increasing our knowledge of the influence of physical and chemical agents upon the noxious properties of venom. Some of these researches were modified repetitions of work already done by others, but the majority were novel, and appear to me to cast considerable light upon the subject.

Especially do they clear the ground for more just conceptions of the real value and therapeutic possibilities of antidotes. Without them, also, no fitting idea of the singular energy of this poison could be formed, nor should we be able to conceive of the tenacity with which its powers are preserved in the presence of violent chemical reagents and extremes of heat and cold.

I was well aware that the dried venom retained its potency after two years of climatic changes, and that even the fresh poison, although prone to partial decomposition, might also remain active, after a sojourn of several weeks in an atmosphere of $65^{\circ}$ to $70^{\circ} \mathrm{F}$.

In the experiments upon the influence of extreme temperatures, I was obliged to resort to the following means :-

First. I established the fact that dilution did not injure the venom; and next, that minute quantities, as one-eighth or one-half of a drop, were fatal to the reedbird within a few hours, more or less. As it was impossible to use large amounts of venom, owing to the economy with which $I$ was forced to employ it, I arranged a tube of such size, that a marked half inch held one drop of a mixture made by adding four drops of water to one of the venom.

Experiment.-The marked tube was drawn to a capillary point, and a little venom sucked up into it, and so manipulated as to leave in the tube one drop of the mixture, representing one-fifth of a drop of venom. By very gentle suction, this was next drawn two inches up the tube, and the capillary point below, closed in the blowpipe flame.

Thus prepared, the tube was plunged in a freezing mixture, and kept at a temperature $3^{\circ}$ to $4^{\circ}$ above zero $\mathrm{F}$. At the close of half an hour, the tube was placed in water at $70^{\circ} \mathrm{F}$., and when the contents became fluid, the point of the tube was broken off, and the venom ejected into the breast tissues of a reed-bird, which died convulsed in twenty-seven minutes. Two repetitions of this experiment gave no different result. 
The same little apparatus was also employed in the following experiments on the effects of heat on the venom. In each case the tube was charged, sealed at one end, and placed in water of the required temperature. In sustaining the standard of heat, it occasionally happened that the temperature rose one or two degrees too high, but this in no way affected the general result or its value. When the higher temperatures were used, the finger was sometimes placed on the open end of the tube, both to prevent the bubble of air below the venom from enlarging in the heat șo as to expel the fluid above it, and also for the purpose of limiting evaporation.

'The results attained are expressed in the following' table:-

\begin{tabular}{|c|c|c|c|}
\hline \multicolumn{4}{|c|}{$\begin{array}{l}\text { TINE OF ENPOSERE IN ALL THE CASES TWENTT OR THIRTY MTNUTES. } \\
\text { AMOUNT OF VENOM ONE-FOCRTH TO ONE-EIGHTH OF } \triangle \text { DROP. }\end{array}$} \\
\hline No. & \multirow{2}{*}{$\frac{\text { Temperature. }}{112^{\circ} \mathrm{F}}$} & Tisible effects on the renom. & Result twhen injected into the breast of reed-birds. \\
\hline 1 & & None & $\{$ Killed in 35 minutes. Convulsions and marked \\
\hline 2 & $120^{\circ} \mathrm{F}$ & None & Death in 27 minutes, conrulsions, local signs. \\
\hline 3 & $130^{\circ}$ to $134^{\circ} \mathrm{F}$. & None & Death in 39 " " " " \\
\hline 4 & $140^{\circ}$ to $142^{\circ} \mathrm{F}$ & None & Death in 45 \\
\hline 5 & $\left\{\begin{array}{l}\left(\frac{1}{2} \text { drop of venom }\right) \\
148^{\circ} \text { to } 151^{\circ} \mathrm{F} .\end{array}\right.$ & $\left.\begin{array}{l}\text { Slight coagulation } \\
\text { took place. }\end{array}\right\}$ & Death in 43 \\
\hline 6 & $180^{\circ}$ to $184^{\circ} \mathrm{F}$. & Coagulation & Death in 48 " " " " \\
\hline $\begin{array}{l}7 \\
8\end{array}$ & $\begin{array}{l}212^{\circ} \mathrm{F} \\
212^{\circ} \mathrm{F}\end{array}$ & $\underset{\text { Dense coagulation }}{\text { " }}$ & $\begin{array}{l}\text { Death in } 2 \text { hours. No convulsions or local signs. } \\
\text { No malady, except marked feebleness for } 2 \text { or } 3 \text { hours. }\end{array}$ \\
\hline 10 & $212^{\circ} \mathrm{F}$ & " & $\left\{\begin{array}{l}\text { laboriously for a time, but finally recorered. } \\
\text { Slight and doubtful local signs. }\end{array}\right.$ \\
\hline
\end{tabular}

The results exhibited in the table seemed to show that, while freezing did not alter the porvers of the venom, it lost its toxicological vitality at a temperature of $212^{\circ} \mathrm{F}$.

Upon re-examining this question at a later date, and with larger quantities of venom, I came to the conclusion that I had been mistaken, and that the most prolonged boiling was inadequate to destroy the virulence of the venom. The error into which I previonsly fell was due to the following causes:-

I have shown that after boiling, the active portions of the poison were the supernatant fluids, and not the coagulum. Now, when the amount employed was small, and the boiling was conducted in tubes of moderate calibre, the quantity of fluid surrounding the coagulum was in proportion minute. The larger part of it, therefore, clung to the tube, and was practically lost. That which adhered to the precipitate proved insufficient, in most cases, to destroy life, although some of the animals suffered from its use.

In Angust, 1860, a year after the first examination of this point, I carefully studied it anew. Not less than four drops of venom were employed in each case, and the process of boiling was varied in duration, so that in some cases it was continued for five minutes, in others for half an hour or more. Thus prepared, the 
coagulum and the supernatant fluid were thrown into the tissues of full-grown pigeons. Of six thus treated, all died with the usual symptoms.

In a second series of experiments, to which I have already alluded (see chemistry of the venom), the coagulum and supernatant fluid were separated by filtration; the coagulum washed, and the two products injected separately into two pigeons. In eight experiments of this kind it was found that the coagulam by heat was always innocent, the fluid as uniformly poisonous. It is unnecessary to relate these cases in detail, but it was further observed that the fatal cases died with the usual rapidity, a fact which permits us to suspect that the venom loses no power by being heated, and that the albuminoid compound, which constituted the coagulum, was not poisonous before its condition was altered by elevation of temperature.

We thus arrive at the conclusion that the venom of the Crotalus is toxically unaltered by freezing or boiling, and of course by the intermediate temperatures to which it may be subjected.

It is not a little curious that the animals which perished from the injection of boiled venom exhibited very trifling local evidences of the action of the poison. I am unable to offer any plansible explanation of this curious deficiency.

Influence of Certain Chemical Agents on the Activity of Venom.-In the following observations upon the influence of chemical agents on the activity of the Crotalus poison, certain necessary precautions were carefully attended to, without which the results attained would have been of but trifling value. Thas, for example, in using strong acids, alkalies, etc., it was necessary to make sure that the caustic action of these substances did not prove fatal to animals as small as the reed-bird. This end was obtained by carefully neutralizing the substances employed, after they had been allowed to affect the venom for a time. Where this could not be done, as with alcohol, etc., the result was checked or tested by experimenting with the substance alone, free from the presence of the venom.

It will be sufficient to give detailed accounts of some of these experiments, and to state merely the results of the remainder; since the precautions employed were similar in all the cases.

Alcohol.-I cannot find that Fontana actually mixed this fluid with venom, and then essayed its powers, with the object of ascertaining to what extent they were modified. Dr. Brainard ${ }^{1}$ was probably the first to make this direct observation, not only with alcohol, but also with oil of turpentine, and the solutions of nitrate of silver, ammonia, soda, and potassa: He found that the mixture of these agents with venom did not alter or delay its action, provided the reagents were not of caustic strength.

Experiment.-The venom to be used having been previously tested and found to be potent, two drops of it were treated with twenty-five drops of alcohol. A dense coagulum formed, and at the close of ten minutes the mixture was injected into the breast tissues of a pigeon, which died, with slight local signs of poisoning, at the close of thirty-seven minutes. A check experiment was made at the same time, to learn how much the amount of alcohol used (twenty-five drops) would 
affect the pigeon when injected alone. It appeared to cause slight stupefaction, which passed off rapidly.

Experiment.-About one-third of a drop of venom was treated with a drachm of alcohol. The mixture, which was allowed to evaporate to about seven drops, was placed under the skin of a reed-bird. It died in twelve minutes. When eight drops of alcohol were used alone, the bird was a good deal stupefied for two hours, but no serious result was observable.

Experiment.-About one-half of a drop of venom was mixed with about one drachm of alcohol, and kept four weeks. The precipitate at the bottom was then collected into a pipette, dried, redissolved in water, and thrown under the breast skin of a reed-bird. Slight local evidence of poisoning was visible, but the bird died within nine hours; an unusually long period. A repetition of this experiment gave a more sudden result, the bird dying in two hours.

A great number of observations similar to those just related convinced me that mere mixture with alcohol did not render the venom innocent.

As it appeared from Dr. Brainard's experiments, that in mingling the venom with active reagents, he had used these in a diluted state, I made a number of observations to learn whether or not these agents would affect the potency of the poison when allowed to act on it without previous dilution.

Experiment.-About one-third of a drop of pure venom was put upon a glass slide, and three drops of strong nitric acid were dropped upon it. Coagulation occurred, and in twelve minutes the acid was neutralized with liq. potassæ, and the mixture injected in three places into the breast and thigh of a reed-bird, which died in three hours. The wound was red, and not dark as usual, a fact which may have been owing to the presence of the nitrate of potassa. This observation was repeated twice with like results.

Similar experiments were made with strong sulphuric and muriatic acid, and with ammonia, chlorine-water, iodine, soda, and potassa. None of these agents destroyed the virulence of the venom. It is to be observed that in each case the contact was preserved during several minutes, and that the substances employed were neutralized before making the several injections. ${ }^{1}$

1 When renom was mingled with certain of these agents, such as iodine in solution, tannic acid, etc., and then injected, the constitutional symptoms declared themselves as usual in the pigeons employed, but the local phenomena were more or less wanting. With this latter fact Dr. Brainard has made ns acquainted, so far as iodine is concerned. 


\section{CHAPTE V.}

\section{TOXICOLOGY OF THE VENOM OF THE CROTALUS.}

THE strange and subtle poison which we have hitherto considered chemically, will hereafter claim our attention in its relations to animal and vegetable life. In the course of study thus laid down, we shall be called upon to examine, first, its influence upon the lower vegetable existences. Secondly, its power to affect higher vegetable organisms, and the germination of seeds. Thirdly, its activity with relation to the lower animals; and, fourthly, the influence of the venom upon the mammalia, such as the dog, and, finally, man himself.

The subject of the power of serpent venom to destroy vegetable life has attracted the notice of but two, among the many observers who have studied the poison of Indian, European, or American reptiles. Neither of the observers alluded to has investigated the matter very fully, and I have, therefore, endeavored to fill the void thus left, as completely as possible.

Before I proceed to detail my own results, it will be proper to state, briefly, the conclusions at which others have arrived. ${ }^{1}$

Dr. Gilman says: "During the process of robbing several species of serpents (of venom), I inoculated several small, but vigorous and perfectly healthy vegetables with the point of a lancet weil charged with venom. The next day they were withered and dead, looking as though they had been scathed with lightning."

The experiments thus described are so very limited, and so wanting in statement of details, that it is difficult to accord to them any great value as scientific evidence. Even in so trifling a matter as this, the sources of error are numerous, and we have a right to demand every possible knowledge as to the temperature and season, the size of the plants, the amount of venom employed, and the effect of wounding similar plants to the same extent, but without the use of the venom. ${ }^{2}$

1 On the Venom of Serpents, B. J. Gilman, A. M. M. D., LL. D., St. Louis Med. and Surg. Jonrnal, 1854 , p. 25.

3 An amusing story, which passed throngh three persons, reached the Philosophical Transactions (vol. xxxviii. p. 321) in the following form: "Sir Hans Sloan learned from Col. Beverley (Hist. of Va., $2 d$ ed. p. 260) that Col. James Taylor, of Metapony, had stated to him that, having found a Rattlesnake, they cut off his head, with three inches of his body. A green stick, the bark being peeled off, was put to the head. It bit it, when small green streaks were observed to rise up along the stick towards the hand. At this juncture, the Colonel wisely dropped the stick, which, in a quarter of an hour, of its own accord, split into several pieces, and fell asunder from end to eud." 
The only remaining authority upon this portion of our subject, is Dr. Salisbury. ${ }^{1}$ A large female rattlesnake, without food for a year, died, and on dissection its poison ducts supplied Dr. Salisbury with a small amount of venom. This was used on plants, without having been tested upon animals.

"About fifteen minutes after its removal, four young shoots of the lilac (Syringa vulgaris), a small horse-chestnut of one year's growth (Esculus hippocastanum), a corn plant (Zea mays), a sun-flower plant (Helianthus annuus), and a wild cucumber vine, were severally vaccinated with it. The vaccination was performed by dipping the point of a penknife into the poisonous matter, and then inserting it into the plant, just beneath the inner bark. No visible effect from the poison was perceptible until about sixty hours after it had been inserted. At this time, the leaves above the wound, in each case, began to wilt. The bark in the vicinity of the incision exhibited scarcely a perceptible change; in fact, it would have been difficult to have found the points, had they not been marked when the poison was inserted.

"Ninety-six hours after the operations, nearly all the leaf-blades in each of the plants, above the wounded part, were wilted, and apparently quite dead. On the fifth day, the petioles and bark above the incisions began to lose their freshness, and on the sixth day they were considerably withered. On the tenth day, they began to show slight signs of recovery. On the fifteenth, new but sickly-appearing leaves began to show themselves on the lilacs, and the other plants began to show slight signs of recovery in the same way. Neither of the plants was entirely deprived of life."

Dr. Salisbury afterwards comments upon the fact of the edges and apices of the leaves being the parts first attacked. He also states that the leaves below the points of inmoculation were altogether unaffected, while those on the side upon which the venom was inserted were the first to suffer.

These experiments were made in June.

An objection to the want of a precedent test experiment upon animals as to the virulency of the poison used has been above suggested. This objection, it is true, loses some weight in the presence of a positive result. I have mentioned it, however, because it was possible that the secretion of the snake in question might have been altogether harmless, and the apparent results upon the plants only the effect of a mechanical injury to their tissues. This very result occurred to me during the summer of 1859 .

A large snake, nearly five feet long, was sent to me from Iowa. It came in a very small, flat box, and was so coiled that it must have been difficult for it to move. When I removed it from its confinement it was sluggish, and was only induced to bite upon being much irritated. During the month of July the snake made no use of the bath in its cage; and, like the rest, took no food, nor did I feed it as I did some of its companions. A week before its death, there is a record on my notes of its having bitten a pigeon, which recovered in spite of a deep wound from

${ }_{1}$ Influence of the Poison of the Northern Rattlesnake (Crotalus durissus) on Plauts. By J. H. Salisbury, M. D., N. Y. Journ. of Med., vol. xiii. New Series, 1854, p. 337. 
one fang in the thigh. The snake was found dead on the seventh day after this occurrence.

Upon careful dissection, I found that the venom gland and the ducts on the right side, were full of a bloody fluid, with a faint alkaline reaction, and containing an abundance of club-shaped epithelial cells. The gland on the left side was nearly empty; its tissue was stained with blood. As I was curious to learn whether or not the altered poison had lost its power, I collected all the fluid contents of both glands, and their ducts, and inoculated with them the back, breast, and thigh of a pigeon, inserting in all about nine drops. The pigeon was slightly affected after the lapse of an hour, and was disposed to seek a corner and sleêp. Four hours later, however, it was seemingly none the worse for the operation. A small oozing of serum took place from one of the wounds in the back, soine days afterwards, but the pigeon suffered no permanent injury.

This result was enough to convince me that disease might alter the secretion of the venom glands, as it sometimes does that of the human salivary glands. I have alluded to it here, in order to fortify my criticism upon Dr. Salisbury's experiments. It is further to be observed, that Dr. Salisbury did not make any comparative observations, by wounding in a nearly similar manner, but with a clean weapon, plants of the same species and of equal size.

Beyond the points alluded to, there seems to be no objection to the experiments of Dr. Salisbury. He certainly appears to have been entirely successful in poisoning plants, with Crotalus renom; since, of eight plants injected, each and all seem. to have suffered the same changes.

I have been the more willing to quote these results in full, because my own efforts to affect plants in the same way were singularly unfortunate. The point on which onr experiments admit of no comparison is in regard to the species of the plant employed. At the season when I made my researches upon plant poisoning, I was unable to obtain the same plants as were used by Dr: Salisbury.

My first experiments upon plant poisoning were incidental to an examination of the power of Crotalus venom to prevent the occurrence of fermentation. After ascertaining, as I have already stated, that the conversion of starch into grape sugar was in no way interfered with when the venom was added to the mixture, I proceeded to ascertain whether or not the vinous fermentation would also take place in its presence.

Accordingly, a small amount of poison having been procured as usual, I found that it was fatal to a reed-bird, and then proceeded to make the following experiment.

Experiment.-Two test tubes of equal size, and capable of holding about one and a half ounces each, were fitted with corks, through which ran glass tubes, long enough to reach to the bottom. At the lower end, the contained tubes were bent at an acute angle, and drawn to a fine orifice. Above the cork they were also bent so as to form a double U-curve external to the test glass. Each of the test glasses was then filled with a solution of sugar in water, twenty grains of sugar being placed in each apparatus. To No. 1 were added a few drops of yeast, and to No. 2 about the same aniount of yeast, together with five drops of venom. Both test tubes were next corked with care, so as to exclude any bubbles of air, and the 
level to which the fluid rose in the tubes having been unarked, they were finally placed in an atmosphere of $75^{\circ} \mathrm{F}$. Through accident the temperature was allowed to rise to $128^{\circ} \mathrm{F}$. It afterwards fell to $80^{\circ} \mathrm{F}$., was kept at this during two hours and a half, and was then abandoned to the atmospheric temperature, which varied during the experiment from $69^{\circ}$ to $77^{\circ} \mathrm{F}$. Experiments previously made, convinced me that the accidental rise of temperature would not be likely to injure the venom. The action of the fermont was unusually slow, but at the end of fortyeight hours both solutions had fermented, the test glasses were half full of carbonic acid gas, and the fluid thus displaced had risen through the tubes and overflowed exterually.

Experiment.-On this occasion, I modified the process by leaving the ten drops of yeast in contact with three drops of venom for two hours, at a temperature of $79^{\circ} \mathrm{F}$. In all other respects, the experiment resembled that last described. Within thirty-nine hours, both tubes had fermented freely. The remnant solutions within the test-tubes contained an abundance of yeast fungus, and I was, therefore, driven to the conclusion that the venom does not interfere with alcoholic fermentation, nor with the accompanying growth of sporules.

The next observations upon the effect of the venom on the lower vegetable growths, were accidentally introduced to my notice. They appear to me to be still more decisive than those last mentioned.

During the warm weather of August, I had mixed two or three drops of venom with eight or ten of water, and left the mixture in a corked test-tube on my table. It was neglected during two weeks, and when microscopically examined, was found to contain a number of what I took to be the sporules of fungi. During the month of September I repeated this observation upon some dilnted poison which had been left in a test-tube during three weeks. In this specimen, I found an abundance of sporules.

As it was possible that the solution of venom might, by decomposing, have lost its virulence, I tested it by inoculating with it the breasts of two reed-birds which died with the usual local and general symptoms within two hours.

In passing to my experiments upon a higher order of plants, I began by using dried venom about two years old, but, as my experiments upon animals will show, of a potency only inferior to that of the freshest material.

Experiment.-During the month of June, 1859, four young shoots of tradescantia, a very succulent and rather tender trailing plant, were selected for experiment. Each of the shoots was split half way through, and about one-third of a grain of dry, pulverized venom was dropped into the opening, which was then allowed to close on the poison. The plants were next well watered, and a drop or two allowed to fall on the line of the incision. Four other shoots, two on the same, and two on other plants, were similarly, or even more mutilated, and in all cases the shoots chosen were from five to seven inches long. During a week, no result was obtained from these experiments. After that period, two of the unvenomed shoots, and one of the poisoned, became sickly, and gradually lost most of their leaves within the ensuing fortnight. So complete a negative result forbade any definite conclusions. 
Later in the year, during the month of September, and early in October, I repeated these experiments upon the following plants, viz :-

A young shoot of the common bean, four inches high.

A young dahlia six inches high, and constituting the whole plant.

A long flower, or budding flower-stalk of medicinal colchicum, C. Autumnale, about ten inches high.

Three branches of geranium, growing on a large and healthy plant.

A small succulent garden weed, three inches high, of a species unknown to me.

I had no duplicates of the dahlia, bean, and weed mentioned above, which I could wound as a means of comparison, but in the case of the colchicum, I wounded, without poisoning, the remaining flower-stalk, which was rather more fully in bloom, and in the geraniums I wounded, in like manner, three branches, of sizes about equal to those of the stalks which I both wounded and poisoned.

The mode of introducing the venom, which, in these cases was perfectly fresh, and of tried and known potency, I varied in several ways. In the dahlia and colchicum I merely raised the outer bark longitudinally, and with a fine pipette slipped one drop of venom into the opening. I then bent the stalk slightly, so that the divided bark would rise a little from the surface beneath, and thus hold the venom by capillary attraction.

The weed was inoculated by splitting it near to the earth, and inserting a full drop of venom. The geranium branches were each surrounded by a little lip of wax, within which I put from one to two drops of the venom, and then filled the cups with four or five drops of water, having previously punctured the stems, so as to place the incisions below the level of the poisoned water. The water was renewed twice a day, and into one of the geranium branches I introduced, three days later, about one-third of a drop of venom, just above the wax. The cups fell off after four or five days, but neither in the bean, dahlia, colchicum, or geranium, did the leaves die, or the plants in any way suffer, although they were watched daily, during three weeks.

The weed alluded to was an accidental growth in the pot with the geranium. It appeared to droop two days after the poisoning. This was due, I presume, to a very cold night, after which the plants were carried into the house, when the one in question very soon revived. In many successive efforts to poison other plants with venom, I failed in every instance.

It is clear from the foregoing statements, that the venom of the Crotalus is not fatal to the growth of the lower orders of vegetable existence; but, unfortunately, no such definite inference can be drawn with regard to plants higher in the scale. My own experience, it is true, would, if considered alone, entitle me to assume the inactivity of Crotalus venom within the tissues of the plants essayed, and this conclusion would gain value, also, from what we know of the mode of. its influence upon animals, and from the facts which we have made known as to the power of some forms of vegetative life to defy its influence. But, in the face of strong affirmative results, such as were obtained by Dr. Salisbury, I am unwilling to draw from my own negative experiments the same definite opinion which I should otherwise have felt authorized to base upon then. As I was indisposed to 
allow the question to remain without further answer, I made a number of experiments upon the ability of seeds to germinate in the venom, hoping to obtain in this manner a more complete solution of my doubts.

Here, owing to the circumstances of the experiment, the result may again be a negative one, and may still be open to all the doubts which encumber negative results.

Experiment.-October 5th, 9 A. M. I placed in each of two short test-tubes eight drops of water, and to one of them added one and a half drops of venom of known activity. On both tubes, upon the surface of each of the fluids, I laid a mesh of cotton wool, and upon it in each vessel fifteen canary seeds. The water in the two tubes was kept always at the same level, by the daily addition of the requisite amount of fluid. On the ninth day, none of the seeds in the renom had germinated, while two in the water were sprouting.

Twenty-one days after the observation began, the venom-tube offered no signs of seed-growth, and smelled very unpleasantly. The germs in the water were nearly half an inch in height.

As the small number of seeds which germinated in the water made it possible that none but incapable seeds might have fallen to the share of the venom-tube, I repeated the experiment without other variation of the circumstauces than the substitution of mignionette seed for those last employed, and the use of a bell glass to limit the too rapid evaporation. Twenty seeds were allotted to each vase. This observation began Oct. 15th. On Oct. $24 \mathrm{th}$, none of the seeds in the venom capsule had sprouted, while three of those in the water were in healthy bud, and some a little above the mesh of cotton. One additional test was required to add to these observations all the strength that could be given to them. It was possible that the venom, in decomposing, had lost its potency, and, as detailed previousiy, I tested it on animals, but still found it actively poisonous. At various times these experiments were again and again repeated, with slight modifications, but with no other result than continual failure to germinate on the part of seeds put in contact with venom.

It appeared probable from these observations, that venom has the power to prevent the germination of the seeds of plants such as those which I have mentioned above.

Action of Venom on Animal Life.-We have now reached a point where we turn from the influence of the venom upon vegetables, to study its power to affect animal existence.

In place of doubtfully deciding as to the cause of death, we are summoned to witness the operations of a substance which sometimes acts with a potency so swift as to defy observation, and which has a power to alter the blood and tissues in a manner, and with a celerity, which is a source of unending wonder, even to one who, by daily repetitions, has become familiar with the changes thus produced.

In the course of study now before us, I shall examine, as fully as possible, the effect of the venom upon cold-blooded animals, including the Crotalus, and upon various classes of warm-blooded animals.

After this general survey of the symptoms and pathology of the acute and chronic forms of venom poisoning, in these various classes of animals, I shall ex- 
amine separately the influence of the venom upon the muscles, nerves, bloodvessels, and blood itself. This general practical examination will enable us to review the theories hitherto in vogue, and to ascertain, if possible, the proximate mode in which this mysterious substance may be supposed to act.

In following the track here pointed out, I shall relate, at length, the cases, symptoms, etc., observed in a considerable number of animals, and I shall allude, briefly, to a still larger number whose cases it will be needless to state in detail. Although I shall thus record more experiments than have been made by any other observer who has studied the subject of Crotalus poisoning, it will, I fear, be but too plain that the research is one which demands the labors of many, and is, indeed, of such a nature that some of the questions involved in it, can only be settled by persons of greater leisure than myself, and who, at the same time, are so situated as to be able to procure a constant supply of fresh snakes.

It would, perhaps, be more in order to begin this section of our subject by an examination of the relations of serpent venom to the absorbing surfaces. It will, however, prove a convenience, as well as an economy of space, if, in place of this we defer the study of the absorption of venom until we have fully considered its effects on animals; since, in so doing, we shall be obliged to detail many of the facts which bear upon the deferred question.

It will be remembered that, upon page 50 of this Essay, I stated that, on several occasions I had noticed the production of fungi in moist venom, long kept upon my table, in an atmosphere of from $64^{\circ}$ to $70^{\circ} \mathrm{F}$. I have also observed in the same and in other specimens of venom long kept, and somewhat diluted, that after seven to ten days, the poison acquired an odor of a peculiar and very disgusting character. The production of this animalized and indescribable stench was accompanied by the appearance of vibriones, and, a few days later, of rotiferæ and other minute forms of animalcular life. The occurrence of these little beings in a fluid so deadly, prompted me to learn whether or not it had lost, by decomposition, any part of its specific nature as a poison; for, although I was aware that the cuticles of higher animals opposed a perfect resistance to the passage of the venom, I did not suppose that the delicate organisms here spoken of could, by any possibility, escape its action, when born and developed within it. At all events, this view opened to me a channel for observation of which I had not thought before, and whose value $I$ therefore proceeded to test, as stated on page 52, by determining what power yet remained in the venom which had become the nidus of so much active vitality.

It was my intention to examine, in the next place, the effect of the venom upon leeches, fish, eels, and crustacean animals, but for reasons which it is needless to relate, I was obliged to postpone these observations until some future occasion.

I was the more desirous, however, of making these examinations, because Fontana had already decided that leeches, snails, and slugs, were unaffected by the venom of the viper, and because some of his numerous observations in this direction were open to criticism, from his having failed to observe the animals as long as he should have done after the infliction of the poisoned wound, a precaution which, as I shall show, is absolutely essential when studying the influence of the venom upon cold-blooded animals. 
Action of Venom on Frogs.-This industrious and most able writer is also the only one who has recorded the effects of the viper poison on frogs, ${ }^{1}$ and, so far as I am aware, no one has repeated these observations. It is to be regretted that he did not state the size of the frogs bitten, since in such facts, or in the fresher state of his snakes, might have been found the reasons why the frogs which were subjected to the Crotalus venom, usually lived so much longer than those upon which the learned Abbé experimented. In the total want of knowledge as to the power of rattlesnake poison over frogs, I shall quote the passage from Fontana, in which he relates the results he obtained when making use of viper poison.

He says, "I procured fifty of the largest and strongest frogs I could meet with. I had each of them bit by a viper, some in the thighs, others in the legs, back, head, etc. Some of them died in less than half an hour, others in an hour, and others again in two, three hours, or somewhat more. There were some again that were not affected, whilst others that did not die became nevertheless swelled. There were, likewise, others among them that fell into a languishing state, their hind legs that had been bit, continuing very weak, and even paralytic. In some of them I contented myself with introducing cautionsly into a wound, made with a lancet at the very instant, a drop of venom. These last, however, lived longer than those I had bit; neither of them, however, escaped. I constantly took the precaution to prevent the venom I introduced into the wound being carried out by the blood that flowed from it. Some of these frogs swelled very much, others but little, and others not at all. The wounds of almost all of them were inflamed more or less. There were some, however, that died very suddenly, without the smallest mark of inflammation. A short time after these animals had been either bit, or wounded and venomed, the loss of their muscular force, as well as that of the motion of their extremities, was very evident. When they were set at liberty they no longer leaped, but dragged their legs and bodies along with great difficulty, and could scarcely withdraw their thighs when they were pricked with a needle, of the pain of which they seemed almost insensible. By degrees they became motionless and paralytic in every part of the body, and after continuing a very short time in this state died."

With this exception, and a few further remarks by the same author, we are without information as to the effect of viper venom upon the frog.

Of the effects of Crotalus venom upon the same animal, we know as little, and, so far as I am aware, only a single recorded experiment of this kind is to be found in the writings of American authors $;^{2}$ their only observations upon cold-blooded reptiles having been made on the Crotalus itself, or other serpents. We shall now proceed to study the details of the experiments which I have made upon coldblooded animals.

Upon classifying the cases before us, it will be discovered that they divide them-

${ }^{1}$ Fontana on Poisons, Chapter VI. p. 34, vol. i. Translation by J. Skinner, London, 1787.

a A single observation by Harlan. 
selves naturally and conveniently into two classes, which I shall term acute and chronic, or primary and secondary poisoning.

While in the batrachia the distinction between these two sets of cases is sufficiently clear, it is less well marked than in warm-blooded animals. At the time I was engaged upon this portion of my investigation, the active serpents in my collection were not so large as those which I afterwards received. This may account for the fact that, although I have some records of frogs more or less acutely poisoned, the majority of those bitten lived long enough to exhibit, in a marked manner, the secoudary lesions which I shall have occasion hereafter to describe.

The class of cases which I shall term acute, were marked by the negative character of the symptoms. In them the local signs of poisoning were very slight, and the changes in the blood which occurred where life was prolonged after a serious bite, were absent, or but very slightly marked.

Experiment.-A large frog recently caught, was attached to a string and lowered into a cage containing four snakes, none of which were over thirty-six inches long. As I had often observed, no provocation induced them to strike the frog, and, therefore, after many vain efforts, I drew a snake into the snake-tube, and placed the frog in its jaws. The serpent bit with eagerness, and the frog, uttering a cry, leaped from its re-opened jaws to the floor, and for a few moments used its legs so well as to avoid being caught. When at length it was secured, I searched in vain for the fang wound, which must have been very small; I did not discover it until after death, although I was sure that the skin had been penetrated, because a large bubble of air had found entry to the dorsal sub-cuticular sac.

The presence of air in this situation often enabled me to be confident that the fang had pierced the skin. It is occasioned by the attempt on the part of the serpent to withdraw its fang, which, catching, raises the loose skin, and creating a partial vacuum, thus draws air alongside of the fang into the subjacent cavities. A little quivering on the right flank, also, caused me to suspect that as the part bitten. Except in dogs, who shiver so much from mere fright, the local muscular twitchings alluded to are also of some value in calling attention to the part bitten. Two hours after this frog was poisoned, it was dead, having exhibited during the interval occasional convulsive motions of the limbs.

P. M. Dissection.-As soon as all motions, reflex and other, were at an end, the thorax and belly were laid open. The intestines responded to irritants. The heart was beating feebly, but in all of its cavities, and was large and dark. It ceased to pulsate at the close of three hours and ten minutes after the poisoning, and on being opened, was found to contain blood which coagulated perfectly after short exposure. The clot was well formed and firm. The muscles were irritable to all forms of stimulus during eleven hours, and, as I have usually observed, this property lasted longest in the muscles under the chin. ${ }^{1} \quad$ Nervous irritability existed until the close of the fourth hour. The seat of the wound was the right flank, into the muscles

1 Brown-Séquard, Bernard, Vulpian, and before them, Fontana, have noted the long retention of irritability by the diaphragm muscles. In the frog, the sub-mental group corresponds in function to these, as I have showu elsewhere. 
of which the fangs had entered obliquely, both teeth taking effect. There was more serun than usual in the dorsal sac, through which the weapons passed, and their track was marked by a little darkening of the neighboring muscles.

In twenty-four hours the muscular parts about the bite were almost diffluent, while the rest of the frog had no odor, or any other sign of putrefaction.

Experiment.-A large snake, from which $I$ had in vain attempted to extract venom, was secured in the snake-box as usual. Before releasing it, I placed a small frog, about four or five inches long, in its mouth, so that when it bit, which it did fiercely enough, the fang entered the belly. Slight local quivering of the nearer muscles, and some convulsive extensions of the hind legs, were the only marked signs, and no notable changes in the pupil was perceived until death took place, when it dilated. At the close of sixty-two minutes, neither voluntary or reflex motions could be elicited.

$P$. M. Section.-The wound exhibited no local evidences of poisoning. The aperture in the skin was small, and but one fing had entered. In passing through, or ont of the sub-cuticular abdominal walls, the fang tore these structures, so as to make a distinct opening, through which a little serum from the dorsal sac had passed, and carrying with it a little blood, had found its way into the peritoneal cavity. None of the abdominal viscera were transfixed. The ventricle of the heart beat only for fifteen minutes after it was exposed. The auricles beat feebly for one hour and forty minutes after this period. The nervous irritability was extinct everywhere thirty minutes after voluntary and reflex movement ceased, while the muscular irritability lasted but half an hour longer, and was thus entirely absent when the auricles of the heart were still pulsating. The blood in the heart clotted on exposure.

Experiment.-A small snake was teased until it struck a frog of medium size, and was itself so canght that it hung for a moment, when I drew the frog out by pulling on the string with which I had secured it. Upon inspection, it seemed that the fang had struck upon the spine. On being released, the frog appeared very uneasy, and for ten or twelve minutes was incessantly leaping about in the glass vessel in which it had been placed. At the close of half an hour, the frog became suddenly quiet, and shortly after was attacked with a general quivering of the muscles, followed by the loss of volitional control. Slight reflex acts were still capable of being produced, when the limbs were violently stimulated by mechanical means, but at the close of an hour from the period of poisoning, these also ceased, the eyelids became motionless when touched, and the frog being considered dead, was opened.

P. M. Section.-One fang was found to have entered the spine, and slightly wounded the medulla, which was rather too much injected with blood, but otherwise unaltered in structure. All the remaining viscera were healthy, and the heart was still acting with all its cavities as late as two hours and a half after the poisoning, when the observation stopped for a time. Four hours later, the organ had ceased to pulsate, and was ouly possessed of a slight localized irritability under stimulus. The blood was well coagulated.

The above quoted instances were the only cases of rapid death which I was called upon to observe in this class of animals. Their discussion will occupy us at another time. 
From a large number of instances of death in frogs, from the secondary or chronic action of the venom, I have selected the most interesting, and those which best illustrate the nature of the symptoms.

Experiment.-Temperature $84^{\circ} \mathrm{F}$. A very large frog was struck by a snake two and a half feet long, on the back of the pelvis, upon the left side. Twenty-five hours and five minutes after the blow, the frog was re-examined, and found to be inert and sluggish, but still able to move. During the intervil, it occupied a glass jar containing a large wetted sponge, and partly open at top. The back of the frog was darker than usual, and presented a fluctuating mass of fluid beneath the skin. The eyes were natural, the respirations occurred now and then, and the lymph-hearts, at the end of the spine were acting as usual. One day later the frog's condition was much as before. On the third day it was motionless, except under excessive stimulus, when it leaped once or twice, or if placed on its back, turned itself over with great difficulty. On the fourth day the swelling on the back diminished somewhat, and the subcuticular sacs of the legs became swollen.

From this time the frog gretv weaker; although put in water daily for an hour or two, and every pains taken to preserve it in a healthy state. It died during my absence on the fifth day.

P. MI. Section.-The muscles in the track of the fang which had not entered deeply, were dark in color, and underwent extreme decomposition within twentyfour hours, while the rest of the body was not sensibly affected. About the wound, in the dorsal sac, were large quantities of bloody serum, which coagulated feebly upon exposure. The other sacs, wherever examined, were also filled with bloody serum, and a similar fluid was found in the peritoneum and pericardium. Bloody mucus flowed from the mouth and nostrils, and the stomach and mucous surface of the intestines were stained with frequent patches of extravasated blood. The lungs were shrunken, but contained no blood. The heart, which was pale and unirritable, contained only two minute and very pallid clots, adherent to the auricular walls. The muscles of the legs and the flanks responded feebly to galvanism during one hour and thirty minutes after exposure. Those of the forelegs were also irritable, but, singularly enough, the muscles under the jaw had lost their power to act. The muscles were generally pale, owing to the great loss of blood: The sheaths or fascia were stained with blood in nearly every part of the body, and even between the separate muscles and the bone. There was no post-mortem rigor observed.

Experiment.-Temperature $74^{\circ} \mathrm{F}$. A large frog was bitten fiercely by a snake three feet long, which thrust one fang deeply into the left thigh. The other fang missed the leg entirely. During the five succeeding hours, the subject was watched by an assistant, who described the wound as exuding bloody serum, while the animal remained in one position, quite motionless. It died during the following night, when unobserved, and was found the next day in a state of rigor, a good deal shrunken, although great pains had been taken to keep it constantly moistened.

P. M. Section.-The bitten leg was greatly swollen, and the muscles beneath were livid with extravasated blood. Everywhere in the injured limb the muscles were deeply stained with blood, and this appearance was not confined to this limb, but 
existed also in the leg not bitten. About the bite, the muscular structure was almost difluent, and could be torn with the utmost ease. A slight effusion of blood was found under both forelegs, in the axillary spaces. Elsewhere the organs were healthy. The heart was unirritable, and contained a little thin uncoagulated blood. Nervous irritability was extinct, and that of the muscles absent, except under the chin, where it remained for an hour or more after exposure.

Experiment.-Temperature $74^{\circ} \mathrm{F}$. A second frog of large size was bitten twice by the same snake which had just bitten the last one. On each occision, a single fang entered, the leg and the thigh being thus wounded. From these wounds, a bloody serum continually oozed, until I ceased to observe it. Certainly, a drachm or more of fluid exuded in this manner. On the second day, matters were as before. On the third, the frog was very sluggish. The bitten leg was enormously swollen to the very end of the toes, which, on being held up to the light, were seen to be distended with red serum. The skin of this member was also soaked, in places, with extravasated blood. On the fourth morning, the frog was found to have died during the night.

P. M. Section.-Slight rigor mortis. The bitten leg was literally soaked in blood to the extreme edges of the web, and was everywhere swollen by this local accumulation. The flexors of the thigh were filled with blood, so as to be dark crimson throughout their thickness. A little bloody fluid was present in most of the sub-cuticular sacs. The heart was pale, bloodless, and nnirritable. The other organs were normal. The nerves and muscles proved to have lost their power to react under stimulus. The little blood found in the vessels was diffluent. As in some other cases, the fluid of the dorsal lymphatic sac coagulated feebly upon exposure to the air.

Experiment.-Temperature $73^{\circ} \mathrm{F}$. A small frog was bitten on the back, below the scapula, by a snake about three feet long, which had already used its fangs once within twenty-four hours. The fang-mark was not visible, but from the presence of air in the dorsal sac, I was convinced that the weapon had entered. The muscles about the bitten part immediately began to quiver, and this motion soon extended to both flanks. The frog became rapidly weak, and within an hour and a half could not turn when laid on its back, and was unable to use its hind legs. At this time the pupils were contracted, the eyes balf closed, and the lids of the right organ completely insensible, the left one nearly so. The frog shortly afterwards lost all voluntary power, even in the forelegs, but exhibited slight reflex phenomena up to the fifth hour, when it was apparently dead.

P. M. Section.-The wound passed through the muscles below the scapula, and into the liver and peritoneal cavity, which contained a little bloody fluid. The heart was beating forty-four to the minute, auricles and ventricle acting. Half an hour later the auricles alone were acting, and these were arrested during the ensuing period of ten hours, although carefully protected from desiccation. The nerves everywhere were highly irritable, but this passed away completely within half an hour. The muscular irritability remained good during two hours. Ten hours later, no muscle responded to irritants. The small amount of blood found in the heart was fluid. It is to be remarked that, in some of these cases, nothing 
was more difficult than to ascertain whether the minute amount of blood present was coagulated or not. Both lungs were gorged with blood, and the intestines were dotted with specks of extravasated blood, although no free blood was found in the intestinal canal.

The cases above quoted illustrate nearly every peculiarity of the effects of the venom upon batrachia, whether affecting them rapidly or slowly.

It is necessary to the completion of this study, that we recount, also, the manner in which the dried venom of the Crotalus acted upon these cold-blooded animals. In one respect its action is undoubtedly peculiar.

I have already alluded, in several instances, to the dried venom of the Crotalus. The specimen used in the following experiments was given to me by Prof. Leidy, who received it from my friend Prof. Wm. A. Hammond. It was obtained in Kansas, in the autumn of 1857 , by a process similar to that which I have described on page 28. It had been allowed to dry into thin yellow scales, and was preserved in this condition in a small bottle, not very well secured from the air.

Prof. Christison had already stated that cobra poison, fourteen years old, was still effective. Mangili ${ }^{1}$ had ascertained the same of viper poison eighteen months old.

Orfila, ${ }^{2}$ in recounting the experiments of the author last named, observes that they proved contradictory of the statements of Fontana, ${ }^{3}$ an assertion which is only partially correct, since the learned Abbe distinctly states that viper poison is active after being preserved for several years in the cavity of a dry fang. He adds, moreover, that the powdered and dried venom had been kept by him for several months without loss of its power, and he also adduces Redi'st experience to the same effect. At the close of these statements he remarks, however, that the poison may lose its potency by being kept, and that this took place frequently when he attempted to preserve it longer than ten months. As we shall have occasion to see, this is not the only instance where the learned Abbé has been misquoted and misunderstood. Few authors of such merit as Fontana have had so little justice at the hands of those who have followed them, and this remark applies not alone to his work on the Viper, but to his researches on Ticunas, and to other labors, many of the results of which have been assiduously re-discovered by more modern observers.

Experiment. Poisoning by Dried Venom.-Temperature $79^{\circ} \mathrm{F}$. A frog of middle size received in the muscles of the back a small quantity of dried venom. An unenvenomed wound of corresponding size was inflicted upon the other side of the spine. On inspection, twenty-one hours after, the frog was found seated and quiet. During half an hour no respiration occurred. Upon tonching the eye, the frog breathed once and moved its entire body, after which no further motion could be provoked, and the animal seemed to be dead.

$P$. M. Section.-On comparison, the two wounds were so much alike, that no dif-

1 Mangili, Annales de Chimie et de Physique, Février, 1817, from Giornale di Fisica Chimica, etc., vol. ix. p. 458.

a Orfila, Traité de Toxicologie, t. ii. p. 852.

s Fontana, vol. i. Chapter XXII. p. 65.

4 Redi, see also Russell, p. 63. 
ference eould be pereeived between them. Not the least sign of swelling, eongestion, or inflammation, was visible about either. The heart, which was large and dark, beat fifteen in the minute, all its eavities aeting feebly until it was eut out, at the close of half an hour.

The nerves of the legs were irritable for rather over an hour, and the museular exeitability endured but two hours longer, when post-mortem rigor eame on. The cardiae blood coagulated very well.

Experiment.-A little dried venom was placed in the museles of the thigh of a frog. As the wound bled rather freely, a seeond portion was inserted in the lumbar muscles. The frog died during the ensuing night, within twenty-one hours of the poisoning. When examined, there was not the slightest local sign of the presence of venom, nor was there bloody serum in any of the lymphatic saes. The nerves and museles were unexcitable. The heart was at rest, and was not irritable. It contained a little coagulated blood. Other viseera healthy.

Experiment.-A fang reeently shed, together with a small quantity of dried venom, was buried in the museles of the back. After death, the museles about the imbedded fang were softened, and dotted with points of blood. A little bloody serum was found in the cuticular sae of the wounded thigh. About the spot wounded with the dry venom, there was a little redness, but no softening or extravasation. The remaining symptoms of the ease are valueless in this connection.

The elief reason for quoting the above eases here, is to call attention to the almost utter absence of local symptoms when dried venom was used in frogs.

Effect of the Tenom upon the Crotalus.-This research resolves itself into two propositions, or rather, questions. First, Can the Crotalus kill its own species? Seeond, can any individual snake destroy itself?

The first of these queries has been more or less completely answered, as regards certain Indian snakes, the viper of Europe, and our own Crotalus. Russell made a Cobra bite a nooni-paragoodoo near the anus. It died in one hour and a quarter. A little local diseoloration existed about the wound, and the lungs were full of blood. A Cobra bit another Cobra, with a negative result. How long it was observed, is not stated.

A Coodum-nagoo bit a Cobra, the two fangs taking effect, the result, as before, being negative. All of these snakes were venomous.

A Coodum-nagoo bit a Tortutta, a harmless serpent, which perished within two hours.

Fontana's experiments on the effect of the venom of the viper upon its own kind, were briefly as follows :-

One viper was bitten by another several times. The ivounds swelled a little. It was killed by Fontana after thirty-six hours, and found to have been deeply wounded, the bites being a little inflamed and swollen.

A middle-sized viper reeeived from two large ones six fang wounds. The viper remained agile, and was well at the end of four days. When killed, it was found

\footnotetext{
${ }^{1}$ Russell, p. 56.

'Fontana, rol. i. p. 29 et seq. Skiuner's translation.
} 
to have been bitten through and through. The wounds were somewhat inflamed. Five other vipers thus bitten, did not die. Length of observation not mentioned. Again, a portion of skin having been removed from the backs of four vipers, seven vipers were made to bite them. None of the bitten animals died, and only one of them was at all languid, and had a little swelling about the wound. Three vipers were wounded in the back, and the wound filled with venom. The wounds inflamed, but did not swell. The animals seem to have been killed at the end of several days. A viper was forced to bite itself; it did not die. Another was made to bite on a piece of jagged glass, so that its mouth was wounded as the poison flowed into it. On the seventh day the wounds were healed.

M. Bernard ${ }^{1}$ recently repeated Fontana's experiments, and found that a viper which had been both bitten and inoculated artificially with venom, died on the third day. Upon this experiment, M. Bernard criticizes Fontana, as having observed the viper and pigeons together, and having concluded that, because the coldblooded animal was not affected so soon as the other, that it was incapable of being killed by the venom. As we have seen, however, some of Fontana's experiments were observed during periods of time much greater than that required to destroy the viper observed by M. Bernard. Thus, although Fontana was most probably mistaken in his conclusions, he did not fail in the point criticized, from any glaring neglect of continued observation.

The American authorities upon this matter are brief, but decided. They refer principally to the porver of the snake to destroy itself, and to this point, indeed, my own experiments have been directed, since it was plain that if the individual could thus be made to kill itself, there could be no added difficulty in comprehending its ability to kill its fellows.

Besides including the general proposition, the question before us has a specific interest, from the fact that snakes are often accidentally hurt about the mouth, and that abrasions of this cavity must frequently occur. We are, therefore, called upon to say why the snake suffers so little from wounds on which a poison so deadly to other animals must fall from time to time.

Our own writers ${ }^{2}$ state almost unanimously that the Crotalus is able to kill itself. Without quoting them in full, it is enough to add that their experiments were commonly made by switching a snake until it turned and struck itself. Death is usually described as following within a few minutes.

At the close of a series of experiments on warm-blooded animals, I made use of some of my largest snakes in the following manner:-

Experiment.-Temperature $65^{\circ}$ to $75^{\circ} \mathrm{F}$. A small snake about twenty-seven inches long, was caught by the neck, and its tail placed in its mouth. It bit, but did not wound. A portion of skin having been removed from the back, it was

1 Claude Bernard, Leȩons sur les Effets des Substances Toxiques, ete., 1857, p. 291.

Dr. Brown-Séquard appears to have made experiments upon the Viper, but I have been unable to find his paper.

2 Burnett, p. 323. 
allowed to bite again, and when the fangs were fixed in the naked muscles, the upper jaw was violently pressed downwards, so as to wound the part deeply.

Upon the sixth day, the wonnd was covered with a gray exudation, such as is usually found upon the healing surface of the wounds of serpents. This snake died on the fourteenth day. The tissues about the bite were congested, the gall-bladder full, mucus in the stomach, the venom glands dark from effused blood.

Experiment.-A large snake was made to bite himself twice, in a space near the cloac, where the skin had been removed. This serpent also died on the fourteenth day. The wound was apparently healthy, and not to be distinguished from any other wound, except that the muscles about it were a little softened. The blood was uncoagulated, but there was 110 other visible lesion of any internal organ.

Experiment.-On the same day a large snake, fifty-six inches long, had a small portion of the skin on the back loosened and turned over, so as to make a flap. On this wound was placed about a drop of venom from the snake itself. The poison was finally thrust into a number of superficial cuts made in the muscles on which the drop fell. On the second day, the snake being well to appearance, half a drop of its own venom was put in a superficial wound half way up the back. This wound seemed to excite the snake, which, on being replaced in its box, continued in very rapid and violent motion for some minutes, as though in pain. On the sixth day, both wounds were covered with gray exudation, and beneath, the muscles were soft, but in this, as in other cases, no effusion of blood existed about the wound. The snake was sluggish, and indisposed to bite. It died on the tenth day.

P. MI.-There were no visceral lesions, except that one lung contained a little effused blood. The venom glands were dark and congested. The heart blood coagulated firmly, thirty minutes after removal. In all probability this serpent died from some other cause than venom poisoning.

Experiment.-A snake forty-six inches long was secured, and the skin just above the anus removed from a space of about one inch by two. On this, the snake bit itself three times, throwing out a good deal of venom which was thrust deeply into the muscles of the part. On the second day, the wounded muscles were softened, but no blood was effused. The wound had been re-covered with skin, and secured by sutures. At the close of two weeks this snake was healthy, and bit eagerly. The wounds were partially healed.

Experiments.-Three large serpents were made to disgorge their venom, and the poison from each snake was injected under the skin of its back, with the aid of a small syringe and trocar. The snakes, which I will distinguish as numbers one, two, and three, received respectively ten, eight, and seven drops of poison.

No. 1 died in thirty-six hours. The wound was surrounded by softened tissues, but was not stained with blood. The organs generally were normal, except the stomach, which contained bloody mucus. The heart was full of clotted blood.

No. 2 died in sixty-seven hours. The local appearances in this case were much as in the last one, but less extensive. The interior organs were healthy, and the heart contained two loose and soft clots.

No. 3 died during the seventh day. The wound, in this case, penetrated the muscles, which were dark and much softened. The blood in the heart was mostly 
diffluent, presenting but a single small congulum of loose structure. The intestines were spotted with ecchymoses, and the peritoneal cavity contained about a drachm of fluid blood.

I may add to these cases the numerous instances in which $\mathrm{I}$ have wounded the mouths of snakes, or torn the vagina dentis, while robbing them of poison. On none of these occasions has any serious result followed the injury, even where venom had fallen upon the abraded surfaces in considerable amount.

The above experiments were on the whole so definite in their results, that I did not think it necessary to multiply them. I had very many times injured snakes far more than these were injured by their own fangs, or the preparatory manipulations, and I, therefore, felt at liberty to conclude that the animals employed on these latter occasions really died from the venom. The length of time required for this to occur was curious, and far exceeded in most of them that which was noted in Bernard's case, or in the many instances of which $I$ have been told where rattlesnakes had stricken themselves.

One of the factors in the experiment, and one which has been too much neglected, is the temperature, which in my own cases was very moderate during the day, and fell a good deal lower at night, the observations having been carried on during a cool period in September, 1859. M. Bernard, Russell, and Fontana, give no record of the temperature during their observations. That it is a very important condition in the venom poisoning of the cold-blooded batrachia I have frequently observed, and it is highly probable that in all cold-blooded animals the elevation of temperature carries with it an increase of danger from poisons, and especially from those of a septic nature.

When we examine the pathological effects of the venom in warm-blooded animals, we shall see that, while the general phenomena were essentially the same as in cold-blooded reptiles and batrachia, they were far more rapidly produced. The Crotalus itself was a good illustration of this contrast, and was in other respects exceptional in the mode in which it was affected, since, while the muscles were altered, as in warm-blooded creatures, the blood coagulated better than was usual in them, and the visceral lesions were less severe, and less frequent. On the other band, while the frog was for its size remarkably unimpressible by Crotalus venom, the phenomena which in it accompanied the examples of slow poisoning, were in no respect different from those developed in the warm-blooded animals. To this subject we shall recur, after studying the effects of the venom upon the higher animals. 


\section{CHAPTER VI.}

\section{TOXICOLOGICAL ACTION OF THE VENOM UPON WARM-BLOODED ANIMALS.}

WE shall now enter, without other comment, on the study of the effects of Crotalus venom upon warm-blooded animals.

Of all warm-blooded creatures, birds are most susceptible to the influence of this poison. So sudden, indeed, were its effects in some of them, that when the dose of the venom was large, there was hardly time to observe the resultant phenomena. In larger birds this extreme sensibility to the poison also existed, when the dose was in proportion greater. So minute, however, was the quantity required to kill a small bird, such as the reed-bird, that under certain circumstances these little creatures became very delicate tests of the presence or relative activity of the venom. .

Experiment.-A pigeon was lowered into the snake-box, and was struck once, high up on the back, by a snake of middle size, which had just used its fangs. Upon this oceasion, both fangs were buried deeply. On being released, the pigeon walked across the table, and seeking a comer, remained at rest, until, at the close of three minutes it fell down, and immediately began to breathe convulsively, now and then gaping, and making efforts to rise. The difficulty in the respiration seemed to be due to the general weakness, which interfered with all the other movements at the same time. The bird became more and more feeble, the breathing more labored, and at the end of the seventh minute the head fell to one side, the breathing ceased, and the bird died without convulsions.

P. M. Section.-Both fang marks were surrounded by circles of extravasated blood, about three lines in breadth. The motor nerves of the wings and legs were irritable nine minutes after death. The museles remained irritable during twentynine minutes, when post-mortem rigor appeared in the legs, and soon became general. The heart beat with all its cavities, four minutes after respiration ceased. Both auricles and ventricles were sensitive to mechanical stimulus nine minutes after death. Two minutes later, the ventricles ceased to respond, but the auricles were more or less irritable fifteen minutes after death. The blood coagulated moderately well. It was very dark, but on exposure became bright red.

Experiment.-Temperature $74^{\circ} \mathrm{F}$. A pigeon secured by a string was thrown into a snake-box. Two snakes of middle size, two and a half to three feet long, struck at it as soon as it began to flutter. The pigeon was at once removed and put on the table, where, in two minutes it showed signs of weakness, staggered to and fro, and at last, as usual, sought refuge in a corner. At the sixth minute, its breathing became labored and jerking, and the muscles about the wound were twiteling 
locally. At the sixteenth minute, the breathing was still jerking, but more rapid, the bird crouched as if asleep, the eye natural ; the pupil, if changed at all, a little contracted. At the thirty-sixth minute the head fell, the eyes closed, respiration became rare and labored, and the pupils contracted. Cloac temperature $104 \frac{1}{2}{ }^{\circ} \mathrm{F}$. At the fortieth minute, the head was bent suddenly forward on the breast, and after three such motions of a convulsive nature, respiration ceased at the forty-second minute.

$P$. M. Section.-The head was cut off at once, and the blood received in a capsule. It was dark, but became red on exposure, and coagulated firmly, at the close of four minutes. Nervous irritability existed feebly in the sciatic nerves, nine minutes after death. Elsewhere it continued to the twelfth or thirteenth minute, when a probe thrust down the spine occasioned no motion. Ten minutes after death the muscles were everywhere very irritable. Thirty-three minutes after death this property was present only in the thighs and the diaphragm. In both of these localities it was still perceptible fifty-six minutes after death. Ten minutes later, I could not feel sure of its existence. The heart, which was large and dark, ceased to beat ten minutes after respiration stopped, and two minutes later had totally lost all irritability to stimulus. The auricles contained a little dark blood, chiefly uncoagulated, with the exception of two small and soft clots.

Experiment.-A snake four feet long was secured and made to bite a pigeon, which it seized so that one fang entered the knee. This pigeon had recovered from a former bite with the loss of a portion of the pectoral muscles. It was well and active. Upon its being bitten, I threw it from me, but, to my surprise, its wings were motionless, and it fell a dead weight on the table, and did not afterwards breathe or move. Thirty seconds elapsed between the bite and the death.

$P$. $M$. Section.-Some little delay occurred, owing to the unexpected nature of the death, and on exposing the heart within three or four minutes, it had ceased to beat, although it responded to stimulus feebly and locally for a few minutes longer. The nerves in the thigh were irritable during twenty-eight minutes. The muscles everywhere lost their irritability within two hours and ten minutes.

Cases of chronic or secondary poisoning were, naturally, rare in birds, and if they survived a few hours, they frequently recovered. The following cases illustrate sufficiently well the chronic form of poisoning.

Experiment.-Temperature $77^{\circ} \mathrm{F}$. A large white pigeon was thrown into the snake-box, the inmates of which seemed, for a time, reluctant to use their power. Finally a snake two feet in length bit the pigeon once in the breast, and became so entangled, that bird and serpent rolled over together. On examining the wound, two fang marks were found in the pectoral region, but so much of the venom had been cast upon the neighboring feathers, that I presumed the wound could not be rapidly mortal. Three hours after its infliction, the bird drooped a little and was disposed to sleep. A few hours later this tendency had passed away, but the wound was dark and swollen from effused blood. No signs of active inflammation existed. On pressure, a little serous blood flowed from the wound. Within five days the skin gave way and the parts beneath sloughed to the bones. At the close 
of this process on the sixth day, the bird died, probably of mere exhaustion and constitutional irritation.

Experiment.-Two pigeons were bitten by a snake which had made frequent and recent use of its fangs. Both birds were purposely exposed in such a way that they were bitten in the thigh. Both were enfeebled by the poison and seemed disposed to sleep. One of them sunk slowly; lower and lower, until its head touched the table, when it rolled on its side. It died without convulsions nearly eleven hours after the bite. The second pigeon, which was also the last bitten, died in violent convulsions with the head thrown backwards, during the eighth hour.

P. M. Section.--In neither of these birds was the blood coagulated, nor did it pass into that state upon exposure. In the pigeon first struck the pericardium was very full of serous blood, but no other organ was altered. In the second pigeon, the lungs, air passages, and mouth were full of blood, the mucous walls of the stomach were deeply congested in spots, and the peritoneal surface of the small intestines was marked with star-like points of extravasated blood.

Experiment. - A pigeon was struck in the back by a small snake, only one fang entering. The bird was placed on the table, where it iustantly sought a corner and in ten minutes fell into the usual stupor with jerking, abrupt respiration. This condition seemed to lessen an hour later, but only for a time, and the bird finally sinking down, became weaker and weaker, and died without convulsions at the close of five hours and a half. The pupils gradually contracted before deatl, and suddenly dilated afterwards.

P. M. Section.-The wound in the back was dark, and a little thin dark blood oozed from it. The tissues around it for an inch or more, were soaked with extravasated blood, which had even passed through between the ribs, so as to stain the tissues behind the intestines and crop. The heart was large and full of perfectly fluid blood. No other lesions were observed, except that the pericordial serum was a little bloody.

My chief reason for recording at length the cases above reported, is to show the great increase in the internal lesions which occurs when the venom is long in killing the animal. Among these changes, it was found, as a general rule, that the blood was most affected, and least coagulable, the longer the death was delayed.

I have not thought it necessary to report in full the whole of the numerous cases of the malady in the pigeon. In some instances, the birds recovered from the immediate effect of the poison to die of the secondary lesions induced by it. In others, the death was sudden and early, and in a third class it was delayed for a few hours. All of these find illustration in the cases already quoted. One point, however, appeared to me to demand further attention.

When a number of any class of animals are poisoned, certain phenomena and lesions occur constantly, others exceptionally; and this is true of what are usually known as diseases, as well as of more easily studied cases of poisoning. To illustrate this, I have selected seven cases of a fatal character in pigeons, none of which have been reported in the foregoing pages. To save space, I have presented them in tabular form, so as to show, at a glance, the variety of symptoms and patho- 
logical appearances which may occur. No cases of very early death are admitted into this report.

\begin{tabular}{|c|c|c|c|c|c|c|}
\hline No. & $\begin{array}{l}\text { No. of } \\
\text { fang } \\
\text { marks. }\end{array}$ & $\begin{array}{l}\text { Locality } \\
\text { bitten. }\end{array}$ & $\begin{array}{l}\text { Duration of } \\
\text { life from time } \\
\text { of bite. }\end{array}$ & $\begin{array}{l}\text { Occurrence of } \\
\text { eonrulsions. }\end{array}$ & Internad lesions. & State of blood. \\
\hline 1 & 1 & Thigh. & 2 hours. & None. & None. & Loosely coagulated. \\
\hline 2 & 2 & Breast. & $\begin{array}{l}4 \text { hours aud } \\
10 \text { minutes. }\end{array}$ & Noue. & $\begin{array}{l}\text { Spots of extravasation under } \\
\text { the peritoneal surface of the } \\
\text { intestines and on the,heart. }\end{array}$ & $\begin{array}{l}\text { Chiefly uncoagulated, one } \\
\text { small heart clot of loose } \\
\text { texture. }\end{array}$ \\
\hline 3 & $\begin{array}{l}2 \\
1\end{array}$ & $\begin{array}{l}\text { Back and } \\
\text { Breast. }\end{array}$ & $\begin{array}{l}2 \text { hours and } \\
17 \text { minutes. }\end{array}$ & Violent. & None. & Coagulated well. \\
\hline 4 & 2 & Breast. & 5 hours. & $\begin{array}{l}\text { Slight spasms } \\
\text { at death. }\end{array}$ & & $\begin{array}{l}\text { Coagulated loosely after a } \\
\text { few minutes. }\end{array}$ \\
\hline 5 & 1 & & $\begin{array}{l}9 \text { hours and } \\
10 \text { minutes. }\end{array}$ & & $\begin{array}{l}\text { Bloody sorum in perieardium, } \\
\text { bloody mueus in lung. }\end{array}$ & Blood diffluent. \\
\hline 6 & 2 & Back. & 3 hours. & $\begin{array}{l}\text { Slight at } \\
\text { death. }\end{array}$ & $\begin{array}{l}\text { Ecehymosed spots ou the } \\
\text { heart, abundant yellow } \\
\text { serum in perieardium. }\end{array}$ & $\begin{array}{l}\text { Blood diffuent; one small, } \\
\text { soft clot in right auricle. }\end{array}$ \\
\hline 7 & 1 & Leg. & $\begin{array}{l}6 \text { hours and } \\
30 \text { minutes. }\end{array}$ & None. & No visible lesions. & Blood perfectly fluid. \\
\hline
\end{tabular}

The remaining observations were made upon reed-birds, and were principally incidental to researches upon special points to which I shall have to refer so much at length in another place, that it is needless to duplicate them here. The reedbird proved so susceptible a test, that one-eighth of a drop of venom sufficed in most cases to destroy it, the length of life in these instauces being always in inverse ratio to the amount of poison employed.

Among warm blooded quadrupeds, I have examined the influence of venom on the rabbit, the guinea pig, and the dog. On the first mentioned animal I have made ten observations. Of these, I shall report two at length, the remainder in full tabular form. Upon the guinea pig I have made only four experiments, all of them incidental to special points of research, and not so fully reported in my note book as to enable me to detail at length their symptoms and lesions.

Experiment. Poisoning of Rabbits.-A large white rabbit was lowered into the snake-box, and was instantly struck by a sinall snake. The wonnd took effect on the left hind paw. The rabbit was removed and put upon the table, when it rolled over, gasping and slightly convulsed, and was dead in one minute.

$P$. MI-No lesion was found in any organ. The fore feet twitched for some few minutes after death, and the skin muscles moved to and fro in a singular manner. The heart was beating actively, but feebly, just after death, and continued locally irritable for over an hour and a half. The muscles and motor nerves were perfectly excitable several minutes after death. The blood coagulated firmly and rapidly; a perfect case of acute poisoning.

Experiment.-In this instance the animal was struck once in the back by a large snake already exhausted by frequent use. A few minutes after the bite took place the rabbit was seized with weakness, gritting of the teeth, and rapid respiration. It passed urine and feces, and remained feeble during some hours. From this period the weakness abated somewhat, but the back continued to swell. On the second day the local signs were improving, but the animal had passed a very albu- 
minous urine, and a large amount of blood mixed with feces. The symptoms of general weakness now increased, the hind legs began to drag, the motions were uncertain, and the bloody purging grew worse. The rabbit died on the third day, during my absence.

P. M. Section.-Rigor mell developed. The period of death being uncertain, the irritability of the tissues was not tested. The wound was surrounded by half an ounce or more of dark fluid blood. The ressels in the neighborhood were full of a similar fluid, but there was no vascular redness, like that of acute inflammation. The muscles in the track of the bite, which was a double fang mark, were remarkably softened and could be torn with the utmost ease. The brain was highly congested, and there mas a good deal of bloody serum in the cavities of that organ. Similar congestion existed in the spinal canal, and at sereral points the white nerrous tissue was stained with small patches of blood. The lungs were healthy. The pericardium was curiously distended with bloody serum. The heart was contracted and contained but little blood, and that dark and diffluent. The intestines were spotted at intervals with ecchymoses four to five lines in diameter and apparently just beneath the serous corering, the carity of which contained a little bloody serum. The intestines from the osophagus to the rectum were dotted with ecchymoses and filled, especially the large gut, with blood and mucus. The right kidney was large and absolutely soaked with dark fluid blood. The left kidney was more healthy. The bladder and ureters contained a good deal of bloody urine. How the rabbit lived so long with such a singular complication of serious lesions it is difficult to conceive. In most cases of chronic poisoning, some one or trro organs may become the seat of local extrarasations, but for extent and character of lesion this case stands alone in my experience.

\section{TABLE OF STMPTOMS IF EIGHT RABBITS}

\begin{tabular}{|c|c|c|c|c|}
\hline So. & $\begin{array}{l}\text { Duration of life } \\
\text { after bite. }\end{array}$ & $\begin{array}{l}\text { Earls local symptoms } \\
\text { and place of wound. }\end{array}$ & General symptoms. & Sode of death. \\
\hline 1 & 38 minutes. & $\begin{array}{l}\text { Slight smelling in } \\
\text { fore shoulder. }\end{array}$ & $\begin{array}{l}\text { Prostration and loss of power without loss } \\
\text { of sensation or cerebration, jerking respi- } \\
\text { ration, general twitching. }\end{array}$ & $\begin{array}{l}\text { Gradual, Tithout conral- } \\
\text { sions. }\end{array}$ \\
\hline 2 & $\begin{array}{l}5 \text { hours and } 4 \\
\text { minutes. }\end{array}$ & $\begin{array}{l}\text { Hind right leg } \\
\text { swelled enormons- } \\
\text { ly up to the spine. }\end{array}$ & $\begin{array}{l}\text { Prostration, gritting the teeth, local and } \\
\text { general tmitehing, jerking respiration, } \\
\text { gradual loss of power, with continued } \\
\text { ability to hear, see, se., until near death. }\end{array}$ & $\begin{array}{l}\text { Gradual, with slight ge- } \\
\text { neral convalsion; head } \\
\text { thromn forwards, feet } \\
\text { extended. }\end{array}$ \\
\hline 3 & $\begin{array}{l}1 \text { hour and } 10 \\
\text { minntes. }\end{array}$ & $\begin{array}{l}\text { Teck: slight smell- } \\
\text { ing, local twitches. }\end{array}$ & $\begin{array}{l}\text { Sadden loss of motor power, gaping, pros- } \\
\text { tration, very quick respiration. }\end{array}$ & Gradual, no convalsions. \\
\hline 4 & 27 minutes. & $\begin{array}{l}\text { Teck; slight strell- } \\
\text { ing, local twitches. }\end{array}$ & Sudden prostration. & Violent conrulsions. \\
\hline 5 & 13 minutes. & Right hind leg. & $\begin{array}{l}\text { Loss of motor power, prostration, jerking; } \\
\text { respiration, general twitching. }\end{array}$ & Tiolent conrulsions. \\
\hline 6 & 9 hours. & Left fore part. & $\begin{array}{l}\text { Prostration, gradual loss of motion, gritting } \\
\text { the teeth, jerking respiration not so well } \\
\text { marked as usual, singular and incessant } \\
\text { morement in the skin mnscles. }\end{array}$ & $\begin{array}{l}\text { To conrulsions; gradual } \\
\text { and easy death. }\end{array}$ \\
\hline 7 & 12 minutes. & $\begin{array}{l}\text { Teck and head; } \\
\text { local tritehing. }\end{array}$ & $\begin{array}{l}\text { Sudden prostration and loss of motion, } \\
\text { respiration quick and labored, not jerk- } \\
\text { ing. }\end{array}$ & $\begin{array}{l}\text { Gradual, Trith slight con- } \\
\text { ralsive motions of the } \\
\text { limbs and skin mascles. }\end{array}$ \\
\hline s & $\begin{array}{l}2 \text { hours and } 9 \\
\text { minutes. }\end{array}$ & Left fore leg. & $\begin{array}{l}\text { Srmptoms of meakness suddealy dere- } \\
\text { loped, } 15 \text { minutes after bite; respiration } \\
\text { jerking. }\end{array}$ & $\begin{array}{l}\text { Gradual and easy; no } \\
\text { convulsions. }\end{array}$ \\
\hline
\end{tabular}

1 In all of the abore cases the heart pulse became rapid and feeble. 
TABLE OF LESIONS IN THE EIGHT RABBITS MENTIONED ABOVE.

\begin{tabular}{|c|c|c|c|c|c|}
\hline No. & Local appearances. & Heart and lungs. & Abdominal viseera. & Nerrous system. & Blood. \\
\hline 1 & $\begin{array}{l}\text { Small area of extrava- } \\
\text { sated blood. }\end{array}$ & $\begin{array}{l}\text { Heart dark, relaxed, and } \\
\text { full of hlood, on right } \\
\text { side especially. }\end{array}$ & Healthy. & $\begin{array}{l}\text { Slight fulness in } \\
\text { the ressels of } \\
\text { the brain. }\end{array}$ & $\begin{array}{l}\text { Coagulated pret- } \\
\text { ty well. }\end{array}$ \\
\hline 2 & $\begin{array}{l}\text { Extensive effusion of } \\
\text { blood,partly clotted, and } \\
\text { reaching up the leg to } \\
\text { the flank and down to } \\
\text { the foot, and soaking the } \\
\text { muscles to the bone. }\end{array}$ & $\begin{array}{l}\text { Heart contained a good } \\
\text { deal of blood on both } \\
\text { sides; a little bloody } \\
\text { serum in the pericar- } \\
\text { dium. }\end{array}$ & $\begin{array}{l}\text { The cæcum con- } \\
\text { tained a goorl } \\
\text { deal of dark } \\
\text { blood in patch- } \\
\text { es. }\end{array}$ & $\begin{array}{l}\text { The usual vas- } \\
\text { cular fulness } \\
\text { only. }\end{array}$ & $\begin{array}{l}\text { One small clot in } \\
\text { left ventricle, } \\
\text { and elsewhere } \\
\text { the blood was } \\
\text { fluid. }\end{array}$ \\
\hline 3 & $\begin{array}{l}\text { Slight extravasion of } \\
\text { blood. }\end{array}$ & Heart full on both sides. & $\begin{array}{l}\text { Intestines dotted } \\
\text { with small spots } \\
\text { of extravasated } \\
\text { blood. }\end{array}$ & None. & $\begin{array}{l}\text { Blood uncoagu- } \\
\text { lated. }\end{array}$ \\
\hline $\begin{array}{l}4 \\
5\end{array}$ & $\begin{array}{l}\text { Slight extravasation. } \\
\text { Slight and thin layer of } \\
\text { extravasated blood. }\end{array}$ & $\begin{array}{l}\text { Heart full on both sides. } \\
\text { Heart as usual, no le- } \\
\text { sion. }\end{array}$ & $\begin{array}{l}\text { None. } \\
\text { None. }\end{array}$ & $\begin{array}{l}\text { None. } \\
\text { A little bloody } \\
\text { serum in the } \\
\text { ventricles of } \\
\text { the brain. }\end{array}$ & $\begin{array}{l}\text { Coagulated well. } \\
\text { Loosely coagula- } \\
\text { ted. }\end{array}$ \\
\hline 6 & $\begin{array}{l}\text { Part enormously swollen } \\
\text { with blood, partly in } \\
\text { loose clots when let ont } \\
\text { by incision at the third } \\
\text { hour. }\end{array}$ & $\begin{array}{l}\text { Bloody serum in pe- } \\
\text { ricardium and both } \\
\text { plenræ; two extensive } \\
\text { extravasations in the } \\
\text { right lnng; a rare oc- } \\
\text { eurrence. }\end{array}$ & None. & $\begin{array}{l}\text { Great vaseular } \\
\text { fulness. }\end{array}$ & $\begin{array}{l}\text { Blood uncoagu- } \\
\text { lated. }\end{array}$ \\
\hline 7 & $\begin{array}{l}\text { Scarcely a trace of any } \\
\text { lesion except the fang } \\
\text { wound. }\end{array}$ & $\begin{array}{l}\text { No lesion; right side of } \\
\text { heart much distended } \\
\text { with hlood. }\end{array}$ & None. & None. & $\begin{array}{l}\text { Blood perfectly } \\
\text { coagulated. }\end{array}$ \\
\hline 8 & $\begin{array}{l}\text { Extravasated blood be- } \\
\text { tween skin and muscles } \\
\text { up to the thigh. }\end{array}$ & $\begin{array}{l}\text { No lesion; heart large } \\
\text { and full of blood in all } \\
\text { of its cavities. }\end{array}$ & $\begin{array}{l}\text { A ferr small spots } \\
\text { of blood under } \\
\text { the peritoneum } \\
\text { of the small in- } \\
\text { testines. }\end{array}$ & None. & Uncoagulated. \\
\hline
\end{tabular}

Effect of Crotalus Venom on Dogs._-Thus far we have dealt with animals who were almost inevitably destroyed by the bite of the Crotalus. The canine species are far less liable to die, because their larger size is in itself a protection, as must be evident, when we consider that the poison is active in proportion to the amount injected, and that this will be the same, whether the animal bitten be a bird or a horse. In the following cases, therefore, some will be found to have resulted favorably. On the other hand, the most rapidly fatal termination was consequent upon a number of bites, and took place at the close of twenty minutes. On this point I have a brief explanation to make, before going further.

At the time of my experiments upon dogs, my snakes had been often used and handled, and had taken but little food, although in confinement from two to five weeks. It was not to be expected that, under these circumstances, they should prove as deadly as if they had been fresh, and were biting for the first time during some weeks or months. I have thought proper to make this prefatory statement, because it is well known that very often dogs have been destroyed in one, two, or three minutes after the bite of a fresh animal.

The following experiments were selected from a series, made with the view of establishing a rate of mortality, so as to compare the results with those obtained when a supposed antidote was employed. They were made with care, the snakes employed having been previously left undisturbed during a week.

With the defects which underlie this plan, so far as it has reference to antidotes, 
we have here nothing to do, and the cases are quoted only ou account of their value as such.

Experiment.-A large Spaniel, weighing sixteen and a half pounds, was muzzled, and lowered into the box containing one large snake, which struck it fiercely in the right fore-shoulder, and again, an instant afterwards, a little higher up. Upon a careful removal of the hair, only one fang seemed to have acted in either wound. The blows appeared to be excessively painful at the time, but upon removing the dog at once, he gave no after signs of pain or distress. Within twenty-five minutes he was languid, and remained standing with his head down, as though sick and confused. The local twitching about the wounds was highly marked, but there was no general fremitus, and the respiration was only quickened a little, without being either jerking or laborious. During the ensuing twenty-four hours, the dog refused to eat, but drank at frequent intervals, and passed urine and clay-colored stools. He was able to move about, but preferred to remain at rest.

The wound was not swollen, but when examined with care, a slight hardening of the neighboring tissues could be felt, extending two inches around the wound.

On pressure, a little bloody serum could be forced out of the fang track. This continued to be the case during three days, when pus also flowed out. The local evil was very limited, however, and the animal was so well on the ninth day, that it was used for another purpose.

Experiment.-The dog employed in the last observation was perfectly well, and eating and drinking as usual, when he was bitten in the left fore-shoulder, and in the left hind leg below the knee. Both wounds swelled, that in the shoulder most. The local fremitus was very remarkable, and extended up and down the hind leg, and for some distance around the anterior wound. Althongh the dog whined at intervals for some hours, and, to appearance, suffered considerably, the parts bitten soon ceased to swell, and but little oozing took place from either wound. No suppuration occurred, and the dog was entirely well within two days.

Experiment.-A black and white mongrel setter, weighing thirty pounds, was lowered into the cage. The only snake in the box struck him repeatedly, but without seeming to canse much pain. Upon looking for the wounds none conld be detected, and the snake was, therefore, caught in the loop as usual, and held to the dog again, until it bit eagerly. Still no wound beyond slight abrasions could be found, and on the bitten skin lay adherent a large fang. On inspecting the snake's mouth, I found that both fangs were recent, and not yet anchylosed in their maxillary sockets. The snake's skin was loose, and was shed entire two days later. Two other snakes were next caught and made to bite the hind leg and fore-shoulder of the dog. The latter wound gave great pain, and the swelling extended to the neck and chest. The local trembling was slight. There were no marked general symptoms, except a slight ineffectual effort to vomit, half an hour after being bitten, and some evidence of general feebleness which passed off in five hours. Next day the dog was well and active, eating and drinking as usual. He remained thus for ten days, during which time the wounds grew smaller, and from that in the shoulder oozed a little red serum, and finally some pus, but neither in this or in other cases 
did the skin slough extensively. I found in most. instances only a small orifice leading into an abscess cavity, which was rarely above the size of a large walnut.

Experiment.-A white mongrel, weighing seventeen pounds, was placed in the cage with a large snake. He was struck at once in the left hind thigh, and again by the same serpent about three inches above the first wound. The dog suffered terribly, and during two hours whined and yelled incessantly. Enormous swelling occurred, involving the whole limb up to the pelvic joint. Two hours after being struck the dog was weak, but still kept his feet, and drank almost without ceasing. His respiration was occasionally jerking, his heart as usnal rapid but feeble. No local or general fremitus was noted. At the third hour he was again howling frightfully. The weakness was greater than before, and he staggered in his gait, but the other symptoms were unchanged. Four and a half hours after the poisoning, the dog became still weaker, ceased to drink, and finally lay down. The parts wounded were still enlarging. At this time he vomited a little food and mucus, and soon after purged and urinated. From this time he began to mend, and although he howled all the following night, he was able to run about the next day, with only a slight appearance of lameness. The wonnd discharged blood, and at length bloody pus, and finally pure pus, up to the period of recovery, three weeks later. During the first week of this time, the dog took scarcely any food, and was subject to profuse dysenteric discharges, so that he became remarkably emaciated. From this condition he gradually improved, all the symptoms abated, and at the end of the third week he was as fat as when first injured.

The cases here related are selected from a larger number of a similar nature, all illustrating the more or less grave character of the symptoms, and also the possibility of recovery, even under apparently unfavorable circumstances. The next case, and the last of this kind, I have placed alone, because it has especial value, as showing how exceedingly grave may be the signs of poisoning, and yet how rapid and complete may be the rally and escape.

Experiment.-A small brown terrier was struck twice on the fore leg and shoulder by a large snake, which I held in the loop, as usual. Within ten minutes the dog vomited, urinated, and passed solid feces. All this time he whined a good deal, and finally, at the fifteenth minute, lay down on his side, breathing in jerks, and twitching in almost every muscle. No fremitus could be seen at the wound, owing, perhaps, to the swelling, which was great, and might readily have concealed it from view. An hour after being bitten, the dog had a slight convulsion, and vomited again. Meanwhile I could scarcely feel the heart beat, and the respirations were long and labored. On leaving this animal, late in the evening, and abont seven hours after he was hurt, he was lying on the floor, scarcely breathing, and nearly pulseless. He had passed liquid and very dark stools, and some water. Even at this period, his sensorium seemed unaffected, and he felt injuries, heard well, and followed with his eyes the movements about him. To my surprise, when I entered my laboratory the next morning, the dog ran by me and attempted to escape; I caught him with ne little difficulty. His wound was like a hump on his side and back, and discharged fluid blood in occasional drops. The floor of the box in which 
I had left him contained a good deal of dark, semi-fluid excrement streaked with blood, and he had drunk nearly the third of a bucket of water during the night.

The remaining instances of Crotalus bite in dogs were all fatal, and were selected, like the last series, as being the most illustrative records in my possession. It will be observed, as I have already stated, that no deaths took place so early as to give us perfect specimens of acute poisoning with absence of visceral lesions, and with a perfectly red and coagulable blood. That such cases may occur in the dog, under more favorable experimental conditions, I cannot doubt from what I have already seen in other animals.

Experiment.-A dog of mongrel bull-terrier breed, weighing thirty-one pounds, was lowered into the cage, where he was struck on the outside of the right hind leg in the thigh. He drew up the leg when released, and whined for a few minutes. The wound, which was double, bled a drop or two, and the muscles about it twitched considerably at intervals for an hour, when this symptom was obscured by the swelling. His pulse, which was naturally about 145 and irregular, was, at the fifth minute, 140 and regular, respiration 35. At the fifteenth minute he lay down, much weakened, pulse 160 and feeble, respiration 40 . At the twentieth minute the bowels moved loosely, with a gray discharge, and there seemed to be some tenesmus in the rectum. Twenty-fifth minute, pupils so far natural and mobile; he could stand when urged, but lay down again at once, and was much weaker. Forty-fifth minute, pulse 160, respiration 45 and laborious. Fifty-fifth minute, loss of power in the hind legs. Eightieth minute, respiration quick and labored, and so irregular as to make it impossible longer to comnt the heart pulses. The eyes were natural, and followed my motions; and he wagged his tail when fondled. At this time the observation was temporarily interrupted, and, on its resumption at the third hour, the dog was found dead. He had no foam about his mouth, and probably died quietly.

P.M. Section.-The whole muscular and areolar tissue of the leg and thigh, half way up and down the limb, was dark with infiltrated blood. About the wound the swelling was due to a mass of blood partially congulated. The extravasated blood extended through the limb, and on the inside it passed half way up the sartorius and adductors, and along the sheath of the vessels to within two inches of the femoral ring. Nearly an inch of the sheath was clear of it, but one-lialf inch below the ring the tissues were shaded with blood, and the same appearance was seen around the ring itself. From this point the extravasation extended under the peritoneum, into the pelvis, and on to the inner face of the ilium. The color of the tissues thus stained was a brilliant scarlet. The abdominal viscera were lealthy, except that the mucous membrane of the lower bowels was somewhat congested. The lungs were sound. The heart was relaxed, the right side full, the left nearly empty. The blood on the right side was a little darker than that on the left; on both sides and everywhere else it was perfectly fluid and free from clots. Placed in a vial, it remained fluid until decomposition ensued. Two hours at least after death, some of the blood globules found in the. heart were slightly indented; those taken from the small vessels of the ear were perfectly normal. At 
the period of examination, the muscular and nervous irritability had entirely departed.

Experiment.-A young dog, weighing nine and a half pounds, of terrier breed, was lowered into a box containing a fresh snake. The snake struck at him twice without effect, once striking to one side of the part aimed at, and the second time miscalculating its distance. The third blow took effect, but I could not ascertain the exact locality wounded. The dog cried ont, as though in great pain. Within five minutes he was trembling in every muscle. At the twentieth minute he was so much better that I subjected him to a second bite, which took effect on the neck in front, above the left shoulder. The dog at once lay down, then rose, and passed water and solid feces, and, at the fifth minute from the second bite, fell on his side, and vonited freely. The vomiting was instantly followed by general convulsions, in which the limbs were extended and the head thrown back. Meanwhile, the heart was very feeble, the breathing laborious, and the pupil contracted. The character of the respirations at this time was singular. Eight or ten rapid respirations took place, and then none occurred until twenty seconds had elapsed. The heart-beat, previously 180 to the minute, fell, at the fifteenth minute after the second wound, to 80, and became remarkably feeble. At the seventeenth minute the respiration stopped, and the heart pulse, though so weak as to be counted with difficulty, rose to 156 , falling again, at the twenty-fourth minute, to 58 , when it became indistinct through weakness. The pupils rapidly dilated.

P. II. Section was delayed twenty-four hours. Post-mortem rigor came on first about the fore legs and neck, and was complete four hours after death. It was so strong as to snap a small cord with which I had drawn the legs of the dog apart. The wound was the seat of an extravasation which had passed over the shoulder and on to the neck. The vessels near it were filled with dark and difiluent blood. The muscles near the wound were softened and readily torn. The heart contained an abundance of blood chiefly fluid, with a number of small clots of very loose structure, in the right side and somewhat less in the left cavities. In the pericardium there was about an ounce and a half of bloody serum. The abdominal organs were healthy, and the peritoneum contained only a little straw-colored serum. The bladder was partially contracted, and held an ounce or two of slightly albuminous urine.

The brain was normally firm, though somewhat congested, and its vessels were distended with fluid blood and a few bubbles of gas. At the side of the long sinus a little blood seemed to have soaked through all the membranes to the bone, but there was no large quantity of blood present at this spot, and no coagulum. It looked like a post-mortem stain.

Experiment.-A white dog, weight nineteen and a half pounds, of unknown or mixed breed, was exposed for a special purpose, to be bitten by several snakes, all of whom had used their fangs or been robbed of venom within four days. The dog was hit at least six times, and perhaps received some wounds which escaped notice. Those found on removing the skin were in the neck and face, fore-shoulders and hind legs. There were absolutely no marked symptoms in this case, except increasing weakness, and consequent vomiting. The bowels also were moved and water 
was passed. The breathing then became jerking and labored. The fremitus, at first localized in some of the bites, soon became general, until it disappeared before the profound debility, which seemed to affect the entire economy. Three hours after the poisoning the animal died without convulsions. At the moment of the infliction of the wounds, there certainly was great pain, but at no time afterwards was this sensation expressed. Until near death, the cerebral functions appeared to preserve their integrity, so that the dog wagged his tail on being patted, and even followed with his head the motions of the flies which hovered over him. The numerous bites were really the most formidable lesions found after death. Around them, in each case, was an irregular circle of extravasated fluid blood. None of them, however, were much swollen, although the amount of blood spread out in their layers and soaked into the museles must have been considerable. Except some congestion of the vessels of the brain and its membranes, there was no morbid appearance in any viscus. The right heart was full of fluid blood. The left heart also contained more blood than usual, and its color was a little brighter than that of the other side.

Experiment.-A white mongrel bitch, weighing fifteen pounds, was put in the cage with a large snake, which had not used its fangs for ten days. The snake struck the animal with both fangs just above the eye, and again, after some teasing, on the inside of the thigh high np. This latter wound gave great pain, and the bitch, when lifted from the box, yelled and whined during several minutes. On examination, it was found that only one fang had taken effect in the thigh. Around this was a growing circle of flattened swelling, of which the dark color was easily seen through the skin, which in this place was white and very delicate. During half an hour the animal stood on her feet, her head hanging a little, and blood running so freely from the wound in the thigh, that an ounce or two may have been thus lost within an hour of the period of the bite. At the close of the half hour the bitch suddenly staggered, and fell on her side, then rose and again fell. The heart, which before the poisoning was 154, rose immediately after the bite to 175 , stimulated, perhaps, by pain and terror. When the animal fell the pulse was about 160, and irregular and feeble. After this, its force diminished gradually, but the rhythm changed very little until just before death, when it fell rapidly. An hour after the bite, the animal still lay on her side making efforts to vomit. Upon lifting her up she succeeded in vomiting a little mucus. At this time she also passed a loose stool, and soon after lying down again, made water freely. The urine ran over a board on which the dog lay. A little of it drawn up with a pipette, proved to be acid and to contain no albumen. One hour and twenty minutes after the poisoning, the head was suddenly thrown back, the pupils contracted and the limbs extended, although not violently. At the close of this momentary convulsion, the bitch drew a long breath and expired.

$P$. M. Section.-The wound was a good deal swollen, and contained some looselyclotted blood, and much more that was quite fluid, and so continued upon removal. The tissues in the track of the fang were only a little softened, but the thigh was literally soaked with blood down to the periosteal membrane, which was darkly stained. The other wound was but little swollen. The brain was apparently 
healthy. The lungs were normal, the pericardium contained a little bloody serum, the heart was marked over the right ventricle with three star-like spots of ecchymosis, and a little ribbon of extravasated blood ran along each side of several of the smaller coronary veins.

The abdominal organs were healthy, and the intestines the seat of active movement. The extravasation in the thigh extended up through the femoral ring, and over the brim of the pelvis, so that the areolar tissues between the left side of the bladder and the pelvic bones were filled with fluid blood. The heart had ceased to beat when the animal was examined, but it acted for a few seconds when galvanized, and was locally and feebly irritable for half an hour. The muscles were excitable during about the same time, and the diaphragm a little longer. The sciatic nerves responded during thirteen minutes, and the phrenic nerves during twenty-eight minutes.

Experiment.-A small brown dog, weighing twelve pounds, was struck with both fangs by two snakes, one biting him on the muzzle, and one on the side. The wound on the side did not swell, that on the flank formed within two hours a prominent, almost pendulons mass, several inches long and wide. Within ten minutes this animal became feeble and reeled about, as if giddy. At length he lay down on his side, breathing heavily. The muscles about the flank wound twitched a good deal at first, and the general fremitus was well marked within thirty minutes. It passed off after half an hour longer, only recurring at intervals. Meanwhile the dog lay quiet, and although evidently sensible of surrounding objects, seemed in no pain. The heart-beat, which, after the bite, was strong and rapid, became scarcely perceptible to the hand. At the time the dog lay down, he passed urine and solid feces, but did not attempt to vomit. After lying thus for five hours he died quietly.

$P$. M. Section.-The wound on the flank presented the usual appearance. The skin beyond the bitten nostril was puffy and tumid, the nostrils exuding bloody mucus. All the thoracic organs were normal, the heart as usual, the right side full of fluid blood, with some loose dark clots, the left side almost empty. Elsewhere the organs were healthy, excepting the kidneys, which were full of blood, and presented the appearance of acute congestion. On further inspection, a long thin clot was found in the left ureter, and bloody urine in the bladder below. Brain not examined.

The cases above reported represent so well the character of the pathological lesions in mortal cases of Crotalus bite, that it would be needless to intrude them upon these pages in larger number. 


\section{CHAPTER V I I.}

\section{ACTION OF THE TENOM ON THE TISSUES AND FLUIDS.}

IN this section, the subject of absorption, hitherto deferred, naturally presents itself at the outset.

The most important of the questions raised in this comnection, regards the power of the stomach to absorb the venom of serpents, a question to which Redi ${ }^{1}$ gave a negative reply, founded on the experiments of his viper cateher, and upon one of his own on a kid, to which he gave internally the venom of four vipers. Fontana, ${ }^{2}$ on the other hand, took the affirmative, owing to a single experiment on a pigeon, down the throat of which he poured nearly thirty drops of venom, killing it thus in six minutes. ${ }^{3}$

Prof. Mangilit has since repeated these experiments, and arrived at the conclusion that the venom of the viper is harmless, when taken internally. These results were founded on the most satisfactory data, and leave no room to doubt that the venom is innocuous when thus administered. Before and since his experiments, many observers have been found bold enough to taste, and even to swallow, the venom of serpents. Thus, Mead and his assistants tasted the venom of the viper, Russell ${ }^{5}$ tasted the poison of the Cobra, but does not seem to have swallowed it, although he has credit in some of the books for having done so.

In our own country, experience upon this matter is limited. Harlan ${ }^{6}{ }^{6}$ who gave the venom internally to a single young dog, without effect, and Jeter, ${ }^{7}$ who states that when given to fasting cats and dogs, it causes sickness, and is followed by the usual consequences of snake bite, are the only authorities, if we except an extraordinary statement made by Burnett ${ }^{8}$ upon the authority of another person, whose

${ }^{2}$ Francis Redi, Nobilis Aretini Experimenta. Amstelodami, 1675. Ex. Italico Latinate Donata, p. 14. .

Also, Celsus, who says of the renom of suakes, "Non gustu, sed in vulnere noceut ;" and Lucan before him, puts into the mouth of Cato "Morsu virus habent, et fatum deute minantur; pocula morte carent." Fontana, vol. ii. p. 323.

a Fontana, vol. ii. p. 321.

${ }^{3}$ Fontana had previously arrived at the negative conclusion from experiments upon dogs, who took, however, very small doses. Vol. i. p. 58.

4 Mangili, quoted in OrGila, Tox. Gén., vol. ii. p. 852, from 'Il Giornale di Fisiea Chemica, ete. Vol. ix. p. 458 (1817).

${ }^{5}$ Russell, p. 63.

${ }^{6}$ Harlan, Physiologieal Researehes, p. 501.

7 Jeter, p. 20.

${ }^{8}$ Burnett, Proc. Bostou Soc. of Nat. Hist., vol. iv. p. 323. 
imaginative powers must have been of the strongest. Other native authors state that the poison has this or that taste, but do not directly assert that they have acquired such knowledge by personal experiments.

I have already stated that I found the venom tasteless. I did not venture to swallow it, feeling no inclination to repeat the rash acts of the servants of Fontana and Redi.

As regards the question of absorption by a mucous surface, I once saw incidentally made, a rather curious experiment to which I have already referred.

A large Crotalus swallowed a mouthful of its own venom, but, although watched for several weeks, it seemed to have suffered no ill consequences.

From the experiments of Harlan, Mangili, Russell, Davy and others, it seems to be sufficiently proved that the unbroken mucous surface of the mouth has no power to absorb the venom of serpents, and that the stomach also is incapable of admitting this poison to the system in any form possessing noxious properties.

Circumstances interfered to prevent me from extending my experiments on absorption to the length which $I$ contemplated, but $I$ hope to resume them at a future period. I have, however, performed two experiments upon pulmonary absorption, which possess so much interest that it would scarcely be proper to omit them.

Experiment.-A large pigeon was placed between my knees and somewhat compressed so as partially to empty the lungs. At this moment a small tube, well rounded and with an opening on the side near the end, was thrust carefully through the glottis and down into the trachea. As soon as the tube was in place $I$ blew into its upper orifice, thus discharging into the trachea its entire contents, consisting of about two drops of venom with a little water. This manœurre, suddenly followed by relaxation of the pressure on the respiratory organs of the bird, secured the passage of the venom into the smaller bronchi, and perhaps even into the air-vesicles themselves. A good deal of wheezing and coughing ensued, and within ten minutes the pigeon became drowsy, rocked to and fro, and at the close of thirty-eight minutes fell down. Convulsions followed at the forty-third minute, and terminated in death at the forty-ninth.

P. M. Section.-The heart was still irritable and contained a little loosely clotted blood on both sides. No lesions were visible, except in the lungs, both of which contained large extravasations of dark blood soaked through their tissues to such an extent as to make it impossible to say, whether or not, it was fluid or coagulated.

Experiment.-Another pigeon was treated in the same manner as the one last described, except that the venom used was three weeks old, and amounted to two drops. Death, without precedent convulsions, took place at the close of eight and a half hours. The blood was diffuent in every locality examined, and the left lung contained a large extravasation of dark blood.

The above cases render it probable that the delicate lung tissue offers no permanent barrier to the passage of the venom. There is, however, a possibility of fallacy in these experiments, and it is still desirable that they should be repeated on a larger scale, and on higher animals.

The Wound.- The wound made by the fang sometimes penetrates half an inch, 
but is oftener more superficial. So far as a fatal result is concerned, it seems to be inclifferent, whether the bite takes place about the head and neck, or in the limbs. ${ }^{1}$ The local quivering which is so common, seems to depend upon the muscles of the part having been wounded and envenomed, whereas, when the venom enters only the areolar or adipose tissue, this symptom either does not occur at all, or occurs only after a time. The swelling, which in a large majority of cases surrounds the wound, is never inflammatory in the first instance, at least in animals, and especially in those which die, and in which the rapidly increasing loss of tones forbids the presence of such a condition. In some of the animals who recover, secondary inflammation and gangrene, with more or less formation of pus may ensue. The primary swelling, then, is always due to a collection of blood, sometimes partially coagulated, at others perfectly fluid, and apt to leak drop by drop, out of the open fang track, when the opening is large, and the part bitten is highly vascular.

The effusion of blood in such large quantities as sometimes takes place, is explained by the rapidity with which its fibrin undergoes destruction at high temperatures $\left(100^{\circ} \mathrm{F}\right.$.), and in the presence of such amounts of venom as are occasionally injected. Under these circumstances the usual arrest of hemorrhage by coagulation of the fibrin of the blood fails to take place, and the incoagulable blood soaks through all the neighboring tissues.

In other instances, as we have seen, the blood about the wound clots, owing either to the relatively small amount of venom present, or to the fact of a sudden and great escape of blood from some vessel of larger size than is usually punctured by the fang. In no case are the clots thus formed of very firm texture. ${ }^{2}$

The veins about the wound are commonly found to be filled with dark and uncoagulable blood, so that the effect here described, is exerted not only upon the effused fluid, but also upon that which is still retained within the vessels.

Effect of the Venom an the Muscles.-The influence of the venom upon the muscles of the wounded part has been already described. It appears to be due to the direct action of the venom upon the sarcous elements.

As I supposed it possible, however, that the mere puncture might be competent to cause protracted local quivering, I punctured exposed muscles, with dry fangs, previously boiled, and then stopped with wax. Slight twitches followed, but no further results were visible. When, on the other hand, I exposed the living muscle and moistened it with venom, the twitching took place as usual, while, when the venom was injected through the fang into the interior of the muscle, the convulsive quivering was yet more active and prolonged. To ascertain whether or not this was due to direct stimulation of the muscular tissue, or to an indirect influence first affecting the nerves of the part, I executed the following experiment:-

1 Unless the mere swelling destroys life, or the poison be deposited near a large vessel.

2 It is said that the pig is not liable to die from Crotalus bite, and it is well known that it attacks the Rattlesnake with vigor and-success. Its comparative immunity may, possibly, be due to the fact that its skin is very thick and tough, and that the large deposit of sub-cuticular adipose tissue is scantily supplied with bloodvessels. Notwithstanding this, I am assured upon competent authority, that when the pig is struck in thin and vascular parts it enjoys no peculiar privilege. 
Experiment.-A large frog was poisoned with woorara. This active agent possesses the power to paralyze the motor nerves, and to leave the muscles in a highly irritable state. ${ }^{1}$ The animal was thus placed in the same condition as though the whole motor nervous system had been removed by dissection, without serious injury to the remaining parts. It was found that in a frog so prepared, and in which the motor nerves no longer responded to irritants, the muscles still quivered as long as usual when bitten by the snake, so that I felt free to infer that this interesting local phenomenon was in reality due to the direct influence of the venom upon the ultimate sarcous elements.

After a few minutes, or at the utmost, half an hour, these spasmodic movements cease; but without entirely exhausting the irritability of the muscles, which will, sometimes, continue to respond to other stimulants until their structure is more profoundly altered by the continued action of the venom. The quivering often extends to the whole muscular system, but although a frequent, this is not an invariable symptom, and is liable, in dogs, to be confounded with the fremitus of terror, to which they are very subject. It is in them a more common symptom of the poisoning than it is in rabbits, while in birds the general quivering is very rarely met with.

The influence of the venom upon the duration of muscular irritability I have examined in many animals, but especially in frogs. Many of these observations were made in very hot weather, but were finally resumed, in the early autumn under more favorable conditions for the preservation of the muscular functions.

Both in the cases of acute and of chronic poisoning, the muscular irritability of the frog was lost earlier than is usual in other modes of death.

Notwithstanding this result, the property in question was perfect at the time of the death, and for a short space afterwards, especially in acute cases, while, in some rare instances, it survived in the chin muscles during twenty-four hours.

The muscular irritability of the warm-blooded animals left them very rapidly, but was often so well marked at, or just after, death, as to forbid us to refer the death to the loss of muscular irritability as the immediate, or even the remote cause.

Rigor Mortis.-The action of the venom did not seem to prevent the occurrence of the strongest rigor mortis. It came on in different animals at varying periods, but, so far as I have observed, was never entirely absent in any case. Even when the blood was perfectly diffluent, this post-mortem phenomenon was noted, a fact which should utterly forbid us in connect its occurrence with the coagulation of the blood, as was at one time a not uncommon opinion.

Ultimate Effect of Venom on Muscles. - The final influence of venom upon the muscular structure was extremely curious. In every instance it softened it in proportion to the length of the time during which it remained in contact with it, so that after even a few hours in warm-blooded animals, and after a rather longer time in the frog, the wounded muscle became almost diffuent, and assumed a dark

1 Cl. Beruard, Leçons sur les effets des substances toxiques et médicamenteuses. Bailliere et fils. Paris, 1857 , p. 239 et seq. 
color and somewhat jelly-like appearance. The structure remained entire until it was pressed upon or stretched, when it lost all regularity, and offered the appearance under the microscope of a minutely granular mass, dotted with larger granules. The altered character of the muscle is illustrated in Fig. 12.

Fig. 12.

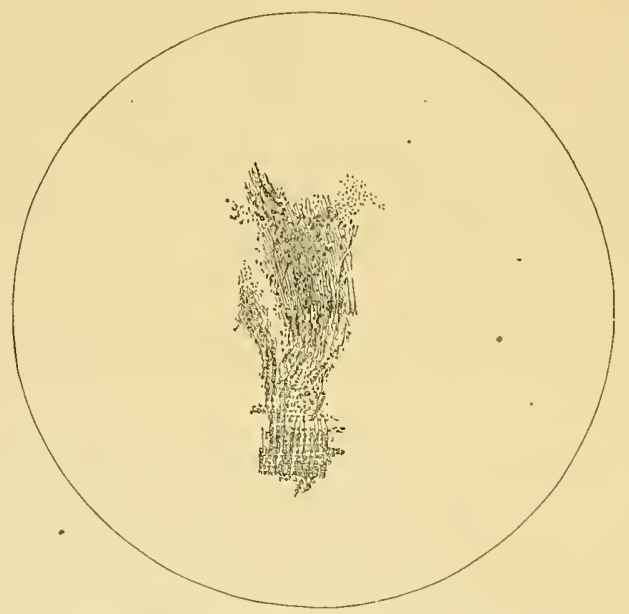

Appearance of muscular fibre when mechanically disturbed after contact with venom.

Effect on the Heart.-Continuing the study of the action of the venorr on muscular parts, it remains to examine the extent to which the heart is influenced.

This question is one of extreme interest, and of no less difficulty. It is so important, however, in its bearings upon the causation of death in acute poisoning, that I have spared no pains to investigate it by every menns in my power.

My first observations were made by exposing the heart of the frog, and observing it before and after the animal was bitten. Many of these observations failed partially, or entirely, owing to the frogs having survived long enough to pass into the stage of secondary poisoning.

In most of the cases of acute poisoning the rhythm and force of the heart became affected before the respiration was suspended, and the organ continued to pulsate more or less perfectly for some time after all voluntary and reflex motion had ceased.

It is scarcely requisite to detail these observations more fully, since examples may be found in the chapter which treats of the action of the venom on the batrachia. I shall therefore limit myseif to stating that, under the influence of Crotalus venom the batrachian heart becomes enfeebled, and acts more slowly; that it continues to act after the limbs have ceased to respond to stimulus by reflex acts, and that it usually stops before the motor nerves lose their vitality.

As the heart of the frog is remarkably independent of the respiratory and other 
functions, and as, moreover, it will beat longer, when cut out and suspended, than it usually does when subjected in its normal situation to the influence of the venom, it is difficult to avoid the conclusion that it is more or less directly affected by it. It seemed to me equally plain, however, that it was not owing to the arrest of the heart that the animal died. In fact, the heart continued to act after some of the principal nervous functions, such as reflex acts, were over, so that their loss was not due to an arrested circulation.

The study of the effect of venom on the hearts of warm-blooded animals was one of still greater difficulty. This arose from the fact that their functions are more closely related to one another, so that the cessation of respiration necessarily leads to loss of cardiac power, and vice vers $\hat{a}$; since, however, the determination of the question before us was essential to a proper study of the remedies for venom poisoning, I felt forced to continue my researches in this direction, notwithstanding the obstacles in my path.

As in the frog, I began by a series of simple observations upon the changes in the heart which were apparent to the eye. For this purpose, I opened the chests of rabbits sufficiently to obtain a view of the heart, the action of which was sustained during the experiment by artificial respiration.

Experiment.-Small male rabbit; pulse 280; respiration 120. Struck at 12 o'clock, 32 minutes, in the right flank. The animal fell in two minutes. Artificial respiration was at once used, aud, owing to want of caution, the right lung was torn, and the diaphragm ruptured. The chest was then opened. The lheart was acting very rapidly, and pretty well up to the thirteenth minute, when its rhythm became disturbed, the right and left cavities acting separately. The respiration was continued, with brief intervals, up to the sixty-third minute, when the aurioles alone responded, and the observation terminated.

Experiment.-Small black female rabbit. A string was placed under the trachea. The heart beat too rapidly for numeration. Bitten thrice in the side by a small snake at 6.15 P.M. Fourth minute, pupils contracting. Fifth minute, head falling. Seventh minute, slight general convulsions; respiration feeble and laboring. Tenth minute, slight convulsions; pupils dilated. Twelfth minute, respiration stopped, and a tube being placed in the trachea, regular artificial respiration was accomplished while the chest was opened, and the heart exposed. At first, the heart beat regularly, but not very strongly. At the eighteenth minute, its rhythm became altered, two auricular contractions taking place during each ventricular act. At the twenty-second minute, the organ was acting very feebly, the auricles alone beating, and the respiration was therefore discontinued.

Experiment.-Small male rabbit. In this case, the artificial respiration was made before the natural movement was over, about forty-four minutes after the bite was inflicted. No convulsions were observed. Although the artificial respiration was admirably sustained, the rhythm of the heart became disturbed within twelve minutes, the auricles beating twice as fast as the ventricles. Before this occurred, the heart acted well, except that it did not seem to possess the energy which it usually does under other circumstances.

Experiment.-Large male rabbit. The trachea was prepared as usual, except 
that a tube of sufficient size was placed in it before the bite, so that no time might be lost.

The animal was struck twice in the left thigh at 4.20 P.M. At the seventh minute it fell, and at the thirtieth minute, the respiration being very feeble, artificial respiration was made, and the chest opened. The heart was acting well, but not perfectly, the same want of completeness in its systole being seen as was noticed in former cases. At the close of the sixtieth minute from the time of the bite, the organ became more markedly feeble, and the ventricles acted but rarely. In this, as in all other like observations, the heart remained irritable to galvanism for a short time after it ceased to pulsate, and locally responsive for a still longer period. It was plain enongh from these experiments that the artificial respiration was capable of prolonging the cardiac functions, but not usually for any great length of time. Moreover, the heart was. always found beating in animals poisoned, and opened as soon as respiration ceased. Again, its tissues were always alive to stimulus for a short period after its rhythmic movements stopped, so that there was evidently no such complete local paralysis of the muscular structures as is caused by upas-antiar or corroval. When an animal is poisoned with these lastmentioned substances, death begins at the heart; and so complete is the palsy of this organ, that the most violent galvanic stimulus fails to provoke in it the least response, even when applied immediately after it has ceased to pulsate rhythmically.

These views were strengthened by the following experiment: Being aware that the young of warm-blooded animals approximate to the condition of cold-blooded creatures, in regard to the comparative independence of their cardiac and respiratory functions, I exposed several kittens of a week old to be bitten. As soon as respiration ceased their hearts were laid bare, and found to be beating quite actively. Thus, in one case, the kitten was bitten thrice, by as many rather exhausted snakes, between three minutes of six, and eleven minutes after six.

At 6.19 P. M. sensation was gone in the limbs; and at 6.23 , all motion ceased, except occasional diaphragmatic acts. At 6.25 , the dorsal spine was divided, and no movement took place, the left sciatic remaining perfectly irritable. During this time the heart continued to act regularly, and at 6.44 , was still able to respond to stimulus by feeble, but repeated pulses; one stimulation being followed by three or four complete pulsations.

In all human cases of Crotalus poisoning, the general feebleness which follows a severe bite is most notable. As we have seen, there is reason to believe that at least a part of this deadly prostration may be due to an effect on the heart, while on the whole, there is not reason to suppose that its tissues are so paralyzed às to permit us to assert that death begins at the cardiac centre.

As it was pessible that I might be deceived as to the appearance of lack of power in the heart, I subjected the matter to more accurate examination. For this purpose, I instituted the following experiments :-

Experiment.-A large brindled dog was properly secured on the table, and his

1 See a paper on new varieties of woorara by Prof. Hammond and the author, Amer. Jour. of the Med. Sci., July, 1859. 
right femoral artery laid bare. The brass nozzle of M. Bernard's cardiometer ${ }^{1}$ was tied fast in the vessel, and the blood allowed to act on the column of mercury.

At 4 o'clock, 58 minutes, the pulse being 99, and the respiration 21, the constant pressure in the artery was found to be represented by eighty millimetres of the column of mercury, which at every heart beat rose to 115 millimetres.

The following record was then obtained:-

Time.

4.58 to 5.14

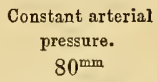

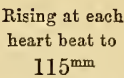

Difference. $35^{\mathrm{mm}}$

A clot forming, the colnmn ceased to move. The tube was eleansed and replaced at 5.16, when again a clot formed, and the artery was tied, and the left carotid laid bare. On inserting the tube in this latter vessel, the record was as follows:-

$\begin{array}{lccc}5.58 & 110 & 145 & 35 \\ 6 & \text { " } & \text { " }\end{array}$

6.1 One large snake was allowed to bite the dog's left thigh. The dog struggled, and the muscles about the wound quivered remarkably.

Respiration perfect as yet. Heart pulse 115, respiration 22.

6.7 Pulse beats 120 , respiration somewhat laborious.

$6.9 \quad 102 \quad 120$

$6.10 \quad 105 \quad 115$

A clot having formed, the tube was again removed, cleaned, and replaced.

At this time a clot formed, and as some blood was lost in replacing the tube, the observation terminated. The artery was tied, and the dog set at liberty. He was very sick for two or three days, but finally recovered, surviving the ligation of two arteries, and the bite of the snake.

Experiment.-A yellow mongrel of middle size was secured as usual. About two ounces of blood were lost while placing the tube in the carotid. At 5 o'clock, 30 minutes, the column rose to 114 millimetres, and at each heart beat to 127 millimetres, so that 13 millimetres represented the heart force.

These figures remaining the same during two minutes, and the respirations being 26 , and tranquil, the dog was bitten by three snakes, so as to be the more profoundly affected.

1 The cardiometer consists of a vessel, abont three inches high, and of the same diameter. A glass tube, with a seale of millimetre divisions, passes down to the bottom of the ressel, and is open at both ends. A second tube opens through the top of the vessel into its interior, and is provided with a stopcock. To its nozzle is attached a short caoutchoue tube, which is terminated by a brass tube, made to fit the artery selected for trial. The main vessel is now filled with mercury up to 0 of the scale. The caoutchonc tube is next filled with a strong solution of earbonate of soda, and secured in the artery. The stopeock being turned, the mercury rises to a point which marks the height of a column of mercury capable of being sustained by the constant pressure under which the blood circulates in the arteries. At each heart beat, and at each deep expiration, the column rises a little, to fall anew, as the increased pressure thus exerted is remored. 


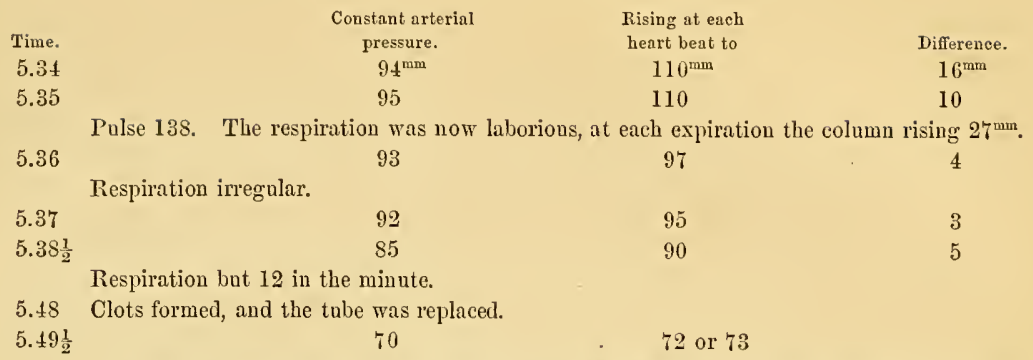

The heart pressure was now so slight, that $I$ feared lest a clot might exist in the trunk of the artery, and therefore repeated the observations on the femoral artery, which gare atrising in deep expiration to-

67

56
3

Still doubtful as to the correctness of the observation, I allowed a small jet of blood to escape, and having thus made sure of the absence of clot, replaced the tube, and at once marked at-
56

3

The respiration was now labored and slow, the pulse being about 190 .

At 6.23, the artery was cut across, and the dog allowed to bleed to death. Despite the slow and embarrassed breathing, the blood ran red from the divided vessel. It clotted rery well in three to five minutes. The effect of the venom on the force of the heart is well seen in the above stated experiments. In them, and in other like observations, the power of the ventricular systole diminished very rapidly soon after the bite, and at the same time, or just afterwards, the general loss of towe was strikingly indicated by the diminution of the independent arterial pressure. In the first case, the animal rallied from the early effect of the venom, and the heart force increased, although not so much as to regain completely its primary power. The cases just stated were selected from a series of seven similar experiments, which I do not think it requisite to quote at length. In all of them the results were the same in kind, althongh varying somewhat in degree.

In most of these cases, the heart suffered somew hat before respiration was enfeebled or visibly altered. But it was possible that the respiration might be embarrassed, and yet not in so marked a manner as to betray itself to the eye. I thought it likely that by destroying the normal respiratory influence, and sustaining the heart by insufflation, I might be able to place the cardiac organ in a condition which would render it independent of any possible influence from the pulmonary organs.

At first, I attempted to attain this end by cutting both pneumogastric nerves, and thus destroying the main channels through which impressions originating in the lungs are conveyed to the heart. My first experiments failed, owing to my having used young dogs in whom the section of both nerves above the point at which the recurrent laryngeal nerves are given off, never fails to cause asphyxia by collapse of the lips of the larynx. To guard against this result, which, even in older animals, embarrasses the respiration, I placed a tube in the trachea, before dividing the nerve trunks. The respiratory acts became immediately very deep and labored, 
and, as usual, the heart began to beat with excessive rapidity, but with such feebleness as to raise the mercurial column in the cardiometer only five or six millimetres at each systole. With so feeble a beat it would have been difficult to estimate any such slight increment of feebleness as.might at first be produced by the venom. Reluctantly, therefore, this method, which had promised so much, was abandoned. I finally succeeded by resorting to the method detailed in the following cases, which I have chosen for record here, as being sufficiently illustrative of the series to which they belong.

Experiment.-A small black and yellow cur-bitch was secured as usual. The pulse was 140 ; respiration 29 . The trachea was opened, and a tube placed in it. Next, the medulla oblongata was destroyed by pithing, during which about four ounces of blood were lost. Respiration instantly ceased, and the heart-pulse rose to 160 . Artificial respiration was now made about forty times in the minute.

The femoral artery was opened, and the cardiometer tube fitted in it, and secured at 5.20 P. M. The constant of arterial pressure was sixty millimetres, the heart beat raising the column from six to twenty millimetres. During three or four minutes these numbers remained about the same, and accordingly a standard of comparison having thus been attained, the dog was bitten twice in three minutes by two snakes of large size. In the next two minutes, the column fluctuated between sixty-seven and seventy-five millimetres, thus giving but eight millimetres to represent the heart force. The change was so notable, that my assistants supposed a clot might be forming, and the tube was therefore removed, cleansed, and replaced. It was perfectly patent, and the artery was unobstructed.

Six minutes after the bite, the constant was forty millimetres, with ten millimetres of rise at each systole. At the eighth minute, the constant was thirty millimetres, the rise fifteen millimetres. This was, however, the maximum, and usually the heart force was but four to five millimetres. The constant was now rapidly falling. The heart beat very irregularly, never raising the mercury above twelve millimetres. There was usually one strong pulsation, and then four feeble ones, of two to four millimetres.

The quivering about the wound continued very remarkable thronghout the observation. Upon studying this case, it appeared that the heart and the constant of arterial pressure were both affected very early, but I was not disposed to regard all the ultimate effects as due to the venom. In a case so removed from normal physiological conditions, and so surrounded with causes of depression, it was only possible to draw an inference from the occurrences of the first few minutes after the introduction of a new element-the bite of the snake.

Additional observations, similar to that just recorded, went equally to show that the heart loses power in the first stage of Crotalus poisoning, and that the constant arterial pressure undergoes a rapid and singular diminution. Considerations above stated, would have induced me to question still more rigidly the results of experiments of so complicated a nature, were it not that they are so well supported by all the preceding evidence, and by the numerous records of symptoms in cases of venom poisoning in man.

It is proper to add that in some instances of death, in rabbits, for example, arti- 
ficial respiration failed almost totally to sustain the cardiac power; but even in these the heart remained irritable to direct stimulus, and there was consequently no such thorongh paralysis of the sarcous elements as is seen in some other poisonings.

Action of Tenom on the Capillary System.-The experiments on the heart force furnish incidental information as to the absence of capillary irritation from the presence of venom in the circulation.

John Reid, of Edinburgh, has very well shown in his experiments on asphyxia that when black blood, or any other stimulant, enters the capillaries, the arterial pressure increases largely, as is proved by the rise of the mercury in the cardiometer. No such increase of pressure followed the introduction of venom into the system, and we may therefore infer that it exerts no very marked influence of this kind upon the ressels in question.

In frogs, poisoned by venom, the capillary circulation is unaltered, until the heart itself becomes too feeble to sustain it.

When the frog's foot is placed under the microscope, and wetted with venom, no change occurs, because the skin refuses to admit the poison. If we attempt to introduce it into the web through a wound, the mechanical irritation produced by the instrument so affects the local circulation as to baffle the observer completely.

Action of the Venom upon the Intestinal Movements.-The motions of the intestinal canal were unaffected by Crotalus poisoning, and in all cases were as active as after other modes of death.

Action of the Tenom upon Citiary Movement.-In a number of cases of acnte and chronic poisoning, I examined the cilia from the mucous membrane of the throat of the frog. Their activity appeared to be undisturbed in both forms of the malady.

Action of the Venom on the Nerrous System. Direct Effects of Tenom on Nerve Trunlis.-The older observers had already shown that the direct contact of venom and nerve matter produced no early local paralysis of the nerve thus treated. I have repeated and modified these experiments, making use of the venom of the Crotalus.

Experiment.-The leg of a frog, prepared as if for use for a galvanoscope, was placed in a wide test-tube, and the long sciatic nerve laid upon a glass slide. Upon applying gentle mechanical or galvanic irritants to the nerve trunk, the muscles of the leg moved freely. A drop of pure venom was then let fall on the nerve, along which it ran by capillary attraction, so as to wet about one-third of an inch of its length. At the close of ten minutes the nerve still reacted well. In a second case treated in the same way, but subjected to rather more of the venom, the nerve acted well after eighteen minutes; and in a third nerve similarly situated, irritability was excellent at the close of thirty-two minutes.

In a second series of experiments, the same conclusion was reached by another route.

Experiment.-A large frog was chosen, and the right sciatic nerve isolated in almost half an inch of its course. A little gutter of wax was slipped under the nerve, and a rather thin solution of venom in water applied to the nerve trunk during five minutes. The wax groove, in which lay the nerve, served to retain 
the venom in contact with its exterior. At the close of seven minutes the leg still moved with ease, when the frog's body was irritated. The nerve was then incised lengthwise, and a little pure venom dropped within the slit and on the nerve.

A minute amount of moisture being applied to the nerve, with the aid of a camel's hair brush, from time to time, it was found to carry impressions to or from the nerve centres quite well at the end of an hour. On irritating the right foot, both legs were moved freely, and on irritating the unwounded left leg, a like result was observed. When released, the frog leaped about, using both legs with ease and activity. Twenty-four hours later it was still able to use both legs, although the muscles about the wounded part were softened by the venom, a change which had not visibly acted on the nerve trunk. The frog finally recovered. Upon several occasions, as opportunity offered, I repeated these experiments, but without arriving at any other conclusion than that the venom exerted no early action upon the vital properties of nerves to which it was applied.

Action of the Venom upon the Sensory and Hotor Nerves, and upon the Nerve Centres.-In the conduct of this portion of my research, I endeavored to ascertain which order of nerves was first affected by the venom. For this purpose,

Experiment.-I tied the left femoral artery of a frog high up, and then had the frog bitten in the back by two snakes. At the seventy-sixth minute all motion, voluntary. and reflex, had ceased. On galvanizing the right sciatic nerve, no reflex acts ensued, but the muscles of the right leg moved as freely as those of the other limb, which I had insulated from the effects of the venom by cutting off its circulation. The motor nerves were therefore unaffected. If the sensory nerves and the centres had been also capable of transmitting impressions, and responding to them, there would have been reflex movements produced.

Numerous repetitions of this experiment convinced me that either the sensory nerves had lost their powers, or that the nerve-centres were at fault. This question was set at rest by the following means :-

Experiment.-A frog was poisoned, and as soon as all movement was over except that of the heart, the spine was divided, and a probe thrust up and down. No motion resulted. The irritability of the motor nerves in the sciatic trunk was next tested, and found to be nearly perfect.

The loss of nervous function begins, then, at the centres; and such being the case, we cannot infer logically that the sensory nerves are paralyzed, but only that they have no longer any means of expressing their sensibility, if it still exists.

These experiments were repeated again and again upon warm-blooded animals, in whom the action of the heart proved capable of being sustained for a time by artificial respiration.

Experiment.-A large rabbit, màle, was twice struck at 5.10. At 5.20 it fell, and in twenty-eight minutes from the time of the bite, the respiration stopped. Artificial insufflation was then employed, as usual. It seemed to sustain the heart's action pretty well for about twelve minutes. During this time the dorsal spine was cut across; no motion resulted. A probe being thrust up and down the spine, feeble quivering of the nearer spinal muscles took place, but the limbs did not 
move. On dividing the sciatic nerves, free motion was observed, and the phrenic trunk was likewise irritable.

In another set of cases, the centres and nerve-trunks were galvanized immediateiy after the natural respiration censed, and before the heart was quite at rest. Still, the same results were observed, so that it became clear that death took place rather from paralysis of the centres than from loss of function in the efferent nerves.

The duration of irritability in the motor nerves of the frog was observed to be less under venom poisoning than under death by decapitation, for example. It is to be borne in mind, however, that where the heart ceases to beat, or beats too feebly to circnlate the blood, the loss of nerve power may be due to this cause alone, as Kölliker has very well demonstrated. Yet, as we have seen, this source of fallacy may be readily eliminated.

Eiffect of the Tenom upon the Calorifacient Functions.-In very acute cases of Crotalus poisoning, death may occur so suddenly as to preclude the possibility of a fall of temperature. The following experiment is a fair type of what occurs in most cases which do not perish within a few minutes.

Experiment.-Temperature of the air $72^{\circ} \mathrm{F}$. At eight minutes to five P. M., a very accurate thermometer capable of indicating tenths of degrees ${ }^{1}$ was placed in the cloac of a pigeon, and was found to mark $10 \mathrm{~S}^{\circ} \mathrm{F}$. As the pigeon became tranquil, it fell to $107.5^{\circ} \mathrm{F}$. The pigeon was then exposed to the bite of a snake two and a half feet long. Great quivering of the muscles ensued.

At the tenth minute, the temperature was $107.2^{\circ} \mathrm{F}$., respiration 31.

The following record was then obtained :-

\begin{tabular}{|c|c|c|c|}
\hline \multicolumn{2}{|c|}{$\begin{array}{l}\text { Time after death. } \\
\text { 14th minute }\end{array}$} & \multirow{2}{*}{$\begin{array}{c}\text { Temperature. } \\
106.8^{\circ} \\
105.5\end{array}$} & \\
\hline 19 th & " & & \\
\hline $22 \mathrm{~d}$ & “ & 105.8 & \\
\hline 25 th & “ & 104.8 & \\
\hline 28th & “ & 104.3 & The bulb at this time slipped a little further into the eloac. \\
\hline 31 st & “ & 104.4 & \\
\hline 34 th & $"$ & 104.4 & \\
\hline $37 \mathrm{th}$ & " & 104.2 & Respiration 40 . \\
\hline $40 \mathrm{th}$ & $"$ & 103.9 & Respiration jerking. \\
\hline $43 \mathrm{~d}$ & " & 103.5 & \\
\hline 46 th & “ & 103.3 & \\
\hline 49 th & " & 103.1 & \\
\hline $52 d$ & " & 103. & Respiration 52. \\
\hline 55 th & “ & 102.5 & Slight convulsions. \\
\hline 58 th & $"$ & 101.5 & Respiration irregular and slow-12. \\
\hline $61 \mathrm{st}$ & $"$ & & Respiration ceased. \\
\hline $62 d$ & “ & 101.3 & \\
\hline $63 d$ & “ & 100.9 & \\
\hline 66 th & " & 100. & \\
\hline
\end{tabular}

${ }_{1}^{1}$ This instrument was made by J. W. Qucen \& Co., the well-known opticians, No. 924 Chestnut Street, Philadelphia, to whom I am indebted for much valuable aid in making and altering the numerous instruments which from time to time have been necessary in various physiological researches. 
The observation here ended. The heart blood clotted very rapidly, but not very firmly. In addition to these facts, I may observe that in dogs who survived the first action of the venom, and died at the close of twenty-four or thirty-six hours, the temperature of the rectum was found to be a degree or more below the normal standard. On the near approach of death it fell rapidly.

The experiments just related point plainly to the necessity of sustaining the normal temperature of the body in severe cases of Crotalus bite. The value of this precaution in other forms of poisoning has been admirably illustrated by M. Brown-Séquard. All that he has said of narcotic and other depressing agents applies with equal force to the cases before us. ${ }^{1}$

Effect of Venom on the Blood.-The study of the vital fluid in cases of acute or primary poisoning is of a merely negative value. An animal, and especially a warm-blooded animal which dies within a minute or two, or after even a longer time, presents us with none of those profound alterations of the blood which characterize all instances of secondary poisoning. A pigeon, for instance, is stricken, it droops, falls, and dies within thirty seconds, as may happen. Its blood is red, and coagulates perfectly. Its blood-corpuscles are ideally healthy. The tissues and fluids beyond the wound are, pathologically, as they would be after poisoning by opium or woorara. In such a case no physiologist could impute the death to an altered blood, and its positive or negative effects on the essential nutrition and oxygenation of nerve and muscle. The line of difference here between acute or primary, and chronic or secondary poisoning by Crotalus venom, is drawn most definitely, and although every possible variety of modified cases may occur, so as to mingle the two modes of death into one deadly draught, the two sets of fatal cases will still remain characteristically separated, and by no stronger difference than that of the pathology of the blood in the respective instances.

If in the secondary poisonings we examine first the obvious physical characters of the blood, we shall observe that it is very dark in all parts of the body, but somewhat redder in the left than the right lieart. Both the color and the accumulation in the veins seen to be due to the apnoea which ushers in the death, as is clear from what I already have said, and from the experiments which I shall presently relate in connection with the question of coagulation.

As I have before stated, the longer the death is delayed, the more apt is the blood to become incoagulable. So diffluent was it in some cases, that I have poured it from glass to glass like water and kept it thus until it decomposed completely. In other cases the heart contained a few loose and very weak clots, and in others again, only rare shreds of coagulum were met with.

What effect has the direct mixture of venom and blood? what becomes of the fibrin in venom poisoning? and what is the cause of the change in the condition of the fibrin? are the material questions which naturally present themselves for answer.

Experiment.-One drop of venom was put on a slide and a drop of blood from a

${ }^{1}$ Experimental Researches applied to Physiology and Pathology, by E. Brown-Séquard, M. D., of the Faculty of Paris, etc. etc. N. Y. H. Bailliere, 1853, p. 26 et seq. 
pigeon's wounded wing allowed to fall upon it. They were instantly mixed. Within three minutes the mass had coagulated firmly, and within ten it was of arterial redness.

Experiment.-One drop of arterial blood from the pigeon was mixed with one of venom. Coagulation took place as usual, but the blood did not darken.

The last experiment was repeated, substituting venous blood, coagulation ensued, and on exposure the blood became of arterial redness.

Experiment. - Two drops of venom were added to one of pigeon's blood. Congulation took place within four minutes. Pure blood from the pigeon was frequently found to coagulate a little sooner than this. So small a degree of retardation may have been due to the thick and gummy nature of the admixed venom.

As I was anxious to verify these observations, I instituted a number of experiments, some of which are briefly stated in the table below. Simple as the conduct of such experiments may seem, they are liable to fallacies. If, for instance, care be not taken, the blood coagulates before time is allowed to mix it with the venom. Or again, the mechanical process of mingling is carried on too long, and the feeble clots which alone are formed in the case of some animals, may thus be so broken up as to escape notice in the minute amounts of blood we are compelled to employ.

\begin{tabular}{|c|c|c|c|c|}
\hline No. & Kind of blood used. & $\begin{array}{l}\text { Amount of venom pre- } \\
\text { viously mixed with one } \\
\text { or two drops of water. }\end{array}$ & Amount of blood. & Result. \\
\hline 1 & Crotalos durissus. & One drop. & About ten drops. & Coagulated within half an horrr, clot \\
\hline 2 & " 4 & One-half of a drop. & About twenty drops. & Coagulated in ten minutes. \\
\hline 3 & 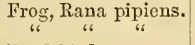 & $\begin{array}{l}\text { One-fifth of a drop. } \\
\text { One-half of a drop. }\end{array}$ & $\underset{4}{\text { Six drops. }}$ & Coagulated well. \\
\hline 4 & Reed-birk. & One-fifth of a drop. & Five drops. & $\begin{array}{l}\text { Clot formed rapidly, and was so loose } \\
\text { and weak that it broke up completely } \\
\text { and easily during the process of min- } \\
\text { gling the blood and the venom, and } \\
\text { at first led to the belief that none } \\
\text { had formed. }\end{array}$ \\
\hline 5 & " & One-fifth of a drop. & & $\begin{array}{l}\text { Coagulated loosely. All the clots in } \\
\text { this blood were of this nature. }\end{array}$ \\
\hline 6 & Dog (a small & One-quarter of a drop. & & Coagnlated perfectiy well. \\
\hline & brown terrier). $\}$ & $\begin{array}{l}\text { Une-half of a drop. } \\
\text { One-fifteenth of a drop. }\end{array}$ & & " $\quad$ " \\
\hline 7 & Man. & One-fifteenth of a drop. & Seven drops. & " 6 \\
\hline
\end{tabular}

The specimens of blood described in this table were usually set aside after coagulating, and the watch-glasses in which they were placed remained covered with smaller ones during twenty-four hours, the temperature being from $78^{\circ}$ to about $82^{\circ} \mathrm{F}$. To my surprise, the clots, which were in some instances very firm, became in all more or less altered during this period of time. The blood was darker, the structure of the clots softened and partially or entirely dissolved.

It becomes clear from these results that the mixture of venom and blood does not alter the vital fluid at first in any way which is appreciable to our senses. The blood drawn into venom and rapidly mixed with it in any proportion, clots as firmly as usual. After a time, however, it seems that a catalytic change is induced, the clot softens, and even becomes perfectly redissolved when the amount of mingled venom has been large and the temperature of the air high. This alteration of the formed clot, external to the body, finds its illustration within the system in those cases of 
chronic poisoning, in which the fibrin of the blood, subjected to long contact with venom, finally loses its power to coagulate. When under ordinary circumstances, in summer weather, blood is protected from desiccation, the clot not unfrequently softens after a fer days, or even entirely redissolves. This change, however, is produced by extensive putrefactive alterations in the blood, and is most readily induced in the blood of such persons as are anæmic, or still more rapidly in the blood of some reptiles and fish. The condition of diffluence attained within twentyfour hours, under the influence of the venom, was such as usually requires, in pure blood, several days of warm weather to effect. It is proper to add that in almost all of the specimens of mingled blood and venom the odor made it evident that putrefactive changes had taken place, an inference which was further justified by the evidence which they soon afforded of continued progress in this direction.

Fontana' $\mathrm{s}^{1}$ observations on the subject of the direct action of venom on blood are altogether insufficient and unsatisfactory. He seems to have been of opinion that admixture with venom darkened the blood, and prevented coagulation. In this view he differed from Mead. Dr. Brainard, ${ }^{2}$ so far as I am aware, was the first to state that when the animal bitten dies soon, the blood is coagulable, and that when death is delayed, it ceases to exhibit this condition.

The statements of Dr. Brainard in regard to changes effected in the blood-disks by Crotalus, or rather Crotalophorus venom, prepared me to find them more or less altered in my own cases. He seems to have held an opinion, common enough at the date of his paper, ${ }^{3}$ namely, that woorara owed its potency to a serpent venom, and that this poison as well as true venom seriously injured the blood-globules, and produced a fatal result by causing their arrest in the capillaries. Fontana, who examined the blood after death from viper bite, and who studied the mixture of blood and venom, states that it prevented coagulation, but that he found the globules unaltered.

The general result of my own experiments on this subject may be very briefly summed up. I have made very many careful examinations of the blood-disks of frogs, birds, dogs, etc., which had been killed by snake bites. In a few rare cases of prolonged secondary poisoning, I found a small proportion of the globules altered and indented on the edge, but in no case were these changes very remarkable. In primary or acute poisoning, I have never been able to detect the least alteration in the blood-cells. It should be needless to add that I examined the cells taken from the heart and from capillaries, and that these observations were made so soon as death took place.

I have also studied the effect on the disks of mixing the venom with blood, but even in these circumstances no notable change took place in the blood-disks within any brief period of time, as half an hour. Whether or not this direct contact would affect them after a longer time, I cannot say, and it is a question which is partially open for further study.

${ }^{1}$ Fontana, vol. i. pp. 313 and 384. Skinner's Translation.

${ }^{2}$ Brainard, op. cit.

${ }^{3}$ Essay on a New Method of Treating Serpent Bites, etc., by Daniel Brainard, M. D. Chicago, 1854, pip. 14, and plates. 
Dr. Burnett ${ }^{1}$ states that direct union of venom and blood causes the disks to lose their tendency to arrange themselves in rows. This observation, also, I am unable to verify entirely. Where the blood and venom were mixed in equal quantities, the nummulation of the disks was very often prevented, but the poison is so glutinous and gum-like that its mechanical properties may be very well supposed to exert some effect on this process, and certainly, so far as I have seen, the presence of venom to the amount of a tenth or twentieth in no way retarded, much less stopped, the union of the globules of freshly-drawn blood.

One other observation was yet to be made to complete the study of the influence of venom upon the varions parts of the blood. It was clear that in slow venom poisoning the blood plasma became profoundly altered. As it was possible that the contents of the blood-disks might also undergo a like degradation without of necessity involving changes in the form of these elements, I examined the blood of several guinea-pigs to determine whether, after death from Crotalus bite, the blood would still crystallize. In some of these cases the blood was very feebly clotted, in one only was it perfectly fluid. In all of these, specimens of blood from the heart afforded me, after the usual preparation, beautiful crystals, nor did these differ in form, size, or color, from the characteristic tetrahedrons of the blood of this animal.

In order to complete my study of the blood, I desired to ascertain the rate at which the fibrin disappeared from the vital fluid.

Experiment.-The first observation on this point was made upon a small dog, weighing about ten pounds. A tube was placed in the left carotid artery, that blood might be drawn from time to time. The various portions of blood were received in glasses of like shape, which were labelled and set aside.

At 4.15 minutes P. M., a drachm of blood was drawn from the artery; it congulated perfectly well in three or fonr minutes.

At 4.20 , at 4.24 , and 4.26 , the dog was bitten by separate snakes, which had been frequently used within four days. From the second wound ran a little blood, which collected in the hollow of the groin, and coagulated feebly.

At 4.37 about half an onnce of blood was drawn. At 4.36 the dog fell.

At 4.46 I removed about two drachms of blood. Like that removed at 4.37 , it clotted perfectly.

At 4.55 respiration ceased, just as a fourth specimen was taken, and at 4.58 all motion was over. The specimen last collected coagulated rather freely.

The wound in the flank was at once laid open, and about two drachms of fluid blood collected from the tissues, which were soaked down to the bones. The heart blood, being drawn into a seventh glass, was still found to be coagulable, but the clot which formed was by no means so perfect as in the blood first drawn.

At the close of twenty-four hours, the temperature being abont $7 \delta^{\circ} \mathbf{F}$., the specimens one, two, and three were unaltered, and had no unpleasant odor; number four was slightly altered, but the blood from the heart was already unpleasant in smell, and that from the wound was quite putrid. At the end of a second period of twenty-four hours, these changes were much more marked. 
Experiment.-In a second case, the dog, which was large and vigorous, survived the bites several hours, and died during my absence. He was bitten by a strong and fresh snake at 5.15, and again by a second at 5.18. At 5.57, blood drawn from the femoral artery was red and perfectly coagulable. At the close of two hours, the blood drawn still clotted well. At this time, as I have said, I ceased to observe him. He was able to walk when I left him, and was drinking eagerly. I do not suppose that he could have died before five or six hours from the time of the bite. Eighteen hours after, I returned to find him dead and rigid. His blood was everywhere dark and fluid.

Experiment.-In another instance during the spring of 1859, a dog was accidentally dropped into my snake-box. He was bitten in a dozen places by as many snakes, and perished in about eighteen minutes. His blood was entirely fluid, and so remained. This was the most rapid case of alteration of the blood with which I have met.

The last observation of this series was one of great interest, owing to the fact that the dog survived very serious visceral lesions and lived during two days with his blood in a condition of complete diffluence.

Experiment.-The dog, a small terrier weighing about fifteen pounds, was intended to make one of a set of observations on the value of Bibron's antidote. For this purpose he was placed in the snake-box, where instantly he was struck twice by a large snake, both wounds being double fang marks, and both being in the right flank. On removing him I observed that from one of the wounds blood was running in a thin stream. After it had run for some time, I caught a few drops in a watch-glass, and found that it coagulated well. Before I thought fit to use the supposed antidote, I was called aray. Returning at the end of an hour I found the dog standing with his head pendent, having just vomited glairy mucus. His pulse was quick and feeble, his respiration occasionally panting. The bemorrhage had ceased. Owing to an accident which at this time deprived me of the supply of Bibron's antidote, which I had prepared, I was unable to make further use of the animal in the manner proposed, and not desiring to lose the observation altogether, I utilized the opportunity in the following way:-

One hour and a half after he was bitten I drew a drachm of blood from the jugular vein. It clotted perfectly.

Four and a half hours after the bite a drachm of blood from the same vein coagulated equally well.

Twenty hours from the time of the poisoning, the dog was found lying on his left side, having passed slimy and bloody stools in abundance. At intervals he seemed to suffer much from tenesmus, but was so weak that he stood up with difficulty. His gums were bleeding, a symptom I had seen before, and his eyes were deeply injected. At this time about two or three drachms of blood were drawn. It was very dark, and formed within five minutes a clot of feeble texture.

Twenty-seven hours and a half after the time at which he was bitten, the dog was weaker. His hind legs were twitching, and the dysentery continued. Three drachms of blood were drawn as usual, but no clot formed in this specimen, although it was set aside and carefully watched for some time. While I was col- 
lecting the fluid for observation the dog suddenly discharged per anum at least four ounces of dark, grumous blood. At this time I supplied the dog with water, and left him. Fifty-four hours after the bite he was seen again, and found to have drunk frecly of water, and to have passed fewer stools. Up to this date he declined all food.

From this time he improved rapidly, and took with eagerness whatever nutriment was offered. On the fourth day his blood again exhibited a clot, although it was very small and of loose texture. I made no further examinations of the blood. The dog lost flesh as he gained strength, and had profuse suppuration from an abscess in the bitten flank. At the close of two weeks he was active and well, except that the wound was still open.

The case last related is doubly valuable, as pointing out even in a single instance the time at which the blood became altered, and also as showing, once more, how profound may be this change, and how perfect the recovery.

The study of envenomed blood has thus far tanght us-1st. That in animals which surrive the poisoning for a time, the blood is so altered as to render the fibrin incoagnlable.

$2 \mathrm{~d}$. Experiments in and out of the body have given proof that this change is gradual, and that the absence of coagulation is not due to checked formation of fibrin, but to alterations produced by the action of the venom in that fibrin which already exists in the circulating blood.

3. The influence thus exerted is of a putrefactive nature, and imitates in a few hours the ordinary results of days of change. It is probably even more rapid within the body, on account of the higher temperature of the economy.

4th. The altered blood retains its power to absorb gases, and thus to change its own color.

5th. The blood-corpuscles are unaffected in acute poisoning by Crotalus venom, and are rarely and cloubtfully altered in the most prolonged cases which result fatally.

6 th. The contents of the blood-globules of the guinea-pig can be made to crystallize as is usual after other modes of death.

Altered Relation between the Blood and Tissues.-Among the most constant and most curious lesions in the cases of secondary poisoning are the ecchymoses which are found on and in the viscera of the chest and belly; most frequently affecting the intestinal canal, they may and do occur in any cavity and on any organ. These spots contain blood whose globules are more or less deformed, but still of dimensions not less than usual. As they do not take place until the blood is considerably altered, and as the intra-vascular blood-disks undergo no apparent change, this leakage of the blood into the serous cavities and areolar interspaces is plainly due to the loss of coagulating power in the blood, or to alterations in the vascular tubes, or perhaps to both. Unfortunately, we can but revive anew the unanswered question as to the possibility of the escape of blood-disks through yet unwounded vessels. It is likely, however, that the tissues share in the incipient putrefactive fermentation which characterizes prolonged cases of this poisoning, and are more or less weakened thereby; so that, with a degraded blood, and, of a consequence, with an embarrassed capillary circulation, aided by laboring respiration, we can 
readily conceive how capillary ruptures may take place, and so give rise to transudations of blood in any portion of the body.

I have grouped together all the visceral lesions, because it seemed to me that, however various the seat of the affection, it was, in all organs and throughont the tissues, alike in its character. In other words, owing to the changes in blood or tissues, or both, extravasations are met with in the lungs, brain, kidneys, serous membranes, intestines, and heart. As a result, we may have functional derangement grafted on the main stem of the malady, and the accompaniments of bloody serum in the affected cavities, bloody mucus in the intestinal canal, and bloody urine in the bladder.

Cansation of Death in Acute and Chronic Crotalus Poisoning.-Perhaps scarcely one intelligent medical reader will have followed me thus far without arriving at the conclusion that the venom of the Crotalus, like that of other snakes, is a septic or putrefacient poison of astounding energy. This very obvious view has long been held by toxicologists, and the cases and experiments of this paper assuredly do not weaken it.

The rapid decomposition of the blood, and of the tissues locally acted upon by the venom, leaves no doubt upon the matter, and makes it apparent that an incipient putrefaction of this nature may so affect the blood as to destroy its power to clot, and, perhaps, also to nourish the tissues through which it is urged.

The alterations thus brought about are probably the results of a continued fermentative change, which, begun by a small amount of poison, is gradually made to involve in fatal change the whole mass of the circulating fluids. Like all fermentations, however, the rapidity depends on temperature and on the amount of the primary ferment. In one instance, a dog, struck by eight snakes, died in eighteen minutes, and exhibited an uncoagulable blood. I am aware of no other case of loss of coagulating power so rapid. It was rendered thus by the number of localities from which the ferment attacked the system. On the other hand, the frog, a small animal, receives the same dose of venom as would have entered the tissues of a larger animal, yet it resists the poison most remarkably, by virtue of its powers as a cold-blooded creature, existing at the temperature of the atmosphere itself.

Admitting, then, that the changes effected in the blood may be sufficient to account for the fatal results in chronic cases of poisoning by Crotalus, are we justified in referring to similar causes the sudden deaths which sometimes take place in small, or even larger animals, in whose tissues or fluids we can detect no change whatsoever?

In the present state of this inquiry, the question scarcely admits of a positive answer. It is clear that in acute cases, the symptoms of depression are most marked, and the heart and nerve centres are suddenly and fearfully enfeebled, so that their irritability is lessened, and is finally lost earlier than occurs in other forms of death. If now, we knew of no other property of the poison than this one, we could properly pause here, and regard the venom as having a specific influence on the heart, and on the nervous irritability of some part of the cerebro-spinal centres, such as characterizes certain of the better known poisons, such as corroval, woorara, upas, opiurn, aconite, etc. Since, however, we are aware that serpent venom, after remaining for a time in the body, has a specific power of attacking at least one element of 
the blood, and through its degradation, perhaps, of affecting the whole circulating fluid, we are naturally inclined to ask whether this power may not also be invoked to explain even the ultimate nature of the sulden cases of death from the venom. If, for instance, a pigeon is struck by a snake, and dies in thirty seconds, its tissues normal in appearance and its blood unaltered, have we any logical right to infer that the blood may have been inappreciably, but fatally, altered, so as to be unable to sustain the life of the tissues which it feeds? Is it this possible, but imperceptible, change in the blood which acts to produce those losses of irritability in the nerve-centres which we have been led to regard as the proximate cause of early and rapid death? If such be the case, then the suddenness of the general change in the blood must account for the failure of life, becanse it can be shown that animals whose blood is considerably altered may live for some time, or even survive to renew and refibrinate their vital fluids.

The cause of death in chronic or secondary poisoning may, with propriety, then, be referred to the incipient putrefactive changes which affect the blood, as well as to the continued influence of the agencies which first act to depress the heart's action, and destroy nerve function.

The cause of death in the acute cases, where the result is so sudden that no change is perceptible in the blood in the vessels, is amply explained in the preceding pages. But, while we are able to state where death begins, and in what order the functions succumb, we are still far from knowing why, or precisely how, this or that structure is affected. The proximate causes are open to experimental study, the ultimate reason, as we have seen (page 95), is as yet unknown.

Summing up, then, what we have learned of the acute form of poisoning, we may feel justified in concluding, 1st. That the heart becomes enfeebled shortly after the bite. This is due to direct influence of the venom on this organ, and not to the precedent loss of the respiratory function. Notwithstanding the diminution of cardiac power, the heart is usually in motion after the lungs cease to act, and its tissues remain for a time locally irritable. The paralysis of the heart is, therefore, not so complete as it is under the influence of upas or corroval.

$2 \mathrm{~d}$. That in warm-blooded animals, artificial respiration lengthens the life of the heart, but does not sustain it so long as when the animal has died by woorara, or decapitation.

3d. That in the frog, the heart-acts continue after respiration has ceased, and sometimes survive until the sensory nerves and the nerve-centres are dead, the motor nerves alone remaining irritable.

4th. That in warm-blooded animals respiration ceases, owing to paralysis of the nerve-centres.

5th. That the sensory nerves, and the centres of nerve power in the medulla spinalis and medulla oblongata, lose their vitality before the efferent or motor nerves become affected.

6 th. That the muscular system retains its irritability in the cold-blooded animals, acutely poisoned, for a considerable time after death.

7th. That the first effect of the venom being to depress the vital energy of the heart and nerve-centres, a resort to stimulants is clearly indicaterl, as the only rational mode of early constitutional treatment. 
Analogy between the Symptoms of Crotalus Poisoning and those of Certain Diseases. -I am unwilling to leave this unsatisfactory, but necessary part of my task, without calling attention to the singular likeness between the symptoms and lesions of Crotalus poisoning, and those of certain maladies, such as yellow fever. ${ }^{1}$ If for a moment we lose sight of the local injection, and regard only the symptoms which follow, and the tissue changes which ensue, the resemblance becomes still more striking.

In both diseases, for such they are, we have a class of cases in which death seems to occur suddenly and inexplicably, as though caused by an overwhelming dose of the poison. In both diseases, these cases are marked by symptoms of profound prostration, and in both the post-mortem revelations fail to explain the deatl. I have spoken, as an example, of yellow fever, but similar instances are not wanting in cholera, typhoid, and typhus fevers, and in scarlatina.

A second class of cases, both of Crotalus poisoning and of yellow fever, survive the first shock of the malady, and then begin to exhibit the train of symptoms which terminates in more or less complete degradation of the character of the blood. Varying remarkably among themselves, exhibiting, as it were, preferences for this or that organ, all of these maladies agree in the destruction of the fibrin of the blood which their fatal cases frequently exhibit. In yellow fever, the likeness to venom poisoning is most distinctly preserved, as we trace the symptoms of both diseases to the point where the diffluent blood leaks out into the mucous and serous cavities. The yellowness which characterizes many yellow fever cases, I do not find described as a current symptom of the venom malady, but it is often mentioned as one of the accompaniments of the period of recovery from the bite. ${ }^{2}$ It is, indeed, most probable, that if 'small and repeated doses of venom were introduced at intervals into the body of an animal, a disease might be produced even more nearly resembling the malady in question. In the parallel thus drawn, I have given but the broad outlines of resemblance, nor was it to be expected that the minor details would be alike. From a general and philosophic point of view, this similarity is sufficiently striking to make me hope that the complete control of one such septic poison for experimental use, may enable us in future to throw new light on those septic poisons of disease whose composition we know nothing of, and whose very means of entering the body they destroy, is, as yet, a mystery:

1 This analogy has been noted by S. L. Mitchill, by Magendie, and by Gaspard, who has also called attention to the resemblance between ordinary putrefactive poisoning, such as arises from injection into the blood of decayed animal substances, and the poisoning by venom. Neither in this, or in any other cases of the kind, is the likeness perfect; and while, to use a naturalist's phrase, we recoguize these septic maladies as of one genus, we cannot regard them as so nearly allied as to be mere varieties of one species. Yellow fever and putrefactive poisoning both begin, in the mass of cases, with a ferer, which is absent in the first stages of venom poisoning; and there are other and wide differences which it is needless to enumerate here. See Gaspard, Journal de Physiologie, tome iv. p. 2 et seq., and tome iii. pp. 81-85 of same Journal. See also La Roche on Yellow Fever, vol. ii. p. 597.

2 Jaundice, occasionally observed in France as an early symptom of viper bite, has been usually regarded as the jaundice of fear, a cause which certainly cannot be invoked to account for the icterus seen in late stages of the malady caused by the venom. 


\section{CHAPTER VIII. \\ CROTALUS POISONING IN MAN.}

TuE cases of Rattlesnake poisoning in man have been separated from the rest of this paper, owing to the difficulty of grouping the phenomena of human poisoning with those observed in animals. This difficulty arose from the imperfect reports of such cases as have been recorded, and from the fact that, in man, the symptoms were possibly modified, in some instances, by the remedies used, and were thus no longer comparable with such as had been seen to exist in animals submitted to no modifying treatment. Some of these objections would, of course, disappear in a collection of cases so large as to enable us distinctly to separate the essential from the induced, or accidental features of the malady. Unfortunately, although I have collected at least fifty cases of Crotalus bite, the most of these scarcely deserve the name of medical reports, and among the whole number I have been able to select but sixteen which were sufficiently rich in details, to be of the slightest value. The numerous gaps in the accompanying table, show but too well the want of full medical statements of the order and character of the symptoms, even in these select cases, and it is humiliating to observe that, of the four postmortem examinations of the lesions in this mode of poisoning, but two were made in this country.

If, then, in the table of symptoms in man, and in the following remarks upon them, such a lack of detail is met with as would disgrace the most ordinary report of " an interesting case," the blame must rest where it belongs, with the physicians of our own country, who have failed thus much in their duty as medical observers.

It is impossible to review the whole field of observation upon this important subject, without arriving at the conclusion that whatever may be the degree of virulence in the poison of different venomous snakes, its mode of affecting the system varies but little, whether the bite be inflicted by the Viper, the Copperhead, the Rattlesnake, or the dreaded, but not more deadly, Cobra. Thus, in each case, we have the local poisoning, the constitutional malady, and the possibility of inexplicably rapid death on the one hand, and of a strange zymotic disease upon the other. There may yet remain some room for doubt as to whether the apparent difference in the activity of the venom from various serpents is not due to the quantities formed or stored up in each case, and to unobserved peculiarities in the structure and form of the poison apparatus. However this may be, it is quite certain that two cases of rattlesnake poisoning may sometimes differ as much as either one of them will, from a case of Moccasin or Cobra bite. This fact should make us cau- 
tious in asserting distinctions between the mode of action of the venoms of the several poisonous serpents upon evidence of any limited number of facts.

With these brief preliminary remarks, we shall pass to the consideration of the symptoms of Crotalus bite in man. In this review, I shall make use not only of the cases in the accompanying table, but also of the many brief notices of cases which were found unfit for tabular analysis. All that I have to say at present with regard to antidotes and treatment, will be found at the close. 
TABLE OF OROTALUS

\begin{tabular}{|c|c|c|c|c|c|c|c|c|}
\hline No. & Reporter. & Sex. & $\begin{array}{l}\text { Seat of mounds, } \\
\text { i. } e \text {, fang marks. }\end{array}$ & $\begin{array}{l}\text { Early loeal } \\
\text { symptoms. }\end{array}$ & $\begin{array}{l}\text { Later local } \\
\text { symptoms. }\end{array}$ & $\begin{array}{c}\text { Immediate or early } \\
\text { constitutional } \\
\text { symptoms. }\end{array}$ & $\begin{array}{l}\text { Respiration and } \\
\text { circulation. }\end{array}$ & $\begin{array}{l}\text { General later } \\
\text { symptoms. } \\
\text { Nervous system. }\end{array}$ \\
\hline 1 & Moore & Male & $\begin{array}{c}\text { Instep twice } \\
\text { bitten }\end{array}$ & $\begin{array}{l}\text { Pain, swelling, } \\
\text { hemorrhage } \\
\text { from bites }\end{array}$ & $\begin{array}{l}\text { Continued pain, and } \\
\text { swelling to the knee }\end{array}$ & None stated & None stated & $\begin{array}{l}\text { Probably none of } \\
\text { moment }\end{array}$ \\
\hline 2 & W. Mayrant & Male & Throat & $\begin{array}{l}\text { Swelling and } \\
\text { pain }\end{array}$ & $\begin{array}{l}\text { Caustics used. Small } \\
\text { slough }\end{array}$ & $\begin{array}{l}\text { Sudden and exces- } \\
\text { sire prostration; } \\
\text { vomiting; locked- } \\
\text { jaw; loss of speech }\end{array}$ & $\begin{array}{l}\text { Feeble fluttering } \\
\text { pulse }\end{array}$ & $\cdots$ \\
\hline 3 & W. Mayrant & Male & $\cdots$ & Pain & $\cdots$ & $\begin{array}{l}\text { Violent romiting } \\
\text { and prostration }\end{array}$ & $\cdots$ & $\cdots$ \\
\hline 4 & W. E. Homer & Male & $\begin{array}{l}\text { Bend of elhow, } \\
\text { two fang marks }\end{array}$ & $\begin{array}{l}\text { There seems to } \\
\text { have been none } \\
\text { felt (see re- } \\
\text { marks) except } \\
\text { itching }\end{array}$ & $\begin{array}{l}\text { Itching, pain great, } \\
\text { swelling }\end{array}$ & Apparently none & $\begin{array}{l}\text { Feeble pulse, res- } \\
\text { piration easy }\end{array}$ & $\begin{array}{l}\text { Convulsion; mind } \\
\text { generally clear up } \\
\text { to deatl }\end{array}$ \\
\hline 5 & H. B. Phillips & Female & $\begin{array}{l}\text { Struck twice } \\
\text { on foot }\end{array}$ & $\cdots$ & $\begin{array}{l}\text { Inguinal glands en- } \\
\text { larged ; great pain } \\
\text { and swelling; mot- } \\
\text { tled skin }\end{array}$ & $\begin{array}{l}\text { Vomiting, depres- } \\
\text { sion, and thirst }\end{array}$ & $\begin{array}{l}\text { Feeble, pulse } 60 ; \\
\text { great gen'l swell- } \\
\text { ing; great thirst; } \\
\text { loss of speech; } \\
\text { tongue swollen }\end{array}$ & Mind clear \\
\hline 6 & Post & Male & $\begin{array}{l}\text { Last phalanx } \\
\text { of middle } \\
\text { finger }\end{array}$ & $\begin{array}{l}\text { Small jet of } \\
\text { blood from } \\
\text { wound; swell- } \\
\text { ing }\end{array}$ & $\begin{array}{l}\text { Continued swelling } \\
\text { up to pectoral mus- } \\
\text { eles, followed by } \\
\text { great discoloration }\end{array}$ & $\cdots$ & $\begin{array}{l}\text { Pulse } 2 \frac{1}{2} \text { hours af- } \\
\text { ter bite } 80 \text {, not } \\
\text { weak; after this } \\
\text { it became faster, } \\
\text { to } 120 \text {, and more } \\
\text { and more feeble }\end{array}$ & Excited manner \\
\hline 7 & J. Trowbridge & $\begin{array}{l}\mathrm{Male}, \text { rt. } \\
12 \text { year's }\end{array}$ & $\begin{array}{l}\text { Foot near } \\
\text { small toe }\end{array}$ & $\begin{array}{l}\text { Swelling and } \\
\text { pain }\end{array}$ & $\begin{array}{l}\text { Leg swollen to the } \\
\text { groin; great pain } \\
\text { and discoloration }\end{array}$ & $\begin{array}{c}\text { Probably none of } \\
\text { the usual symp- } \\
\text { toms, none stated }\end{array}$ & $\begin{array}{l}\text { Pulse rapid } 2 \frac{1}{2} \text { hrs. } \\
\text { after bite }\end{array}$ & $\cdots$ \\
\hline 8 & Withmire & $\begin{array}{l}\text { Male } \\
\text { (boy) }\end{array}$ & Ankle & $\begin{array}{l}\text { Pain and } \\
\text { swelling }\end{array}$ & $\begin{array}{l}\text { Continued pain and } \\
\text { swelling }\end{array}$ & $\ldots$ & $\ldots$ & $\cdots$ \\
\hline 9 & Hammond & Male & - Finger & $\begin{array}{l}\text { Pain and } \\
\text { swelling }\end{array}$ & $\begin{array}{l}\text { Pain and swelling dis- } \\
\text { appeared after use } \\
\text { of antidote, and re- } \\
\text { turned in } 10 \text { minutes }\end{array}$ & $\cdots \quad \cdots$ & $\cdots$ & $\cdots$ \\
\hline 10 & $\begin{array}{l}\text { Hammond } \\
\text { (Coolidge) }\end{array}$ & $\begin{array}{l}\text { Female } \\
\text { at. } 15 \\
\text { years }\end{array}$ & Finger & $\begin{array}{c}\text { Pain, swelling, } \\
\text { and discolora- } \\
\text { tion }\end{array}$ & $\begin{array}{l}\text { Pain, swelling, ete., } \\
\text { to the elbow }\end{array}$ & $\begin{array}{l}\text { Depression and } \\
\text { nausea }\end{array}$ & $\cdots$ & $\begin{array}{l}\text { Case too short for } \\
\text { the later constitu- } \\
\text { tioual symptoms } \\
\text { to dovelop }\end{array}$ \\
\hline 11 & $\begin{array}{l}\text { John Louis } \\
\text { Xantus. } \\
\text { (de Vésey.) }\end{array}$ & Boy & Leg & Pain, swelling & $\begin{array}{l}\text { Increasing pain and } \\
\text { swelling }\end{array}$ & Prostration & $\cdots$ & Great prostration \\
\hline 12 & Home & $\begin{array}{l}\text { Male } \\
\text { (the re- } \\
\text { porter) }\end{array}$ & $\begin{array}{l}\text { Thumb and fin- } \\
\text { ger twice bit- } \\
\text { ten, four fang } \\
\text { wounds }\end{array}$ & $\begin{array}{l}\text { No immediate } \\
\text { swelling }\end{array}$ & $\begin{array}{l}\text { Swelling, pain ex- } \\
\text { tending rapidly up } \\
\text { the arm, which grew } \\
\text { cold and sloughed } \\
\text { before death }\end{array}$ & $\begin{array}{l}\text { Incoherence possi- } \\
\text { bly due to drunk- } \\
\text { enness and alarm }\end{array}$ & $\begin{array}{l}\text { Pulse feeble, } \\
\text { throughout } 100 \text { to } \\
138\end{array}$ & $\begin{array}{l}\text { The mind confused } \\
\text { at first, became } \\
\text { clear; depression, } \\
\text { nausea, faint feel- } \\
\text { ings; vomiting on } \\
\text { the second day }\end{array}$ \\
\hline 13 & Woodhouse & Irale & Finger & $\begin{array}{l}\text { Pain, shock, } \\
\text { and nausea }\end{array}$ & $\begin{array}{l}\text { Pain, swelling of } \\
\text { hand and arm, and } \\
\text { axillary glands, ve- } \\
\text { sications over the } \\
\text { lymphatics on third } \\
\text { day }\end{array}$ & Nausea & $\cdots$ & $\begin{array}{ll}\cdots & \cdots\end{array}$ \\
\hline 14 & Harlan & IIale & $\begin{array}{c}\text { Metacarpal } \\
\text { joint of finger, } \\
\text { two fang } \\
\text { wounds }\end{array}$ & $\begin{array}{l}\text { Bleeding from } \\
\text { the punctures; } \\
\text { swelling, disco- } \\
\text { loration }\end{array}$ & $\begin{array}{l}\text { Extensive swelling } \\
\text { and pain }\end{array}$ & $\begin{array}{l}\text { Repeated and sud- } \\
\text { den fainting and } \\
\text { pallor }\end{array}$ & $\begin{array}{l}\text { Feeble pulse; diffi- } \\
\text { cult respiration; } \\
\text { hiccough }\end{array}$ & $\begin{array}{l}\text { Delirium, restless- } \\
\text { ness, anxiety, in- } \\
\text { somnia, incessant } \\
\text { thirst }\end{array}$ \\
\hline 15 & Itchison & $\begin{array}{l}\text { Female } \\
\text { et. } 12 \\
\text { years }\end{array}$ & $\begin{array}{c}\text { Instep, two } \\
\text { fang punctures }\end{array}$ & $\begin{array}{c}\text { Slight swelling } \\
\text { and discolora- } \\
\text { tion }\end{array}$ & $\begin{array}{l}\text { Intense pain shoot- } \\
\text { Ing up the leg }\end{array}$ & $\begin{array}{l}2 . \text { hours after the } \\
\text { bite almost mori- } \\
\text { bund; pulse feeble } \\
\text { and wavy; surface } \\
\text { cold and perspir- } \\
\text { ing; face swollen; } \\
\text { mind wandering; } \\
\text { pupils dilated; } \\
\text { subject to sensory } \\
\text { delusions }\end{array}$ & $\begin{array}{c}\text { Feeble pulse until } \\
\text { the stimulus acted }\end{array}$ & $\begin{array}{l}\text { Delusions, etc., } \\
\text { passed away un- } \\
\text { der the use of the } \\
\text { stimulus }\end{array}$ \\
\hline
\end{tabular}

Twice bitten on Swelling and No increase of the Within 10 minutes The physician removed the limature adult the palm and discoloration at primary swelling af- pallor, coldsweats, in consequence of the swelling, etc., between the least partially ter removal of the anxious expres.

thumb aud fore. due to the liga- ligature

finger on the ture, which was

back of the applied 3 or 4

thumb, the last minutes after wound was the bites single sion, general de-The pulse became The limbs insenpression feeble $(50)$ but sible, repeated rose to 110 before syncope, pupils death; noisy res- contracted, mind piration 1 clear

At the seventh hour there was a swelliug of the lip; no general tumefaction; great anxiety; painful and difficult deglutition aud respiration. 


\begin{tabular}{|c|c|c|c|c|c|c|c|c|c|}
\hline No. & $\begin{array}{l}\text { Secretions and } \\
\text { discharges. }\end{array}$ & $\begin{array}{l}\text { State of } \\
\text { skin and } \\
\text { tempera- } \\
\text { ture. }\end{array}$ & $\begin{array}{l}\text { Result of } \\
\text { disease. }\end{array}$ & $\begin{array}{l}\text { Duration of } \\
\text { disease. }\end{array}$ & $\begin{array}{l}\text { Mode } \\
\text { of } \\
\text { death. }\end{array}$ & $\begin{array}{l}\text { Local and gene- } \\
\text { ral consequences } \\
\text { if recovery } \\
\text { occurred. }\end{array}$ & $\begin{array}{c}\text { Local } \\
\text { treatment. }\end{array}$ & $\begin{array}{c}\text { General } \\
\text { treatment. }\end{array}$ & Remarks. \\
\hline 1 & ... & $\ldots$ & Cure & At work in 3 days & $\cdots$ & $\begin{array}{l}\text { Limited local } \\
\text { suppuration }\end{array}$ & $\begin{array}{l}\text { Ammonia, liga- } \\
\text { ture }\end{array}$ & Ammonia & $\begin{array}{l}\text { Mild case; alludes } \\
\text { to } 14 \text { cases of } \\
\text { snake bite suc- } \\
\text { cessfully treated } \\
\text { with anmonia. }\end{array}$ \\
\hline 2 & $\cdots$ & $\cdots$ & Curo & Within 24 hours & $\ldots$ & $\begin{array}{l}\text { Small local } \\
\text { slough }\end{array}$ & Caustic & $\begin{array}{l}\text { Alcohol and red } \\
\text { pepper; } 2 \text { quarts } \\
\text { of whisky given } \\
\text { in one night, and } \\
\text { renewed as the } \\
\text { pulse foll }\end{array}$ & Severe case. \\
\hline 3 & $\cdots$ & $\cdots$ & Cure & In 12 hours & $\cdots$ & $\cdots$ & $\cdots$ & $\begin{array}{l}\text { Whisky one quart } \\
\text { in } 10 \text { or } 12 \text { hours }\end{array}$ & \\
\hline 4 & $\begin{array}{c}\text { Dark bilious } \\
\text { stool, vomiting }\end{array}$ & $\begin{array}{l}\text { Extremities } \\
\text { cold }\end{array}$ & Death & $\begin{array}{l}\text { In about } 18 \text { hours, } \\
\text { without convul- } \\
\text { sions }\end{array}$ & $\cdots$ & $\cdots$ & $\begin{array}{l}\text { Cups, scarifica- } \\
\text { tion, ete. }\end{array}$ & $\begin{array}{l}\text { Ammonia, olive } \\
\text { oil, no persistent } \\
\text { treatment }\end{array}$ & $\begin{array}{l}\text { In this case the } \\
\text { man was some- } \\
\text { what intoxicated } \\
\text { when bitten. }\end{array}$ \\
\hline 5 & $\begin{array}{c}\text { Constant romit- } \\
\text { ing, loss of } \\
\text { speech }\end{array}$ & $\ldots$ & Cure & $\begin{array}{l}\text { Much better in } 30 \\
\text { hours, well in } 3 \\
\text { weeks }\end{array}$ & $\cdots$ & $\cdots$ & $\begin{array}{l}\text { Scarifications, } \\
\text { blisters }\end{array}$ & $\begin{array}{l}\text { Carb. ammonia and } \\
\text { arsenic }\end{array}$ & Severe case. \\
\hline 6 & None mentioned & $\cdots$ & Death & 5. hours, coma & $\cdots$ & $\cdots$ & $\begin{array}{l}\text { Suction follow- } \\
\text { ing on incom- } \\
\text { plete excision } \\
\text { within half an } \\
\text { hour, ligature }\end{array}$ & $\begin{array}{l}\text { Carb. ammonia and } \\
\text { brandy in as large } \\
\text { doses as the pa- } \\
\text { tient could be pre- } \\
\text { vailed on to take }\end{array}$ & \\
\hline 7 & $\ldots \cdot$ & $\ldots$ & Cure & $\ldots$ & $\cdots$ & $\cdots$ & $\begin{array}{l}\text { Frictions, with } \\
\text { olive oil }\end{array}$ & $\begin{array}{l}\text { Jij of olive oil } \\
\text { given every half } \\
\text { hour }\end{array}$ & $\begin{array}{l}\text { Relates } 3 \text { other } \\
\text { cases of cure by } \\
\text { olive oil, all in- } \\
\text { completely told. }\end{array}$ \\
\hline 8 & $\begin{array}{l}\text { Nausea and } \\
\text { vomiting }\end{array}$ & $\cdots$ & Recovery & 24 hours & $\cdots$ & $\cdots$ & $\begin{array}{l}\text { Repeated appli- } \\
\text { cations of tinct. } \\
\text { iodino }\end{array}$ & None & \\
\hline 9 & $\ldots$ & $\cdots$ & Recovery & 1 hour & $\cdots$ & $\cdots$ & None & $\begin{array}{l}\text { Bibron's antidote, } \\
\text { given twice (dose } \\
\text { gtt. } x \text { ) }\end{array}$ & $\begin{array}{l}\text { No general symp- } \\
\text { toms occurred. }\end{array}$ \\
\hline 10 & $\cdots$ & ... & Recovery & Relief in 1 hour & $\cdots$ & $\begin{array}{l}\text { Suppuration on } \\
\text { back of hand, } \\
\text { perhaps from } \\
\text { local treatment }\end{array}$ & $\begin{array}{l}\text { Suction,ligature, } \\
\text { free incisions, } \\
\text { iodine injec- } \\
\text { tions }\end{array}$ & $\begin{array}{l}\text { Bibron's antidote, } \\
\text { given twice (dose } \\
\text { gtt. x) }\end{array}$ & $\begin{array}{l}\text { Expressed distinet } \\
\text { relief from the use } \\
\text { of the bromine. }\end{array}$ \\
\hline 11 & $\ldots$ & $\cdots$ & Recovery & Within 48 hours & $\cdots$ & .. & $\ldots$ & $\begin{array}{l}\text { Bibron's antidote, } \\
\text { given twice (dose } \\
\text { gtt. } x \text { ) }\end{array}$ & $\begin{array}{l}\text { Effects of } 2 \text { doses } \\
\text { of bromine said } \\
\text { to be immediate } \\
\text { aud well marked. }\end{array}$ \\
\hline 12 & $\left\{\begin{array}{l}\text { Vomiting on } 2 d \\
\text { day, diarrhoa } \\
11 \text { th day, and } \\
\text { continuously } \\
\text { until death }\end{array}\right.$ & $\begin{array}{c}\text { Constant } \\
\text { coldness of } \\
\text { extremities }\end{array}$ & Death & Seventeenth day & $\begin{array}{l}\text { Asthe- } \\
\text { nia } \\
\text { from } \\
\text { typhus } \\
\text { state }\end{array}$ & $\cdots$ & Ammonia & $\begin{array}{l}\text { Chiefly by ammo- } \\
\text { nia and alcoholic } \\
\text { stimuli, with such } \\
\text { other remedies as } \\
\text { the symptoms de- } \\
\text { manded }\end{array}$ & $\begin{array}{l}\text { A severe case, well } \\
\text { reported }\end{array}$ \\
\hline 13 & $\begin{array}{l}\text { Nausea and ro- } \\
\text { miting on move- } \\
\text { ment during five } \\
\text { days }\end{array}$ & $\ldots$ & Recovery & $\begin{array}{l}\text { Gradual, the ge- } \\
\text { neral symptoms } \\
\text { passed off on the } \\
\text { fifth day, the lo- } \\
\text { cal results were } \\
\text { persistent during } \\
\text { some months }\end{array}$ & $\ldots$ & $\begin{array}{l}\text { Slough, exfolia- } \\
\text { tiou of last pba- } \\
\text { lanx, anchylo- } \\
\text { sis of first joint } \\
\text { of finger }\end{array}$ & $\begin{array}{l}\text { Incision, suction, } \\
\text { ligature, am- } \\
\text { monia }\end{array}$ & $\begin{array}{l}\text { Tookin a few hours } \\
\text { one quart of } 4 \mathrm{th} \\
\text { proof brandy and } \\
\text { a } \frac{1}{2} \text { pint of whis- } \\
\mathrm{ky} ; \text { intoxication } \\
\text { ensued but lasted } \\
\text { only four hours }\end{array}$ & \\
\hline 14 & $\begin{array}{l}\text { Continual nau- } \\
\text { sea \& vomiting, } \\
\text { pain \& stricture } \\
\text { at epigastrium }\end{array}$ & $\cdots$ & Recovery & $\begin{array}{l}\text { Left his bed in a } \\
\text { week, depression } \\
\text { passed off on the } \\
2 \text { d day }\end{array}$ & $\cdots$ & Suppuration & $\begin{array}{l}\text { Ligatures, free } \\
\text { excision, am- } \\
\text { monia, repeat- } \\
\text { ed washing }\end{array}$ & $\begin{array}{l}\text { Camphor, ammo- } \\
\text { nia, opium, and } \\
\text { treatment by } \\
\text { symptoms }\end{array}$ & Severe case. \\
\hline 15 & $\begin{array}{l}\text { Vomitiug of bile } \\
\text { took place after } \\
\text { a dose of carb. } \\
\text { ammonia, but } \\
\text { did not recur }\end{array}$ & $\begin{array}{l}\text { Cold and } \\
\text { perspiring }\end{array}$ & Recovery & $\begin{array}{l}\text { Speedy relief from } \\
\text { use of stimulus, } \\
\text { and sudden and } \\
\text { complete cure } \\
\text { within } 24 \text { hours }\end{array}$ & ... & $\begin{array}{l}\text { Remarkable and } \\
\text { entire relief } \\
\text { from hooping- } \\
\text { cough, under } \\
\text { which the pa- } \\
\text { tient had suf- } \\
\text { fered }\end{array}$ & $\begin{array}{l}\text { Scarification, } \\
\text { cups, local sa- } \\
\text { line bath, seda- } \\
\text { tive fomenta- } \\
\text { tions }\end{array}$ & $\begin{array}{l}\text { Free use of stimu- } \\
\text { lants, } 80 \text { grains of } \\
\text { carb. ammonia, } \\
\text { and three pints of } \\
\text { brandy in a few } \\
\text { hours, without } \\
\text { causing intoxica- } \\
\text { tion }\end{array}$ & \\
\hline 16 & $\begin{array}{l}\text { Involuntary uri- } \\
\text { nary and fecal } \\
\text { evacuations, vo- } \\
\text { miting one bour } \\
\text { after bite }\end{array}$ & $\begin{array}{l}\text { Cold and } \\
\text { moist }\end{array}$ & $\begin{array}{l}\text {. } \\
\text { hour res } \\
\text { tition m } \\
\text { cult, pr } \\
\text { and de } \\
\text { rently } \\
\text { mind cl }\end{array}$ & $\begin{array}{l}9 \text { hours, somerelief } \\
\text { followed the se- } \\
\text { vere symptoms } \\
\text { caused by remov- } \\
\text { ing the ligature, } \\
\text { butduring the } 8 \text { th } \\
\text { spiration and deglu- } \\
\text { aore and more diffi- } \\
\text { ulse imperceptible, } \\
\text { eath ensued appa- } \\
\text { from syncope; the } \\
\text { ear to the close }\end{array}$ & 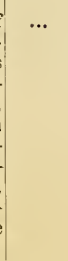 & $\begin{array}{l}\text { Ligature in } 3 \text { to } 4 \\
\text { minutes, actual } \\
\text { cautery within } \\
18 \text { minutes of } \\
\text { the bites }\end{array}$ & $\cdots$ & $\begin{array}{l}\text { Half ounce of olive } \\
\text { oil, a sedative } \\
\text { enema, and leech- } \\
\text { es to the throat, } \\
\text { seem to have been } \\
\text { the whole treat- } \\
\text { ment }\end{array}$ & e. \\
\hline
\end{tabular}

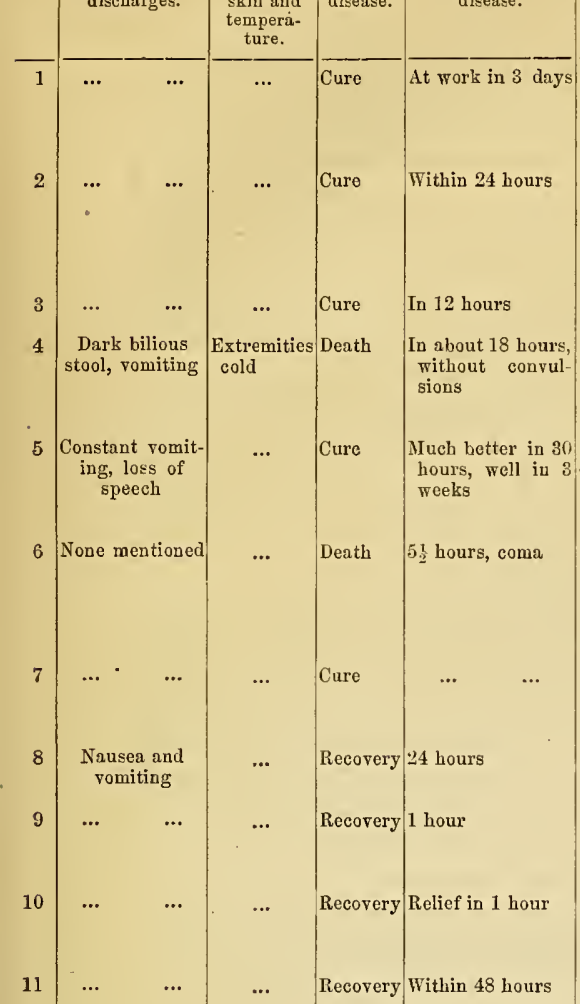
day, diarrhcea coldness 1 th day, and continuously Nausea and ro miting on movearing five

Continual nausea \& romiting,

Vomiting of bile ammonia, bu did not recur cult, pulse imperceptible, 
Sex.-It is needless to state that men are the most frequent subjects of Crotalus bite, owing to the nature of their occupations, which necessarily bring them within reach of the reptile. Children and women are sometimes bitten, and, as may be seen from the table, even young children may. recover from the effects of the accident. It is not possible or right to infer from this, that young or weakly persons suffer no more than the strong or fully grown, because we do not know how much venom may have been inserted in each case. Thus, a child struck by an exhausted snake would have a far better chance of escape than a vigorous man bitten by a serpent which had been caged for months. This element is, of course, deficient in calculations upon the prognosis of our ordinary maladies, such as typhoid fever and others, since in them the severity of the resultant symptoms alone informs us as to the probable amount of poison received by the system. In the present instance, it is an important, and usually an attainable factor, in estimating the probabilities of any given case, which it never can be in those modes of septic poisoning which we call diseases, and know only through their symptoms.

The Situation of the Wound.-In almost every reported case, the wound has been upon an extremity. A woodman steps over a log which conceals a snake; a child thrusts an arm into the hollow trunk, where a serpent lies; or, an intoxicated man, ignorant and reckless, puts his hand into a snake cage, or handles a snake which is benumbed with cold, and to appearance harmless. Another not uncommon cause of bite, is due to want of caution in dealing with serpents which have been wounded, or even decapitated. One of the best of the reported cases, that of Dr. Woodhouse, was thus produced.

Locai Symptoms.-The pain of the wound made by the snake is usually the earliest symptom, but it is by no means a constant phenomenon in either men or animals. Thus, while one reporter speaks of the sudden and intense pain, another does not mention it at all, or expressly states that the wound was at first disregarded. In most instances, the bite is certainly painful, and when we consider the hooked form of the fangs, the double wound, the injection of a foreign fluid, and the final forcible withdrawal of the teeth, we can feel no surprise that, in most cases, pain is felt, and may wonder that it is not felt in all. Certainly we need not look to the specific nature of the venom, to explain the primary pain here described.

The succeeding local symptoms are almost inevitably swelling, discoloration, and increasing pain. The reader who has followed this Essay thus far, will have no difficulty in explaining at least two of these symptoms. The swelling is due, not to inflammation, but to a large or small collection of effused blood about the wound.

In some loose tissues the amount thus accumulated may be very great, but in other cases the anatomical peculiarities of the part wounded may limit the early extravasation of blood, by confining it under a fascia, of which I have seen repeated examples in animals. The discoloration is to be explained in the same manner.

Hemorthage from the wound may limit, for a time, the last two symptoms. It is, however, a rare occurrence, and depends upon the size of the external opening: of the wound inflicted by the fang, and perhaps, also, upon the character of the vessels accidentally encountered by the fang. In one of the dogs whose medical history is recorded in this Essay, the hemorrhage from the fang wounds amounted to several ounces. 
In estimating these early local evidences of poisoning in man, as well as the local signs which follow, it is well to remember that in almost every instance the ligature was applied at once, and very tightly. In animals bitten and not subjected to the ligature the swelling occurs, it is true, but forms much more slowly than is usual in the cases of men.

The primary local symptoms thus described increase progressively, so that within a period which varies extremely, the swelling and discoloration extend up the bitten limb, accompanied on their march by pain of the most excruciating character. At this time, and after the first few minutes, the increase in the local symptoms is probably due to the influence of the septic poisoning upon the tissues near the wound, to the irritation thus resulting, and to the direct and indirect effect of the venom upon the local circulation. Thus the extremity becomes larger and more and more discolored until the skin offers every tint of an old.bruise. Vesications appear on the surface, the pain lessens, the local temperature early diminished, falls still lower, and unless the poison has ceased to act, or a potent remedy has interfered, gangrene ensues, and the system, already weakened by the effect of the poison upon its own tissues, dies in the effort to separate the mortified and corrupted part.

If, on the other hand, the poison is not present in a dose so large as to insure these fatal effects, or is properly antagonized by medical agents, the swelling dectines, and the pain disappears, with a celerity which every practitioner or reporter has assumed to be evidence of his own still, or of the utility of his therapeutic means, but which, as we shall have reason to see, is in reality, an essential and most striting feature of the Crotalus malady, and is either attributable to none of the remedies employed, or to every one of the scores of them which popular credulity has placed like blunt weapons in the too yielding hand of the physician.

It is rather remarkable, that only one reporter, Dr. Woodhouse, has alluded to the occurrence of swelling in the lymphatic glands of the part bitten. His case was in other respects somewhat peculiar, inasmuch as the lymphatic trunks also appear to have been inflamed, which is not a common symptom of Crotalus bite. The venom usually seems to enter the system through the bloodvessels alone, and to sap the life of the parts with which it comes in contact, without of necessity involving the lymph vessels or their glands.

Local Results. - It is not very easy to form a correct estimate of the local consequences in the cases which finally recover. This difficulty will be explained upon glancing over the column of local treatment in the table, when it will be observed that ligatures, the cautery, excision and incision, alone or combined, were resorted to with a freedom dictated by therapeutic despair or the fears of the sufferer and his friends.

It is hence impossible to learn positively how much was due to remedies, how much to disease. It seems, however, to be certain that in many cases slight or extensive local suppuratious follow the cure, that in others local gangrene and sphacelus of flesh and bone occur, while in the graver cases, the economy is too seriously deranged to enjoy the power of spontaneously amputating the mass of a limb. The well-known case reported by Sir E. Home (See Table of Crotalus Poisoning in Man, Case 12), approached most nearly to the condition last described. In 
this instance the poison produced great local swelling. When the system began to recover from the primary depressing effects of the venom, it found the bitten arm for the most part dead. Intense inflammation ensued as the patient rallied, but being unequal to the effort of repair, he died before it was accomplished.

In connection with the local signs, it is as well to note that no reporter has described in man the local twitching which is so common in dogs and other animals.

The constitutional symptoms of Crotalus poisoning sometimes declare themselves very early, and if we can believe their reporters, almost immediately after the bite. It is more probable, however, that an interval of several minutes elapses, or that the faintness of terror and pain has been mistaken for the constitutional effects of the venom. In a few instances these symptoms do not announce themselves for twenty or thirty minutes, but aside from these exceptional cases, it seems evident that the general manifestations of the influence of the venom on the system appear with a rapidity which is sufficiently surprising, so that the local symptoms are sometimes overshadowed and forgotten for a time, in the singular phenomena which claracterize the systemic disturbance.

The principal constitutional effect of the venom is a general prostration of the most appalling character. Sometimes within a few minutes, sometimes within one or two hours, this condition of profound sedation attains its height. The snake strikes and the faintness comes on while the person injured is endeavoring to kill the reptile. Or, as in another instance, he walks for some time and suddenly finds his limbs giving way beneath him.

I have looked in vain through the reports for any evidence of a primary stimulating power on the part of the poison, but neither in the published cases, or in my own observations, have I met with any early symptoms of excitement which might not with reason be attributed to terror and pain.

The condition of prostration referred to, is accompanied by a variety of phenomena which are in general such as accompany the action of any sudden and violent depressing agency. The patient staggers or falls, cold sweats bathe the surface, nausea and vomiting ensue, the pulse becomes quick, and rapid, and feeble, the expression anxious, and, in a few cases, the mind slightly disturbed.

A patient dying in this condition wonld probably exhibit no lesion of fluid or solid, and would be an example of acute or primary poisoning, such as sometimes occurs in the early stage of epidemics of cholera or yellow fever. So great, however, is the power of resistance on the part of man, owing, perhaps, in some degree to his bulk, that very early death seems to be a rare incident of venom poisoning, so rare, indeed, that I have met with no reported example of its occurrence.

If death does not intervene, the local symptoms soon begin to play a more important role, and the swelling and discoloration extend up the limb, and pass on to the trunk, so that when the arm has been wounded, half of the chest and back have been seen to be discolored, as though severely bruised.

Neanwhile, the signs of general blood-poisoning develop themselves, and within a few hours, or a day, the face and other parts become swollen and puffy. At the same time, the general weakness remains well marked, as shown by repeated syncope, the heart quick, feeble, and fluttering, and the respiration labored. 
In the majority of cases, the slight mental disturbance now passes away, and the mind remains singularly clear to the close, whatever the event may be. In other instances, as in Dr. Harlan's case, delirium, restlessness, and insomnia are present, but in general the nervous symptoms of this and of the earlier stage of the malady are confined to slight incoherence, and to rare sensory delusions.

The state of the secretions and discharges seems to have been thought of so little moment, that in most of the cases they are not even alluded to. For example, the state of the urine is not spoken of in any one instance. The vomiting is so frequent and so enduring a symptom, that it is more constantly referred to; but of the character of the evacuation thus effected, we learn almost nothing. From the fact that in some of the cases the reporter states that it was necessary to give a purgative to complete the cure, we may, perhaps, infer that in the milder cases, at least, no diarrhoea occurred. In two of the fatal cases, diarrhoea came on late in the disease, and in one we are told that the stools were of a dark bilious character, but beyond this we are left in ignorance.

Four fatal cases are found in the table. Of these, the most rapid was that of the medical man, reported by Dr. Post (Table, Case No. 6) ; the malady ending in death by coma, within five hours and a half. This was the nearest approach to a case of acute or simple primary poisoning, which we have met with in man.

M. Pihorel's case (Table, Case No. 16) died quietly in about nine and a half hours, without loss of intellect, but with a rapidly increasing difficulty of breathing and swallowing.

Dr. Horner's case (Table, Case No. 4) terminated about eighteen hours after the bite was inflicted. One or two hours before death, the patient had a general convulsion, with involuntary evacuation from the bowels, but without any foaming at the mouth. He appears to have regained his senses after this time. Just before he expired, he complained of pain in the colon, said he felt sleepy, closed his eyes, and died quietly without agony, and without convulsions.

In the third of the fatal cases, Sir E. Home's (Table, Case 12), the sufferer rallied from the primary-poisoning, and died on the seventeenth day, with well expressed typhous symptoms.

The duration of the various cases, and their mode of recovery or death, is of considerable interest. If we analyze the table of sixteen cases, we shall find that, as I have just stated, the four fatal cases terminated in five and a half hours, nine hours, eighteen hours, and seventeen days respectively. If, again, we analyze these four cases with respect to the question of death from primary or secondary poisoning, we shall discover that Case No. 12 (Home's) survived not only the early effects, but also, to a great extent, the constitutional affection, and perished in the effort to get rid of the gangrenous arm.

On examination, the blood proved to be coagulable. It is probable that the blood had survived the infected condition, and was gradually regaining its normal standard.

Case No. 4 (Horner) seems to have been a fair representative of those instances of Crotalus poisoning which I lave termed secondary or chronic. The patient 
never rallied completely from the depressing effect of the venom, but he was found after death to have a perfectly incoagulable blood.

Case No. 16 (Pihorel) died in nine and a half hours. It seems to have ended before the blood lost its coagulability, so that, although the veins of the bitten arm contained but little clotted blood, large coagula of loose structure were found in the main venous vessels of the trunk, and in the right auricle.

Case No. 6 (Post) was not examined after death. Of the remaining twelve cases of the table, all recovered within variable periods. Where the patient was several days or longer indisposed, the delayed recovery was usually due to the local lesions, rather than to prolonged constitutional malady.

In connection with the history of the amelioration or cure, in almost every case, we are struck by one fact, which is of singular value, because its neglect has led to almost every one of the fallacies attending upon the use of the supposed antidotes which have attained to a local or general notoriety. If the reader will glance at the Table of Crotalus poisoning in man, and at the column headed "Mode of Recovery," he will observe that in almost every case the relief from urgent symptoms was sudden, and the completed cure almost nearly so. If, again, he will look at the column in which are grouped the constitutional symptoms, he will certainly feel some astonishment at their gravity in relation to the character of the convalescence. So extraordinary was this contrast, that within a few hours, or a day in most cases, the patient, whom the physician regarded as almost moribund, went on horseback to see him, or was able to move about the house, or engage in his ordinary avocations. The general practical inference will at once suggest itself, upon an examination of the numerous and varied remedies employed. It will then be seen that, under the most different systems of treatment, the several cases grew better, or entirely recovered, with equal abruptness. Are we not driven to the absurd conclusion that each and every remedy is equally useful, or to the more logical inference that sudden relief and rapid recovery are peculiarities which belong to those cases of Crotalus bite in which the amount of venom injected has not been so unusually large as to insure a fatal ending?

The bearings of these conclusions upon the study of antidotes require but little comment, and must at once suggest themselves to every thoughtful physician. It is almost needless to add that the reporters have nsually assumed the suddenness of the cures to be due in each case to the peculiar therapeutic means employed.

I have already described the local consequences of the bite. The various reports make no mention of constitutional results succeeding recovery. One very curious statement, however, is found in connection with case No. 5 (Phillips). The patient, a female, was suffering when bitten, from a severe attack of hooping-cough, of which she was suddenly and completely cured by the effects of the venom.

$P$. M. Section.-The three cases of post-mortem examination offer very little, save negative information, as to the character of the lesions.

The Head.-Dr. Horner found the brain of a healthy consistence, but congested so that the cortical substance was of a deep brown tint. A good deal of serum oozed from the cut surfaces. About a drachm of transparent serum was present in each lateral ventricle. The medulla spinalis was healthy; its tunica arachnoidea 
being somewhat turbid in places, as if from some former cause. The veins of the pia mater and the vertebral veins were full of blood.

M. Pihorel makes a similar report of his case. He found some thickening of the cerebral arachnoid, which was also adherent to the pia mater, but to what extent he does not state. The blood of the sinuses and of the dura mater was fluid. The same condition as to fulness of blood, and the same slight excess of serum in the ventricles and sub-arachnoid spaces, existed in Sir E. Home's case.

Thorax.-Dr. Horner found all the thoracic organs healthy, except that the left ventricle of the heart was described as hypertrophied. The heart was nearly empty, owing to the escape of its fluid when the head was opened.

M. Pihorel found the walls of the trachea and bronchial tubes congested, a spot of distinct inflammation corresponding to the cricoid cartilage. The trachea and bronchiæ were full of a red and frothy mucus. The lungs were healthy and crepitant, but were somewhat congested ("premier degré d'engorgement sanguin"). Two inches below the pharynx the oesophagus was narrowed, but no notable alteration of its tissues could be discovered.

In Sir E. Home's case the lungs were healthy, the anterior fold of the pericardium was dry, resembling a dried bladder. The cavity of this membrane contained half an ounce of serous fluid, frothy from admixture with gases which escaped in bubbles.

Abdomen. Horner's Case.-The peritoneum contained a few ounces of serum. The mucous membrane of the stomach was intensely injected with blood, and most remarkably so in the wrinkles of the mucous membrane. It exhibited neither ecchymosis or softening, and contained the articles prescribed in the morning, with but little gas.

The mucous coat of the small intestines was dotted "with patches of acute inflammation. These spots were of a lively red and very numerous, especially in the jejunum. This latter intestine had its parietes considerably thickened by an infiltration of serum, and was partially filled with a dark bilious matter. The colon was sound but contracted, and contained at its head some hard fecal excrement. The liver was yellow and enlarged, which was attributed to the habits of the patient."

M. Pihorel found all the abdominal organs healthy. Sir E. Home describes the stomach in the case of Soaper as turgid with blood. All the other abdominal organs were healthy. In Pihorel's and Home's cases the blood was more or less coagulated. In Horner's it was everywhere perfectly fluid. Dr. Horner says that the muscles were of a brownish yellow color throughout the body.

The local swelling in Dr. Horner's case was due to serous infiltration; in that of M. Pihorel, but little swelling existed during life after the ligature was removed, and at the post-mortem inspection the tumefaction of the bite between the two metacarpal bones extended only half an inch around it. The bite on the dorsal face of the thumb was not at all swollen. The muscles in these localities were unaltered. Sir E. Home's case presented at the time of death extensive sloughs of skin on the arm and forearm. A large abscess existed on the outside of the arm, elbow, and forearm. The parts in the immediate neighborhood of the bite and in the palm were healthy, except that there was a little extravasated blood in the 
areolar spaces. The skin still adhered to the biceps flexor muscle in the arm and to the flexor muscles in the forearm, by a dark-colored cellular tissue. Elsewhere in the arm and forearm, the skin and muscles from the axilla down were separated by a dark fluid of an offensive odor, containing sloughs of the dead cellular tissue floating in it. "The muscles had their natural appearance everywhere, except on the surface which was next to the abscess. Beyond the limits of the abscess, blood was extravasated in the cellular membrane, and this appearance was observable on the right side of the back as far as the loins, and on the right side of the chest over the serratus major anticus muscle."

Dr. Horner's case occurred in Philadelphia, in the month of July, and was examined four and a half hours after death. M. Pihorel does not give the exact date of his case. It took place at Ronen, and from various allusions in the text of his report, it is plain that the weather was cold. The examination did not occur until five days after death, but the cold was so great that the body is said to have been in excellent preservation. Sir E. Home's case occurred in London, during the month of October. It was examined sixteen hours after death.

Antidotes.-It might naturally be supposed that the question of antidotes and remedies would be considered fully and experimentally, at the close of this Essay. Such, indeed, was my intention when I began the present investigation, but it soon became clear to me that a just and useful experimental testing of this matter was out of the question until I became thoroughly acquainted with the habits and movements of the Rattlesnake, the precise character of the venom, and its various modes of acting on the system. Portions of this information were to be found scattered through books and journals, but these disjointed studies were incomplete, and it soon grew more and more apparent that a consideration of the entire subject, and a certain fimiliarity with the powers of the poison must still, of necessity, precede an investigation of antidotes. Impressed with this idea, $I$ have endeavored, in the present paper, to render more easy the still difficult task of examining the therapeutics of Crotalus bite.

It was well said by a distinguished physician, that there are always a great number of medicines for those diseases which are either very easy or very difficult to - cure. Such has been the fate of Crotalus poisoning to a remarkable degree, for not only have physicians exhausted their ingenuity in the discovery of antidotes, but the popular medicine of log-cabin, or rough border clearings, has contributed to its strange therapentics, some twenty or thirty plants which owe their reputation to Indian traditions, and to other, and often accidental, circumstances.

Each one of these remedies has acquired a local credit; has passed from the people to the physicians; has seemed to cure in their hands, as it had done in those of the good wife or herb doctor, and finally, after going the rounds of the daily press and the medical journals, has died a natural death, or received a fatal blow at the bedside of some too deeply injured patient. Accepted upon slight evidence, and thrown aside upon equally feeble proof of inutility, such has been the career of the many and famous antidotes, which in this and other lands have embarrassed the therapeutics of these much-dreaded injuries.

While, however, the larger part of the reputed constitutional remedies are 
mere sudorifics, or entirely inert, the local therapeutics of Crotalus bite have been always of the most decisive and potent character. Without entering into the listory of these means, I desire to assign to them their proper place in the treatment, and also to define the real limits of their utility. We shall, therefore, discuss them in turn, and for this purpose shall divide them into, 1st, Those which remove the poison and the poisoned part, as excision, amputation.

$2 \mathrm{~d}$. Those which partially remove the venom, and more or less detain it in the wounded part. In this class, we have a variety of agents acting in ways as various, as

Searifications.

Ligature.
Suctions.

Caustics.

$3 d$. Those agents which, being injected into the wound, or wounded part, are supposed to destroy the venom, or to render it innocuons, as injections of iodine.

4th. Local applications of various substances, as alcohol, ammonia, indigo, olive oil, etc.

Class 1st. Excision, the only local means which proposes to remove at once and entirely, the poison and the poisoned part has been occasionally resorted to. Dr. Harlan, Case 14 of the Table, used it freely. In another instance, in France, even amputation of a finger was promptly and successfully resorted to in a case of Crotalus bite.

Excision and amputation are more or less usefully available, as the resort to them is more or less early, and their utility is also increased when a ligature has been so applied as to arrest the local circulation, immediately after the bite. In the French case, the instant ablation of the part was perfectly successful; in Dr. Harlan's case the malady was extremely grave after the operation, and we have, indeed, no means of saying whether or not it proved useful. It seems likely that in so severe a case, the removal by excision of any part of the poison might favorably determine the issue of the almost balanced chances. Necessarily, excision would be unavailable where the fang had buried itself deeply in a part like the neck.

Where the snake has been long confined without using its venom, ${ }^{1}$ so that the amount injected has probably been great, and where the part bitten is a small extremity, excision, or, rather, amputation, would be justifiable. Where, on account of the serpent being at large, we cannot judge as to the quantity of poison stored up in its ducts, and where excision would affect important parts, it is certainly better to accept for the patient the ordinary prognostic chances of the poisoning, under a less heroic local treatment. Above all, is it to be remembered that, while it may be good practice to amputate a finger within a few moments of the bite, the value of the operation lessens as we recede from this period, because the poison exerts its power so rapidly, that its effects soon pass beyond the reach of any justifiable operation, and excision then could do only what other and safer means might effect.

1 It is curious that the fatal cases found in the journals were nearly all occasioned by the bite of snakes which, during long imprisonment, had accumulated a large amount of venom. 
Class $2 d$ of local means acts in ways so various as to make it necessary to consider these separately.

Scarifications.-It is not easy to see how mere incisions could be of much value, unless made expressly so as to cut off the wound from the system, by destroying for a time its vascular comnection with the centres. Where ablation or excision is no longer justified, incisions may be made into the part, and so directed as to traverse the line of the fang wounds.

Suction. Cups.-Suction by the mouth is an ancient practice, and one which is supposed to be effectual. It is not probable that the narrow fang-track would allow of the return of the poison under any suctorial power of which the lips are capable, unless the wound were unusually large. Where a previous incision has been carried deeply throngh the bitten part, it is possible that suction may remove some of the venom, but as Dr. Pennock has shown, it is more likely that the cups and suction merely delay the constitutional poisoning, by retarding the local circulation and the subsequent distribution of the venom. Either may be thus of value, as Barry proved in regard to cups, but neither can do more than afford time for the administration of general and more permanent local means. Cups are available only in certain localities; suction by the lips may be used on the small extremities, in advance of all other means.

Ligatures.-The first resource in serpent bite has been to tie a ligature around the limb. Of course, there are localities in which this camnot be done, and where only cups can be used. The value of the ligature has been repeatedly tested, not only in this, but in other modes of poisoning, and it is perfectly clear that a ligature tightly applied above the wound will, for a time, secure the system from the consequences of the venom inoculation. But this is all which it can do. Time is obtained for the use of other means, both local and general, and then a period arrives when the swelling and interrupted circulation threaten the bitter member with gangrene, and at last the plysician reluctantly loosens the band which quarantined the deadly material, and the system passes rapidly under its influence. Allowing the ligature-as we must do-to be of the utmost value for a time, can we not derive from its use yet further advantages, without subjecting our patients to the sudden influx of the poison when the guarding band is loosened? Two precautions will probably insure the requisite end. Let the cord be loosened for a few minutes at a time, and at intervals, with a constant eye to the constitutional symptoms, and let the delay secured by the ligature be used not only to apply local means, but to administer general remedies. This method, which I shall term the intermittent ligature, seems to have been first employed by the well known naturalist, Prof. Holbrook, of Charleston, South Carolina, in conjunction with Dr. Ogier. Their experiments, which were numerous and satisfactory, have never been published.

The precautions in the use of the ligature which I have just recommended have been advocated singly, or together, by several more recent authors, and especially by Drs. Alexander and Jeter.

Several writers have recognized the danger of suddenly removing the ligature, and it would be casy to criticize some of the reports of treatment in which the 
above precautions have been neglected, and where the sudden prostration which ensued was most appalling.

Dr. Alexander relates a singular, but instructive case, in which the ligature was retained for sixteen hours. Meanwhile, the parts below were swollen and vesicating, but the system remained unaffected, and readily passed under the influence of stimulants. Either during the profound intoxication which ensued, or soon after, at all events, sixteen hours from the time of the bite, the ligature was removed. The swelling at once passed the line of the ligating cord, and advanced up the leg to the body. The patient died in two hours after the release of the previously isolated poison. Instructed by this sad case, the reporter directs that the ligature should be merely relaxed, and the pulse kept up with stimulants as required, and that the cord should be tightened or loosened as the symptoms direct. This plan is so clearly recommended by common sense, that it is needless to dwell upon it further.

Unfortunately, the ligature can be used only when the bite is on an extremity. In other cases, cups may be similarly employed, but even these are not always available, as where the nose is the part bitten, and moreover, they are not always at hand.

Caustics.-These agents are supposed to be useful, not only by destroying the tissues, and so unfitting them for absorption, but also by chemically acting on the venom itself. So far as they do act on the tissues, they are beneficial, when fully applied along or through previous incisions. As to their power to alter the venom, it is clear that the actual caitery does do this effectually, but, as we have seen, potassa, soda, ammonir, and the undiluted mineral acids do not affect its toxic potency. Except, then, as they alter the tissues, it were better to reject them, and to depend upon the actual cautery alone, where such means is deemed of value.

Class 3d.-Dr. Brainard, some time ago, directed attention to the injection of an iodized solution of iodine, as a means of destroying the activity of Crotalus venom. His process is as follows: Ten grains of iodine and thirty grains of iodide of potassium are dissolved in one ounce of water. The bitten part is first cupped, or a ligature is applied on the limb, until the tissues are swollen with serum sufficiently to enable the injection to be diffused through the distended areolar spaces. The sharp point of a trocar, or injecting-tube, is then pushed laterally into the bitten part, and the injection effected by pressing down the piston of the syringe, while the exhaustion of the cup is still carried on. Apart from the antidotal value of this ingenious method, it is clear that the necessary apparatus is not easily procurable in time to be of use. Moreover, Dr. Brainard adds that, to render it effectual, we must be provided with cups of various curves adapted to fit the surfaces of the boily and limbs. Dr. Brainard states that the iodine does not act as a caustic. M. Reynose, in an admirable paper, has examined the statements of Dr. Brainard, and especially with reference to the action of iodine as an antidote to woorara. He arrived at the conclusion that the iodine was a caustic, and that its value was due to this fact, a conclusion in which his experiments did not entirely justify him. 
The question of the reality of the influence of the iodine upon the active qualities of Crotalus venom still rests upon rather insecure ground. It certainly seems to have been successful in pigeons, but the fallacies which surround these researches are numerous and baffling, and the experimentum crucis of mixing the iodine with the venom before innoculating with it, was not made by Dr. Brainard. To set the matter at rest, I have recently made a number of experiments. It was apparent that if animals previously bitten could be saved by subsequent injections of iodine into the part, they should run no risk when a mixture of venom and the iodine solution was thrown into their tissues. On pursuing this method, I observed, as Dr. Brainard had done, that the local symptoms were slight, or did not appear at all, but whereas his cases recovered, mine died despite the absence of local phenomena. The explanation of this latter fact, as well as the full details of numerous observations upon the use of reputed constitutional antidotes, I shall set forth at length in a future essay. At present I can only add that iodine as a local antidote has uniformly failed in my hands, although every means was taken to give it a fair trial. It is proper to state here that Dr. Brainard made use, not of the Crotalus, but of the Crotalophorus tergeminus, or prairie Rattlesnake of the west. As yet, Dr. Brainard's antidote has never been employed upon the body of man, except by Dr. Coolidge, who unfortunately used the Bibron treatment at the same time.

Class 4th.-Consists of various substances which have been applied to the skin on and about the wound, or placed in contact with the raw surfaces of the incisions or excisions. Among them are warm and cold water, ammonia, alcohol, olive oil, etc. My own experiments, and the observations of others, justify us in rejecting them altogether, so far at least as they are supposed to exert specific power.

Although, as I have already said, I consider this essay as but a preparation for the full experimental examination of the treatment of serpent bite, I do not wish to conclude without some comment upon the constitutional remedies which I have necessarily been called upon to survey and judge in the course of my researches. A host of these may be dismissed with a word, but before I criticize those of greater pretension, it will be proper to make some statements regarding the misconceptions which have crept into this part of the subject.

If, as I have elsewhere urged, we could dismiss from view the mode in which the virus enters the body, and were called upon to consider only the resultant malady, we would as little have dreamed of specifics or real antidotes, as we now do in yellow fever, or ordinary putrefactive poisoning. We should at least have confessed that such belonged only to the hopes of therapentics, and not to its attained realities. Such, however, is the tangible and visible nature of the poison that we have been continually seduced into the idea that we must possess some available and directly efficient means of actually neutralizing its power, when once in the system itself.

Apart, then, from the question of local antidotes, which is altogether a different matter, what probability is there that we really possess specific general remedies? Even here, the knowledge that our local means, however active, and with all our power to place them in direct contact with the venom, are but too ineffectual, should at least have taught us to receive with wise mistrust every account of constitutional antidotes. 
Antidotes considered with reference to the system at large, are of only two kinds. Those which meet the poison in the ressels of the economy, and then and there chiemically alter it, so as to destroy its potency, and those which, like most of our medicines, are absorbed, circulate, and counteract the effects of the poison. Thus a sedative may counteract a stimulant, and vice versa, and each would, in this sense, be for the other a physiological antidote; but would in nowise correspond with the popular conception of an antidote.

The remedies which still hold repute as antidotes are few in number. They are ammonia, olive oil, arsenic (as the Tanjore pill), Bibron's antidote (Bromine), and alcoholic stimuli.

The pretensions of ammonia in this connection have been long since settled by the experiments of Fontana on Vipers, and of Brainard on Crotalophorus. I have also tested its supposed utility in cases of animals poisoned by Crotalus venom, and it will answer our present purpose to add that it failed almost uniformly. Notwithstanding the continued faith still reposed in it by some, and the cures attributed to its use, I am convinced that it has no powers which alcohol does not enjoy to a superior degree, and I feel equally sure that its exhibition should never be allowed to supplant the use of other and better stimulants. That it has no value as a chemical antidote, the experiments elsewhere related in this paper sufficiently prove, if proof were wanting.

Olive oil is another remedy which has been gravely urged and has received the support of numerous successful cases. What these are worth, or with what allowance they should be entertained, has, I trust, been set in clear light by the general argument which I have founded on all the cases which I have analyzed. After the experiments of Fontana on its use in Viper poisoning, it is strange that the most confident should have dared to employ it again.

Arsenic, unlike olive oil, certainly does not belong to the class of expectant remedies. Its use in snake-bites comes from the East, where as the "Tanjore pill" it attained great celebrity.

This well-known medicine is composed of arsenious acid, three East Indian roots, two of which are purgative, and one an acro-narcotic, mixed with pepper and the juice of the wild cotton plant. Two of the pills, containing each three-fourths of a grain of the arsenic, are given at once, and one at the close of an hour, a rather formidable dose of so active a medicine. Russell (p. 65), who examined this remedy, was not satisfied with it, nor am I aware that it has retained its celebrity, or that any one has used it in Rattlesnake bite.

Bibron's antidote is a more novel remedy, of the value of which I am not fully prepared to judge. Its history is rather curious. Mr. Xantus obtained it in the first place from Prince Paul, of Wurtemberg, the well-known traveller and naturalist. This gentleman stated that it had been invented and employed by Prof. Bibron, of Paris, but neither Mr. Xantus or Dr. Hammond has been able to find any printed account of $i t$, nor have I been more successful. The chief evidence in its favor rests upon a considerable number of experiments made by Dr. Hammond and Mr. Xantus, and upon three cases reported by the same observers. Mr. Xantus states one fact which I have been thus far unable to verify, namely, that 
dogs which were under the influence of the antidote, were for some time incapable of being affected by Rattlesnake bites. This experimenter states that after seventeen experiments, in which three dogs were at different times bitten by seventeen different serpents, he met with no case in which the antidote failed. These results are not stated with sufficient precision as to the condition of the suake, the number of fang-marks, or the place of the bite, but they are still sufficiently interesting to awaken further research.

Dr. Hammond was not so fortunate as Mr. Xantus. He experimented with the antidote on a wolf which was appareutly saved by the use of the bromine after being once bitten, but upon another occasion, having been thrice bitten, died suddenly, exhibiting, however, some evidence of having been aided by the remedy. A dog severely injured by snake-bite was successfully treated by Dr. Hammond with the bromine antidote.

One of the cases of man in which Dr. Coolidge (Dr. Hammond's Report) used this antidote, was also treated with local injection of iodine, and must, therefore, be laid aside. The patient expressed herself relieved by the use of the antidote.

The case directly reported by Dr. Hammond also seemed to experience great assistance from the antidote, so that even the local symptoms were promptly relieved by its use. No local means seem to have been employed, and the case is thus unusually free from complication.

Mr. Xantus' case was said to have been almost hopeless when the bromine was employed. The worst symptoms rapidly subsided when the antidote was given, although but two doses were used. Were it not for our knowledge of the natural history of the malady, and of the strange suddenness with which cases almost moribund rapidly amend, we could not fail to be greatly impressed with the evidence thus furnished. As it is, perceiving no obvious adaptation of means to ends, we can only await the issues of a larger and more general experience to determine the question.

My own experiments upon the use of this antidote were made on sixteen dogs, and were conducted with scrupulous care. It does not suit my present purpose to enter into the details; it will suffice to state that their results were nearly negative. Of eight dogs bitten and treated with the antidote, two died; while of eight bitten, and not so treated, three died.

The last of the reputed antidotes which we shall criticize is alcoholic stimulus. In one form or auother this has been employed in India and in this country, and no single remedy is so much in repute along our borders or in our Rattlesnake regions. Perhaps the evidence in its favor is not much better than that which exists for some other means, but its real strength, in the lack of proper and numerous reports, lies in its obvious adaptation to the wants of those who seek its aid. Moreover, the experiments on the state of the heart and nervous system of animals, in the first stage of the Crotalus malady, clearly indicate a condition of things which is to be met alone by the use of supporting agents, and these the most rapid and effective which we can command.

When, too, we consider the state of a person bitten, and constitutionally affected, we perceive at once that we have to deal with a degree of prostration which instantly 
snggests the free use of stimulus. When this is given, and is successful in raising the pulse, the result is commonly a rapid and easy cure, but the amount of alcoholic fluids necessary to secure even partial intoxication is scarcely credible. Quarts of brandy have been thus taken by delicate females and mere children without injury, and almost without effect. This alone is, to some extent, evidence in favor of the remedial means under discussion.

It is very plain, then, that in the state of profound sedation, or, rather, prostration, which ushers in the general malady, stimulants are distinctly indicated. It is also clear that the means thus pointed out is a physiological antidote, a counteractive agent, and is to be used to an effect and with certain precautions.

When, therefore, a person has been bitten, it would be proper slightly to intoxicate him, then to loosen the previously applied ligature or cup, and watching the pulse, and relaxing or tightening the ligating cord to control thus the inlet of the poison, with the aid of the stimulus destroy its effects in detail. Finally, the stimulus should be most cautiously and by degrees abandoned, with continued regard to the state of the system.

There is a popular, I might almost have said a medical belief, that the condition of perfect protection is complete intoxication. Two or three authors, as Jeter, Alexander, and others, protest against this idea, and with every appearance of right on their side.

Profound drunkenness is a condition of sedation and not of excitement, and yet the whole object of using alcohol in snake-bites has been among rational men to stimulate and not to lull or depress the system. In fact, it is well known that persons who were at the time "dead drunk," or nearly so, have been bitten by Rattlesnakes, and have obtained thereby no immunity from the effects of the bite. Dr. Brainard, who is opposed to the use of stimulus in Crotalus bite, thinks the evidence in its favor insufficient, and thus sums up his argument against its utility:-

"When mixed with alcohol, the venom is rapidly fatal, if inoculated." This opinion is correct, but has no value as in opposition to the constitutional use of stimuli, because they are not to be regarded as chemical antidotes, and their direct reaction with the venom becomes, therefore, a matter of indifference.

Dr. Brainard also urges that when venom is injected into the tissues, or introduced into the stomachs of birds or small animals bitten, it only hastens death.

This, he adds, is nut conclusive, because alcohol is a poison to birds and other small animals. The authority for these statements I have been unable to find. It is not Fontana, and I cannot discover in Dr. Brainard's papers that the conclusion here stated is based upon his own experiments. If true, it would have little value, the real point in question being whether stimulation is useful in cases of Crotalus bite. To determine this, we should intoxicate animals and then inoculate them with known amounts of venom, or first inoculate and then give the stimulant. Moreover, we should resort to as large animals as can easily be managed; the venom being so fatal to all small animals, and especially to birds, as to give but little time for remedies. Again, in small animals, and particularly in birds, it is not always easy to ascertain and gorern the degree of stimulation which may be present or desirable. 
The last argnment against stimulants used by Dr. Brainard, is the fact that intoxicated persons have died from Crotalus bite. He states that he has authentic information as to four such cases. Now it is plain, as I have urged, that deep drunkemmess is not the condition which we desire, and it is most probable that a person who was in this state would be overcome by the venom with more than common ficility, as indeed may be inferred from Dr. Brainard's statement. If, however, the cases which he refers to were only somewhat intoxicated when bitten, it would be very requisite to kinow whether or not any means were taken to sustain the stimulation, without which the primary state of excitement would very soon disappear before the terrible depression caused by the poison.

The remaining instance of death from a bite given to an intoxicated man is the case of Adam Lake, reported by Dr. Horner. The particulars are as follows: The patient was in the habit of drinking daily from half a pint to one pint of alcoholic liquors, and, as was seen at the autopsy, was constitutionally the worse for this habit. When somewhat intoxicated, he was bitten at the bend of the arm, both fangs entering. Some time, I presume at least two or three hours, passed by before he sought aid, and during this period so little effect was produced that he paid no attention to the wound until the itching annoyed him. From this time he was under treatment, the arm rapidly swelling and becoming painful. Now, Crotalus poison may produce but slight local effects, but when it is in such amount as finally to kill, it does not long delay the exhibition of its infuence on the system. Yet in this person, who did afterwards die, some time evidently elapsed without any constitutional expression of poisoning. Was this reprieve due to the partial intoxication of the sufferer? Whaterer answer we may give, it is quite clear that this was no case to quote against the use of stimulants, since, in addition to what I have urged, we learn yet further that with the exception of a little ammonia and two half-ounce doses of sp. vin. dilut., used late in the malady, he took no stimulants, and that no regular effort was made to sustain or renew the primary stimulation, which, at first, had so guarded his system.

It sometimes happens that the physician finds it impossible to produce stimulation in the presence of so potent a sedative as the venom. When this is the case, it is possible that absorption does not occur with sufficient rapidity, or at all events, that cases may occur, where it is necessary to stimulate fully and suddenly.

Under these circumstances I would recommend inhalation of the fumes of warm alcohol, or even of ether if used with caution.

While advocating the employment of stimuli as rational therapeutic means of meeting a most obvious indication, it is proper to admit that cases have been and will be encountered, in which the dose of venom has been so great, that no remedy is of any avail. Such, however, must be rare, and it is on the whole more than probable that the danger from the bite of the Rattlesnake has been over-estimated, and that in a large majority of cases the patient would recover, even if unassisted by any remedy.

Where stimulants are of any use, the patient commonly recovers without further difficulty. In some cases, however, which attain to the stage of alteration in the blood, we have to deal with conditions which are also present in other cases of 
putrefactive poisoning, but for which we have no remedies of well determined power. Possibly, tonics, astringents, and continued stimulation might be of some value in supporting the strength until the blood recovers its normal condition.

In the foregoing brief indication of my views as to the proper treatment of Crotalus bite, $I$ have endeavored to make it plain that in the absence of any certain specific, this malady should be treated as the symptoms dictate, and that no other guide can-be safely or conscientiously followed in the present condition of the therapeutics of this mode of poisoning.

It would be improper to close these pages without repeating that I have given my views as to treatment, in the briefest and most condensed manner, and that every eriticism of the treatment advised by others, and every remedial method recommended by myself, rests upon the authority of experiments which I shall detail at length on a future occasion.

I sincerely trust that the publication of this essay may induce the physicians of this country to study more zealously, and record more exactly, every case of snake poisoning which may fall nnder their notice, since, without such aid, it is impossible for the most ardent student to do justice to the subject, and since it is only by a large accumulation of experience, that any fair appreciation of the true value of . remedies can be attained. 



\section{A PPENDIX A.}

\section{AN ENUMERATION OF THE GENERA AND SPECIES OF RATTLESNAKES, WITH SINONYMY AND REFERENCES.}

Bт E. D. COPE.

I.

Тнат large assemblage of serpents, known as the Viperide of Bonaparte, Viperina of Gray, or Solenoglyphes of Duméril, exhibits the most perfect degree of development of those points of structure which distinguish all venonous serpents from those that are innocuous. Of the subgroups of genera and species contained in this "family," or "suborder," none is more truly representative than that denominated by the authors just mentioned, Crotalina, Crotalidæ, and Crotaliens respectively, and which is characterized by the possession of a deep pit in the maxillary region, in front and below the level of the eye. Preëminent among the Crotalina for size, strength, and power of inflicting injury, are those species in which the tail terminates in a jointed corneous appendage, termed the rattle, from which their name of Rattlesnakes is derived. These serpents exhibit two types of form, which are distinguished by the following characters:-

Anterior part of the top of the head covered by small scales.

Caupisona.

Anterior part of the top of the head covered by nine plates, symmetrically arranged. CRotacus.

In the following pages will be given an ennmeration of the species of these two genera, under their correct names, with a description of the Caudisona horrida, the species which has been the subject of Dr. Mitchell's experiments.

II.

\section{CAUDisona LaURenti.}

1768. Caudisona : LAURENTI, Specimen Synopsis Reptilium, p. 92.

1789. Crotalus : LACÉpìDE, Histoire Naturelle des Serpens, II, 130. Nec Linnæi.

1802. " " DAudin, Histoire Naturelle des Reptiles, V, 297.

1817. “ Cuvier, Règne Animal, II, 77.

1830. “ " WAGLER, Naturlich. Syst. der Amphibien, p. 176.

1837. “ Schregex, Essai sur le Physionomie des Serpens, II, 555.

1842. " "GRAY, Zoological Miscellany, p. 51.

1843. " " FitziNGER, Systema Reptilium, p. 29.

1849. " "Gray, Catal. Brit. Museum, p. 19.

1853. " BaIrd et Girard, Catal. Serp. Smitlıs. Inst., p. 1. 
1854. Crotalus : DuMéril, Erp. Gènérale, TII, 1453.

1830. Uropsophus: WAGLER, Natur. Syst. der Amph., p. 176.

1842. " "Gray, Zool. Misc., p. 51.

1843. " " " "

1849. " "Gray, Cat. Brit. Mus., p. 19.

1843. Urocrotalon : Fitzixger, Systema Reptilium, p. 29.

\section{Caudisona durissa.}

1768. Caudisona durissa: Lavrent, Spec. Syn. Rept., p. 93. Erclus. cit. Catesb. et Habitat.

1766. Crotalns durịsus : Lrñzess, Syst. Nat. Edit, XII, I, 372. Citatio prima; [Amoen. Acad., I, 500, 1748. Crotalophorus durissus, descriptio prima, p. 501, nec secunda]. Citatio tertia falsa ; [Seba II, 95, f. 2, Caud. terrifica delineatur].

1788. " "var. $\gamma$. Gmelin, Linn. Syst. Nat., I, 1081.

1789. " " Lacép̀̀De, Hist. Nat. Serp., II, 423, Excl. cit. Laureuti. Nee "Le Durissus," tab. xviii, f. 3 , p. 390 , ubi C. horrida (hujus enumerationis) delineatur.

1790. “ " " Bonvaterre, Ophiologie, p. 2.

18I7. " " " Cuvier, Regue Animal, II, 78.

1820. " " “ Merrem, Syst. Amphib., p. 156. Homonyma accurate enumerata.

1830. " " “ Grifrith, Cuv. Règne Animal, IX, 267.

1853. " " " "

1859. " " “ Cope, Proc. A. N. S., p. 337. Exclus, homon. C. cascacella Wagl. et spec. "No. 3."

1802. “ " horridus: Daudin, Hist. Nat. Rept., V, 311. Ex́clus. cit. Linn. Laurenti, Lacépède.

1837. " " " "Schlegel, Essai, II, 561. Exclus. cit. Laurenti, Wagler, Neuwied.

1854. " " Duméril, Bibron, VII, 1472. Exclus. cit. Linn. Wagl. (in Spix Serp. Braz.), Neuw. ?Gray.

Icones -? Seba, tab. xlv, 4. ?Bonnat, tab. iii, f. 1. Daudin, V, 69, I. ? Schlegel, Essai, tab. xx, xii, xiii, siv. ? Dum. Bibr., lxxxiv, bis, 2. ?? Cuv. Règne Animal (Edit. Andonin, Blanch. ete.), pl. xxxii. Dict. Sei. Nat. Cloquet, Poiss. et Rept., t. xxir.

Habitat.-In Guiaua, ? Mexico.

\section{Caudisona terrifica.}

1768. Caudisona terrifiea: LAURentr, Spec. Syn. Rept., p. 93.

1789. Crotalus boiquira: LAcépède, Hist. Nat. Serp., II, 130, 390. Excl. fig. I, tab. XVIII, et cit. Kalm.

1802. " " simns: DAUdr, Hist. Rept., T, 321.

1824. “ " easeavella: WAGLER, Spix Serp. Braz., 60.

1825. “ c horridus “Daud:" NeUw. Natnrgeschichte Brazil., p. 435.

1849. “ “ ? GRAy, Catalogue Brit. Mus., p. 20. Exclus. eit. Liun. Dandin, Schlegel; et homonym. horridus, adamanteus, rhombifer, Oregonus.

1827. “ durissus: Bore, Isis von Oken, p. 562.

Icou.-Seba, xcv, f. 1. Spix Serp. Braz., xxiv. Neuwied Naturgeschichte Braz., tab.? Habitat.-In Brasilia, Guiana.

\section{Caudisona Loeflingii.}

1833. Crotalns Loeflingii : Hombondt, in Humboldt et Bonpland, Recueil d'Observ. de Zoologie et Anat. Comp., p. 6.

Habitat._In Venezeula. 


\section{Caudisona adamantea.}

1799. Crotalus adamanteus: PAL. De Beauvois, Trans. Am. Phil. Soc., IV, 368.

1842. " " " HolвRook, N. Am. Herp., ПI, 17.

1853. " " " B.TRD et GIRARD, Catal. Serp. Smiths. Inst., p. 3.

1853. " " " LE Conte, South. Med. and Surg. Journ., IX, 664.

1790. " ?horridus: Bonsat. Ophiologie, p. 1. Excl. cit. Linn. Mus. Ad. Fried. et 'Tab.

"1801. " " rhombifer : Latreiche, Hist. Rept., III, 197."

$1802 . \quad$ " " DAODIN, Hist. Rept., V, 525.

1854. " " " DumérIL, Bibron, Erp. Gen., VII, 1471.

1802. " durissus: SHAw, Gen. Zool., III, 333.

1853. " terrificns: Le Conte, Proc. Acad. Nat. Sci. Philada., VI, 419. Exclus. homon. Caudisona terrifica Laur., p. 418.

1859. " " CoPE, Loc. eit., p. 337. Exclus. homon. terrifica Laur.

1842. ? Crotalus Oregonus: Ноцввоок, N. Am. Herp., III, 21.

1853. " " " Baird et GIRARD, Cat. Serp., p. 145.

Icones._? Shaw, Gen. Zool., III, t. lxxxix. Daudin, Hist. Rept., V, pl. lx, figs. 22, 23. Holbrook,

N. Amer. Herp., III, t. ii. U. S. Pacific R. R. Rept. Reptiles, tab. xxiv, f. 2.

Habitat.-In "United States" orieutalibus circa oram Naris Nexicani et "South Carolina," in America Septentrionali.

\section{Caudisona atrox.}

1853. Crotalus atrox: Batrd et GIRARD, Catal. Serp. Smiths. Inst., p. 5.

1859. " " Batrd, U. S. and Mex. Boundary Surv. Reptiles, p. It. U. S. Pacific R. R. Rept., X. Whipple's Rept., p. 39.

Icones.-U. S. and Pac. R. R. Rept. Reptiles, t. xxir, f. 3. U. S. and Mex. Boundary Survey, Reptiles, t. i.

Habitat.-In Texas.

\section{Caudisona lucifer.}

1852. Crotalus lucifer: Bamp et Gmard, Proc. Acad. Nat. Sci. Philada., p. 177, et (1853), Catalogue, p. 6.

1858. " " " GIRARD, Herpetology U. S. Expl. Exped., p. 187.

1859. “ “ “ Barrd, U. S. Pacif. R. R. Report, X, Williamson's Report, p. 10.

1859. " " "Cooper et Stckuer, Tat. Hist. Wash. Terr., p. 295.

Icones.-U. S. Pac. R R. Surv. Rept. Reptiles, Williamson's Rept. Reptiles, tab. xi. Girard, Herp. U. S. Ex. Exp., tab. xv, figs. 1-6.

Habitat.-In Oregon, California.

\section{Caudisona Le Contei.}

1852. Crotalus Le Contei : Halroweld, Proc. Acad. Nat. Sci. Philad., VI, 180.

1853. " “ " "

1859. " " " " $" \quad$ U. S. Pac. R. R. Rept., X, Williamson's Rept., p. 18.

1853. " confluentus: "Say," Baird et Girard, Catal. Serp. Smiths. Inst., p. 8. Exclus. homon. C. confuentus Say.

1859. “ “ Baird, U. S. and P. R. R. Surv. Rept., Whipple's Rept., p. 40. U. S. and Mex. Bound. Surv. Reptiles, p. 14.

1859. " " COOPER et Suckier, Nat. Hist. Wash. Ter., p. 295.

Icones.-Sitgreave's Exped. Colorado and Zuni, tab. xriii (icon pej.). U. S. Pac. R. R. Surv.

Rept. Reptiles, tab. xxiv, fig. 4. Ibid. Williamson's Rept. Reptiles, tab. iii. Cooper and

Suckley, Nat. Hist. Wash. Terr., tab.'xii.

Habitat.-Iu Nebraska usque ad "Rocky Mountaius," Texas et "New Mexico." 


\section{Caudisona confluenta.}

1823. Crotalus confuentus: SAY, Loug's Exped. Rocky Mts., II, 48.

Icon.-Nulla.

Habitat._-"Red River," eirca fontes.

\section{Caudisona tigris.}

1859. Crotalus tigris: Kennicotr, U. S. et Mex. Boundary Surv., II, Reptiles, p. 14.

Icon.-Loc. cit., tab. iv.

Habitat.-In Eremis Gila et Colorado, "New Mexico."

\section{Caudisona lugubris.}

1859. Crotalus lugubris : JAN, Rev. et Mag. de Zoologie, p. 156.

Icon.-Jan Prodrome d'un Iconogr. Descr. Ophid., tab. E, f. 4.

Habitat.-Iu Mexico.

\section{Caudísona horrida.}

1766. Crotalus horridns: Linnaus, Syst. Nat. Ed. XII, I, 572. Primó cit. Mus. Ad. Fr., I, 39, nbi "Frons tecta squamis obtusissimis, palpebræ superiores planæ magnæ" legatur. Porro Catesby Carol. Hist. (A) et Amoenitat: Acad. (B) citantur. (A. "Vipera caudisona americana," et "T. c. a. minor" describuntur, pp. 41, 42; sed "V. c. a. minor caput scutis magnis instructum habet."1) (B. In. Amoen. Acad., II, 139 . C. durissa (hujus enumerationis) (Amoen. Acad., I, 500) citatur! et "Virginianis rattlesnake" denominatur!) Secundo eit. Seba, 95, f. 1, ubi C. terrifica delineatur!!

\begin{tabular}{|c|c|c|c|}
\hline 1802. & " & “ & SHaw, Gen. Zool., III, 317. \\
\hline 1817. & “ & " & CUvier, Règue Animal, II, 78. \\
\hline 1830. & " & “ & GraY, Synopsis Rept., p. 78. \\
\hline 1830. & “ & " & Guerin, Iconogr. R. Anim., tab. n. 23 , f. 2. \\
\hline 831. & “ & “ & Griffith, Cuv. Règue Animal, IX, $28 \%$ \\
\hline 1853. & $"$ & “ & Le Conte, Proc. Acad. Nat. Sci. Philada., VI, 417. \\
\hline 859. & “ & “ & Cope, Proc. Acad. Philada., p. 338. \\
\hline 1801. & “ & durissus : & Latreille, Hist. Rept., III, 190." \\
\hline 1802. & “ & " & DadDin, Hist. Rept., V, 304. Exclus. cit. Liuu. Laurenti, Lacẻp. \\
\hline 1825 . & " & “ & $\begin{array}{l}\text { HarLan, Journ. Acad. Nat. Sci. Plilada., p. 368. Exclus. cit. Liun. Laur. } \\
\text { Ibid. Med. and Phys. Res., p. } 132 .\end{array}$ \\
\hline 1837. & “ & “ & $\begin{array}{l}\text { Schleget, Essai sur le Phys. Serp., II, 365. Exclus. descrip. color., p. } 366 \text {, } \\
\text { et homon. Uropsophus triseriatus Wagl. et Crot. confuentus Say. }\end{array}$ \\
\hline 1839. & “ & “ & STorer, Report, Rept. Mass., p. 233. \\
\hline 1842. & " & " & HoLbrook, N. Am. Herp., III, 9. Exclus. cit. Linn. \\
\hline 1842. & “ & “ & DE KAY, Zoology of New York, pt. III, 55. Exclus. cit. Linn. Say. \\
\hline 1853. & “ & “ & LE Conte, Southern Med. and Surg. Journ., p. 663. \\
\hline 1853. & “ & “ & Baird et Girard, Catal. Serp. Smiths. Inst., p. 1. Exclus. eit. Linn. \\
\hline 1854. & “ & “ & BAIRD, Serpents of New York, p. 9. Exclus. cit. Linn. \\
\hline 1854. & " & " & $\begin{array}{l}\text { Dumérn, et Bibron, Erp. Gen., VII, } 1465 \text {. Exclus. cit. Linn. Latreille, } \\
\text { Wagler. }\end{array}$ \\
\hline 1859. & “ & “ & $\begin{array}{l}\text { BaIrd, U. S. Pac. R. R. Expl. Surv., X. Whipple's Rept. Reptiles, p. } 39 . \\
\text { Exclus. cit. Linn. }\end{array}$ \\
\hline & “ & “ & ?JAN, Rev. et Mag. de Zool., p. 153. \\
\hline
\end{tabular}

1 Linnaeus Syst. Nat., in C. miliarii diagnosi. 
"1801. Crotalus atrieaudatns : LatreiLle, Hist. Rept., III, 209."

1827. " " " "Bore, Isis von Oken, p. 562 .

1830. " " " " "Wagler, Nat. Syst. Amphib., p. 177.

1812. " " GraY, Zool. Miscell., p. 51.

1843. Urocrotalon durissus: Fitzinger, Syst. Rept., p. 29.

1849. Uropsophus durissus: Gray, Catal. Brit. Mius., p. 19. Exclus. cit. Linn. et homon. confluentus Say, rhombifer Latr., triseriatus Wiegm. Wagl. Gray.

1826. ? Crotalus Catesbaei Hempr.: Fitzinger, Neue Class, p. 63, fide Gray.

1851. ? Urocrotalon Catesbyanum Fitz.: Dresrng, Syst. Helminth., II, 431.

Icones._Catesby, Hist. Car., II, tab. xlii. Lacépède, Serp., II, tab. xviii, f 3 . Shaw. Zool. III, t. lxxxviii. Dandin, V, t. lxviii. Guerin, Iconogr. R. Animal, t. xxiii, f. 2. Schlegel, Essai, xx, f. 15, 16. Dict. Univ. Hist. Nat. Atlas, II, t. xiii. f. I. Dum. Bibr. Erp. Gen. Atlas, t. lxxxiv, bis. fig. 1. Holbrook, N. Am. Herp., III, t. i. De Kay, Zool. New York, pt. III, Atlas, fig. 19. Baird, Serp. New York, t. i, f. 1. U. S. Pac. R. R. Expl. Rep. $\mathrm{X}$, Reptiles, t. xxiv, fig. 1 .

Habitat.-In "United States" orientalibus, usque ad "The Plains."

This species may be distinguished by the following peculiarities :--

Upon the top of the extremity of the muzzle there are two subtriangular shields (prefrontals) in contact with each other. A large oval shield covers the region over each eye (superciliary). These shields are in contact anteriorly upon each side with a smaller one, which is in contact anteriorly with the prefrontal, and forms upon each side, the external shield of a cross series (post-frontals) immediately behind the prefrontals, which is usually composed of five plates. The remaining part of the upper surface of the head is covered with small subtuberculous scales.

The shields bounding the upper lip (superior labials) are from twelve to fourteen in number, the fourth or fifth the largest; those bounding the lower lip (inferior labials) thirteen to fifteen. Three rows of scales separate the eye from the superior labials. Two plates in front of the eye (preoculars), the lower usually reaching the pit in the side of the face; the upper larger, and separated from the hinder of the two plates between which the nostril is pierced (nasals), by two or more small plates (loreals). The scales of the body are in twenty-three or twentyfive longitudinal rows, all keeled, the row on each side next the shields of the abdomen (gastrostega) faintly.

The ground color above varies from bright yellowish tawny or fulvous to black brown; beneath from whitish yellow to black gray. A light line extends from the superciliary plate to the angle of the mouth, behind which is a dark band or blotch. Upon each side of the medial dorsal line there are two series of brown or black spots. The spots of the upper or medial series are larger, rhomboid, running obliquely upwards and backwards. They are frequently confluent across the middle line of the back anteriorly; always upon the posterior half of the body. The spots of the lower series encroach slightly upon the gastrostega, and posteriorly, unite with those of the middle series, to form zigzag cross bands. Anteriorly they sometimes alternate with the central series, or rather become confluent with an indefinite alternating series, and joining the extremities of the former, enclose the ground color, which thus forms a series of light spots. Of these transverse bands or rows of spots there are twenty-one, more or less, from the head to 
the anus. In southwestern specimens, a narrow rufous band frequently extends along the median dorsal line throughout the whole length. Tail nearly always entirely black.

This species is found from Maine to Kansas, and from Louisiana to Florida.

\section{Caudisona molossus.}

1853. Crotalus molossus: BaIrd et Girard, Catal. Rept. Smiths. Inst., p. 10.

1859. " " " BaIRD, U. S. et Mex. Bound. Surv. Reptiles, p. 14.

1854. “ ornatus : Hallowell, Proc. A. N. S. Philada., VII, 192, etc.

1859. " " " U. S. Pac. R. R. Expl. Rept., Parke's Rept. Reptiles, p. 23.

Icones.-U. S. Pac. R. R. Rept. Reptiles, xxiv, f. $5 . \quad$ Ibid., Parke's Rept., lab. ii. U. S. and Mex. Bound. Surv., tab. iii.

Habitat.-In "New Mexico."

\section{Caudisona lepida.}

1860. Caudisona lepida : Kennicotr, MSS.

Icon.-Nulla.

Habitat.-In Texas australi.

\section{Caudisona cerastes.}

1854. Crotalus cerastes: Haluoweld, Proc. Acad. Nat. Sci. Philada., p. 95.

1859. " “ " “ U. S. Pac. R. R. Expl. Rept. Williamson’s Rep. Rept., p. 17.

1859. " " " Barrd, U. S. and Mex. Bound, Surv. Reptiles, p. 14.

Icon.-U. S. ct Mex. Bouud. Surv., pl. iii.

Habitat._In Eremis Colorado et Gila.

\section{CROTALUS LINNeUS.}

1766. Crotalus: Linnæus, Syst. Nat. Ed., XII, 372.

$1788 . \quad$ " Gielin, Syst. Nat., I, 1080.

1790. " " Bonnaterre, Ophiologie,p. 1.

1820. " " Merrem, Tent. Syst. Amphib., p. 156.

1827. " BoIE, Isis, p. 562.

1825. Crotalophorus : Gray, Ann. Philosophy, p. 205.

$1849 . \quad$ " " Cat. Brit. Mus., p. 17.

1842. " " Ноцввоок, N. Amer. Herp., III, 25.

1853. " Baird et Girand, Cat. Serp. Smitlis. Inst., p. 11.

1826. Caudisona: Fitzinger, Neue Class. Rept., p. 63.

1830. " W "WGLer, Nat. Syst. Amphib., p. 176.

1832. " " Bonaparte, Saggio, p. 24.

1842. " "Gray, Zool. Misc., p. 51.

1843. “ " Fitzinger, Syst. Rept., p. 29.

\section{Crotalus miliarius.}

1766. Crotalus miliarius : Linneus, Syst. Nat. Ed., XII, จ. 1, 372.

1788. “ " " GMelin, Linu. S. N., I, 1080.

1789. " " " LACÉPÈDE, Hist. Serp., II, 421.

1790. " " Bonnaterre, Ophiol., p. 1. 
1802. Crotalus miliarius: SHAw, III, 336.

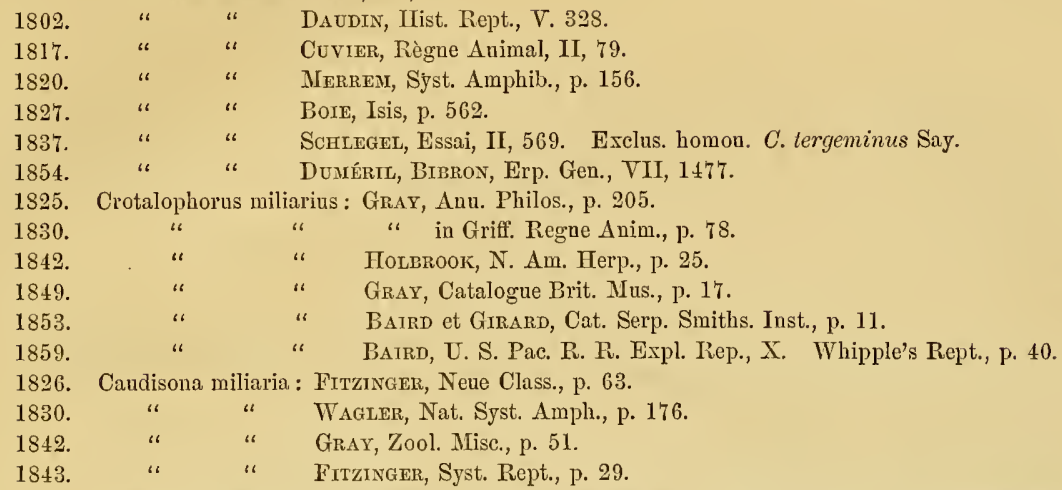

Icones.-Catesby, Hist. Car., II, t. xlii. ?Bonnaterre, Ophiologie, t. i, f. 1. Schlegel, Essai, t. xv, f. 17, 18. Holbrook, N. Am. Herp., III, t. iv. Dum. Bibr. Erp. Gen., lxxxiv, bis. f. 5. U. S. Pac. R. R. Surv. Rept., X, Reptiles, t. xxiv, f.

Habitat.-In "United States" circa oram maris Mexicani, "South Carolina," et Arkansas.

\section{Crotalus Edwardsii.}

1853. Crotalophorus Edwardsii : BATRD et GiraRd, Catal., p. 15.

1854. " " " " " "

1859. " " " BArnd, U. S. and Mex. Bannd. Surv., p. 15.

Icones.-U. S. Pac. R. R. Expl. Rept., X, Reptiles, tab. xxiv, fig. 8. U. S. and Mex. Bound. Surv., t. v, f. 1.

Habitat.-In Texas.

\section{Crotalus tergeminus.}

1823.

1824.

1827.

1827.

1854.

1830.

1842.

1849 .

1856.

1842.

1849 .

1853.

1854.

1850.

1830.

Crotalus tergeminus : SAY, Long's Exped. Rocky Mts., I, 499.

$\begin{array}{lll}" & \text { " } & \text { Boie, Isis, p. } 270 . \\ " & \text { Harlan, Journ. Acad. Nat. Sci., V, } 372 . \\ " & \text { " } & \text { Bole, Isis, p. 563. } \\ & \text { " } & \text { Duméril, Bibron, VII, 1479. }\end{array}$

Crotalophorus tergeminus: Gray, Syuops. Rept., p. 78.

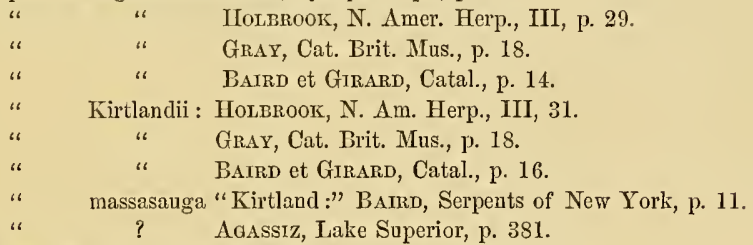

Caudisona tergeminus: WAGLen, Nat. Syst. Amph., p. 176.

Icones.-Holbr. N. Am. Herp., III, f. 5, 6, Agassiz, Lake Superior, t. vi, f. S. Baird, Serp. New York, t. i, f. 2. Ibid. U. S. Pac. R. R. Expl. Rep., X, Rept., t. xxv, figs. 9, 11.

Habitat.-In "Indian Territory," Nebraska, usque ad Michigan et Ohio. 
III.

The descriptions of the following supposed species do not coincide with those of any species known to modern naturalists:-

Crotalus dryinus: Linnæus, Syst. Nat., I, 372 (1766). Quoted by Gmelin, Lacépède, Bonnaterre, Daudin, Merrem.

Crotalus horridus: Boddaerv, Nova Acta, VII, 16 (1783). Quoted by Gmelin, Le Conte.

The following names refer to species which I cannot identify with, or distinguish from known species either on account of want of specimens, imperfect descriptions, or references which cannot be unravelled.

Crotalus adamanteus: JAN, Rer. et Mag. Zool., 1859, p. 153.

Crotalus atricaudatus: MerReM, Syst. Amphib., 157.

Crotalus cumanensis: НuмвоцDт, Humb. et Bonpl. Recueil d'Observ., p. 6 (1833).

Crotalus durissus: BoDdaent, l. c. Merrem, I. c.

" " var. a Girelin, Syst. Nat., I, 1081 (1788).

Crotalus exalbidus: BoDdaERT, l. c.

Crotalus horridus: JAN, Rev. et Mag. Zool., 1859, 153.

Crotalus rhombifer: MerRen, l. c.

Caudisona orientalis: Laurentr, Synops., p. 94 (1768).=Crotalus strepitans Daud., V, 318 (1802).

"Said to be Boa canina." Gray, Synopsis Rept., p. 78.

Caudisona Gronovii: Laurentr, l. c. Perhaps Lachesis mutus, Daud.

Uropsophus triseriatus: Waglen, Nat. Syst. Amph., p. 176 (1830). Gray, Cat. Brit. Mus., p. 116.

Perhaps Caudisona lucifer. Prof. Jan. Iconogr. deser. Ophid., p. 29, places this species in Crotalus (Crotalophorus)!

Crotalophorus consors: Batrd and Girard, l. c. Baird, U. S. and Mex. Bound. Surv. Reptiles, p. 15. Ibid. U. S. Pac. R. I. Expl. Rep., X, Repl., pl. xxiv, f. 7.

The following supposed species, according to Boie, Isis, 1827, 562, is Tropidonotus quincunciatus with a crepitaculum of a Rattlesnake attached:-

Crotalus tessellatus: Hermann, Observat. Zool., p. 271 (1804).

The following species are not Rattlesnakes:-

Crotalus mutus: Linneus, I. c. p. 373 et Gmelin, is Lachesis mutus, Dand.

Crotalus piscivorus: LAcÉPÈDE, l. c. p. $424(1789)=$ C. aquaticus, Bonuat. l. c. p. 3 (1790), is Ancistrodon piscivorus, nobis. 


\section{APPENDIX B.}

\section{BIBLIOGRAPHY. ${ }^{1}$}

Abbatius (Baldus Avgelus). De Admirabili Viperæ natura et de mirificis ejus facultatibus liber. Ragusæ, 1587-91, in 4 . Anatomical description principally of the organs of Generation. [S.]

Acrell (JoH. Gust.). De morsura Serpentum. (Limnæi Amœnit acad., VI., 97. 1762, in 8.) An excellent dissertation on the bite of venomous Serpents. [S.]

Albertus Magnus. Opus animalium. In fol. 1651 .

Reports certain erroneous opinions as to the viper, and denies its coluabitation with the Lamprey. [S.]

Aldovrandus (Ulysses). Serpentum et Draconum historia, libr. 11. Francforti, in fol. 1640 .

Gives descriptions of the viper, etc., with figures. [S.]

Alessandrin I. Ricerche sulle glandoli salivali dei Serpenti a denti solcati o veleniferi confrontate con quelle proprie delle specie non velenate di Schlegel. (Journ. polygr. de Vẻrone, fasc. XXVIII, 47, 1832.) [S.]

Alexander. Medica commentaria. Edinburgh,

II, decad. IV, B., 45. [S.]

On the employment of L'eau de Luce as a remedy. [S.]

Alexander, J. B. Alcohol as an antidote. St. Louis Med. and Surg. Journal, XIII, 116, 1855.

A Los, (Јон.) Dissertatio de Viperis. In 4, 1664. Treats of medicines made from the flesh of the viper. [S.]

Amatus Lustanus. Curationum medicarum centuriæ. Cent. I. cur. I, fol. 20. Cent. III, cur. 14, fol. 230. [S.]
ANDRIEUx. Coup d'œil sur les accidents causés par la morsure des serpents venimenx, ènumération des différents moyens employés pour les combattre. Journ. des Conn. Méd. et Pharm., 181. 1849.

On the action of Mikania Guaco in snake bites. [S.]

Anes. Art de sucer les playes sans se servir de la bouche d'un homme. Amsterdam, 1707. [S.]

Angelini (Bernardino). Del morasso a Vipera chersea rinvenuto sul territorio Veronese. (Bibl. Ital., VII, 451.) [S.]

Anselmier (VICror). Dissertation sur les iudications du cautère actuel dans les plaies virulentes et envenimées. (Théses de Paris, No. CXXIX), 1854.

Reports two successful eases of persons bitten by vipers; the actual cautery the best mode of local treatment. [S.]

Aretaus. De cansis et signis acutorum morborum. (El. Haller), libr. II, cap. II, 100, in 8,1772 .

Speaks of the effect of the bite of the Dipsade and of the employment of theriac as a remedy for the bite of the viper (136). [S.]

Atchison, T. A. Alcohol as an antidote to the venom of the Crotalus. Southern Journal of the Med. and Phys. Sciences, I, p. 47, 1853.

Atwell (Joseru). Observations concerning a man and a woman bitten by a viper. (Philos. Trans. No. CCCCLXIV, 275, 1736.) [S.]

Reports good results from the employment of oil in viper bites. [S. 1

Aunoux. Observations commnniquées à M. Ma-

I As a general rule, the authorities upon the natural history of serpents are not included in the list. For those especially concerning the Rattlesnake, see Mr. Cope's "Genera and Species," p. 119. The works given by Soubeiran in his excellent Bibliography are marked in mine with the letter [S]. 
sars de Cazeles. (Jour. de Mèd., XXXII, 442.)

Reports a case of viper bite treated by applications of the bruised head of the viper, together with theriac and a vinous decoction of the flesh of the viper and of the bark of the ash tree. Recovery in threo days. [S.]

Auzoux (L. I. I.). Dissertation sur la Vipère. (Thèses de Paris, No. CLXII), 1822.

This work gives a general statement of knowledge relative to the viper. [S.]

Avicenne. Canon Medicinæ ex Gerardi Cremonensis versione. In fol. II, libr. IV, fen. 6 , tract 3 , Venetiis, 1608 . De regimine morsionis universali. Et de effngatione venenosorum et de curatione mordicationis Serpentum et speciebus eornm.

Treats of the venom of the viper aud of the treatment of suake-bites. [S.]

Bajon. Mémoire pour servir à l'histoire de Cayenne. Maladies de Cayenne, I, 352-355.

States that the juice of the Tayove (Caladium sagittrfolium) and sugar, are useful in snakebites. [S.]

Baricelit. Falsum viperam in coitu masculnm occidere, ipsumque a catulis in partu necari. Itortulus genialis Bononix, in 12mo, 1617 . [S.]

BaRsTOW. Account of the singular effects from the bite of a Rattlesnake. Philadelphia Med. Museum, III, 61.

The millk of a woman bitten by a rattlesuake, said to have cansed the death of her child, as well as of two puppies and three lambs employed to draw off the milk.

Barton (B. S.). On the supposed powers of Fascination in serpents. [0.] Pamphlet, Phila., 1814. Also, the same in American Phil. Trans., III, 1793. Also, General Observations on the Rattlesnake. Am. Phil. Trans., IV, 1799.

Bartrayr. On the teeth of the Crotalus. Engl. Phil. Trans., abrd. IX, 60, 1793.

Badderon, Brice. Pharmocopée diusée en deux linres, p. 360 , in 4, Lion, 1640. [S.]

Badguter (De Saint Ambroix). Observation d'une morsure de vipère. Journ. de Sci. Méd., XXVIII, 377, IS27. [S.]

Badregard. Anc. Journ. de Méd., VI, 233, 1757.

A case of viper bite treated successfully with the juice of ash leaves, and poultices of the same, as local treatment. [S.]
BEck. Mredieal Jurisprudence, II, 537.

BÉrard. Gazette de Santé, No. 16, 1788.

Advises frictions with olive oil in viper bites. [S.]

Bernard (Cladode). Leçons sur les effets des substances toxiques et médicamenteuses, Paris, ] 857 , p. 388 et seq.

Brief account of viper venom. Experiments to prove the power of the viper to destroy its own kind.

Berninck $(\Lambda$.$) . Dissertatio serpentem sistens$ Præs. S. F. Freuzel. In 4to. Wittebergæe, 1665. [S.]

Bertin (J. E.). Ergo specificum viperæ morsus antidotum alcali volatile. Paris, 149 , in 4 . IIaller, dissert., p. vi, No. 218. [S.]

Best (J. Cr.). Dissertation sur la morsure de la vipère fer-de-lance. Thèses de Paris, No. $106,1823$.

Treats of the cause of death, and thinks that fright has a great deal to do with the production and intensity of the symptoms. [S.]

Blainvilite. Observations on Crotalus Poisoning. Bnll. de la Sociète Philomatique, Paris, 1825, p. 210. [S.]

BoAG (W.). General observations on the bites of E. Indian serpents. Asiatic Researehes, VI, 103, 1801.

Bochart (Samuer). Hierozoicon, sive de animalibus scripture recensuit snis notis, L. F. C. Rosenmuller, in 4, III, pars ii, lib. iii, 1793-96.

Gives the etymology of the word viper, proves that it was known to the Hebrews, and cites many oriental autlorities, \&c., which make mention of the auimal in questiou.

Bonaparte (Lucien). Gaz. Tosc. delle sc. medicofis, p. 169, 1813.

Analysis of viper venom, the only one on record.

Bosc (L. A. G). Vipère Nov. Dict. d'histoire Nat. Déterville, XXXVI, 82, 1819.

Natural history of the viper, with discussions as to its habits. [S.]

Boué (J. F.). Dissertation sur la morsure de la vipère. Thèses de Paris, No. 69, 1823.

Advances cases to prove the gravity of the malady of the viper bite. [S]

Bourdelot (Pierre Michon). Recherches et observation sur les vipères. Paris, in $12 \mathrm{mo}$, also in English, Philos. Trans., VI, 3013, 1671. [S.]

Boyle (Robert). De utilitate philosophiæ expe- 
rimentalis. Pars II, Exercitat, II, par 34.| Lindaviæ, 1 in 4 to, 1692.

Reports cures from using a hot iron, which was brought as near to the wound as it could be borne by the patient. [S.]

Brainard (David, M.D.). On the nature and cure of the bite of serpents, and the wonnds of poisoned arrows. Smithsonian Reports, 1854, p. 123.

Describes woorara, and considers that it owes its poisoning power to a venom. Advocates the nse of iodine as an antidote to be injected into and about the track of the wounds made by serpents or by poisoned arrows.

Bratnard (DAVID). Essay on a new method of treating serpent bites and other poisoned wonnds. 8ro. pamphlet, Chicago, 1854.

Much the same as the last paper (vide supra), with new observations on the phenomena of crotalophorous poisoning.

Brainard and Green. Comptes Rendus de l'Académie des Sciences, p. \$11, 1853.

Contains details of observations on the use of iodine in woorara poisoning and in snake-bites.

Breintnal (C.). Engl. Philosophical Trans. abrd., X, 229 .

Reports his own case of Crotalus bite.

Brickezl. New York Medical Repository, VIII, 441, 1805.

Gives bis own experiments upon the reaction of Rattlesnake venom.

Brogiano (Domenico). De Veneno Animantium naturali et adquisito, p. 38,4 to.

An extremely interesting dissertation on the effects of viper venom upon the economy of man.

Brotonne (DE). Ergo specificum viperæ morsus autidotum alcali volatile. Paris, 1778. [S.]

Bulletin de Thérapentique, XXXI, 70, 1846.

Case of viper bite successfully treated by ammonia. [S.]

Burnetr (W. I.). Proc. Boston Nat. Hist. Society, IV, $311,323$.

On the succession of the fangs in Crotalus, describes his mode of procuring the venom by. chloroforming the suake and then pressing on the glands. Also observation of the effect produced by mingling the renom with blood.

Burton (TVILLIAM). Letter concerning the Viper Catchers, and their Remedy for the Bite of a Viper. (Engl. Phil. Trans., No. 443, 1734.) Reports experiments tried on a man to show the utility of olive oil in viper bites. [S.]

Camerards (Elias). Dissertationes Epistolico physico medicæ. Tubingen, 1712, m. 2. He seeks to prove that the viper is not equally venomous in all localities, and cites facts to support this opinion. [S.]
Cantor. London Zoological Trans., II, 304.

On Pelagic snakes. Action of their venom on the tortoise, ete.

Cardose. Des effets d'une piquire faite par la dent d'nne vipcre morte. Annales de la Soc. de Méd. pratique de Montpellier, serie II, I, 179. [S.]

Carminati (B.). Saggi di osservazioni sui veneno della vipera. Opusc. scelti, I, 58, 1778. [S.]

Catesby. Natural History of Carolina; also cited by Mortimer, Engl. Phil. Trans., 1738, p. 8. Advises the actual eautery as a remedy in snake-bites. Early natural history of the Rattlesnake, etc.

Cauro. Exposition du moyen curatif des accidents produits par' la morsure de l'Arraignée 13 guttata ou Theridion mal mignatte du départment de la Corse, suivi de quelques réflexions sur le mode d'agir de son renin et de celui de la vipère, in 4to. Thèses de Paris, No. 128, 1833.

Proposes a secret remedy, camplior and opium, which he describes as useful in spider bites, and whicb, therefore, he presumes wonld be valuable in those of the viper. [S.]

Caventou. Relation de quelques nouvelles expériences faites par M. Desanlx, arec le venin de la vipère. Archives Général de Médecine, série I, XIII, 518. [S.]

CaYal. Rage communiquéc par la morsure d'un chien, essais de traitement par l'arsenic, l'hydrogène sulphuré et par le renin de la vipère, mort 70 heures après l'invasion des premiers symptômes; nécropsie. Rérue Méd., III, 387, 1831. [S.]

Cazentre (de Bordeanx). Notice sur les propriétés thérapentiques de cédron. (Journ. des Conn. Médico-Chirurg., 1850.)

States that the cedron is an infallible remedy in serpent bites. [S.]

Celsus. De re medica; de medicamentis, lib. V, cap. XIVII, \& 3, Lyon, 1856 , in 8.

Prefers the suction of poisoned wounds to the ligature, to cups, or to incisions. [S.]

Chabert (Jean-Louis). Du Huaco et de ses vertus médieinales in 8, 1853.

Reports marvellous effects of mikania guaco in serpent bites, even of the most terrible kind. [S.]

Charas (Moïse). Nouvelles expériences sur la vipère on l'un verra vne description exacte de tovtes ses parties, la sovrce de son venin; ses divers effets et les remèdes exquis que les artistes peuvent tirer de la vipère tant ponr la guérison de ses molsures que pour celle de 
plusieurs antres maladies. Paris, in 8, 1669. [S.]

Charas (Mö̈se). Srite des notrelles expériences -svr la vipère, in $8,1772-90$. [S.]

Chevaluier (Тн.). Lettre sur l'efficacité de l'arsenic sur la morsure des serpents. Sedillot Recueil périod de la Soc. de Méd. de Paris. III, 409. [S.]

Christison (R.). Treatise on Poisons. 1st Am. from 4th Ediu. ed., Phila. 1845, p. 484.

Clarke (R. W.). Attempt to eure Elephantiasis and Leprosy by the Bite of a Rattlesnake. Lancet, I, 1838 and 1839, 443.

Singular case resulting fatally.

Col de Villars (Élie). Conrs de chirurgie dicté anx écoles de médecine de Paris, III. Traité des plaies, ch. vi, p. $177, \mathbf{3} 746$.

Gives a short description of the symptoms and treatment of viper bites, insists on the necessity of internal treatment, owing to the fact that a part of the venom always enters the blood. [S.]

Colbatch (J.). Cure of the Bite of a Viper. London, 1698, 8vo. [S.]

Collenutius (Pandolph). Libellus de Vipera Venet, 1506. [S.]

Cooper (Samuel). Surgical Dictionary, 1828, p. 274.

Describes the viper, his teeth and his bite, and the mode of treatment. [S.]

Coste. Sur les effets de l'ean de Lnce dans la morsure de la vipère. (Journ. de Méd., XXXIII, 524, 1770.)

Reports a cure by the xise of fomentations of camphorated alcohol and theriac, followed by scarifications, and the application of eau de Luce on the wound. [S.]

Coster. Prophylactique du venin de la vipère. (Clin. des Hôpit., III, No. 43, 1828.) [S.]

Crüger (Daniel). De morsu Viperarum. (Eph. Germ. Acad. Nat. Cur., IV, obs. LXV, 143, I686.)

Treatment of a case of viper bite according to ancient methods, attributes great value to the sperma ranarum. [S.]

Davy (John). On Suake Stones. Asiatic Researches, XIII, 317, in 4 to.

Gives analyses of the stones whose application to the wound is supposed in the east to effect a cure of snake-bites.

DAVy (JoHN). On the poison of three of the poisonous snakes of Ceylon. Davy's Physiological and Anatomical Researches, I. 113, London, 1839; and also the author's account of the interior of Ceylon, London, 1821.

A highly valuable and interesting detail of experiments on venom poisoning.

Decerrs (J. P. E.). Essai sur la morsure des serpents venimeux de la France. Thèses de Paris, No. 27, 1807.

Coutains nothing novel except the opinion that the viper bite is not mortal in man, even when no treatment has been employed. [S.]

Delacoux. Amputation complète de la jambe ganche produite par une ligature circulaire permanente de ce membre. Acad. de Méd. Séances des 30 Juillet et 20 Aon̂t, 1833. Arch. Gén. de Méd., 2e sér. II, 587 et 592. [S.]

The ligature of the limb was used after a viper bite; no absorption of renom took place, but the leg became gangrenous, and was finally amputated. A case in which the remedy was probably worse than the disease. [S.]

Defpech. Précis élémentaire des maladies répatées chirurgicales, II, 135 et 136, in 8vo., 1815. [S.]

Thinks that the viper bite is rarely dangerous. [S.]

Devathis. Moyeu de guérir l'hydrophobie. Anc. Journ. de Mléd., LXI, 365, Mém. de la Soc. de Méd., p. 210, 1783.

This author treated a dog supposed to be mad by allowing him to be bitten numerous times by a viper. The dog died in four hours. The author supposes that if the hites had been fewer the dog would have been cured; and infers that the venom is a specific against hydrophobic rage! [S.]

Demeure. Journ. de la Soc. Gall. de Méd. homœopathique, V, No. 6, 397, Oct. 1854.

Gives the case of a person bitteu by a viper. The symptoms seem to have been of an unusual nature. The cure is attributed to the fact that some of the venom from the bite in the thumb having been absorbed in homcepathic amount, the patient was thus protected from the effects of the remaining poison. [S.]

Delille. Indication de Thérapentiqune directe des morsures les plus vénénenses. Journ. de Physiologie Exp. et Pathol., VII, 113.

Desbors (de Rochefort). Cours èlementaire de Matière Médicale, II, 280, 1789.

Thinks that the effects of the venom of the viper are due to the animal heing enraged, and that it acts on the nervous system, producing a tendency to putrefaction. Advises sudorifies, ammonia, and eau de Luce.

Desmoulins. Mémoires sur le système nerveux et 
l'appareil lacrymal des serpents à sonnettes, de Trigonocephales et de quelques autres serpents. Journ. de Phys., IV, 264, 1824.

Treats of the venom gland of serpents, and desires to prove that it is only an adjunct of the lachrymal apparatus. [S.]

De Vesey (Louis) Xantus. Cases._Experiments with Bibron's Autidote. Am. Jomrn. of the Med. Sci., No. LXX, p. 375, 185 s.

Dezemmeris. Dict. de Médecine, XXX, 822. Contains nothing new. Gives an incomplete bibliography.

Drake. On the use of ammonia in eases of serpent bites. West. Journ. Med. \& Phys. Sci., I, 60.

DUвÉBat. Mort spontauée produite par la morsure d'une seule vipère. Bull. de Thér., $\mathbf{X}$, $198,1836$.

Case of a woman analogous to that reported by Dr. Lngeal. [S.]

DUDLEY (PADL). Account of the Rattlesnake. Phil. Trans. abrd., VII, 409-410, 1722.

On the rattles, on fascination, etc.

Duatès (Alfred). Sur les Vipères Aspis et Pelias. Mèm. de la Soc. de Biologie, II, 115. Gaz. Méd., p. 270, 1850.

Corrects certain errors in regard to the French vipers ; gives details of their habits, etc. [S.]

Duats (Alfred). Note sur le redressement des crochets dans les Thanatopkides. Ann, des Sc. Nat., 3e seir. XVII, 57, au pl., 1852.

Gives a new explanation of the mechanism concerned in elevating the fangs. [S.]

Dumértl (Constant) et Bibron (E.). Erpétologie Générale, VI et VII, 1844. At VII, part II, 1399, Natural History and Anatomy of Serpents; reports case of M. Duméril, bitten by a viper in $\mathbf{1 8 5 1 .}$

Dumíril (Adguste). Note historique sur la ménagerie des reptiles du muséum. Mém. du Musénm, VII, 273.

Contains a large amount of information on the habits of snakes, their food, change of skin, etc.

Duнолт. Vide Aug. Duméril, p. 276.

On the use of cedron as an antidote and prophylactic.

Duncan. On E. Indian Snake-Bites, strychnia as a remedy in. Lancet, I, 507 .

Dusourd. Effets remarquables de l'huile d'olive employée à l'intérieur et à l'extérieur dans les cas de morsure de vipère. Bull. de Therapent., XXVII, 489, 1849.

Approves of the internal use of olive oil in snake-bites. [S.]
Dutertre (Jean Baptiste). Hist. Générale des Antilles habitées par les Français, in 4to, 1667,1671 . [S.]

Duvernor (G. L.). Caractères anatomiques pour distinguer les serpents venimeux. Aun. des Sci. Nat., XXVI, 113, 1830, XXX, 5, 1832.

Gives, amongst numerous other matters, details of the anatomy of the head of the viper; also accounts of experiments upon the poisoning power of venom long kept in alcohol.

Énaux et Chaussier. Méthode de traiter les morsures des animanx enragés et de la vipère, in $12 \mathrm{mo}$, p. 101, 1785 .

Advises cauterization. [S.]

Encyclopædia. See article Serpents, iu the British, Edinburgh, and Rees' Encyclop.

Erndte (Christ. Henr.). Iter Anglicauum et Batanum, 1714, in 8vo. [S.]

Ettmulater (M.). Dissertation de Morsu Viperæ, præs. S. R. Sulzberger, Leipzig, 1665, 1685, in 4 to. [S.]

Fonḱré. Médecine Légale, IV, 11 et 12.

Cites many cases observed in the hospital at Martinique, which died from the bites of the vipers of the marshes of Bos.

Fontana (FÉtix). Ricerche filosofiche sopra il veleno della vipera, in 4to, II, Lucca, 1767. Translated into French in 1781,4 to, II, and into Euglish, by Skinner, in 1787, II, 8vo.

This latter is the edition referred to in the foregoing essay.

Foucher (d'Opsonville). Fssai philosophique sur les mœurs de divers animaux étrangers, 1783, p. 26 , in 8 ro. [S.]

Franzues (Wotfana). Historia animalium iu qua plerumque animalium præcipuæ proprietates in gratiam studiosorum, theologiæ

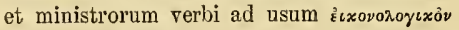
breviter accomodantur, in 18vo, Amster., 1665 , pars $I V$, cap. iii, de vipera.

Dwells on the reproduction of the viper, on the consequences of its bite, and on the remedies; but especially on the viper, theologically considered. [S.]

Fretskarn (Paulens). Dissertatio de veneno Viperarum, in 8vo, 1782. [S.]

Gatanepain. Dissertation sur les effets du venin de la vipère. Thèses de Paris, No. 24, 1807.

Contains nothing novel. [S.]

GaLE (B.). Crotalus bite cured by salt. Engl. Phil. Trans. abrd., XII, 221, 1765. 
GaLen. Opera, XII, Ed. Kuhu, Lipsiæ, 1826, pp. 311-316.

Speaks of various venomous serpents, and of the use of viper flesh in elephantiasis. [S.]

Gaspard (B.). Obserratious sir la morsure de la vipère. Journ. de Pbysiol. Expt. et Pathol. de Magendie, I, 248, 1831.

Reports a case of a woman who was cured of a tertian by the bite of a viper.

Gaspard (B.). On putrefactive poisoning. Journ. de Phys. Exp. et Pathol., VII, 7 et seq.

Gazette Salutaire de Bouillon, 1787. Hnfeland Nenes Annalen, I, 405.

of the use of ammonia locally and interiorly as an antidote. [S.]

Gazette de Santé du 5 Novembre, 1822.

States that dogs may be saved from the effects of viper bite by the application of a cataplasm of the fresh stems of the helleborus niger. [S.]

Grofrroy et Humadid. Mémoire dans lequel on examine si l'hnile d'olive est un spécifique contre la morsure des vipères. Mém. de l'Acad. des Sci., 1737, p. 183.

Concludes that olive oil is not a remedy in these cases, or at least that it is a doubtful one. [S.]

Gerdy (P. N.). Traité des pausenrents proprement dits, 2e édit. p. 152, 1839.

Case of viper bite treated by ammonia. Plan of treatment. [S.]

Giadorod (TIncent). Observations médico-pratiques sur l'efficacité de l'Inula squarrosa contre la morsure de la vipère. Ann. Univ. de Mèdic., 1837; Gaz. Médic., p. 424, 1837. [S.]

Gimman. Soda as an antidote in the bite of the Crotalus. Southern Med. and Surg. Journ., N. S., X, 706.

Gruman (J.). Action of Crotalus Venom on Plants. St. Louis Med. and Surg. Journ., XII, 25, 1854.

Contains, also, notes on other minor matters connected with serpents.

Gockel (Eberhr). De peste et venenis, in 8vo, 1669 , cap. xiv, p. m. 59.

Goesling (I. A.) De spissitudine sanguinis multis in morbis temere accnsata. Gutt., 1747 .

Affirms that the popular opinion as to viper venom greatly thickening the blood is not correct.

Goodyear (AARON). Death from snake-bite at Aleppo. Engl. Phil. 'Trans. abrd., II, 816817.
GoupIs. Sur la ripère de Fontaineblean et sur les effets de sa morsure. Bull. de la Soc. de la Fac. de Mréd. Cah., 5 Mai, 1809. [S.]

GraY (E. W.). Observations on the amphibia of Linnæus, and especially on the means of distinguishing renomons serpents from those which are not so. Engl. Phil. Trans. at large, LXXLX, 21, 1789.

Gray (J. B.). Observations on Vipers. Proc. Zool, Soc., 1834, p. 101.

Gray (J. B.). Teuomous Water Suakes. Proc. Zool. Soc., 1837, p. 135.

Grevin. Deux liures de uenins auxquels il est complétement discouru des Bestes venimenses, thériaques, poisons et contre poisons. In 4to, Auvers, 1618, chap. x, p. 72.

Translations from Nicander in regard to the bite of the viper, etc. [S.]

Griny (J.F.C.). Historia symptomatum a morsu Aspidis productorum et medelæ. Nora Act. Acad. Cur., III, 64, 1767. [S.]

Grive (Lovis DE LA). Antiparalèlle des Vipères romaines et berbes candiotes. Lion, 1632 p. 77. [S.]

Grukire (J. B. Victor). Des renius et des animaux venimenx. Thèses de Paris, No. 9, 1854. [S.]

Gives an analysis of the memoir of Prince Lueien Bonaparte.

Gubler ( $A D$.). Némoire sur l'ictère qui accompagne quelquefois les éruptions syphilitiques précoces. Mém. de la Soc. de Biol., V, 263, 1853.

Contains incidental remarks on the icterus consecutive to the bites of serpents.

Gulden (KLee). Bald. Timoens A. Opera Libr. vii, cas. XVIII, p. 323; libr. v. Epist. XVI, p. m. 824 , in 4 to.

Cases of viper bite. [S.]

Gurisch (MartiN). Consideratio plysico-medicoforensis de saliva humana qua ejus natura et usus insimulque morsus brutorum et hominis, rabies et hydrophobia, demorsurum delecta et defensio, etc. Lipsiæ, 1729, p. 181, de morsn vipèrarum. [S.]

Guyon. Leçons diverses, II, 527.

Describes the treatment of the bite of the viper by saliva. [S.]

Hafenreferrus (Sam.). De cutis affectibus, in 8ro.

Tubingen, 1630, libr. iii, cap. viii, p. 461.

Relates certain facts in regard to the bite of the viper. [S.]

HaLL. Expts. on Crotalus renom. Engl. Phil. Trans. abrd., VII, 412, 1727. 
Hammond (W. A.). On the use of Bibron's Antidote. Am. Journ. of the Med. Sci., No. LXIX, p. 94, 1858.

Hanneuand (Jos. Lod.). Dissert. de viperæ morsu Miscell. Nat. Cur. Dec. II, An. VIII, p. 203, 1689. [S.]

Haxyover, Nützliche Sammlungen, p. 1365, 1756. Adrocates the use of olive oil in viper bites. [S.]

HARder (J. J.). De viperarum morsu dissertatio. Ept. Germ. Acad. Nat. Cur. Dec. II, An. VI, p. 229, 1685.

Relates experiments made to test the truth of Redis' statements. [S.]

Harlan (R.). Medical and Physical Researches, p. 490 , Phila., 1835.

Experiments with Crotalus on animals, antidotes, etc.

Harlan (R.). A case of Crotalus bite in man. The North Am. Med. and Surg. Journ., Phila., 1831, XI, 227.

Interesting case-recovery.

Harris. Asclepias as an antidote in venom poisoning. Sonth. Med. and Surg. Journ., N. S., XI, 414.

Hartilann (G. L.). Précis sur l'histoire naturelle des Vipera Berus, Coluber natrix et Anguis Fragilis, lu à la Soc. d'hist. nat. de SaintGall., 1819. Neue Alpina, I, 169.

Advises as treatment suction, the ligature, and cauterization.

Heerey (O. C.). Use of Bibron's Antidote. Am. Journ. Med. Sci., 1859, No. LXXVI, p. 574 .

Reports a case of its use.

Henjont (VAN). Ontus Medicinæ. Amsterdam, ELzevir, 1548, in 4, p. 17 \%.

Disputes the opinion that the virulence of viper venom is due to the animal being angry. [S.]

Hexpriez. De absorptione et secretione venenosa, 1822. [S.]

Hering (Constantine). The Effects of Snake Poison. Allentown, Pa., and Leipzig, 8ro, 1837. Translated into English in 1844, in the Brit. Quart. Journ. of Homœopathy. A collection of wild absurdities in regard to the analysis of venom, and to its use in hydrophobia, etc.

Herodotes. Histoire, Libr. III, cap. 109.

Speaks of the viper and its mode of propagating. [S.]

Herran. Graine du Cédron employée dans l'Amérique tropicale comme remède contre la mor- sure des serpents. Journ. de Pharna., 3e série, XYIII, 296, 1850.

Thinks the seed of the Simaba Cedron an infallible remedy. [S.]

Hodierna (JoH. BAPT.). De dente viperæ virulento epistola, 1651. [S.]

Hofriann (Fried.). Disputatio de saliva et ejus usu medico, in 4to, 1678, cap. $V$, p. 18. [S.]

Howe (SrR E.). Case of a man bitten by a Crotalus, with additional cases of E. Indian serpent bites. Engl. Phil. Trans. at large, 1810 , p. 75.

Horner (Wu.). Death from Crotalus bite-post mortem examination. Am. Jouru. of Med. Sci, VIII, 397, 1831.

An iuteresting case.

Hubble. Prenanthes Altissima as an antidote. N. Am. Med. and Surg. Journ., I, 447, 1826, from N. Y. Mled. and Phys. Journ., Jan. 1826 .

IRELAND (J.P.). Treatment of suake-bites, cases, etc. Med.-Chir. Trans., II, 394.

East Indian snakes-arsenic as a remedy.

Jagerschmids. De morb. Serpentarum. Miscell. Nat. Curioso Acad. Dec. II, An. 2, p. $2 \pm 0$.

Jeter (A. F.). Poisoued wounds, their distinctive features, and classification, with remarks on the classes; and a special treatise on the nature and treatment of the wounds resulting from the bites of venomous reptiles. Being a report of a committee to the Med. Assoc. of Missouri, 1854.

Contains many points of interest, and a number of experiments.

Joulard. Comptes Rendus de l'Acad. des Sci., XXXI, 1 1 1, 150, vide Herran. [S.]

Journal Encyclopédique, VI, 297, 1772.

External and internal use of olive oil in snake bites. [S.]

Journal de Méd. pratique de Hufeland, Analysé dans. Bibl. Médic., LXXIT, 125, 1821. [S.]

Reports two cases of viper bite, illustrating the proper aud the improper mode of treatment.

Jussieu (Bernard DE). Sur les effets de l'eau de Luce contre la morsure des vipères. Mém. de l'Acad. Roy. des Sci., p. 54, 1747.

Case of a student bitten in the hand. Cure. [S.]

Kalm. Travels in America (Hist. Candisonæ). $1753, \mathrm{II}, 490$. 
Ḱrrker. Éprenve de la pierre de serpent faites ì Vienne par ordre de. S. M. I. Journ. litt. de Nazari, 1668 ; Collect. Academ. part. ètr., VII.

Reports favorable results. [S.]

KNox. On the mode of growth, reproduction aud structure of the poison fangs in serpents. Memoirs of the TVernerian Nat. Hist. Soc., $V$, part ii., $411,1826, \mathrm{pl}$.

Koster. Toyage au Brésil, II, 247.

Permanent effeets of Crotalus bite renewed at the full and wane of the moon.

Krozenstein. Dissertatio de oleorum ex vegetabilibus expressorum salutariusu medico. Hafn, 1773. [S.]

Kuтzchus (J. C.). Dissertatio inanguralis medica de viperarum usu medico. Præs. J. Juncker Halæ., Magd. 1744. [S.]

Lantier (ÉTienne). Dissertation sur la morsnre de la vipère et celle des animaux euragés. Thèses de Strasbourg, 19 Fruct. An. XI, 1803.

An ineomplete abridgment of Fontana's views. Contains no novelty. [S.]

LANGont. De renenis, cap. 33 et 61,1509 . [S.]

LAPRE. Symptômes d'une morsure de Vipère décrits par un médecin qui a failli en être victime. Union. Med., Sept. 1850. [S.]

Ladrentu (J. N.). Synopsis Reptilium emendata, cnm experimentatis circa venena et antidota Serpentum Anstriacorum. Viennæ, in 8vo. 1768.

LE Brun. Observations sur l'nsage des alcalis volatils contre la morsure de la Vipére, qui teudent à prouver que tous les alealis volatils tirés des animanx peuvent, ainsi que l'eau de Lnce, guérir les personnes mordues par les Vipères. Journ. de Méd., XVIII, $150,1763$.

Four cases of viper bite terminating favorably-three of the number being infants. [S.]

LE Contr (J.). On the Venomous Selpents of Georgia. Southern Med. and Surg. Journ., IX, 1853,645 .

A very interesting collection of observations, new and old, on the natural history, habits, and poison of the Georgia serpents.

Lemery (Nicolas). Traité nniversel des drogues simple, p. 812 in 4 to., 1598.

Gives the symptoms of the bite, the mode in which the venom is supposed to act, and the treatment.

Lumperant (G. Paolo). Relazione di nna Vipera cle ha partorito $\mathrm{i}$ viperini per bocea-(in Vallisneri, op. Med. fis., III, 1733.) [S.]

Lindelius (Jor. II.). Dissertatio de Vipera ejusque morsu, in 4to., 1690.

Attributes the action of the venom to the anger of the animal, and denies that there is any difference in danger between the bite of the male and female viper. [S.]

Linnaus (CArouts). Coluber Smolandiæ. Act. Holm, Coll. Acad. part étr., XI, 91, 1772. Insists upon the dangerous eharncter of the bite of this serpent, which is the Vipera Chersea. [S.]

Lugeor. La morsure d'une seule Vipère peut entrainer la mort. Bull. de Thèr., XXV, $211,1766$.

Mlangili (Gracomo). Sul. Veleno della Vipera. Paris, 1809. Bibl. Med., XXXI, 428, 1811.

Shows that the young viper may be killed by venom. States that the viper camnot raise its fangs during the first few days of its existence. Of the effects of ammonia given internally for the cure of viper bites.

Mangiti (Giacomo). Discours sur le renin de la Vipère. Giorn. di fisica chemica, IX, 458, 1817. Aun. de Chimie et de Physique, IV, 159.

Contains experiments to show that the venom of the viper is harmless when taken internally.

Manzini (Nicolas B. L.). Histoire de l'inoculation Préservative de la Fièvre Janne. Paris, Svo. 1858.

The active element of the substanee used in Cuba supposed to be the venom of a Crotalus. The description of the phenomena of the inoculation are very eurious. The likeness between yellow fever and the Crotalus malady is remarked upon at length; but the essential differences are not suffieiently noted.

Martin. Recueil périodique d'observations de Médecine, IT, 412, 1756. [S.]

Masars de Caseles. Vide Audoux. [S.]

Mayer (C. A.). Exercitatio historico-medica de Viperarum usu medico. Altdorf, 1727. [S.] Mayerne (Sir Treo. DE). Engl. Phil. Tr. abid., II, $817-818$.

Marrubium a remedy in viper bite.

Mayrant (WII.). Cases of Rattlesnake bites. Alcoholic stimulants as remedies. Amer. Med. Recorder, VI, 1823, 619.

Mead (Richard). Mechanical account of Poisons. 4to. London, 1673.

Contains Mead's well-known theories and observations upon viper venom. 
Meckel (J. Fréd.). Sur les glandes de la tête des Serpents. Arch. für Anat. und Phys., I, 1. [S.]

Mentzelius (Chrétien). Observation sur les Vipères d'Italie. Eph. Nat. Cur. germ. dec. II, Ann. 2, obs. vii. Collect. Academ. III, 535,1755 .

Observations on the habits of the viper, and the arrangement of its teeth. [S.]

Mescé. Opera, in f. Venetiis, 1762, p. 107, 109. $354,393$.

Gives brief account of numerous medicines used in cases of viper bites. [S.]

Metaxa (Louts). Monographie des Serpents de Rome et de ses environs. In 4to., 1823. Bull. de Férussac, I, 184, 1824.

Describes the organs which secrete and conduct the venom; also, the nature of this fluid, its effects, and the remedies employed. [S.]

MrLler (A. G.). Ammonia as an antidote in Rattlesuake bite. Boston Med. and Surg. Journ., VIII, 1833, 240.

Miqued. Morsures de Vipère, moyen de prévenir l'absorption du virus après la cautérization de la plaie, et de combattre l'engorgement consécutif du membre. Bull. de Thér., XXXV, 283, 1848.

Described by Soubeiran as an interesting and suggestive essay. [S.]

Mongiardini. Essai d'expériences sur le mode d'action du venin de la Vipère dans l'éconmie animale. Analys. Bibl. Médic., XVI, 257,1807 .

Endeavors to prove that the venom of the viper does not canse death by eardiac paralysis, and does not attack only the muscular irritability. [S.]

Monti. Opusc. Scelti., I. Weigel Bibl. Ital., III, 207.

States tbat he found useful the topical application of earth moistened with urine. [S.]

Moore (J.). Ammonia as an antidote in the bite of the Rattlesnake. Am. Jonrn. of the Med. Sci, I, 341, 1827.

Reports cases.

Morgagin (J. B.). Recherches Anatomique sur le siége et les causes des maladies. Trad. Desormeaux et Destonet, IX, Lett. 59, ch. 294, p. 390, 1824 (1761).

Interesting study of the viper bite, \&c., from a therapeutical point of view. [S.]

Mono. Journ. de Leroux, XXXIX, 278.

Used carbonate of ammonia with good effect internally. [S.]
Mortimer (Cromwelt). Case of Wm. Oliver, who allowed himself to be bitten by Vipers, using olive oil locally as a cure. Engl. Phil. Tr. abrd., IX, 61 et seq., 1736. See BURTON and ATWELL.

Moseley. Tropical Diseases, etc., p. 34. Jaundice a secondary consequence of suakebites.

Motre (LA). Chirurgie, Observ., 314. Advises the use of theriac and spirit of wine internally and externally. [S.]

MUller. De glandularum secernentium structurapenitiori, in fol., 1830, VI, fig. 1, 50 . Structure of the venom gland in snakes.

NicAnder. Les Eurres de Nicandre médecin et pöete grec, traduites en vers français. Ensemble derx liures des venins, auxquels li est amplement discouru des Bestes venimeuses, thériaques, poisons et contre poisons par Jaques Gréuin in 4. Anvers, 1617. [S.]

Orfila. Traité de Toxicologie, 5th Ed. Paris, 1852 , pp. 840 et seq.

A good summary of the present state of knowledge in regard to venomous serpents.

OWen (R.). Cyclopædia of Anat. and Phys. Ed. Todd. Articles : Teeth and Reptilia.

Paré (Ambroise). (Euvres, cap. 22, p. 577, in fol. Paris, 1633.

Bite of the viper. Reports his own case. [S.]

Patterson (Wriliams). Four voyages into the Hottentot country and into Caffraria, in 4to., 1791.

Advises the use of the Tanjore pill, and failing this, Madeira wine strengthened with brandy, and given in full doses.

Paulet. Observations sur le Vipère de Fontainebleau, et sur les moyens de remédier à sa morsure, in 8vo., 1805.

Report many fatal cases of viper bite, and tends to exaggerate its gravity.

Paduds (Egineta). Opera, lib. v, p. 8 , in fol., 1532:

Extols the use of garlic and of wine in these cases, etc. [S.]

Peroni. Lettera su un caso di morso d'una Vipera instantaneamente fatale, con reflessioni su tale avrenimento. Giorn. della Soc. Med.Chir. di Parma, XIV, 209.

Phileirs (H. B.). Case of Rattlesnake bite. Am. Journ. of the Med. Sci., VIII, 546, 1831. Use of arsenic (see IRELAND), favorable result.

Pinorel. Observations sur la morsure d'un ser- 
pent a sonuettes. Jouru. de Phys, expćr. et path. de Magendie, VIII, 97. Paris, 1827.

The well-known case of Drake.

Prinorec. Note sur l'appareil secrétaire du venin chez les serpentes a sonnettes. J. de Phys. et Path. Exp. de Magendie, VII, 109.

Platt (Thonas). Letter from Florence concerning some experiments there made upon $\mathrm{Vi}$ pers. Engl. Phil. Trans., VII, No. 87, 5060, 1762.

Poletta (Giov. Bat.) Sul molso della Vipera. Mem. dell' imper. reg. instit. di Lombardia, II, parte ii, 1,1821 .

Failure to cnre canine madness by the bite of the viper. [S.]

Post. Case of Rattlesnake bite ending fatally. Buffalo Med. Journ. and Monthly Rev., IV, $18 \pm 8,115$.

Poutead. Euvres posthumes, III, 73, 1783, in 8vo. [S.]

Contains observations on the use of olive oil in viper bites, and reports many cases of serious symptoms resulting from these injuries. [S.]

Pravaz. Moyens mécanique propres à prévenir l'absorption du virus. Acad. de Méd., Sept. 1828; Arch. Gén. de Méd., 7e série, XVIII, 309, 1828. [S.]

Proposes the use of eups which admit at the same time of lotions being employed. Cauterizes by electricity; gives experiments on animals. [S.]

Prina. Observation sur un empoisonnement par la morsure d'ane Vipère, traité avec succès par des ablutions d'ean froide. Gaz. de Santé, 5 Juillet, 1824.

An exaggerated statement of a case. [S.]

Purple. Cedron as a remedy in snake-bites. N. Y. Joum. of Med., N. S., SIII. 173.

Puzin (J. B.). Observations raisonnées sur quelques faits de médeciue pratique. Thése de Paris, No. 84, p. 54, 1809.

A case of viper bite tending to show that it may be mortal in cold weather, and that the cessation of the symptoms is not a certain sign of cure. Thinks that the venom acts like a ferment.

Quenat (Henry). Des animanx venimenx de la France, p. 21, in 8, 1835.

A highly colored statement of the symptoms of a case of viper bite. [S.]

Raffenead (Deluhe). Indications de Thérapeutiçue directe des morsures les plus vénéneuses.
Journ. de Phys., etc., de Magendie, VII, 110,1827 .

Advises the use of incisions and the cautery in viper bites. [S.]

Rausay (D). Case of suake-bite treated by ammouia. The Med. and Phys. Journ., London, 1804, XI, 332.

Rasby. Ou the Teeth of the Rattlesuake, and experiments on the action of the venom upon animals. Eugl. Phil. Trans. abrd, VII, 416, 1727.

RAYGER (C.). De lapide serpentis pileati contra Viperarum morsum antidotum. Misc. germ. Acad. Nat. Cur., Dec. 1, ann. 4 et 5, p. 2, 1673-74. [S.]

Razorowsкi. Histoire Naturelle du Jorat, I, 118. [S.]

Redi (Françors). Observationes de Viperis scriptæ literis ad gener. dominum Laurentiom $\mathrm{Ma}$ galotti in 18. Amsterd., 1675. Misc. Med. Acad. Nat. Cur., I, 305, 1672. Collect. Acad., III, 27, 1755. [S.]

Gives his own experiments, and refutes the prevalent errors as to the viper.

Pedi (Françots). Experimenta circa res diversas naturales, speciatim illas quæ ex Indiis adfertuntur, in 18, p. 4, Amst., 1675.

On the inutility of suake stones. [S:]

REDI (Françars). Epistolæe ad aliquas oppositiones factas in suas observationes circa Viperas, scriptæe ed. D. Alex. Morus et D. Abb. Bourdelot, in 18. Amst., 1675. Collect. Acad., III, 85, 1755 .

Refutes certain views put forth by Charas. [S.]

Renealuus (Paulus). Observationes, iu 8ro. Paris, 1606. [S.]

Rexwoso. Experimental criticism upon Brainard's views as to Iodine as an antidote in poisoning by woorara. Comptes Rend., XXXIX, 67, and XL, 118, 825, 1153.

Richard (Achrle,). Observations sur la morsure de la Vipère commune, Tipera Berus. None. Journ. de Méd. -Chir. et Pharm., VIII, 279, 1820. [S.]

Reports three very serious cases of viper bite. [S.]

Ridolfi (CAmulo). Sur l'inutilite de la ligature dans la morsure de la Vipère. Ann. Univ. de Méd., 1834. Gaz. MÍd, II, 280, 1834.

Rrverius. Observationes, Cent. IV, No. 96. Proposes the use of garlic internally and externally, and also local treatment by scarifications. [S.] 
RoBert. Cas de morsure de Vipère observé et traité à l'Hôtel Dieu. Bull. de Thér., VII, $307,1834$.

Reports very severe cases treated successfully by ammonia, mercurial frictions, scarifications, ipecacuanha, leeches, etc.

Robinead (Desvoidy). Viviparité de la Vipère rouge. Compte Rend. de l'Acad. des Sci., 21 Oct. 1829; Journ. de Ch. Médic., $\nabla$, 639,1829 . [S.]

States that it is more dangerous than the gray viper; thinks nitrate of silver useful in these cases, and cups and ammonia valueless. [S.]

Rochefort. Histoire Nat. des Antilles, I, 294. Lyon, 1667. [S.]

RoNeAU (J. B.). Observations sur la morsure de la Vipère. Thèses de Paris, No. 121, 1828. Reports fatal cases, and others of great severity. [S.]

Rose (DE). Remède contre la morsure de la Vipère. Fil. Sobez, de 1846; Gaz. Méd. p. 562,1846 .

States that he used with success a cataplasm of the Trifolium lupinella. [S.]

Rousseau (Emmandel). Des serpents venimeux en général, et de la Vipère en particulier. Gaz. de Santé ì l'usage des gens du monde. Three cases of viper bite. [S.]

Roux. Hist. de la Soc. Roy. de Méd., ad. 1782 et ' 83, II, 212, 18-.

Used the ligature, oil "septiques" (sic), and the cautery in viper hites. [S.]

Rudolrhi (respondente Saïfert). Dissertatio sistens spicilegium adenalogiæ, in 4 to. Berlin, 1825. [S.]

Rurz. Recherches sur les empoisonnements pratiqué par les nègres à la Martinique. Annales d'hygiène publique. Paris, 1844, XXXII, 383.

Sabal (A. M.). Experiments with Bibron's antidote. Savanuah Journal of Medicine, Sept. 1858; Amer. Journal of the Med. Sci., Oct. 1858 , p. 575 .

SAGE. Expériences propre à faire connaitre que l'alcali volatil est le remède le plus efficaces dans les asphyxies, avec des remarques sur les effets avantageux qu'il produit dans la morsures de la Vipère, la rage, etc. Paris, 1777 , in 8vo. [S.]

Salisbury (J. H.). Action of venom on plants. N. Y. Journ. of Med., XIII, 337, 1854.

Sauvages (Fr. Borssier). De venenatis Galliæ animalibus. Montpellier, in 4, 1764. [S.]

SaVA. Introduction d'une Vipère dans l'estomac 18 d'un enfant, Filiat Sebez. Gaz. Méd., p. 743,1843 . [S.]

Savary. Lettres sur l'Égypte, p. 62, 1788-89.

SAY. Herpetology, etc. etc. Silliman's Journal, I, 259.

SchleGel. Untersuch der Speïcheldrusen bei den schlangen suit gefurchten Tahnen. Nov. Act. Leop. XIV, 143, 1828; Bull. de Ferussac, XVIII, 462, No. 310.

On the structure of the venom gland and fangs. [S.]

Schlegel. Materiallen für die Stahtarzneikunde, IV, Samml., No. 16.

Treatment of snake-bite by the internal and external use of caustic potassa. [S.]

Schuchmann (Christian). Sur les effets d'une morsure de Vipère. Eph. Germ. Acad. Nat. Cur., Dec. 11, Ann. VII, Obs. 140, 1688; Collect. Acad. VII, 661, 1766.

Cure by the use of theriac and mithridate with moderate heat, as local treatment, and finally with searifications. [S.]

Scuulze (J. II.). Dissertatio de viperarum in medicina usu. Altdorf, 1727. [S.]

Scoutetten. Morsure de la Vipère en France près Metz, suivie d'accidents très grave. Trans. Mèdic., II, 92, 1830.

A case treated at first by bleeding, without good results, and finally treated successfully with' large doses of quinine. [S.]

Scribonius (Largus), (in Matthiale Commentaires).

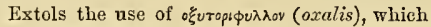
must be gathered before sumrise, and by the left hand. [S.]

Semuedus (Jor. Cvr.). Prgillvs rervm Indicarvm qvo comprehenditrr historia variorvm simplicivm ex Iudia orientali, America, alliisqve orbis terrarum partibvs allatorvm, crra, Abrahami Vateri, in 4. Wittemb., 1572, p. 24 et 53.

Snake stone and "racine de mungo" useful in viper bites. [S.]

Severino (Marc. Aurel.). Vipera Pithya seu de Viperæ natura, veneno, etc., in 4to, 1651. Account of the viper-of his bite, and of the remedies for it. [S.]

Shaw. General Zoology. London, O, III, 368. Contains general information as to the natural history and habits of venomous serpents, etc.

Sigaud. Du Climat et des Maladies du Brésil, p. 394. Use of the venom of the Crotalus in tubercular lepra, with remarks on the effects of the venom of other serpents, p. 431. 
Snmonds. Sur les proprictés médicale du guaco. Journ. de Pharm., 3e série, XX, 357, 1851.

Sloane (Sir H.). Engl. Philos. Trans., abrd., LX, 53,1733 .

Droll snake story, ete.

Sмiтн (Тн.). Structure of the Fang. Engl. Phil. Trans, at large, CVIII, 471, pl. xxii, 1818.

Sonnini (de Manoncour). Observations sur les Serpents de la Guyane, et sur l'efficacité de l'eau de Luce pour en guérir. Journ. de Physique, VIII, 469, 1776.

Reports cases of snake-bite. [S.]

Sonvani. Expériences faites sur l'hydrophobie arec le veniu de la Vipère. Bull. de Thér. XII, 294, 1837.

This singular treatment failed. [S.]

Soubeiran (J. L.). De la Vipère de son venin et de sa morsure. O. Paris, 1855.

A well written essay. The Bibliography is excellent, except as regards the Crotalus.

Sovchay (ABBÉ). Discours sur les Psylles Hist. de l'Acad. roy. des inscripit. ct belles-lettres, VII, 273, 1733 .

Gives a history of the Psylire, and concludes that their power to cure snake-bites was dne only to the suction which they employed. [S.]

Spielizann. Dissert. de animalibus nocivis Alsatia. Argent. 1768. [S.]

Spontones (J. B.). Conachidnelogia sen discussus de pulvere riperino. Romæ, 1648 , in 4 to. [S.]

Sprenger (Conrad J.). Some observations upon the viper. Engl. Phil. Trans. at large, XXXII, 296, 1722. [S.]

Storr (Th. Contr. Christ.) De enris Viperinis, in fol., 1768. [S.]

Stupanas. Dissert. Viperæ et venenorum eorrectio. Basil, 1640. [S.]

Tachenius. Extrait d'une lettre contenant une expérience faite ì Venise de la vertu d'une pierre qui guérit la morsure des serpents. Coll. Acad. I, 262; Journ. des Savants, 1668. [S.]

Thvernier. Remarques touchant la pierre de serpent. Coll. Acad., I, 275, 1755 ; Journ. des Savants, 1668.

Describes the properties of these stones, states where they are found, and gives receipt for making artificial snake stones. [S.]

TAYlor. Effect of Pennyroyal on Crotalus. Engl. Phil. Trans. at large, II, 373, 811, 1665.

This plant said to he fatal to the rattlesnake.

Tredemany (Fr.). Ueher Speicheldrusen der
Schlangen Mlém. de l'Aead. de Munich, p. 25, pl. ii, 1813.

Tixier. Morsure des serpents venimenx, Vipère, morsure de Crotale. Rapport gén. des Trav. de la Soc. des Sei. Mréd. de Gannat, in 8 , p. 25, 1854, par M. Gilliot.

General remarks on the hahits of the viper, etc. [S.]

Towgood (J.). Dissertatio de Vipera. LugdBat., in 4, 1718. [S.]

Tracy (J. G.). Uevilaria grandiflora an antidote to the bite of the Crotalus. Trans. Albany Instit., I, 32.

Trowbridge. Olive oil an antidote to the bite of the Rattlesnake. Buffalo MIed. Journ. and Rev., IV, 203, 1848.

Reports successful cases.

Trudaine (de Montigny). Lettre ì M. Le Marquis de Chesuaie, contenant mue observation sur la gućrison d'une morsure de Vipère, opérée par l'alcali volatil. Journ. de Mićd., XXIV, 162, 1766.

Case of a girl, aged twelve, cured in six honrs. [S.]

Trson. Anatomy of the Crotalus, etc. Engl. Phil. Trans. abrd., II, 797, 1683.

Taluisneri. Risposta in cui dimostra, come nascano naturalmente $\mathrm{i}$ viperini et come le Vipere e gli altri animali si fecondino, spiegando come sia quel raro caso aceaduto, e levando molti errori antichi, alla suddetta serpe, ed a' serpentelli spettanti. Opere fisico-mediche, III, 285, 1733.

Opposes Limperani's views (vide L.), and states that he found good results from the use of spirits of hartshorn in snake-bites. [S.]

VAN Lier. Traité des Serpents et des Vipères qu'on troure dans le pays de Drenthe, auquel ou a ajouté quelques remarques et quelques particularités relatives ì ces espèces de serpents et ì d'autres, p. 84 , in 4. Amsterdam, 1781 (fig.). [S.]

Vargas (Don Pedro Firmin de). Semanario de agrieultura $y$ artes dirigido á los párrocos, IV, 397. Madrid, 1798.

Observations on the use of mikania guaco [S.]

Vater (A.). Dissert. de olei olivarum efficacia et virtute adversus morsum animalium venenatorum, casu singulari confirmata. Wittemb., in 4 to, 1751. [S.]

Vater (A.). Dissertatio de antidoto novo ad- 
versns viperarnm morsus priestantissimo in Anglia detecto. Wittemb., in 4, 1736. Extols the use of olive oil. [S.]

Tescingius. Observationes de viperæ anatome et generatione. Observ. Anat., a Th. Bartholino editw, II, 36 , in 4,1740 .

Points out with accuracy the seat, etc., of the fang teeth. [S.]

Veyrines (C. DE). Dissertation sar la morsure de la Vipère et sur son traitement. Thèse, 15 Mars, 1817.

Reports cases, and describes the pathology of snake-bites. [S.]

Virey. Plantes usitées contre les morsures des serpents venimeux; extrait du travail de Moreau de Jonnès sur le trigonocephalns. Jonrn. de Pharm. et de Chim., III, 143, 1817.

States that the Euphorbias are the most successful remedies. [S.]

Virey. Sur l'aspic rongeâtre on Vipère des environs de Paris. Journ. de Pharm. et de Chim., XIII, 383, 1827. [S.]

Voigt (M. Godofredus). De congressu et partu viperarnm, in 12, 1698. [S.]

Wagner (F'RÉD. Aug.). Observations sur les mœurs de la Vipère commune. Journ. der Practisch. Heilkunde, p. 3 ; Bnll. des Sci. Nat., XXI, 322, 1829.

States that the viper bite is not fatal to vipers. [S.]

WaLKer (E. M.). Experiments with Bibron's Antidote. Am. Jomru. of Med. Sci., Oct. 1858, p. 568 .

Reports an interesting case in man bitten by the Trigonocephalus piscivorus. Took whiskey and 20-drop doses of Bibron's antidote; uearly the whole hand sloughed; amputation and cure. Thinks the recovery due to the antidote.

WVEger. Cas de morsure de Vipère, trachéotomie, gnerison. Wochenschrift für die Gesammte Heilkundt Casper's, I839 ; Gaz. Med., VII, 632,1839 . [S.]

Wmitmin (J.). Iodine an antidote to snake-bites. Northwest. Med. and Surg. Journ., Chicago and Indianapolis, I, New Series ( $V$ of the whole series), 396 .

WiLliais $(J)$. Seven cases of E. Indian serpent bites, treated with ammonia. Asiatic Researches, II, 323.

WiLliais (STEPHeN). Letter concerning the Viper Catchers, and the efficacy of olive oil in curing the bite of Vipers. Eugl. Phil. Trans. at large, p. 27, 1737.

WILlians (S. W.). The Tiola Ovata as a remedy in Crotalus bite. Am. Jonrn, of the Med. Sci., XIII, 310, 1833.

WILLIS (G.). On the bite of the Viper. Assoc. Med. Journ., No. 83, 1854.

Wolff (Weichel). De Paulo a Tipera demorso, in 4 to, 1710 .

Woonhouse. Case of Crotalus bite, reported by the patient. Sitgreave's Expedition to the Colorado and Zuni Rivers, 1851-52; also in Buffalo Med. Journ. and Rev., VIII, 72, 1853.

A well described case of some severity.

Wrder (J. F.). Essai sur l'histoire naturelle des serpents de la Suisse. Lausanne, in 8vo, 1823. Reports cases of viper bite collected by Drs. Schwartz and Lantz. [S.]

Xantus. See De Vesey. 
.

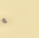




\section{N D E X.}

$\triangle$.

Abdomen, post-mortem appearuces of, 107 .

Absorption of venom, 76 .

Absorption of venom by the lungs, 77.

Abstinence of snakes in captivity, 3.

Acetic acid, effect of, on venom, 33.

Action of renom on warm-blooded animals, 64 .

Action of renom on tissues and fluids, 76 .

Acnte poisoning, rabbit, 67.

Acute poisoning by venom, state of blood in, 89 .

Acute poisoning of frogs by venom, 55 .

Acute poisoning of pigeons, 64 .

Alcohol as a constitutional remedy in Rattlesuake bite, 114 .

- Alcohol as a local treatment, 112.

Alcohol does not injure venom, 45 .

Alcohol, effect of, on venom, 34 .

Alcohol, warm, inhalation of, 116.

Albuminoid compounds in renom, 37.

Alexander on the ligature, $110,111$.

Alkalies, effect of, on venom, 34 .

Ammonia as local treatment, 112.

Ammonia as an antidote, 113.

Amputation as local treatment, 109.

Analogy between Crotalus poisoning and other maladies, 97 .

Analysis of venom, 35 .

Antidotes, 108, 113.

Antidote, Bibron's, 113.

Antidotes, classification of, 113 .

Antidotes, local, 109.

Antidotes, observations upon, 112.

Arsenic as an antidote, 113.

Atchison (Dr.), case of Rattlesnake bite, 100.

B.

Barton (Dr. B. S.) on fascination, 5.

Bernard (Claude), criticism on Fontana, 61.

Bibliography-Appendix B, 127.

Bibron's antidote, history of, 113.

Bichloride of mereury, effect of, on venom, 34 .
Bite of the Rattlcsuake, physiological mechanism of, 20 .

Bite of Rattlesnake, failure of, from miscalculation of the distance, 25 .

Bite of Rattlesnake, failure of, from want of force in the blow, 25.

Bite of Rattlesuake, failure of, from want of complete erection of the fangs, 25 .

Bite of Rattlesnake, failnre of, owing to sudden withdrawal of the fang, 25.

Bite of Rattlesnake, failure of, owing to escape of venom between the fang aud the cxtremity of the duct, 22,25 .

Blindness, partial, of snake, during shedding of skin, 4.

Blood, conclusions as to changes in, 94 .

Blood, crystallization of, after venom poisoning, 92.

Blood, effect of renom on, 89 .

Blood, globules of, observations on, in acute and chronie poisoning, 91 .

Blood and tissues, altered relations between, during renom poisoning, 94 .

Blood, state of, in man after deatl by Rattlesnakebite, 106.

Boiled renom active, 44 .

Bonaparte (Prince Lucien), analysis of viper renom, 35 .

Bone, ecto-pterygoid, 7 .

Bonc, lachrymal, 7 .

Bone, maxillary, artienlations of, 8 .

Bone, palatal, 7 .

Bone, snperior maxillary, 6.

Bones of heads of serpents, arrangement of, to permit of swallowing large animals, 6 .

Brainard (Prof. David), action of venom on blood, 91.

Brainard (Prof. David), use of iodiue as an antidote, 46.

Brainard (Prof. David), iodine as a local antidote, 111.

Brainard (Prof. David), on alcohol as an antidote, $115,116$. 
Brainard (Prof. David), taste of venom, 31.

Brickell, acid reaction of Rattlesuake venom, 31 .

Burnett (W. J,) on blood-globules in venom poisoning, 92.

Burnett (W. J.) on the fang, 16 .

Burnett (W. J.), ingestion of renom, 76 .

C.

Calorification, action of ven om on, 88 .

Capacity of gland and ducts, relation of, to length and weight of snake, 29.

Capillary circulation nuaffected by venom, 86 .

Capsule of renom gland, 11.

Candisona, 119.

Caudisona adamantea, 121.

Caudisona atrox, 121.

Caudisona cerastes, 124.

Caudisona confluenta, 122.

Candisona durissa, 120.

Caudisona horrida, 122, 123.

Candisona loeflingii, 120.

Caudisona Le Coutei, 121.

Caudisona lepida, 124.

Caudisona lucifer, 121.

Candisona lugubris, 122.

Caudisona molossus, 124.

Caudisona terrifica, 120.

Candisona tigris, 122.

Caustics as local treatment, 111.

Cells of sphincter, 15 .

Celsus, ingestion of renom (note), 76 .

Cervical angular muscle, 9 .

Chemical agents, influence of, on activity of renom, 45.

Chlorine water, action of, on renom, 34 .

Chlorohydric acid, effect of, on venom, 33.

Christison (Prof.), dried Cobra venom, active, 59.

Chronic poisoning in pigeons, 65.

Chronic poisoning in the rabbit, 68 .

Chronic poisoning by renom, state of blood in, 89 .

Chronic venom poisoniug, 94.

Ciliary morement unaltered by venom, 86 .

Cloak of the fang, use of (note), 22,

Closure of the venom duct when not in use, 24 .

Coagulation of venom, temperature of, 33 .

Cobra can destroy Cobra, 60.

Color of venom, 29.

Coil, use of portion of, after striking, 22 .

Coolidge (Dr.), case, 100.

Cope, E. D., genera and species, 119-126.

Costo-mandibular muscles, 9.

Crotaline, characters of, 36 .

Crotaline, preparation of, 36 .

Crotalophorus, used by Prof. Brainard, 112.
Crotalus, 124.

Crotalus durissus (see Caudisona, Appendix A), 122.

Crotalus Edwardsii, 125.

Crotalus, effect of venom on, 60 .

Crotalus, habits of, in captivity, 3 .

Crotalus miliarius, 124.

Crotalus tergemiuus, 125.

Cups, use of, in treatment, 110.

Curve of venom duct, use of, 24 .

D.

Death, eausation of, in acate and chronic poisoning, 95.

Death, cause of, in acutc cases, 96 .

Death, cause of, in chronic cases, 96 .

Death, mode of, in human cases of Crotalus bite, 105.

De Blainville, venom gland analogous to parotid, 37.

Decomposition of renom, 32.

De Vesey-see Xantus, case, 100.

Digastricus muscle, 9 .

Discharges, state of, in human cases of venom poisoning, 105.

Dogs, action of Crotalus venom on, 69 .

Dogs, cases of poisoning of, by venom, $69-72$.

Dogs, fatal cases of renom poisoning of, $72-75$.

Dried venom, crystals from, 32.

Dried renom, poisoning by, 59 .

Duet of venom gland, curve of, 15 .

Duct, relations of, to sup. maxillary bone, 24.

Duct, terminal papilla of, $1 \mathrm{~s}$.

Duration of cases of renom poisoning in man, 105 .

Duvernoy, mechanism of the bite, 20 .

\section{E.}

Ecchymoses in sccondary or chrouic poisoning, 94.

Echidnine, 36.

Ether, inhalation of, 116.

Excision as local treatment, 109.

Expression of snake when striking, 21.

External pterygoid musele, action of, 8 .

F.

Fallacies in the use of antidotes, 25.

Fangs, act of elevation of, 21.

Fang, depression of after biting, 22.

Fang, development of, 16.

Fang, divergence of, during act of biting, 23 .

Fang, position and action of, in biting, 22.

Fang, size of, 16. 
Fang, structure of, 15 .

Fangs, periodical fall of, 17 .

Fangs, relation of number of, used in biting, to study of antidotes, 23.

Fangs reserve, succession of, 18.

Fangs, nse of one or both, 23.

Fascination, 4.

Fascination, author's observations on, 5.

Fatal renom poisoning in dogs, $72-75$.

Fermentation, not checked by renom, 49 .

Fibrin, loss of its coagulating power in elronic poisoning, 89.

Fibrin, rate of disappearance of in renom poisoning, 92.

Fontana, amount of venom ejected, 29.

Fontana, action of venom on blood, 91.

Fontana, action of venom on frogs, 54 .

Fontana, action of viper venom on viper, 61

Fontana, color of viper vezom, 30.

Fontana, mechanism of the bite, 20.

Fontana on reaction of viper venom, 31 .

Fontana, taste of viper venom, 30 .

Forcible feeding of suakes, 3.

Frogs, action of renom on, 55 .

Frogs, chronic poisoning of, 57 .

Frozen renom, active, 43 .

G.

Gaspard on analogy between renom malady and other diseases, 97.

Germination of seeds in venom, 52 .

Gilman (B. J.), action of venom on plants, 47 .

Guinea-pig, blood crystals from, after death by venom, 22.

H.

Hammond (W. A.), case of Rattlesnake bite, 100. Hammond (IV. A.) on Bibron's antidote, 113, 114.

Harlan (R.), acid reaction of Rattlesnake renom, 31.

Harlan (R.), case of Rattlesnake bite, 100.

Harlan, ingestion of venom, 76 .

Head, lesions of, in man, 106.

Heart, effect of renom on, 80 .

Heart force lessened by renom, 83,84 .

Hemorrhage from bite in man, 101.

Hissing sound made by serpents, 20 .

Holbrook (Prof.) on nse of intermittent ligature, 110.

Home (Sir E.), case, 100.

Home (Sir E.), mechanism of the bite, 20.

Horner (IV. E.), case, 100.
I.

Ingestion of renom, 76 .

Inhalation in Rattlesnake bite, 116.

Intermittent ligature, 110.

Intoxication, how far nseful in renom poisoning, 116.

Iodine as local treatment, 111.

J.

James on reaction of viper venom, 31.

Janndice of cases of snake-bites, 97.

Jeter, capacity of venom duct in Rattlesnake, 29.

Jeter, color of Rattlesuake venom, 30.

Jeter, ingestion of renom, 76 .

Jeter on ligatnre, 110.

Jeter, taste of renom, 31.

Johnston, Prof. Christopher (note), 22.

Johnston (Prof. Christopher) on the fang, 16 .

Jussien on reaction of viper renom, 3 I.

\section{L.}

Lesions in dogs, 72-75.

Lesions in fatal cases of Rattlesnake bite in man, 106.

Lesions in pigeons, 67.

Lesions in rabbits, table of, 69.

Ligament check, of lachrymal and superior maxillary joint, 7 .

Ligature modifies local symptoms, 102.

Ligatures, 110.

Ligatures, intermittent, 110.

Local consequences in man, 103.

Local symptoms, 103.

Local symptoms absent when renom has been previonsly mixed with iodine or tannic aeid, 46 .

Local symptoms modified by remedies, 102.

Local treatment, applications to wounds, 112.

Loss of skin, description of, 4 .

Loss of skin, relations of, to supply of water, 4 .

M.

Magendie on resemblance of renom malady to putrefactive poisoning, 97 .

Man, Crotalns poisoning in, 98.

Man, Crotalus poisoning in, table of 16 cases, 100.

Mangili, dried venom, 59 .

Mangili on absorption of renom, 76 .

Manipulations (note), 27.

Mayrant (W.), two cases, 100.

Mead, action of renom on blood, 91 . 
Mead on reaction of viper venom, 31 .

Mead, taste of venom of viper, 30.

Mind, state of, in venom poisoning in man, 105.

Mitchill (S. L.) on analogy between yellow fever and venom poisoning, 97 .

Moore (Dr.), case, 100.

Motions of intestines unaltered by renom poisoning, 86 .

Mucous membrane of month of Rattlesuake, reaction of, 31.

Muscles, effect of renom on, 78.

Muscles, irritability of under venom poisoning, 79 .

Muscles, ultimate effect of renom on, 79 .

Myology of venom apparatus, 8 .

\section{N.}

Nerres, duration of irritability in, during effect of venom on, 86 .

Nerves, motor, action of venom on, 87 .

Nerves, sensory, action of venom on, 87 .

Nerrous system, action of renom on, 86 .

Nitric acid, effect of, on venom, 33.

\section{O.}

Odor of Rattlesnakes, 5.

Ogier (Dr.), use of ligature as local means, 110.

Olive oil as an antidote, 113.

Olive oil as local treatment, 112.

Orfila, criticism on Fontana, 59.

Owen (R.), description of fang, 15 .

\section{P.}

Pain of bite, canse of, 101.

Paul (Trince, of Wurtemburg), on Bibron's antidote, 113, 114.

Phillips (A. B.), case, 100.

Pig bitten by Rattlesnake, death (note), 78 .

Pigeons, action of venom on, 64 .

Pigeons, acute poisoning of, 64 .

Pigeons, chronic poisoning of, 65 .

Pihorel (Dr.), case, 100.

Plants, action of venom on, 50 .

Position of suake before striking, 20 .

Post (Dr.), case, 100.

Pterygoideus externus mnscle, function of, during the act of biting, 22 .

\section{R.}

Rabbit acntely poisoned, 67 .

Panby, mechanism of the bite, 20.
Rattlesnakes, gemera and species of (Appendix A), $119-126$.

Reaction of venom, 31 .

Receptacle of venom, 12 .

Recoreries, mode of, in man, 106.

Redi, ingestion of renom, 76 .

Redi, mechanism of the bite, 20 .

Reynoso, criticism on Brainard's experiments, 111.

Rigor mortis after death by venom, 79.

Rotiferæ in venom, 53.

Russell, color of renom of Cobra, 30 .

Russell, experiments on power of Cobra to kill itself and other serpents.

Russell on 'Tanjore pill, 113.

\section{$\mathrm{S}$.}

Salisbnuy (J. H.), action of renom on plants, 48.

Saliva and venom compared, 42.

Scarifications as local treatment, 109.

Secondary poisoning in frogs, 57.

Sex of those bitten, 101.

Suith, mechanism of the bite, 20 .

Solubility of venom, 33.

Soubeiran, anterior tendinous insertion of ant. temporal muscle in vipers, 12.

Soubeiran, mechanism of the bite, 20 .

Specific gravity of venom, 30 .

Spheno-palatine mnscle, action of, 8 .

Spheno-palatine muscle, function of, during the act of biting, 22.

Spheno-pterygoid muscle, action of, 8.

Sphincter of duct of venom gland, 14 .

Stimnlants, use of, in venom poisonin $\mathrm{g}, 114$.

Striking, mode of, action of muscles in, 21.

Suction, nse of, in treatment, 110.

Sulphate of magnesia, effect of, on renom, 34 .

Sulphate of soda, effect of, on venom, 34 .

Sulphocyanide of potassium, absence of, in venom, 34.

Sulphuric acid, effect of, on venom, 33 .

Symptoms, constitutional, in man, 104.

Symptoms, local, in man, 101.

Symptoms of venom poisoning in rabljits, table of, 68.

\section{$\mathrm{T}$.}

Tanjore pill, composition of, 113 .

Tannic acid, effect of, on venom, 33 .

Taste of venom, 30 .

Temperatures, effect of varions, on actirity of venom, 43.

Temporal muscles, 9 . 
Temporal muscles, action of, 10 .

Temporal muscles, anterior, compression of renom gland by, during the bite, $\mathbf{2 2}$.

Tenacity of life in Rattlesnakes (note), 24.

Thorax, post-mortem appearances of, 107 .

Tissue of venom gland, 12.

Toxicology of venom of Crotalus, 47 .

Treatment, local, division of, 109.

Trowbridge (J.), case, 100.

Twitching of muscles about wound, not described in human cases, 104.

Tyson, mechanism of the bite, 20 .

\section{V.}

Venom, actiou of, on animal life, 52.

Venom, action of, on arterial pressure in animals bitten by Rattlesnakes, 83 .

Venom, action of, on blood-globules, 91.

Venom, action of, on capillaries, 86 .

Venom, action of, on cilia, 86 .

Venom, action of, on calorifacient function, 88.

Venom, action of, on frogs, 54 .

Venom, action of, on intestinal motions, 86 .

Venom, action of, on man, 98.

Venom, action of, on nerve trunks, 86.

Venom, action of, on plants, 47.

Venom, albuminous nature of, 34 .

Venom altered so as to lose virulence, 49.

Venom, amount of, in the ducts, 27.

Venom apparatus, anatomy of, 6.

Venom, chemistry of, 33.

Venom, comparison of, to saliva, 42.

Venom, comparative power of, to injure frogs and

Rattlesnakes, 63.

Venom, decomposition of, 32 .

Venom, direct action of, on blood, table of, 90.

Venom does not convert starch into sugar, 38.

Venom, effect of, on blood, 89.

Venom, effect of, on fibrin of blood, 92.

Venom, effect of, on heart of frog, 80.

Venom, effect of, on muscles, 78,79 .

Venom, effect of, on pigeons, 64 .

Venom, effect of, on rabbit's heart, 81 .

Venom gland, 10.

Venom gland, anatomical relations of, 10 .

Venom gland, are its tissue or infusions poisonous? 39.

Venom gland, capsule of, 11.
Venom gland, form of, 10.

Venom gland, relations of, to fascia of external pterygoid muscle, 12.

Venom gland, size and weight of, 10.

Venom gland, structure of, 12.

Venom gland, suspensory ligament of, 11.

$\nabla$ enom, ingestion of, 76 .

Venom of Rattlesnake, effect of reagents on, 33.

Venom of Rattlesnake, proximate constituents of, 37.

Venom of Rattlesnake solnble in water, 33.

Venom of viper, analysis of, 35 .

Venom, physical characters of, 30 .

Venom, physical and chemical characters of, 27.

Venom, power with which it is ejected, 24.

Venom, reaction of, 31 .

Venom, receptacle of, within the gland, 12.

Venom, sediment from, 32.

Venom, sp. gr. of, 30.

Venom, taste of, 30 .

Venom uninjured by acids and alkalies, 46 .

Tertebro-mandibular muscles, 9.

Vibriones in venom, 53.

Virulency of snakes after shedding the skin, 4 .

W.

Water as local treatment, 112.

Withmire (Dr.), case, 100.

Woodhouse (Dr.), case, 100.

Woodhouse (Dr.), swelling of lymphatic vessels and glands, 103.

Wound, bleeding from, 78 .

Wound made by fang, 77 .

Wound, situation of, in man, 101.

Wound, swelling about, cause of, 78.

Wound, twitehing about, 79 .

Wound, veins near, 78.

Wyman (Prof. J.) (note), 22.

Wyman (Prof. J.), on relation of duct to fang, 19.

\section{$\mathrm{X}$.}

Xantus (J.), on Bibron's antidote, 113.

Xantus (J.)—see De Vesey's case, 100.

Y.

Yellow fever, likeness of, to venom malady, 97. 





\section{COLUMBIA UNIVERSITY LIBRARIES}

This book is due on the date indicated below, or at the expiration of a definite period after the date of borrowing, as provided by the rules of the Library or by special arrangement with the Librarian in charge.

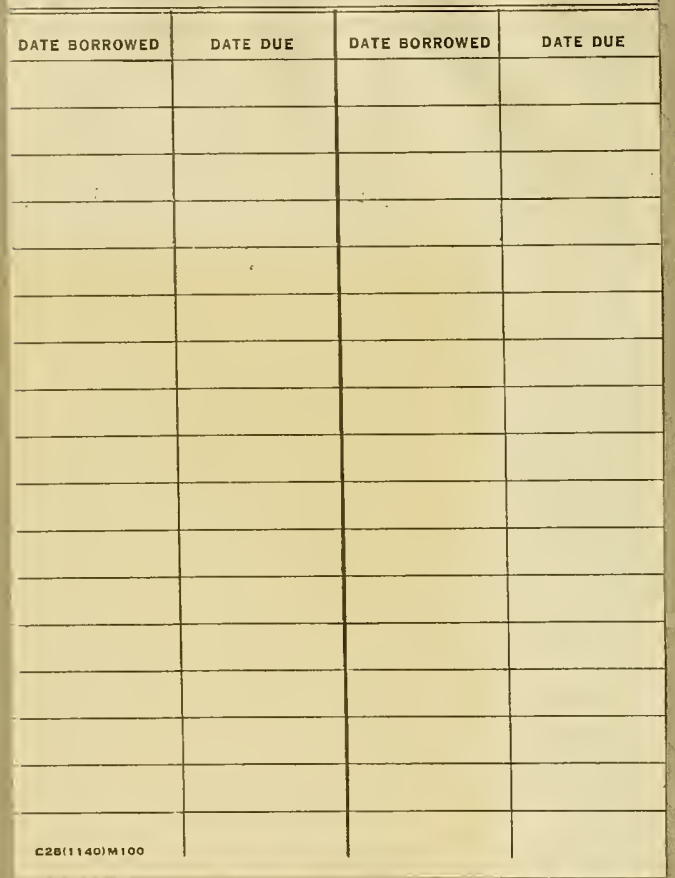



 \\ and}

